University of Louisville

ThinkIR: The University of Louisville's Institutional Repository

Electronic Theses and Dissertations

8-2017

\title{
MiRNA expression changes in arsenic-induced skin cancer in vitro and in vivo.
}

Laila Al-Eryani

University of Louisville

Follow this and additional works at: https://ir.library.louisville.edu/etd

Part of the Medicine and Health Sciences Commons

\section{Recommended Citation}

Al-Eryani, Laila, "MiRNA expression changes in arsenic-induced skin cancer in vitro and in vivo." (2017). Electronic Theses and Dissertations. Paper 2767.

https://doi.org/10.18297/etd/2767

This Doctoral Dissertation is brought to you for free and open access by ThinkIR: The University of Louisville's Institutional Repository. It has been accepted for inclusion in Electronic Theses and Dissertations by an authorized administrator of ThinkIR: The University of Louisville's Institutional Repository. This title appears here courtesy of the author, who has retained all other copyrights. For more information, please contact thinkir@louisville.edu. 


\title{
MIRNA EXPRESSION CHANGES IN ARSENIC-INDUCED SKIN CANCER IN VITRO AND IN VIVO
}

\author{
By
}

Laila Al-Eryani

\author{
A Dissertation Submitted \\ To The Faculty of the School \\ Of Medicine of the University Of Louisville \\ In Partial Fulfillment of the Requirements \\ For The Degree Of
}

Doctor of Philosophy in Pharmacology and Toxicology

\author{
Department Of Pharmacology and Toxicology \\ University Of Louisville \\ Louisville, Kentucky
}

August 2017 



\title{
MIRNA EXPRESSION CHANGES IN ARSENIC-INDUCED SKIN CANCER IN VITRO AND IN VIVO
}

\author{
By \\ Laila Al-Eryani \\ Dissertation approved on \\ August 03, 2017 \\ By the following Dissertation Committee:
}

J. Christopher States, Ph.D.

Carolyn M. Klinge Ph.D.

Shesh N. Rai, Ph.D.

Chendil Damodaran, Ph.D.

Theodore Kalbfleisch, Ph.D. 


\section{ACKNOWLEDGMENTS}

I would like to express my deepest gratitude to my mentor Dr. J. Christopher States for his persistent help, guidance, motivation, patience and very big and kind heart through my Ph.D. journey. I want also to thank my committee members for their guidance, support and assistance starting form Dr.

Damodaran and his lab members and Dr. Tyagi and Dr. Pal for all their technical help. I would also like to thank Dr. Shesh Rai and Dr. Pan for running the statistical analyses. I want also to thank Dr. Kalbfleisch for his help with the NGS data and Dr. Klinge for her advice and helping with troubleshooting. I also sincerely thank the DNA Core manager at the University of Louisville, Sabine Waigel, for all the tremendous help with hybridization microarray analyses and other analyses and being always welcoming and welling to help. Special thank you goes to Vennila Arumugam for all the technical support. My gratitude also goes to members of the Price Institute of Surgery at the University of Louisville, in particular Dr. Galandiuk, M. Robert Eichenberger, Dr. Chien, Dr. Sarojini for the access to instruments and enormous technical help for the LCM and skin lesions study. I would like to thank Dr. Malone for her tremendous help for diagnosing the skin lesions. I sincerely thank Dr. Jala for his technical help with the cell cycle assays and Josiah Hardesty for his technical help with western blot troubleshooting. 
I want also to thank Vanessa States for running the skin lesions preliminary miRNA expression data and Gregory States for designing the program used to facilitate measuring the cells migration. I wish also to thank all the summer students who contributed to the project, Sam Jenkins, who helped tremendously with the LCM, and Jana Peremarti. I also sincerely thank the Fulbright program for giving me the chance to pursue my graduate studies. Without their initial support during my master, I would have been able to pursue my Ph.D. Many thanks to the Integrated Program in Biomedical Sciences (IPIBS) and the department of Pharmacology and Toxicology for supporting me throughout my Ph.D.

Last but not least I am very thankful to my amazing family, mom, dad and lamia along with my friends Banrida, Sabrin, Safa, Heather, Linda and Holly for all their continuous support which without I would never be where I am now.

This work was supported in part by NIH grants R21ES023627, R01ES011314, T35ES014559, R25CA134283, and a Competitive Enhancement Grant from the University of Louisville Office of the Executive Vice President for Research and Innovation.

Finally, I dedicate this dissertation to the memory of a beautiful soul and a very special person that left us too soon, my bother, Luai Al-Eryani. I will always love you, remember you and cherished you and every moment we spent together, you are deeply missed! 


\section{ABSTRACT \\ MIRNA EXPRESSION CHANGES IN ARSENIC-INDUCED SKIN CANCER IN VITRO AND IN VIVO \\ Laila Al-Eryani}

August 03, 2017

Arsenic is a naturally prevalent metalloid. Chronic arsenic ingestion through drinking water causes skin cancer. Arsenic-induced cancer mechanisms are not well defined. Epigenetic changes, including microRNA expression changes, might be playing a role. This dissertation investigates the impact of miRNA expression changes in arsenic-induced skin cancer. MiRNA expression was measure and compared using 3 different techniques, RTq-PCR, hybridization arrays and RNA-sequencing. MiRNAs differential expression in skin lesions was phenotype- and stage-related. Immortalized human keratinocytes (HaCaT) were transformed by chronic low arsenite exposure serving as a model for arsenic-induced skin carcinogenesis. Early changes in miRNAs and target mRNAs contribute to arsenic-induced carcinogenesis. Throughout the time course of arsenic exposure, dysregulation of cells' growth and cancer-related pathways were identified. Comparisons between the miRNA profiles in lesions and cells predict some miRNAs may serve as biomarkers and/or therapeutic targets for arsenic-induced tumors. This dissertation provides strong evidences of epigenetic changes related to carcinogenesis in arsenic-induced skin cancer. 


\section{TABLE OF CONTENTS}

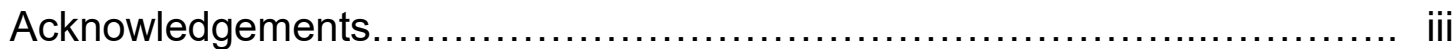

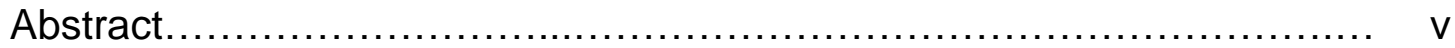

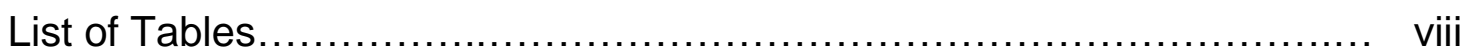

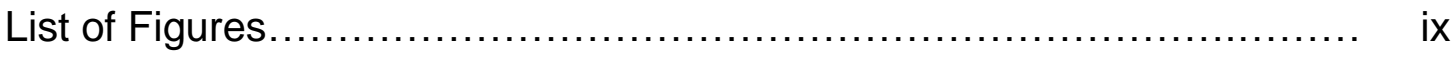

Chapter 1: General Introduction..................................... 1

Chapter 2: MiRNA Expression Profiles of Premalignant and Malignant Arsenic-Induced Skin Lesions

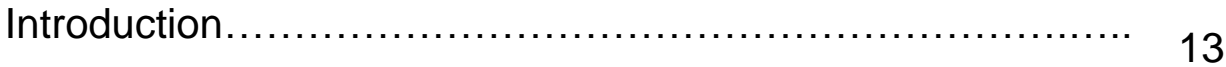

Materials and Methods......................................... 19

Results............................................... 21

Discussion.................................................. 33

Chapter 3: Differentially Expressed MiRNAs and MRNAs at Early Stages of Transformation of HaCaT Cells Chronically Exposed to Low Arsenite

Introduction ........................................... 40

Materials and Methods........................................ 43

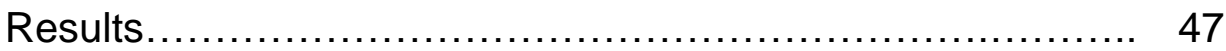

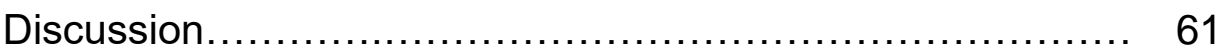

Chapter 4: Cell Cycle Pathway Dysregulation in Human Keratinocytes at Early Stages of Chronic Exposure to Low Arsenite

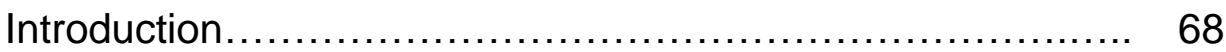

Materials and Methods...................................... 70

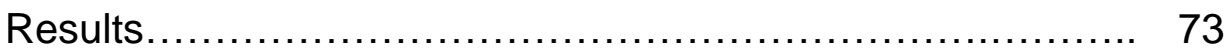

Discussion......................................... 78 
Chapter 5: A Longitudinal Study on Small RNA And MRNA Expression Profiles in The Chronic Exposure HaCaT Model Introduction................................................ 80

Materials and Methods....................................... 83

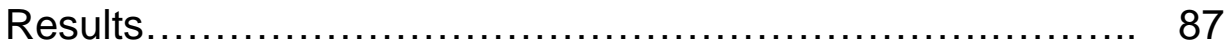

Discussion................................................... 109

Chapter 6: MiRNA Expression Profiles Comparisons Across Three Different Techniques Introduction................................................. 112

Materials and Methods...................................... 114

Results.................................................. 116

Discussion.............................................. 126

Chapter 7: Overall Discussion, Conclusions and Future Directions ....... 129

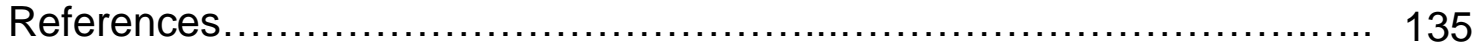

Appendix: List of Abbreviations..................................... 171

Curriculum Vitae......................................................... 174 


\section{LIST OF TABLES}

Table 2.1. Demographics of study population 22

Table 2.2. Differentially expressed miRNAs in Arsenic-induced 27 Skin Lesions and Their Expression

Table 3.1. Differentially expressed small RNAs at both 3 and 7

52 weeks of exposure to arsenite

Table 3.2. Top 10 pathways of the differentially expressed 38 mRNAs at both 3 and 7 weeks that are predicted targets of miRNAs differentially expressed at both 3 and 7 weeks

Table 4.1. Pathways populated by differentially expressed mRNAs 7 weeks

75

Table 5.1. MiRNAs differentially expressed at more than one time point

Table 5.2. Pathway analysis of differentially expressed genes at 7 , 19 and 28 weeks

Table 5.3. Pathway analysis of differentially expressed mRNAs targets of differentially expressed miRNAs

Table 6.1. Differentially expressed miRNAs at 3 weeks of chronically arsenic- exposed/unexposed $\mathrm{HaCaT}$ cells using RT-qPCR array cards

Table 6.2. Differentially expressed miRNAs at 3 weeks in exposed cells vs. unexposed cells to those of unexposed cell vs. skin lesions

Table 6.3. Differentially expressed miRNAs at 3 weeks of chronically arsenic-exposed HaCaT cells in both hybridization microarrays and RT-qPCR array cards

Table 6.4. Differentially expressed miRNAs at 7 weeks of 123 chronically arsenic-exposed $\mathrm{HaCaT}$ cells in both hybridization microarrays and Next-Generation Sequencing (NGS)

Table 6.5. MiRNAs differentially expressed in chronically arsenicexposed $\mathrm{HaCaT}$ cells and arsenic-induced skin lesions 


\section{LIST OF FIGURES}

Figure 1.1. miRNA biogenesis 6

Figure 2.1. Skin Cancer Progression 16

Figure 2.2. Arsenic induced premalignant and malignant skin 24 lesions

Figure 2.3. Differentially expressed miRNA in Arsenic-induced 26 Skin Lesions

Figure 3.1. Impact of arsenite exposure on cumulative $\mathrm{HaCaT} \quad 48$ cell population doubling

Figure 3.2. Exposure and time-dependent Differential Expression 50 of Small RNAs and mRNAs detected by hybridization microarrays

Figure 3.3. Arsenite exposure suppresses miR-548a-3p relieving 56 suppression of TCF7L2 translation and enabling repression of oncogenic pathways

Figure 3.4. miRNA and Target Genes Expression. 58

Figure 3.5. Arsenite exposure effects on MDM2, TP53 and HMG1 60 expression

Figure 4.1. HaCaT cells were exposed to 0 or $100 \mathrm{nM} \mathrm{NaAsO} 2$ for 7 weeks

Figure 4.2. Differential mRNA expression with arsenite exposure. 74

Figure 4.3. $\mathrm{HaCaT}$ cells exposed to arsenite are increased in $\quad 77$ G2/M compartment

Figure 5.1. Arsenite did not affect cell migration 
CHAPTER 1

GENERAL INTRODUCTION

Arsenic is a naturally occurring element that causes a variety of health complications including cancer. Arsenic-induced carcinogenesis mechanisms are still controversial. Several mechanisms including epigenetic changes are proposed. This work is focused on profiling the epigenetic changes, miRNAs changes in particular, in arsenic-induced skin cancers and premalignant lesions from humans chronically exposed to high levels of arsenic in drinking water and in an arsenic-induced skin cancer cell culture model. The results contribute to understanding the role of changes in expression of miRNAs and their target genes in the carcinogenesis process. The results also help evaluate the arsenicinduced skin cancer cell culture model as a squamous cell carcinoma (SCC) model.

\section{Arsenic}

Arsenic is a toxic metalloid that is prevalent in the earth's crust. Arsenic is an acknowledged carcinogen for over 20 years (1). In fact, the skin is the primary target organ for arsenic toxicity and Sir Jonathan Hutchinson was the first to report skin cancer in patients consuming arsenic-based medications in 1887/88 (2). Arsenic has been known throughout history as a medicine and a poison. It has been used in many medical applications since ancient times in traditional 
medicines. It was used to kill pests and humans and as a chemical warfare agent.

Environmental arsenic contamination can be from natural sources or manmade sources such as arsenic-based pesticides, wood preservatives, feed additives and industrial waste (3). Humans are mainly exposed to arsenic through ingestion and the main source is drinking water. Arsenic exists in multiple species in the environment. Aqueous inorganic oxyanions of arsenic, arsenite (As III) and arsenate (As V), are the predominant forms of arsenic in underground water (4). Other sources of arsenic ingestion are food (plants grown with arsenic contaminated water or on contaminated soil, seafood and meat of animals drinking arsenic contaminated water or receiving arsenical growth stimulants in their feed) $(3,4)$. Occupational exposures are common among farmers using arsenic-based pesticides and workers in factories producing these pesticides or where arsenic is used for industrial purposes such in as the glass industry, semiconductors and wood preservatives (e.g. copper-chromiumarsenic (CCA) treated wood) (4).

Arsenic in drinking water is a global health problem. There are large populations in parts of the world that are highly affected such as the Ganges delta encompassing Bangladesh and West Bengal, India, as well as areas in Taiwan, China, Nepal, Viet Nam, Argentina, Bolivia, Chile, Mexico and the U.S.A. (5). Arsenic has been linked to several health problems including pregnancy complications and teratogenicity, developmental defects, neurotoxicity, diabetes, pulmonary disease, cardiovascular disease, vascular disease, skin lesions and 
cancers $(6,7)$. Arsenic causes several cancers including nonmelanoma skin, lung, bladder, kidney and liver cancers (8). Arsenic carcinogenesis mechanisms are not well understood and remain controversial. This dissertation is focused on understanding molecular changes contributing to skin cancer.

\section{Skin Cancer}

Skin cancer is the most prevalent form of all cancers (9). Most skin cancers are a consequence of mutations resulting from DNA damage caused by the ultraviolet radiation in sunlight (10). The second most frequent cause of skin cancer is chronic arsenic exposure. In populations exposed to high levels of arsenic in their drinking water and food, arsenic is a leading cause of skin cancer $(11,12)$. The skin is the primary target organ for arsenic toxicity. Arsenic-induced skin toxicity symptoms first appear as pigmentary changes including raindropshaped lesions and diffuse dark brown lesions followed by arsenical keratosis in the palms, soles and trunk, followed by multiple cutaneous malignancies (13-16). Long-term ingestion of arsenic is associated with different types of skin cancer progressing from premalignant lesions, hyperkeratoses (HK), to the intraepidermal carcinoma (Bowen's disease, BD), SCC, basal cell carcinoma (BCC), and Merkel cell carcinoma $(13,17)$. Sir Jonathan Hutchinson was the first to report skin cancer in patients consuming arsenic-based medications in 1887/88 (2). Non-malignant arsenic-induced diseases include Blackfoot disease, a dry gangrene resulting from ischemic changes in the toes accompanied by ulcers. Blackfoot disease was first observed in the southwest coastal area of Taiwan $(18,19)$. 
Several studies showed that arsenic causes genotoxic damage and chromosomal abnormalities in lymphocytes, buccal cells, and exfoliated urinary bladder cells, which might contribute to arsenic carcinogenesis (20-24). Furthermore, unpublished data from the States lab showed that low levels of chronic arsenic exposure lead to chromosomal alterations in human keratinocytes. Besides chromosomal abnormalities, arsenic causes epigenetic alterations including changes in DNA methylation, histone modification and microRNA (miRNA) expression $(25,26)$. Arsenic-induced changes in DNA methylation and histone modification are extensively studied (25); however, arsenic-induced miRNA alterations are understudied.

\section{MicroRNAs (miRNAs)}

MiRNAs are part of the epigenome and play a fundamental role in the regulation of most mammalian protein codling genes (27). MiRNAs are small, noncoding RNAs that play a crucial role during developmental processes, apoptosis and cell proliferation, and in regulating translation of most mammalian protein-codling mRNAs. In fact, it is estimated that more than $60 \%$ of human protein-coding genes are targeted by miRNAs (28). Aberrant miRNA expression

has been associated with development, progression and response to therapy of viral, immune-related and neurodegenerative diseases, and cancer (29).

\section{MiRNA Processing and Regulation of Translation}

The biogenesis of miRNA takes place in both the nucleus and the cytoplasm producing 21-25 nucleotide endogenous RNAs. The formation of mature miRNA is a two-step process (Fig. 1.1). In the first step, the nascent 
miRNA transcripts (pri-miRNA) are trimmed by the microprocessor complex containing the double-stranded RNA-specific ribonuclease Drosha into premiRNA ( 70-nucleotide pre-miRNA hairpin) $(30,31)$. Then, the trimmed premiRNA is exported from the nucleus to the cytoplasm by exportin 5 where the pre-miRNA gets cleaved into 21-25-nucleotide single-stranded mature miRNA by a protein complex consisting of helicase with RNase motif (Dicer) and HIV1 TAR RNA binding protein (TRBP) $(30,31)$. Along with Dicer, TRBP recruits the argonaute protein Ago2 and other Ago proteins to initiate assembly of the RNAinduced silencing complex (RISC), a ribonucleoprotein complex that binds to one of the miRNA strands to be guided to its target mRNA to regulate its translation (32). 


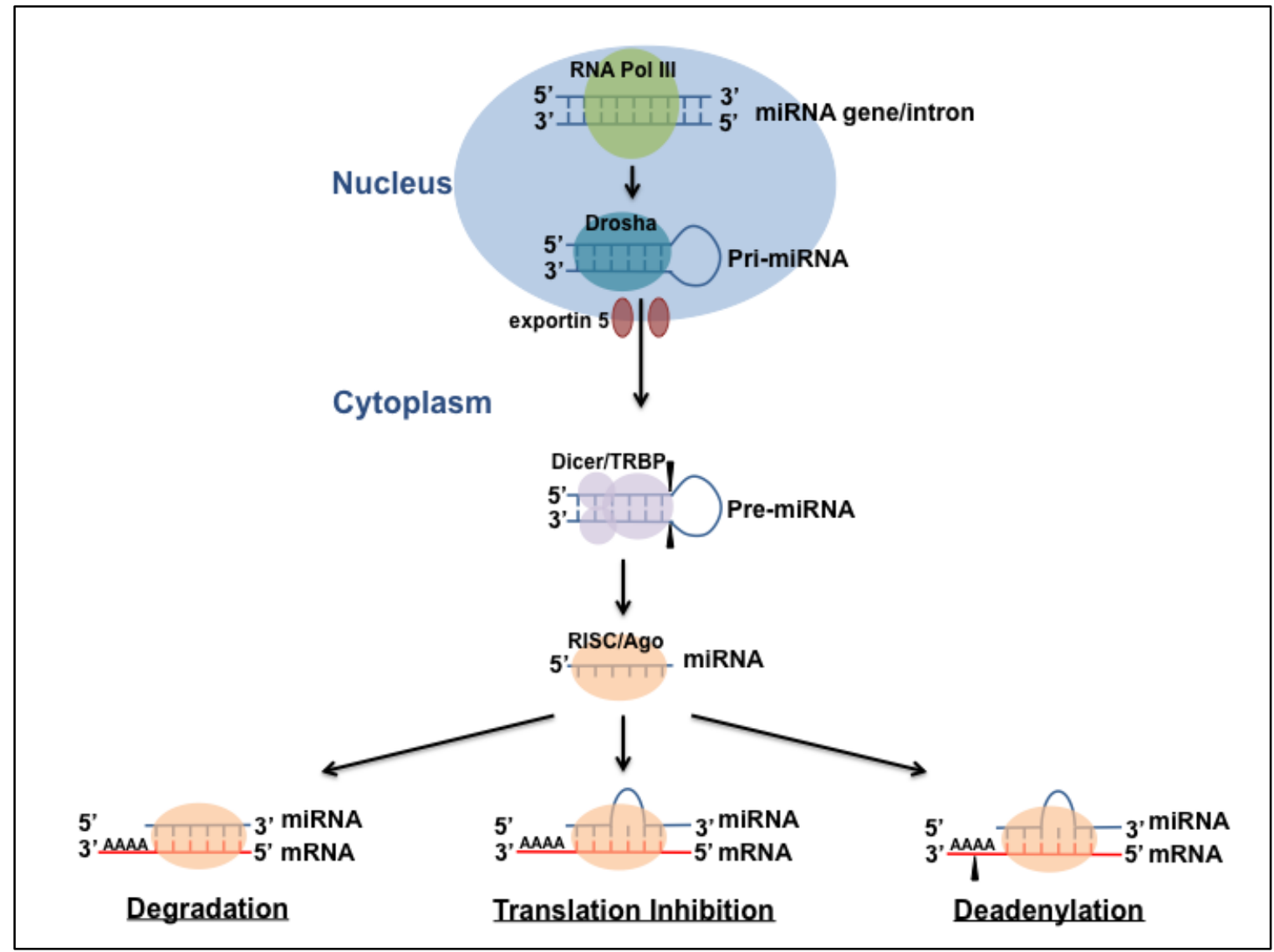

Figure 1.1. MiRNA biogenesis. The figure illustrates the multiple steps of miRNAs biogenesis in both the nucleus and cytoplasm and their role in regulating their target mRNAs. 
MiRNAs target cytosolic mRNA by hybridization to complementary sequences, typically in their 3'-untranslated regions (UTRs) called the "seed region" leading to decreased translation or deadenylation and degradation of the mRNA $(32,33)$. When miRNAs pair perfectly with their target mRNAs, e.g. the seed region of mRNA matches perfectly with the targeting miRNA, that leads to the degradation of the mRNA (34). However, imperfect base pairing leads to repression of mRNA translation and the possibility of restoring translation once the repressor miRNA is degraded (34). Recent studies showed some miRNAs also can bind to the 5'-UTR or the open reading frame (ORF) regions (35). MiRNAs play a role in all the most important processes in every biological system (36). A single miRNA can target hundreds of mRNAs, and the translation of an mRNA can be regulated by multiple miRNAs creating complex feedback and feed-forward gene regulatory loops in a cell. The regulatory loops provide checks and balances within and across gene networks $(37,38)$.

\section{MiRNA Role in Carcinogenesis}

MiRNA expression has been found to be aberrant in different cancers, including cervical, lung, esophageal, oral, pharyngeal and tongue SCC (39). Furthermore, several studies done by the Bechara group demonstrated that the expression of Dicer, Drosha and the RISC components in epithelial tumors, such as cutaneous SCC (CSCC), were deregulated compared to healthy control samples $(40,41)$. Moreover, several studies have demonstrated the association between miRNA expression and tumor development, progression and response to therapy, making miRNAs promising potential biomarkers for disease diagnosis 
and prognosis (35). Furthermore, multiple studies have shown that arsenic can alter miRNA expression patterns in arsenic-induced cancers in vitro and in vivo (42-45).

\section{MiRNAs Expression Dysregulation in Arsenic-Induced Cancers}

Arsenic has been associated with a wide range of health problems including pregnancy complications and teratogenicity, developmental effects, neurotoxicity, diabetes, pulmonary disease, cardiovascular disease, vascular

disease, skin manifestations and cancers $(6,7)$. Numerous studies, mostly in arsenic-induced cancers, showed that arsenic alters both mRNA and miRNA expression patterns $(42,44-50)$. However, fewer studies examined miRNA expression patterns in other arsenic-induced disease such as diabetes mellitus (51-59).

Altered miRNA expression pattern was also reported in multiple studies in arsenic-induced human tumors and transformed cell lines (42-45). Several studies showed that expression of different miRNA families and miRNAs, e.g., the miR-200 and let-7 families and miR-21, was altered with various arsenic species and doses in several arsenic-induced tumors and transformed cell lines (60). These studies suggest that miRNA expression plays a critical role in arsenic-induced tumorigenesis and carcinogenesis. Therefore, longitudinal studies following the differential expression throughout the transformation process are necessary to evaluate the changes critical to arsenic-associated transformation and carcinogenesis. 


\section{Arsenic-Induced Skin Cancer Models}

There are several animal and cell line models to study arsenic-induced cancers. Waalkes et al. established the in utero arsenic exposure model to study arsenic-induced transplacental carcinogenesis (61). C3H mice offspring were exposed in utero to arsenic through drinking water followed by post-natal exposure (61). Multiple arsenic-induced tumors were reported when mice became adults except for dermal tumors (61). Thus, there is no established rodent model to study skin cancers induced in adult animals by inorganic arsenite alone through ingestion, mimicking drinking water exposure $(62,63)$. Arsenic enhanced mutagenicity of skin tumors occurs only in animals co-exposed to another tumor promoter such as 12-O-tetradecanoyl phorbol-13- acetate (TPA) in transgenic TG.AC mice (carry the v-Ha-ras oncogene) (62) or a carcinogen, such as Ultraviolet (UV) light in female hairless mice (Crl: SK1-hrBR) (63).

There are not many cell line models used for both acute and chronic arsenic-induced skin cancer studies. Immortalized cells are needed for chronic exposure studies because it is necessary to maintain these cells are maintained for an extended time required for transformation. Immortalized human keratinocytes $(\mathrm{HaCaT})$ are an in vitro model for normal human keratinocytes that can be used to study arsenic-induced skin cancer $(39,64)$. Pi et al. (2008) showed that continuous exposure of $\mathrm{HaCaT}$ cells for 28 weeks to a low level (100 nM) of sodium arsenite transformed these cells and resulted in an aggressive SCC phenotype upon inoculation of nude mice (39). The concentration of $100 \mathrm{nM}$ sodium arsenite was selected based on an 
epidemiological study of a population in China that consumed well water containing high concentrations of arsenic. The study subjects were diagnosed with chronic arsenic intoxication and arsenic-induced skin lesions and epidermal cancers. Thus, $100 \mathrm{nM}$ sodium arsenite is biologically relevant to that circulating in the study subjects' blood (65). The model has also been reported by Sun et al. as an important model to study the induction of skin cancer by arsenic exposure (66). However, the various stages starting from the early stages of the transformation process in this model have not been studied yet. Furthermore, there has been no further evaluation for the model as an SCC model as suggested by Pi et al. (2008).

In this work, the differential miRNA expression of arsenic-induced in skin cancer in human skin lesions and the differential small RNA and mRNA expression in $\mathrm{HaCaT}$ cells chronically exposed to arsenic were investigated. In fact, the miRNA expression profiles obtained from the arsenic-induced skin lesions are the first to be reported in human arsenic-induced tissues. The results obtained from these skin lesions showed that some miRNAs were phenotype related, e.g. SCC or BCC, or stage related, e.g. malignancy or metastasis. The miRNA and mRNA expression profiles obtained from the HaCaT cells at early time points were done using RT-qPCR and hybridization microarrays. The complexity of the results' interpretation required using a more thorough technique (Next-Generation Sequencing (NGS)) at later time points (19 and 28) of exposure along with 7 weeks for better interpretation. The time points for NGS were selected based on the results obtained from RT-qPCR and hybridization 
microarrays, growth curves of these cells over 32 weeks and reports in the literature of the stages of transformation of these cells.

At early time points ( 3 and 7 weeks), low arsenite was capable of changing the expression pattern of small RNAs along with mRNAs with dramatic changes at 7 weeks. Focusing on some miRNAs and mRNAs differentially expressed at both of the early time points suggested that the early changes in miRNA profiles and their target genes in human keratinocytes contribute to arsenic-induced carcinogenesis. Furthermore, low arsenite at 7 weeks induced differential gene expression indicating dysregulation of cell cycle control, which was confirmed by cell cycle analysis and the slow growth of these cells at the early time points.

The results obtained from NGS showed a greater number of differentially expressed small RNAs and mRNAs after 19 weeks arsenite exposure compared to both 7 and 28 weeks. The results confirmed that most of the transformation related changes happen between 19 and 20 weeks of low arsenite exposure as suggested in the literature (66). Moreover, in this work, the chronic exposure $\mathrm{HaCaT}$ cell model was also evaluated as an SCC model. Comparing the miRNA profiles of $\mathrm{HaCaT}$ cells and skin lesions showed that the HaCaT chronic exposure model is closer to being an arsenic-induced SCC than BCC model as suggested by Pi et al. (39).

The study suggests that miRNAs play an important role in the mechanisms that contribute to arsenic-induced carcinogenesis and skin cancer in particular. Furthermore, the results suggest that some of the miRNAs we 
described could be considered as potential biomarkers or therapy targets for arsenic-induced internal cancers. 


\section{CHAPTER 2}

\section{MIRNA EXPRESSION PROFILES OF PREMALIGNANT AND MALIGNANT ARSENIC-INDUCED SKIN LESIONS}

\section{Introduction}

Arsenic is a naturally occurring element that is prevalent in the earth's crust (67). Exposure to arsenic in drinking water is a worldwide problem and more than 200 million people consume water contaminated with arsenic above the World Health Organization (WHO) recommended limit (10 $\mu \mathrm{g} / \mathrm{L}$, in 2008) $(68$, 69). According to the WHO, exposure to levels of arsenic exceeding the safe limit for more than six months leads to arsenicosis (12). The major areas where a large number of people are exposed to high levels of arsenic in drinking water are mainly in South Asia (Bangladesh, India, Nepal, Cambodia, Viet Nam, Taiwan) and Latin America (Argentina, Bolivia, Chile, Mexico) and to a lesser extent in the U.S.A. (5, 11, 70-79). The Ganges River delta spanning West Bengal in India and Bangladesh has been struggling for decades with the largest mass poisoning in human history from arsenic contaminated drinking water coming from natural sources $(5,80)$. More than 70 million people in 
the delta area consume highly arsenic contaminated drinking water and have high-risk of arsenicosis and a wide range of chronic arsenic exposure-associated health complications such as pregnancy complications and teratogenicity, developmental effects, neurotoxicity, diabetes, pulmonary disease, cardiovascular disease, skin manifestations and cancers $(7,80,81)$. Nonmalignant arsenic-induced diseases also include Blackfoot disease, a dry gangrene resulting from ischemic changes in the toes accompanied by ulcers $(18,19)$. Arsenic has been classified for more than 15 years by the International Agency for Research on Cancer (IARC) as a Group 1 human carcinogen and Group A by the United States Environmental Protection Agency (U.S. EPA) (7). Chronic arsenic exposure causes multiple cancers including those of skin, bladder and lung, and to a lesser extent, liver, kidney, and prostate (82).

Skin cancer is the most prevalent form of all cancers (9). Most skin cancers are a consequence of mutations resulting from DNA damage caused by the ultraviolet radiation in sunlight (10). The second most frequent cause of skin cancer is chronic arsenic exposure. The skin is the primary target organ for arsenic toxicity. In populations exposed to high levels of arsenic in their drinking water and food, arsenic is a leading cause of skin cancer $(11,12)$. Arsenicinduced skin toxicity symptoms first appear as pigmentary changes including raindrop-shaped lesions and diffuse dark brown lesions followed by arsenical keratosis in the palms, soles and trunk, and multiple cutaneous malignancies (13-16). 
Arsenic-induced skin cancer has a different pattern of pathology and progression to malignancy compared to sunlight-induced skin cancer. Actinic keratoses are the premalignant lesions for sunlight-induced SCC while arsenical hyperkeratoses are premalignant lesions of both BCC and SCC in arsenicosis (Fig.2.1) $(83,84)$. 


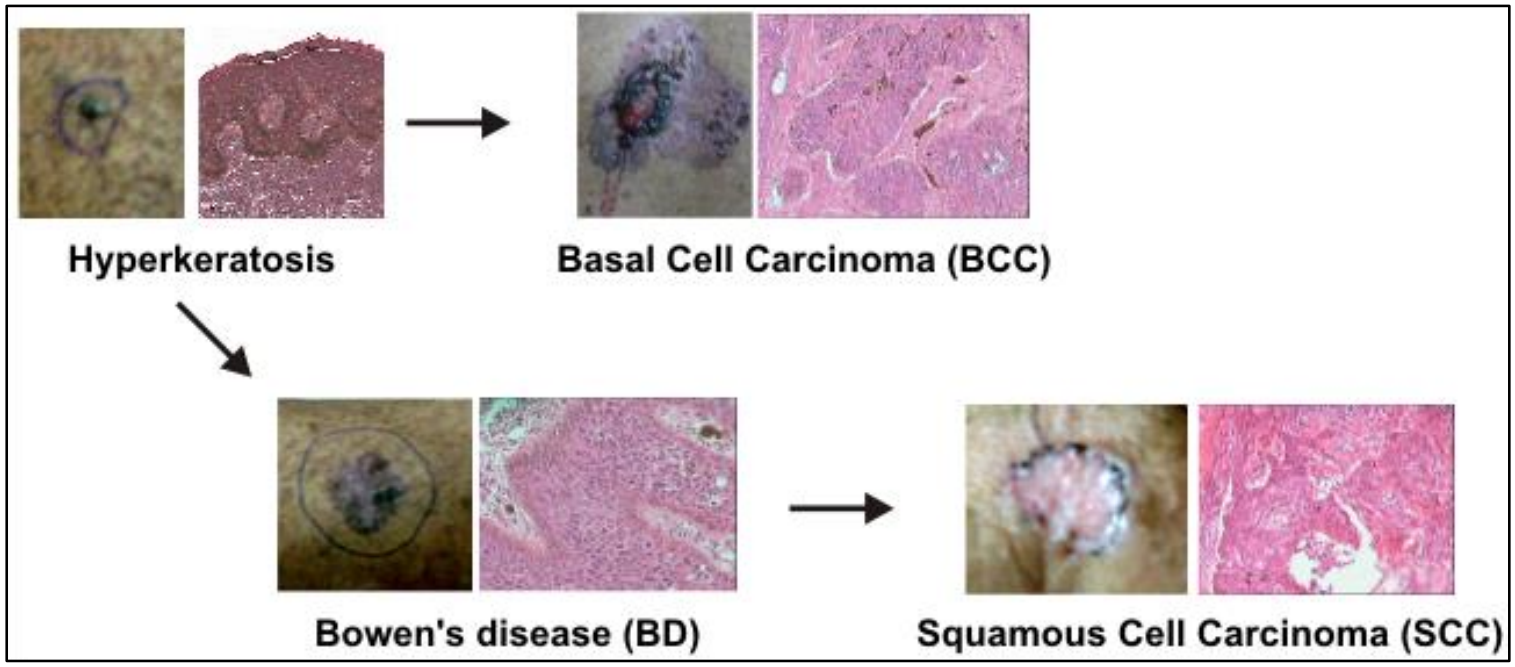

Figure 2.1. Skin Cancer Progression. Progression from the premalignant lesion HK to either of the malignant lesions, BCC directly or SCC through BD (SCC in situ). Shown are photographs of lesions in situ prior to excision with a histological section of the formalin fixed and paraffin embedded sample stained with hematoxylin and eosin on the right. 
Moreover, sunlight causes SCC, BCC and malignant melanoma whereas arsenic exposure does not cause malignant melanoma $(83,84)$. Keratosis or hyperkeratosis in body areas not exposed to the sun is the most distinguishing cutaneous manifestation of arsenicosis (18). Arsenical keratoses are characterized by pathological features such as hyperkeratosis, parakeratosis, arsenical pigmentation, and SCC in situ at a later stage (13). Keratoses' color is usually the skin color or darker and the size is dependent on the disease progression stage, larger lesions generally are more severe (18). The presence of dysplasia in the keratotic lesions is an intermediate stage between premalignancy and malignancy and histological characterization can be challenging. Dysplastic keratoses are immediate predecessors to BD and SCC. Chronic arsenic exposure also causes BD, which is SCC in situ (18). BD and superficial BCC are the most common malignant lesions in arsenicosis (18). BCC is not invasive whereas SCC is a true invasive carcinoma and it tends to progress in later stages of arsenic exposure $(13,18)$. Individuals can have one or several types of skin lesions simultaneously (18).

The mechanisms of arsenic-induced carcinogenesis are not yet clear and there are several proposed mechanisms including epigenetic alterations. miRNAs are part of the epigenome and play a fundamental role in the regulation of most mammalian protein codling genes (27). miRNAs are a family of small noncoding RNAs between 21 and 25 nucleotides in length (27). To add to the complexity of miRNAs' role in regulating gene expression, one miRNA can target several mRNAs and an individual mRNA can be targeted by multiple miRNAs 
creating complex regulatory loops in a cell establishing a balance across gene networks $(37,38)$. Furthermore, the association between miRNA expression and tumor development, progression and response to therapy have been discussed in several studies presenting miRNAs as potential biomarkers for disease diagnosis and prognosis (35). The study presented in this chapter helps in understanding the association between miRNA expression and arsenic-induced skin lesion development and progression, and in obtaining hallmarks of development and progression at different stages of the carcinogenic process. 


\section{Materials and Methods}

\section{a. Sample Collection Criteria and Diagnosis}

Skin lesion samples were obtained as $2 \mathrm{~mm}$ skin punch biopsies from tumors and lesions excised for diagnostic purposes from subjects visiting field hospitals in the Murshidabad district of West Bengal, India. Samples were collected with informed consent provided in native language with approval of the Ethical Committee on Human Subjects at Indian Institute of Chemical Biology and the Institutional Review Board at University of Louisville. The samples were fixed in formalin (light fixation) and embedded in paraffin (FFPE). Gross diagnosis of the samples was performed by dermatologists at the time of lesion excision and confirmed in Louisville histopathologically by a dermatopathologist examining thin sections stained with hematoxylin and eosin (H\&E).

\section{b. Laser Capture Microdissection System (LCM)}

Keratinocytes were isolated from $7 \mu \mathrm{m}$ sections of samples using an Arcturus XT ${ }^{\mathrm{TM}}$ Laser Capture Microdissection System (LCM). The sectioned tissues were first deparaffinized and stained using the Arcturus Paradise Plus staining kit and the isolated cells were collected on macrocaps. Total RNA was purified from the tissues on the macrocaps using Arcturus Paradise Plus FFPE RNA extraction and Isolation Kits. Total RNA quality and quantity were determined using the Agilent RNA 6000 Pico Kit, Eukaryote, version 2.6 and the Agilent 2100 Bioanalyzer instrument (Agilent Technologies, Inc., Santa Clara, CA, USA). Total RNA (50-100 ng) from each sample was reverse transcribed 
and pre-amplified to prepare cDNA using RT kit, MegaPlex Primers and Pre-Amp kit (Life Technologies) following the Megaplex ${ }^{\mathrm{TM}}$ Pools For microRNA Expression Analysis protocol with preamplification.

\section{c. miRNA RT-qPCR array Cards}

Profiling miRNA expression was performed using the TaqMan® Array Human MiRNA A Card v2.0 (polymerase chain reaction (RT-qPCR) array cards, Life Technologies). The array measures the expression of 384 targets; 377 miRNAs and 7 controls. Four of seven controls are U6 RNA, the mean of which was used for normalization in our dataset. The data were collected at 0.1 threshold value on an Applied Biosystems ViiA7 Real Time PCR System. The Ct values were normalized to the mean of $\mathrm{Ct}$ values of U6 RNA ( $\triangle \mathrm{CT}$ method).

\section{d. Statistical analysis}

The $\Delta \mathrm{Ct}$ values were calculated using the $\mathrm{Ct}$ values of the miRNAs from premalignant or malignant lesions and normalizing them to the means of the $\mathrm{Ct}$ values of the reference RNA U6. Statistical analyses were performed by comparing the $\Delta \mathrm{Ct}$ values of the premalignant and malignant lesions using oneway ANOVA by SAS System V9. Cary, NC: SAS Institute Inc, 2003. 


\section{Results}

\section{a. Study Population Demographics and Histopathological Analysis}

The subjects were exposed to high levels of arsenic in their drinking water (51 to $398 \mathrm{ppb}$; mean $106.4 \pm 63.9$, Table 2.1 ), which is similar to well water arsenic levels seen in the northeastern and southwestern United States (85-87). The samples were collected from 35 males (25-60 years old) with urine arsenic levels ranging from 100 to $1,590 \mu \mathrm{g} / \mathrm{L}$ (mean $299.3 \pm 281.9$ ). The subset from which miRNAs in lesions were analyzed had narrower ranges of age, water and urine arsenic ( $47 \pm 3.9,92.7 \pm 41.3,335.8 \pm 324.9$ respectively, Table 2.1$)$. 
Table 2.1. Demographics of study population.

\begin{tabular}{|c|c|c|c|c|c|}
\hline Sample \# & Diagnosis & Gender & Age & $\begin{array}{c}\text { Water Arsenic } \\
(\mathbf{p p b})\end{array}$ & $\begin{array}{c}\text { Urine Arsenic } \\
(\boldsymbol{\mu} \mathbf{g} / \mathbf{L})\end{array}$ \\
\hline $14 \mathrm{E}$ & HK & M & 50 & 91.1 & 240 \\
\hline $28 \mathrm{E}^{*}$ & HK & M & 40 & 61.5 & 140 \\
\hline $19 \mathrm{D}^{\#}$ & HK & M & 50 & 59.8 & 417 \\
\hline $28 \mathrm{~B}^{*}$ & SCC & M & 40 & 61.5 & 140 \\
\hline $26 \mathrm{~A}^{\#}$ & SCC & M & 50 & 59.8 & 417 \\
\hline $18 \mathrm{~B}^{\$}$ & SCC & M & 45 & 79.8 & 100 \\
\hline $8 \mathrm{~A}^{\$}$ & BCC & M & 45 & 79.8 & 100 \\
\hline $17 \mathrm{~A}$ & BCC & M & 49 & 172 & 958 \\
\hline 20C & BCC & M & 48 & 92 & 160 \\
\hline *\# and ${ }^{\$}$ indicate samples from the same individual. \\
\hline
\end{tabular}


The skin lesions were histologically complex, often containing inflammatory infiltrates, thus requiring histopathologic identification of keratinocytes to be isolated for RNA analyses. Inflammatory infiltrates were commonly observed in BCC (Fig. 2.2.A) and SCC (Fig. 2.2.B) samples. Many of the lesions classified as hyperkeratosis on gross examination contained regions of dysplasia often appearing to be early Bowen's disease (Fig. 2.2.C). Thus, the histological diagnosis of the samples was critical, and the HK samples were divided into 2 groups based on histology. The first group included those lesions showing dysplasia and were excluded from analysis (Fig. 2.2.C). The second group included samples which showed no signs of dysplasia (true premalignant lesions, Fig. 2.2.B). HK, which showed no signs of dysplasia (true premalignant lesions), were selected for further processing. The BCC and SCC or BD samples' gross diagnoses also were confirmed histologically. Keratinocytes were harvested from each sample using LCM. LCM technology permitted microscopic precision and the ability to harvest exclusively pathology-proven diseased tissue from biopsy samples while excluding undesired dysplastic cells, or adjacent inflammatory and other nonkeratinocyte tissues. Most samples yielded too little RNA for analysis. Three samples of each lesion type (HK, BCC, SCC) yielded adequate amounts of RNA for analysis. 


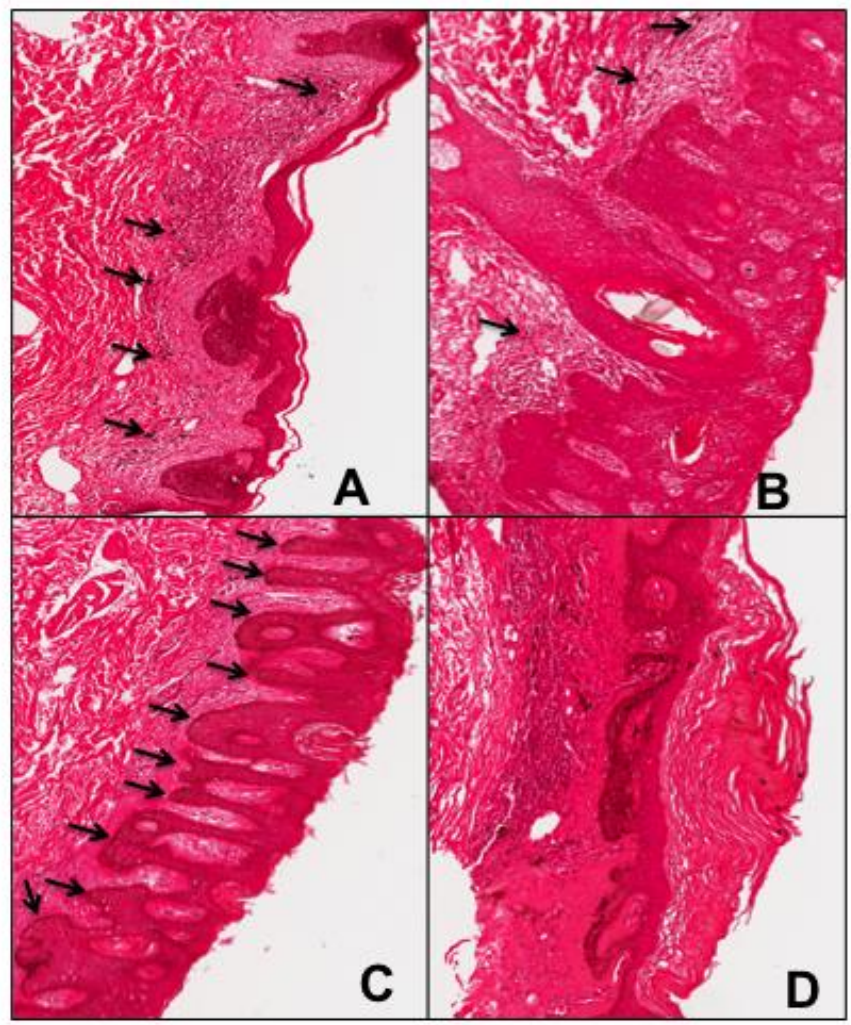

Figure 2.2. Arsenic induced premalignant and malignant skin lesions.

Histological sections of arsenic-induced basal cell carcinoma, squamous cell carcinoma and hyperkeratosis. A. Basal cell carcinoma, arrows point to inflammatory foci. B. Squamous cell carcinoma, arrows point to inflammatory foci. C. Hyperkeratosis with dysplasia, arrows point to areas of dysplasia projecting from the hyperkeratotic region. D. Hyperkeratosis without dysplasia. 
b. miRNA Profiles in Premalignant and Malignant HK, BCC and SCC Lesions

Differential miRNA expression profiles were obtained by comparing expression in three premalignant HK lesions and six malignant lesions (3 SCC and 3 BCC). One-way ANOVA analysis of $\triangle$ Ct values (vs U6 RNA) indicated that thirty-five miRNAs were differentially expressed among the three lesion types analyzed (Fig. 2.3, Table 2.2). Differential expression fell into six classifications (Table 2.2). Two miRNAs were induced in both $\mathrm{BCC}$ and SCC relative to $\mathrm{HK}$ (Fig. 2.3.A, Table 2.2), e.g. these miRNAs were associated with malignancy in general. Two other miRNAs were induced in SCC relative to both BCC and HK (Fig. 2.3.B, Table 2.2), e.g. these were selectively induced in the tumors capable of metastasis. Six miRNAs were selectively suppressed in BCC relative to both SCC and HK (Fig. 2.3.C, Table 2.2). A fourth group of three miRNAs were differentially expressed in $\mathrm{BCC}$ relative to $\mathrm{HK}$, but expression in SCC was not different from either BCC or HK (Table 2.2). A fifth group of three miRNAs were differentially expressed in SCC relative to $\mathrm{HK}$, but expression in $\mathrm{BCC}$ was not different from either SCC or HK (Table 2.2). The sixth group contained eight miRNAs induced in SCC relative to BCC, but not differentially expressed in $\mathrm{HK}$ relative to either SCC or BCC. 


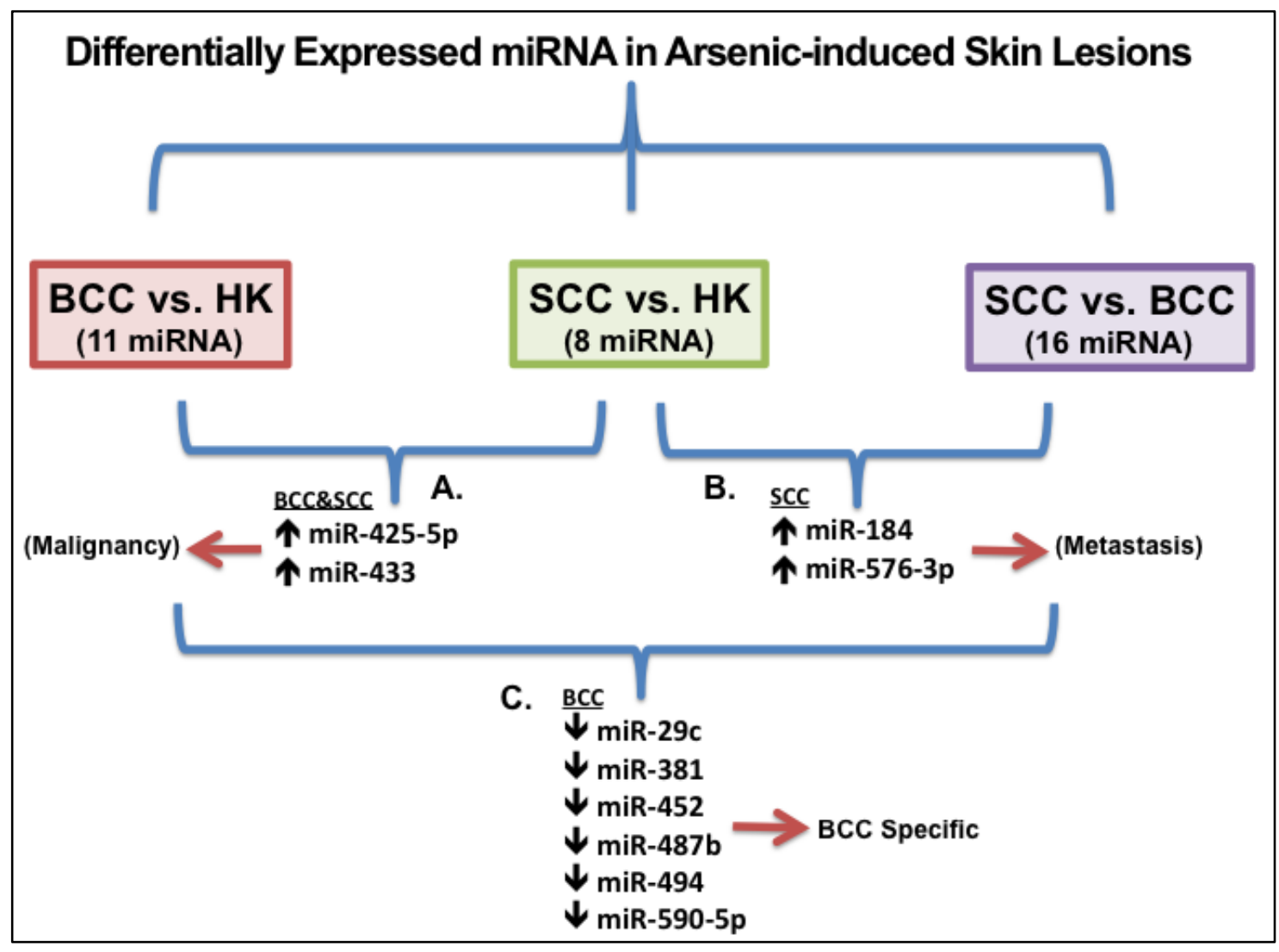

Figure 2.3: Differentially expressed miRNA in Arsenic-induced Skin Lesions. Selected differential expression comparisons are diagramed.

Differentially expressed miRNAs in (A) malignant lesions, both BCC and SCC relative to HK; (B) Specifically in SCC vs HK or BCC.; (C) Specific to BCC vs SCC or HK. Direction of expression changes indicated by arrows. Additional differentially expressed miRNAs are listed in Table 2.2. 
Table 2.2: Differentially expressed miRNAs in Arsenic-induced Skin Lesions and Their Expression Reported in Other Types of Human Cancers.

\begin{tabular}{|c|c|c|c|c|}
\hline miRNA & $\begin{array}{l}\text { Type of } \\
\text { miRNA } \\
\text { (location) }\end{array}$ & $\begin{array}{l}\text { Direction } \\
\text { and fold } \\
\text { change of } \\
\text { expression }\end{array}$ & $\begin{array}{l}\text { Type of cancer and } \\
\text { direction of } \\
\text { expression change } \\
\text { in other studies }\end{array}$ & References \\
\hline \multicolumn{5}{|c|}{$\begin{array}{l}\text { Differential expression BCC and SCC vs. HK (malignant lesions associated } \\
\text { miRNAs) }\end{array}$} \\
\hline $\operatorname{miR}-425-5 p$ & $\begin{array}{l}\text { Intronic } \\
\text { (embedded } \\
\text { within } \\
\text { DALRD3) }\end{array}$ & $\begin{array}{l}\text { 个31 } \\
\text { (BCC vs. HK) } \\
\text { \$56 } \\
\text { (SCC vs. HK) }\end{array}$ & $\begin{array}{l}\text { TGastric cancer, } \\
\text { colorectal cancer } \\
\text { Suggested biomarker } \\
\text { in melanoma }\end{array}$ & $(88-90)$ \\
\hline $\operatorname{miR}-433$ & $\begin{array}{l}\text { Antisense } \\
\text { within RTL1 } \\
\text { retrotransposon } \\
\text { Gag like } 1\end{array}$ & $\begin{array}{l}\text { 个152 } \\
\text { (BCC vs. HK) } \\
\text { (26 } \\
\text { (SCC vs. HK) }\end{array}$ & $\begin{array}{l}\text { Associated with poor } \\
\text { progression-free } \\
\text { survival in High- } \\
\text { grade serous ovarian } \\
\text { cancer (deregulated } \\
\text { in ovarian cancer) } \\
\text { Tumor suppressor } \\
\text { role in liver cancer } \\
\downarrow \text { Gastric cancer } \\
\\
\text { BBladder cancer }\end{array}$ & $(91-95)$ \\
\hline
\end{tabular}

Differential expression SCC vs. BCC and HK (invasion associated miRNAs)

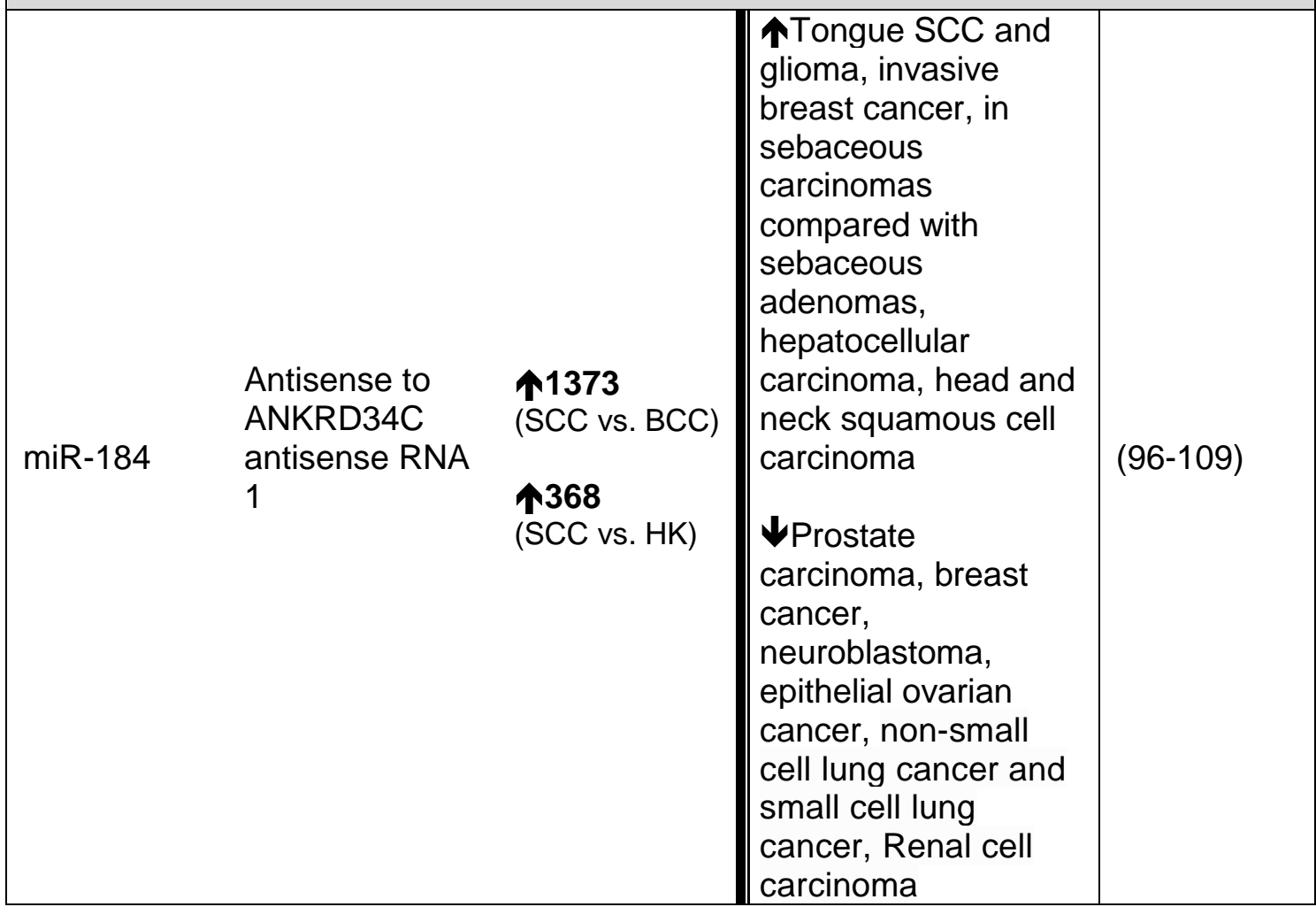




\begin{tabular}{|c|c|c|c|c|}
\hline miR-576-3p & $\begin{array}{l}\text { Intronic } \\
\text { (embedded } \\
\text { within SEC24B) }\end{array}$ & $\begin{array}{l}\text { 个31 } \\
\text { (SCC vs. BCC) } \\
\text { 个55 } \\
\text { (SCC vs. HK) }\end{array}$ & $\begin{array}{l}\text { Bladder cancer, } \\
\text { sera of } \\
\text { nonmelanoma skin } \\
\text { cancer patients (BCC } \\
\text { and SCC, UV light } \\
\text { related), T-cell } \\
\text { precursor acute } \\
\text { lymphoblastic } \\
\text { leukemia }\end{array}$ & $(110-112)$ \\
\hline \multicolumn{5}{|c|}{ Differential expression BCC vs. HK and SCC (selectively suppressed in BCC) } \\
\hline miR-29c-3p & $\begin{array}{l}\text { Within last } \\
\text { exon of } \\
\text { C1orf132, } \\
\text { chromosome } 1 \\
\text { open reading } \\
\text { frame } 132 \\
\text { along with miR- } \\
\text { 29B2 }\end{array}$ & $\begin{array}{l}\downarrow_{111} \\
(B C C \text { vs. HK) } \\
\downarrow_{109} \\
(B C C \text { vs. SCC) }\end{array}$ & $\begin{array}{l}\text { 个Non-small cell lung } \\
\text { cancer } \\
\text { \Bladder cancer, } \\
\text { esophageal } \\
\text { squamous cell } \\
\text { carcinoma, Gastric } \\
\text { cancer, glioma, head } \\
\text { and neck squamous } \\
\text { cell carcinoma, } \\
\text { hepatocellular } \\
\text { carcinoma, Lung } \\
\text { adenocarcinoma, } \\
\text { nasopharyngeal } \\
\text { carcinoma, high- } \\
\text { metastatic lung } \\
\text { cancer, pancreatic } \\
\text { cancer }\end{array}$ & $(113-123)$ \\
\hline miR-381-3p & $\begin{array}{l}\text { Part of MIR381 } \\
\text { host gene } \\
\text { (MIR381HG) }\end{array}$ & $\begin{array}{l}\downarrow_{241} \\
(B C C \text { vs. HK) } \\
\downarrow_{181} \\
(B C C \text { vs. SCC) }\end{array}$ & $\begin{array}{l}\text { ^Osteosarcoma, } \\
\text { glioma } \\
\\
\text { \Oral squamous cell } \\
\text { carcinoma, Epithelial } \\
\text { ovarian cancer, } \\
\text { hepatocellular } \\
\text { carcinoma, colorectal } \\
\text { cancer, gastric } \\
\text { cancer, } \\
\text { breast cancer, renal } \\
\text { cell cancer, colon } \\
\text { cancer, Lung } \\
\text { Adenocarcinoma }\end{array}$ & $(124-133)$ \\
\hline
\end{tabular}




\begin{tabular}{|c|c|c|c|c|}
\hline $\operatorname{miR}-452-5 p$ & $\begin{array}{l}\text { Intronic } \\
\text { (embedded } \\
\text { within GABRE) }\end{array}$ & $\begin{array}{l}\downarrow 73 \\
\text { (BCC vs. HK) } \\
\downarrow_{152} \\
\text { (BCC vs. SCC) }\end{array}$ & $\begin{array}{l}\text { 个Hemangiosarcoma, } \\
\text { Clear Cell Renal Cell } \\
\text { Carcinoma, bladder } \\
\text { cancer } \\
\\
\downarrow \text { Lung } \\
\text { adenocarcinoma } \\
\text { (mir-452-5p), } \\
\text { chondrosarcoma, } \\
\text { gliomas, } \\
\text { osteosarcoma, non- } \\
\text { small cell } \\
\text { lung cancer, } \\
\text { prostate cancer, } \\
\text { head and neck } \\
\text { adenoid cystic } \\
\text { carcinoma in } \\
\text { comparison to head } \\
\text { and neck squamous } \\
\text { cell carcinoma }\end{array}$ & $(134-143)$ \\
\hline $\begin{array}{l}\operatorname{miR}-487 b- \\
3 p\end{array}$ & $\begin{array}{l}\text { Part of MIR381 } \\
\text { host gene } \\
\text { (MIR381HG) }\end{array}$ & $\begin{array}{l}\downarrow_{17} \\
(B C C \text { vs. HK) } \\
\downarrow_{31} \\
\text { (BCC vs. SCC) }\end{array}$ & $\begin{array}{l}\text { Wolon cancer } \\
\text { (487b-3p), high-risk } \\
\text { neuroblastoma, } \\
\text { pediatric glioma, } \\
\text { metastatic prostate } \\
\text { cancer }\end{array}$ & $(144-147)$ \\
\hline miR-494-3p & $\begin{array}{l}\text { One of a } \\
\text { cluster on } \\
\text { Chromosome } \\
14\end{array}$ & $\begin{array}{l}\downarrow_{20} \\
(B C C \text { vs. HK) } \\
\downarrow_{20} \\
(B C C \text { vs. SCC) }\end{array}$ & $\begin{array}{l}\text { TCervical cancer, } \\
\text { colorectal cancer, } \\
\text { Hepatocellular } \\
\text { carcinoma, non-small } \\
\text { cell lung cancer } \\
\\
\downarrow \text { Malignant breast } \\
\text { cancer, esophageal } \\
\text { squamous cell } \\
\text { carcinoma, gastric } \\
\text { carcinoma, oral } \\
\text { cancer, ovarian } \\
\text { cancer, pancreatic } \\
\text { cancer }\end{array}$ & $(148-157)$ \\
\hline miR-590-5p & $\begin{array}{l}\text { Intronic } \\
\text { (embedded } \\
\text { within EIF4H) }\end{array}$ & $\begin{array}{l}\downarrow_{111} \\
(B C C \text { vs. HK) } \\
\downarrow_{391} \\
\text { (BCC vs. SCC) }\end{array}$ & $\begin{array}{l}\text { TCervical cancer, } \\
\text { gastric cancer, vulvar } \\
\text { squamous cell } \\
\text { carcinoma, renal cell } \\
\text { carcinoma } \\
\text { WMalignant } \\
\text { melanoma, breast } \\
\text { cancer, colorectal } \\
\text { cancer }\end{array}$ & $(158-164)$ \\
\hline
\end{tabular}




\begin{tabular}{|c|c|c|c|c|}
\hline \multicolumn{5}{|c|}{ Differential expression BCC vs. HK } \\
\hline miR-139-3p & $\begin{array}{l}\text { Intronic } \\
\text { (embedded } \\
\text { within PDE2A) }\end{array}$ & $\uparrow 144$ & $\begin{array}{l}\downarrow \text { Colorectal and } \\
\text { bladder cancers, } \\
\text { supraglottic laryngeal } \\
\text { squamous cell } \\
\text { carcinoma, } \\
\text { Pancreatic ductal } \\
\text { adenocarcinoma, } \\
\text { breast cancer }\end{array}$ & $(165-168)$ \\
\hline miR-302b & $\begin{array}{l}\text { Anti-sense to } \\
\text { LARP7, part of } \\
\text { multi-miRNA } \\
\text { transcript }\end{array}$ & $\downarrow 56$ & $\begin{array}{l}\downarrow \text { High-grade gastric } \\
\text { adenocarcinoma, } \\
\text { gastric cancer, breast } \\
\text { cancer, } \\
\text { hepatocellular } \\
\text { carcinoma, ovarian } \\
\text { cancer, esophageal } \\
\text { squamous cell } \\
\text { carcinoma }\end{array}$ & $(169-174)$ \\
\hline miR-597 & $\begin{array}{l}\text { Intronic } \\
\text { (embedded } \\
\text { within TNKS) }\end{array}$ & $\downarrow 72$ & $\begin{array}{l}\downarrow \text { Colorectal and } \\
\text { breast cancer }\end{array}$ & $(175,176)$ \\
\hline \multicolumn{5}{|c|}{ Differential expression SCC vs. HK } \\
\hline $\operatorname{miR}-127-5 p$ & intronic & $\downarrow 207965$ & $\begin{array}{l}\downarrow \text { Breast cancer, } \\
\text { gastric cancer, } \\
\text { hepatocellular } \\
\text { carcinoma, } \\
\text { colon cancer } \\
\text { patients' stool }\end{array}$ & $\begin{array}{l}(93,177- \\
179)\end{array}$ \\
\hline $\operatorname{miR}-135 b$ & $\begin{array}{l}\text { Intronic } \\
\text { (embedded } \\
\text { within } \\
\text { BLACAT1) }\end{array}$ & $\uparrow 100$ & $\begin{array}{l}\text { Gastric cancer, } \\
\text { prostate cancer } \\
\text { glioblastoma } \\
\text { ^ Gastric } \\
\text { cancer mucosa, } \\
\text { cervical cancer, } \\
\text { colorectal cancer, } \\
\text { non small cell lung } \\
\text { cancer (highly } \\
\text { invasive), } \\
\text { glioblastoma }\end{array}$ & $\begin{array}{l}(180-188) \\
\text { Yu et al. } \\
2015)\end{array}$ \\
\hline $\mathrm{miR}-187$ & $\begin{array}{l}\text { Intergenic } \\
\text { (chromosome } \\
18 \text { ) }\end{array}$ & $\uparrow 45$ & $\begin{array}{l}\text { A Gastric cancer, } \\
\text { Oral squamous cell } \\
\text { carcinoma, ovary } \\
\text { clear cell carcinoma } \\
\\
\downarrow \text { Colorectal cancer, } \\
\text { clear cell renal cell }\end{array}$ & $\begin{array}{l}(180,189- \\
195)\end{array}$ \\
\hline
\end{tabular}




\begin{tabular}{|c|c|c|c|c|}
\hline & & & $\begin{array}{l}\text { carcinoma, } \\
\text { gallbladder cancer, } \\
\text { prostate cancer }\end{array}$ & \\
\hline miR-493 & $\begin{array}{l}\text { Intergenic } \\
\text { (chromosome } \\
14 \text { ) }\end{array}$ & 个38 & $\begin{array}{l}\text { TGastric cancer } \\
\text { (enhances invasion) } \\
\\
\boldsymbol{\downarrow} \text { Liver metastatic } \\
\text { colon cancer } \\
\text { (antimetastatic effect) }\end{array}$ & $(196,197)$ \\
\hline \multicolumn{5}{|c|}{ Differential expression SCC vs. BCC (invasion and metastasis associated) } \\
\hline let-7e & $\begin{array}{l}\text { Intronic } \\
\text { (embedded } \\
\text { within } \\
\text { SPACA6) }\end{array}$ & $\uparrow 32$ & 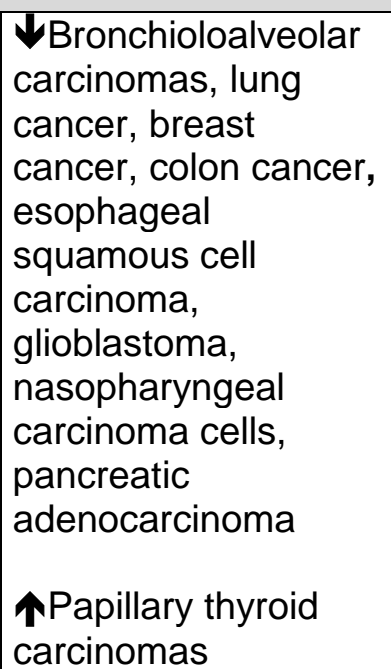 & $(198-207)$ \\
\hline $\operatorname{miR}-15 a-5 p$ & $\begin{array}{l}\text { Intronic } \\
\text { (embedded } \\
\text { within DLEU2) }\end{array}$ & 个120 & $\begin{array}{l}\text { TEsophageal } \\
\text { cancer, glioma, } \\
\text { neuroblastoma, } \\
\text { colorectal cancer } \\
\downarrow \\
\downarrow \text { Breast cancer, B- } \\
\text { cell } \\
\text { Chronic lymphocytic } \\
\text { leukemia, pituitary } \\
\text { adenomas, Prostate } \\
\text { cancer, colorectal } \\
\text { cancer, gastric } \\
\text { cancer, non-small } \\
\text { cell lung cancer, } \\
\text { osteosarcoma, } \\
\text { pancreatic cancer, } \\
\text { prostate cancer, } \\
\text { squamous cell } \\
\text { carcinomas and } \\
\text { adenocarcinomas of } \\
\text { the lung, } \\
\text { hepatocellular } \\
\text { carcinoma }\end{array}$ & (208-223) \\
\hline
\end{tabular}




\begin{tabular}{|c|c|c|c|c|}
\hline miR-95-3p & $\begin{array}{l}\text { Intronic } \\
\text { (embedded } \\
\text { within ABLIM2) }\end{array}$ & $\uparrow 269$ & $\begin{array}{l}\text { NColorectal cancer, } \\
\text { Non-small cell lung } \\
\text { cancer, head and } \\
\text { neck cancer, } \\
\text { pancreatic cancer, } \\
\text { Hepatocellular } \\
\text { carcinoma, glioma }\end{array}$ & (224-229) \\
\hline$m i R-362-5 p$ & $\begin{array}{l}\text { Intronic (One of } \\
\text { a cluster of } \\
\text { miRNAs in } \\
\text { CLCN5) }\end{array}$ & 个125 & $\begin{array}{l}\text { Chronic myeloid } \\
\text { leukemia, } \\
\text { hepatocellular } \\
\text { carcinoma, gastric } \\
\text { cancer } \\
\\
\downarrow \text { Cervical cancer, } \\
\text { renal cell carcinoma, } \\
\text { BRAF-mutated } \\
\text { colorectal cancers } \\
\downarrow \text { (miR-362-5p) ALK- } \\
\text { positive non-small } \\
\text { cell lung cancer, } \\
\text { breast cancer, } \\
\text { neuroblastoma, } \\
\text { colorectal cancer }\end{array}$ & $(230-239)$ \\
\hline miR-502-5p & $\begin{array}{l}\text { Intronic (One of } \\
\text { a cluster of } \\
\text { miRNAs in } \\
\text { CLCN5) }\end{array}$ & $\uparrow 66$ & \begin{tabular}{|l|} 
CConjunctival \\
malignant melanoma, \\
Merkel cell \\
carcinoma \\
\\
$\downarrow$ Colon cancer, \\
breast cancer \\
\end{tabular} & $(240-244)$ \\
\hline miR-518e & $\begin{array}{l}\text { Intergenic } \\
\text { (chromosome } \\
\text { 19) }\end{array}$ & $\uparrow 56$ & $\begin{array}{l}\text { 个Hepatocellular } \\
\text { carcinoma }\end{array}$ & $(245,246)$ \\
\hline $\begin{array}{l}\text { miR-520f - } \\
3 p\end{array}$ & $\begin{array}{l}\text { Intergenic } \\
\text { (chromosome } \\
19)\end{array}$ & 个7973 & $\begin{array}{l}\text { ^GLIOBLASTOMA } \\
\text { TUMOR CELLS } \\
\\
\begin{array}{l}\downarrow \\
\text { nastric carcinoma, } \\
\text { neuroblastoma }\end{array}\end{array}$ & $(247-249)$ \\
\hline miR-886-3p & $\begin{array}{l}\text { Intergenic } \\
\text { (chromosome } \\
5 \text { ) }\end{array}$ & 个13 & $\begin{array}{l}\text { †ALK-positive } \\
\text { Anaplastic large-cell } \\
\text { lymphomas } \\
\\
\downarrow \text { Papillary thyroid, } \\
\text { Small-cell } \\
\text { lung cancer, } \\
\text { squamous cell lung } \\
\text { carcinoma }\end{array}$ & $(250-253)$ \\
\hline
\end{tabular}




\section{Discussion}

Ultraviolet light in sunlight is the most common cause of skin cancer. Exposures have a cumulative mutagenic effect on cellular DNA. Carcinogenesis has been demonstrated when cellular function is disturbed by mutations in tumor suppressors, oncogenes, transcription factors, and nucleotide excision repair proteins (254). Chronic arsenic exposure is the second most common cause of skin cancer. The mechanism(s) of arsenic-induced skin cancer is not completely characterized, but evidence suggests that mutations are not the main driving force $(255,256)$. Other pathways have been hypothesized including DNA repair inhibition, cell cycle pathway dysregulation and epigenetic modification including histone acetylation, methylation and phosphorylation, and miRNA expression alterations $(25,26,257-259)$. In particular, dysregulation of miRNA expression has been implicated in a wide variety of cancers (260).

In the current chapter, the potential role of dysregulation of miRNA expression in arsenic-induced carcinogenesis was investigted. Differential miRNA expression was characterized in human arsenic-induced skin lesion samples collected from individuals exposed to high levels of arsenic in their drinking water. An important observation is that the histopathology of the samples revealed potential confounding characteristics of the lesions especially for the premalignant arsenic-induced skin lesions. The histological diagnosis of the HK samples was critical because many of HK samples showed dysplasia with some even resembling early Bowen's disease. These samples were excluded from the miRNA analyses. However, three HK lesions with no signs of 
dysplasia were selected for further processing and their profiles were compared to malignant BCC and SCC lesions. The age of the samples resulted in loss of RNA integrity reducing yield. Many samples yielded insufficient amounts for the RT-qPCR array analysis. Thus, a weakness of the current study is the small number of samples analyzed. In spite of this limitation, miRNA expression profiles distinguishing the malignant $\mathrm{BCC}$ and $\mathrm{SCC}$ from the premalignant $\mathrm{HK}$ were obtained.

The results showed differential expression of 35 miRNAs in the premalignant and malignant lesions. Some of differentially expressed miRNAs were lesion or stage specific. For example, expression of miRNAs miR-425-5p and miR-433 was higher in both $\mathrm{BCC}$ and SCC relative to $\mathrm{HK}$, with no significant difference in expression between SCC and BCC. This result suggests that increased expression of miR-425-5p and miR433 is associated with malignancy progression from premalignant lesions (Table 3, Fig. 4A.). Consistent with this suggestion, miR-425-5p is an intronic miRNA embedded within the DALRD3 (DALR anticodon binding domain containing 3 gene) and has been reported to be induced in metastatic gastrointestinal cancers such as gastric and colorectal cancer and possibly associated with melanoma (88-90). MiR-433 is embedded antisense within RTL1 (retrotransposon Gag like 1) and studies have shown that it is associated with poor progression-free survival in high-grade serous ovarian cancer patients (91). MiR-433 also is induced in liver cancer (92) and metastatic bladder cancer (94) suggesting it is acting as an oncogene, but it is suppressed in gastric cancer suggesting it is functioning as a tumor suppressor in 
pathogenesis of this cancer type (93). Thus, the role of miR-433 may be context specific.

Similarly, two miRNAs, miR-184 and miR-576-3p, were induced in SCC relative to $\mathrm{BCC}$ and $\mathrm{HK}$ suggesting that the increased expression is associated with the invasive and metastatic phenotype of SCC (Table 3, Fig. 4B.) (13). MiR184 is embedded antisense to ANKRD34C-AS ( ANKRD34C antisense RNA 1) and was reported to be induced in several squamous cell carcinomas including tongue SCC (97) and head and neck squamous cell carcinoma (100), glioma (99), invasive breast cancer (102), hepatocellular carcinoma $(108,109)$, and in sebaceous carcinomas vs. adenomas (104). MiR-184 was reported to be suppressed in prostate carcinoma (96), breast cancer (98), neuroblastoma (101), epithelial ovarian cancer (103), non-small cell lung cancer (105) and small cell lung cancer (106), and renal cell carcinoma (107). Thus, a role as oncogene or tumor suppressor also may be context specific. MiR-576-3p is an intronic miRNA embedded within SEC24B (SEC24 homolog B, COPII coat complex component gene) and is suppressed in bladder cancer, T-cell precursor acute lymphoblastic leukemia, and sera of non-melanoma skin cancer patients (BCC and SCC, UV light related) (Balci et al. 2016; Coskun et al. 2013; Z Liang et al. 2015). Thus, the role of miR-578 is unclear at this time.

Six miRNAs (miR-29c, miR-381, miR-452, miR-487b, miR-494 and miR590-5p) were suppressed in BCC relative to both SCC and HK suggesting that their suppression is BCC phenotype specific (Table 3, Fig. 4C). MiR-29c is embedded within last exon of C1orf132 (chromosome 1 open reading frame 
132), the transcript of which encodes an unknown open reading frame. MiR-29c was found induced in non-small cell lung cancer (261). However, consistent with its suppression in BCC, miR-29c was reported to be suppressed in several cancers including bladder cancer, esophageal squamous cell carcinoma, gastric cancer, head and neck squamous cell carcinoma, hepatocellular carcinoma, lung adenocarcinoma, nasopharyngeal carcinoma, high-metastatic lung cancer, pancreatic cancer and glioma $(113-121,123)$. MiR-381 and miR-487b were both suppressed in BCC. These miRNAs, along with four other miRNAs (miR-539, miR-889, miR-544a, miR-655), are part of the MIR381 host gene (MIR381HG). These other four miRNAs are all 3' of miR-381 and miR-487b and were not differentially expressed among our HK, BCC and SCC samples. Although miR381 was reported to be induced in osteosarcoma and glioma, consistent with our observation of suppression in BCC miR-381 was suppressed in several other cancers including oral squamous cell carcinoma, epithelial ovarian cancer, hepatocellular carcinoma, colorectal cancer, gastric cancer, breast cancer, renal cell cancer, colon cancer and lung adenocarcinoma (124-133). Likewise, we saw that miR-487b-3p was suppressed in BCC and it has been reported as suppressed in colon cancer, high-risk neuroblastoma, pediatric glioma and metastatic prostate cancer (144-147). MiR-452-5p is embedded in an intron of GABRE (gamma-aminobutyric acid type A receptor epsilon subunit gene) and was suppressed in BCC. As for several other miRNAs suppressed in BCC, miR452-5p was induced in several malignancies (hemangiosarcoma, clear cell renal cell carcinoma and bladder cancer), but found to be suppressed in several other 
cancers and sarcomas (lung adenocarcinoma, chondrosarcoma, gliomas, osteosarcoma, non-small cell lung cancer, prostate cancer and head and neck adenoid cystic carcinoma vs. head and neck squamous cell carcinoma) (134143). MiR-494 is one of a cluster of five miRNAs on Chromosome 14, but only miR-494-3p was found to be differentially expressed in HK, BCC or SCC. Contrary to our finding of it being suppressed in $\mathrm{BCC}$ relative to SCC and $\mathrm{HK}$, miR-494 is induced in several cancers (malignant breast cancer, esophageal squamous cell carcinoma, gastric carcinoma, oral cancer, ovarian cancer and pancreatic cancer) (148-157). Rather than inferring its suppression in BCC, perhaps it is induced early in the transformation of keratinocytes to SCC. MiR590-5p is embedded in EIF4H (eukaryotic translation initiation factor $4 \mathrm{H}$ gene). Like several other miRNAs found suppressed in BCC, miR-590-5p was found to be induced in several cancers (cervical cancer, gastric cancer, vulvar squamous cell carcinoma, renal cell carcinoma) and suppressed in others (malignant melanoma, breast cancer, colorectal cancer) (158-164). Thus, the weight of evidence suggests that these miRNAs suppressed in BCC likely are tumor suppressors. This inference is supported by the observation by others that these miRNAs are suppressed in a wide variety of other tumor types.

The three miRNAs with the highest fold change in SCC relative to HK and BCC were miR-520f and miR-184 (both induced) and miR-127-5p (suppressed) with fold changes of 7973,1373 and 207965 respectively (Table 2, Supp. Table 1). MiR-520f is an intergenic miRNA located on Chromosome 19. MiR-520f was found to be induced in glioblastoma tumor cells and suppressed in gastric 
carcinoma and neuroblastoma (247-249). In this data set, miR-520f was induced in SCC relative to $\mathrm{BCC}$ lesions suggesting its possible association with invasive properties of SCC. However, a study on PANC-1 cells (human pancreatic carcinoma cell line) showed that overexpressing miR-520f lead to reversing epithelial-to-mesenchymal transition exerting anti-invasive and antimetastatic effects (262). Thus, the potential role of miR-520f in arsenic-induced SCC is unclear. A study by Wong et al. on tongue SCC cell lines suggested that miR-184 is an oncogenic miRNA or an "oncomir" (97). The study showed that the inhibition of miR-184 leads to reducing cell proliferation and increasing apoptosis in three tongue SCC cell lines (97). MiR-184 was induced in our SCC samples compared to both $\mathrm{HK}$ and $\mathrm{BCC}$ samples suggesting that it is an oncomir that may also play a role in cell invasion considering the invasive nature of SCC tumors. MiR-127-5p was found suppressed in breast cancer, gastric cancer, hepatocellular carcinoma and colon cancer patients' stool (Supp. Table 1) (93, 177-179). These results suggest that miR-127-5p is a tumor suppressor. MiR$127-5 p$ was suppressed only in our SCC samples suggesting that it is maybe more relevant to the invasive properties of SCC tumors. This suggestion is supported by a study showing that miR-127-5p suppresses MMP-13 and IL-1 $\beta$ responses in human chondrocytes and the decreased expression of miR-127-5p enhances the progression of cartilage destruction (263).

Not only does arsenic driven skin cancer have a different pattern of pathology and progression to malignancy than sunlight-induced skin cancer, but also different miRNA expression profiles. The miRNA expression of miR-576-3p 
reported by Balci et al. for sunlight-induced BCC and SCC is not reflected in the miRNA expression profiles of arsenic-induced BCC and SCC in the current study (111), providing further support for the difference in etiology between arsenicinduced and sunlight-induced skin cancers. 
CHAPTER 3

DIFFERENTIALLY EXPRESSED MIRNAS AND MRNAS AT EARLY STAGES OF TRANSFORMATION OF HACAT CELLS CHRONICALLY EXPOSED TO

LOW ARSENITE

\section{Introduction}

Several arsenic toxicity and carcinogenicity mechanisms have been suggested and proposed including abnormal signaling cascades, oxidative stress, and chromosomal aberrations as well as abnormal transcriptional activity and global gene expression (264). Moreover, arsenic can induce environmentally-driven epigenetic alterations that are known to influence disease development, including differential miRNA expression $(265,266)$. MiRNAs play a role in all the most important processes in every biological system (36). A single miRNA can target hundreds of mRNAs, and the expression of a gene can be regulated by multiple miRNAs creating complex feedback and feed-forward gene regulatory loops in a cell. MiRNAs target mRNAs by hybridization to complementary sequences in their 3'-untranslated regions (UTRs) and repress translation (267). Recent studies on some miRNAs showed they also can bind to the 5'-UTR or the open reading frame (ORF) region (35). The regulatory loops provide checks and balances within and across gene networks $(37,38)$. 
Several studies have shown that differential miRNA expression can be a hallmark of cancer and miRNAs can function as potential oncogenes or tumor suppressor genes influencing tumor development, progression and response to therapy $(35,268)$. MiRNAs exhibit differential expression in different cancers, including cervical, lung, esophageal, oral, pharyngeal and tongue squamous cell carcinoma (39). Furthermore, dysregulation of several miRNAs, including miR21, miR-200a, miR-141 and let-7c, has been reported in HaCaT cells after acute or sub-chronic exposure to moderate levels of arsenic $(47,265)$.

HaCaT cells are a spontaneously immortalized human epithelial cell line established in 1988 from adult human skin (64). HaCaT cells are an in vitro model for normal human keratinocytes and are commonly used to study epidermal carcinogenesis (269). HaCaT cells malignantly transformed by chronic incubation in low concentration of sodium arsenite (66) are the only currently available in vitro model to study arsenic-induced skin carcinogenesis $(185,270$ 274). However, miRNA expression profiling has never been obtained in human keratinocytes chronically exposed to low arsenic (100 nM). This chapter is focused on understanding the role of differentially expressed miRNA and their target genes. For broad detection coverage, hybridization microarrays were used to measure mRNAs and small RNAs differentially expressed at the early stages of arsenic-induced skin cancer using $\mathrm{HaCaT}$ cells exposed to $100 \mathrm{nM} \mathrm{NaAsO}$, for 3 and 7 weeks. TP53 and PTEN regulatory pathways were also found dysregulated, offering a potential means for suppression of these tumor suppressors in lieu of mutation playing a role in arsenic induced skin 
carcinogenesis. Moreover, the current chapter discusses the growth curves of the HaCaT cell chronic arsenic exposure model. The growth pattern of the cells changed over the different stages of exposure till reaching transformation. 


\section{Materials and Methods:}

\section{a. Cell Culture and RNA Isolation}

HaCaT cells were the kind gift of Dr. TaiHao Quan, University of Michigan. The cells were cultured in MEM alpha modification media supplemented with $10 \%$ fetal bovine serum, 100 units $/ \mathrm{mL}$ penicillin $/ 100 \mu \mathrm{g} / \mathrm{mL}$ streptomycin) and 2 $\mathrm{mM}$ glutamine. Cultures were maintained at $37^{\circ} \mathrm{C}$ in a humidified $5 \%$ $\mathrm{CO}_{2}$ atmosphere. Multiple cultures of cells ( 4 with and 4 without $100 \mathrm{nM} \mathrm{NaAsO}$ ) were maintained separately for 32 weeks. Cells were passaged twice a week and a million cells were plated per $100 \mathrm{~mm}$ dish every time. At each passage, the cells were counted and population doublings were calculated along with the means \pm SD of cumulative doubling. Statistical analysis was performed by twoway ANOVA, p-value $\leq 0.05$ was considered significant.

$\mathrm{NaAsO}_{2}$ (CAS 7784-0698) was obtained from, Fisher Scientific, Waltham, MA, USA. Total RNA was purified from the cells (quadruplicate unexposed and exposed cultures) after 3, 7, 19 and 28 weeks using the mirVana ${ }^{\text {TM }}$ RNA Isolation Kit (Thermo Fisher Scientific Inc., Waltham, MA, USA). RNA quality was determined using the Agilent RNA 6000 Pico Kit, Eukaryote, version 2.6 and the Agilent 2100 Bioanalyzer instrument (Agilent Technologies, Inc., Santa Clara, CA, USA). All samples used had RIN (RNA integrity number) $>9$.

\section{b. Hybridization Microarray Analysis}

Expression profiles of mRNA and small RNA were obtained for $\mathrm{HaCaT}$ cells exposed to arsenite for 3 and 7 weeks using the GeneChip® PrimeView ${ }^{\mathrm{TM}}$ 
Human Gene Expression and GeneChip $\AA$ miRNA 4.0 Affymetrix arrays. The former, used for measuring mRNA expression, contains more than 530,000 probes that detect over 36,000 transcripts and variants, representing over 20,000 genes mapped via RefSeq or via UniGene annotation. The latter probes for small non-coding RNA transcripts: 100\% miRBase v20 coverage, 30,424 mature miRNA (all organisms), 5,214 human, mouse, and rat miRNA, 1,996 human snoRNA, scaRNA and 3,770 probe sets unique to human, mouse, and rat premiRNA hairpin sequences including three types of small RNAs, snoRNAs, and both stem-loop and mature miRNAs. Biotinylated cRNA was prepared according to the standard protocol for Affymetrix 3' IVT Express Plus Reagent Kit from 250 ng total RNA. Following fragmentation, cRNA was hybridized for $16 \mathrm{~h}$ at $45^{\circ} \mathrm{C}$ to Affymetrix Primeview Human arrays according to the Affymetrix GeneChip 3' array Hybridization User Manual. GeneChips were scanned using GeneChip Scanner $30007 \mathrm{G}$ (Affymetrix) and the GeneChip Command Console 4.0 (Affymetrix). For miRNA 4.0 arrays, biotinylated RNAs were prepared according to the standard protocol for Affymetrix FlashTag Biotin HSR RNA labeling Kit from $800 \mathrm{ng}$ total RNA. Biotin-labeled samples were hybridized for $18 \mathrm{~h}$ at $48{ }^{\circ} \mathrm{C}$ to Affymetrix miRNA 4.0 arrays. GeneChips were scanned using GeneChip Scanner $30007 \mathrm{G}$ (Affymetrix) and the GeneChip Command Console 4.0 (Affymetrix). The CEL files were imported into Partek software Version 6.6 (Partek Inc) and normalized using Robust Multi-Array (RMA) normalization. Contrasts of interest were analyzed using a 2-way ANOVA considering treatment and time. Using Partek Genomic Suite ${ }^{\mathrm{TM}}$, potential targets of 6 of 19 differentially 
expressed miRNAs ( $p$-value $\leq 0.05$ ) at both 3 and 7 weeks were obtained from the TargetScanHuman 6.2 database (2450 genes). Intersecting the target mRNA list with the differentially expressed mRNA lists at both 3 and 7 weeks (323 mRNAs, p-value $\leq 0.05$ ), we obtained a list of differentially expressed mRNAs that are potential targets of differentially expressed miRNAs at both 3 and 7 weeks based on having the same probe annotation number on GeneChip (Fig. 3.2). Data have been deposited in the GEO database, accession number102 GSE97306.

Most of miRNAs lead the RNA-induced silencing complex (RISC) to the $3^{\prime}$ UTRs of their mRNA targets causing degradation or inhibiting translation of the mRNAs $(34,275)$. Using this approach, we obtained a lists of differentially expressed target mRNAs at 3 weeks and 7 weeks with expression direction opposite to that of the targeting miRNAs (differentially expressed miRNAs at 3 weeks, $p$-value $\leq 0.05)$, e.g. induced mRNA targets for suppressed miRNA and vice versa.

\section{c. Immunoblotting:}

Total protein was extracted from the cells (quadruplicate unexposed and exposed cultures) after 7 weeks using Lysis solution $(0.01 \mathrm{M}$ Tris- $\mathrm{HCl} \mathrm{pH} 7.4,1$ mM EDTA, $0.1 \%$ SDS, $180 \mu \mathrm{g} / \mathrm{mL}$ PMSF and $1 \mathrm{X}$ protease inhibitor cocktail (Complete, Roche, Mannheim, Germany)). Lysates were sonicated and protein concentrations were measured using the BCA assay kit (Sigma-Aldrich, BCA1 and B9643). Proteins were resolved by electrophoresis using Bio-Rad 4-15\% Mini-PROTEAN® TGXTM Precast Protein gels. Gels were electrotransferred onto 
cellulose nitrate (wet transfer). Membranes were blocked using 5\% skim milk in Tris-buffered saline containing $0.1 \%$ Tween-20 (TBS-T) for $2 \mathrm{~h}$, then incubated at $4^{\circ} \mathrm{C}$ overnight with the following antibodies diluted in $5 \%(\mathrm{w} / \mathrm{v})$ BSA in TBS-T: rabbit mAb anti-HMG1 (D3E5) (6893S) (Cell Signaling Inc, Danvers, MA) (1:800), mouse monoclonal anti-MDM2 (Santa Cruz Biotechnology, Inc., Dallas, TX.) (1:800), rabbit polyclonal anti-TP53 (\#9282) (1:650), rabbit polyclonal antiPhospho-p53 (Ser15) (1:800) and rabbit polyclonal anti-Acetyl-p53 (Lys382) (1:800) (Cell Signaling Inc, Danvers, MA), followed by an anti-rabbit (for antiHMG, anti-TP53, anti- Phospho-p53, anti- Acetyl-p53) and anti-mouse (for antiMDM2) secondary antibodies conjugated with horseradish peroxidase (Cell Signaling, 7074 and 7076 respectively) (1:3000). PageRuler Plus Prestained Protein Ladder \#26619 (Thermo Fisher Scientific, Waltham, MA) was used as a molecular weight marker. $\beta$-Actin was used loading control using . Antibody reactive bands were detected using Pierce ${ }^{\mathrm{TM}}$ ECL Plus kit (Thermo Scientific, 32132). Imaging and quantitation was done using ImageQuant ${ }^{\mathrm{TM}}$ LAS 4000 biomolecular imager (GE Healthcare Life Sciences, Pittsburgh, PA). Two-tailed Student T-Test was used for statistical analyses. 


\section{Results}

\section{a. Growth Rates of Arsenite Exposed Cells were Slower at Earlier Times and}

\section{$\underline{\text { Faster at Later Times }}$}

At each passage, the population doublings were calculated and the means \pm SD of cumulative doubling were plotted (Fig. 3.1). The results showed that growth rates of arsenite exposed cells were slower at earlier times prior to 19 weeks then the growth curve shifted and the cells grew faster at later times. 


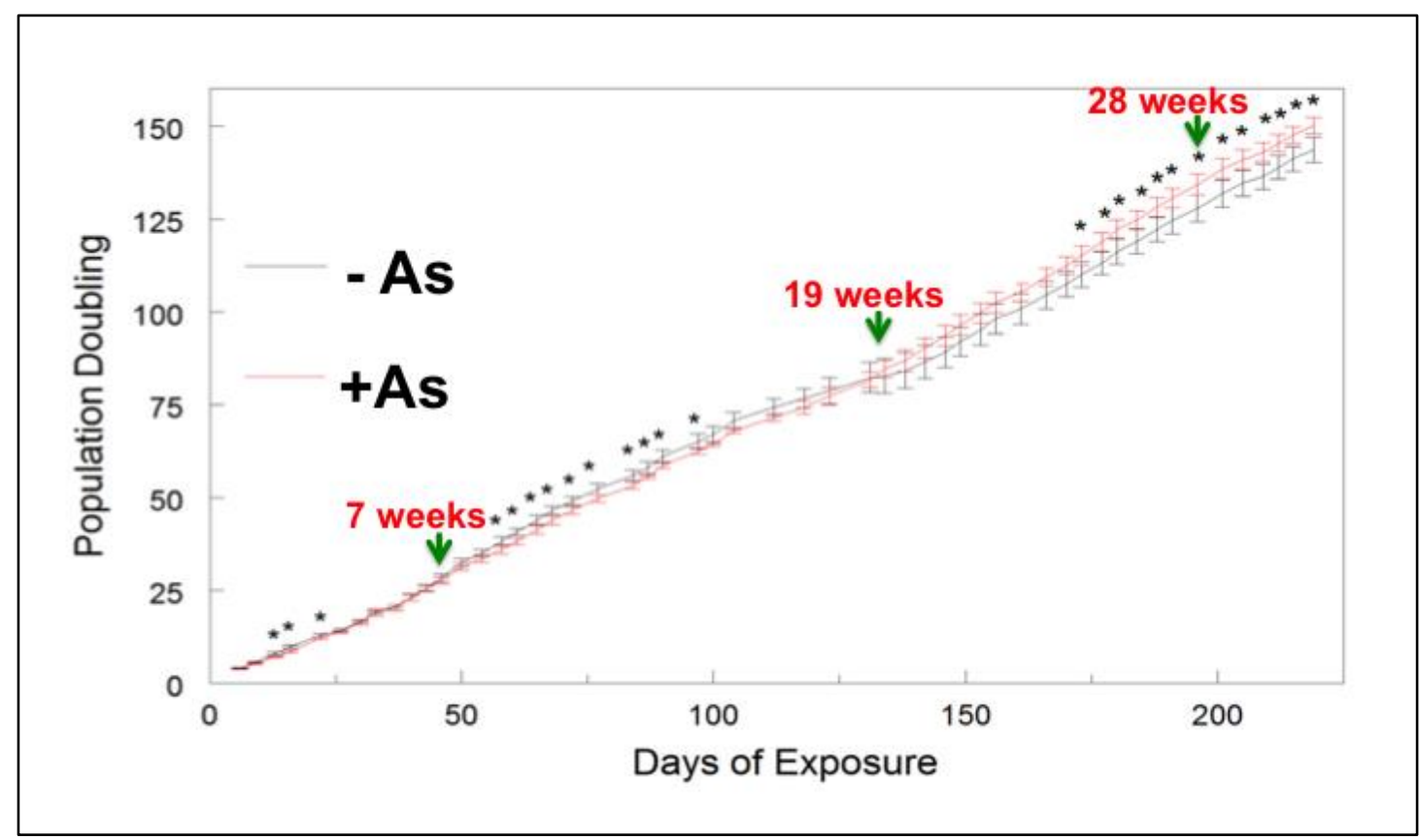

Figure 3.1. Impact of arsenite exposure on cumulative HaCaT cell population doubling. Quadruplicate $\mathrm{HaCaT}$ cell cultures were incubated with 0 or $100 \mathrm{nM} \mathrm{NaAsO}$. Population doublings were calculated and the means $\pm \mathrm{SD}$ of cumulative doubling at each passage were plotted. Growth rates of arsenite exposed cells were slower at earlier times and faster at later times. Statistical analysis was done by two-way ANOVA, ${ }^{*} p \leq 0.05$ 


\section{b. Arsenite-dependent small RNA and mRNA differential expression:}

Samples of RNA purified from quadruplicate cultures of exposed and unexposed HaCaT cells at 3 and 7 weeks of arsenite exposure were analyzed by hybridization to miRNA 4.0 Affymetrix microarrays. The results showed that 293 and 373 small RNAs were differentially expressed respectively after 3 and 7 weeks exposure to $100 \mathrm{nM}$ sodium arsenite ( $\mathrm{p}$-value $\leq$ 0.05) (Fig. 3.2.A). Nineteen small RNAs were differentially expressed at both time points and included 8 snoRNAs, 5 stem-loop miRNAs (miR-339, miR-1228, miR-4309, miR4692, miR-548au) and 6 mature miRNAs (miR-548a-3p, miR-2682-5p, miR3618, miR-8083, miR-1254, miR-645) (Table 3.1). Unsupervised hierarchical clustering of these 19 small RNAs showed exposure-dependent differential expression of 12 small RNAs with 4 increased and 8 decreased compared to unexposed cells at both time points (Fig. 3.2.B). Time-dependent differential expression was observed for 6 small RNAs and this differential expression was reversed by arsenite exposure (Fig. 3.2.C). Analysis of mRNA expression revealed that 1197 and 4840 mRNAs were differentially expressed after 3 and 7 weeks exposure to $100 \mathrm{nM}$ sodium arsenite ( $p$-value $\leq 0.05$ ), respectively, and 323 mRNAs were differentially expressed at both time points (Fig. 3.2.D) 


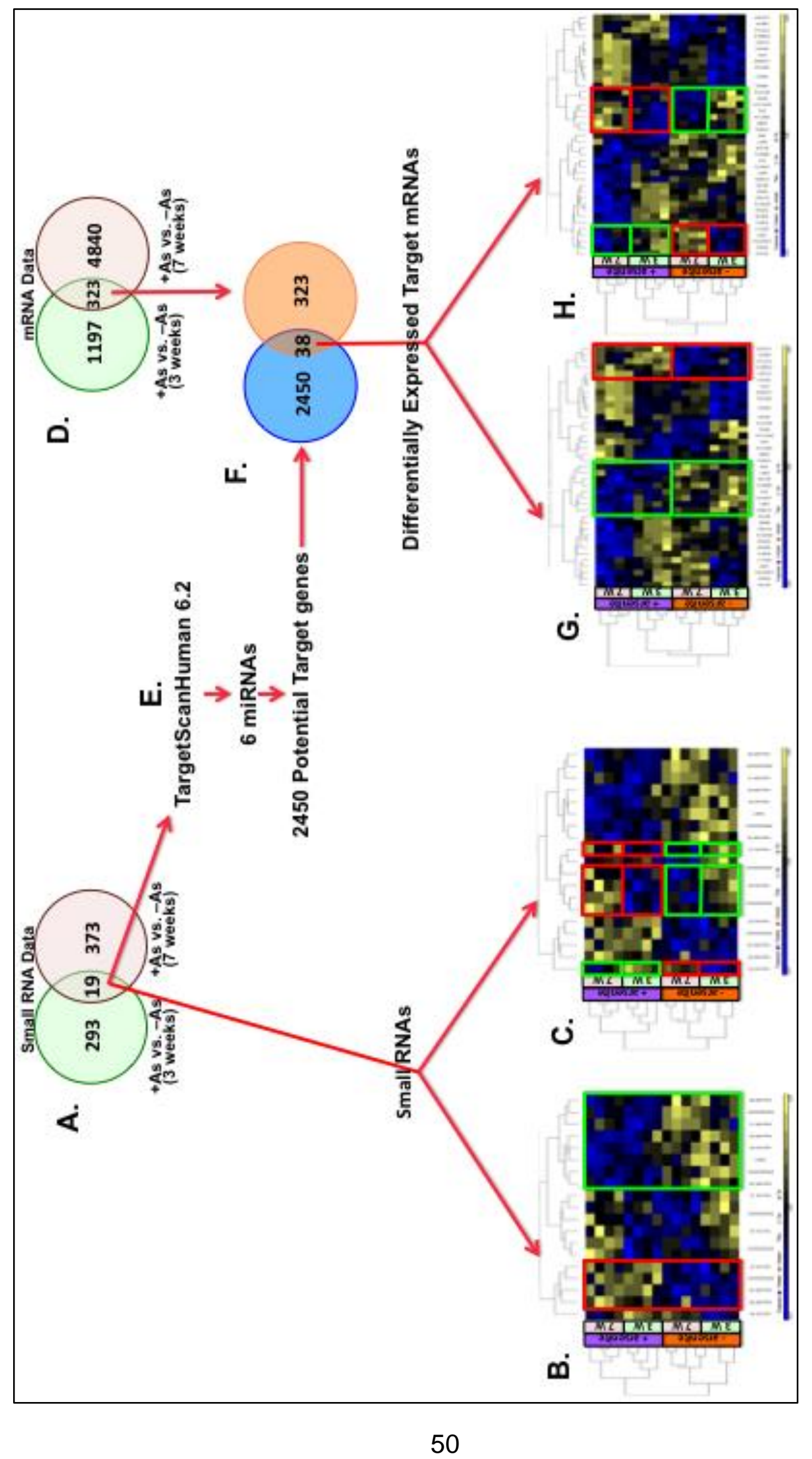


Figure 3.2. Exposure and time-dependent Differential Expression of Small RNAs and mRNAs detected by hybridization microarrays. A) Venn diagrams of differentially expressed small RNAs at both 3 and 7 weeks $(p<0.05)$. B,C) Unsupervised hierarchical clustering of the 19 small RNAs differentially expressed at both 3 and 7 weeks of exposure to arsenite. B) Arsenite exposuredependent induced (red boxed) and suppressed (green boxed) small RNAs. C) Time-dependent differentially expressed miRNAs and the expression pattern is flipped by arsenite exposure compared to non-exposed cells, induced (red boxed) and suppressed (green boxed). D) Venn diagram of differentially expressed mRNAs at 3 and 7 weeks. E) Predicted mRNA targets of 6 differentially expressed miRNAs were found in TargetScan Human V6.2 database. F) Venn diagram of intersection of predicted mRNA targets of differentially expressed miRNAs and differentially expressed 323 mRNAs at both 3 and 7 weeks. G,H) Unsupervised hierarchical clustering of the 39 mRNAs differentially expressed at both 3 and 7 weeks of exposure to arsenite that are predicted targets of 6 miRNAs differentially expressed at both 3 and 7 weeks. G) Arsenite exposure-dependent induced (red boxed) and suppressed (green boxed) mRNAs. H) Time-dependent differentially expressed mRNAs and the expression pattern is flipped by arsenite exposure compared to non-exposed cells, induced (red boxed) and suppressed (green boxed). Analysis was done using Partek Genomic Suite ${ }^{\mathrm{TM}}$. 
Table 3.1. Differentially expressed small RNAs at both 3 and 7 weeks of exposure to arsenite

\begin{tabular}{|c|c|c|c|c|c|c|}
\hline \multirow[b]{2}{*}{ \# } & \multirow{2}{*}{$\frac{\text { Transcript ID }}{(\text { Array Design })}$} & \multirow{2}{*}{$\frac{\text { Sequence }}{\text { Type }}$} & \multicolumn{2}{|c|}{3 weeks } & \multicolumn{2}{|c|}{7 weeks } \\
\hline & & & Fold- & $\mathrm{p}$-value & Fold- & p-value \\
\hline 1. & $14 q \| l-1$ & $\begin{array}{l}\text { CDBox } \\
\text { (sub-type } \\
\text { of snoRNA) }\end{array}$ & -1.197 & 0.04363 & -1.296 & 0.00691 \\
\hline 2. & ENSG00000212338 & snoRNA & -1.246 & 0.02753 & 1.241 & 0.02979 \\
\hline 3. & ENSG00000221345 & snoRNA & -1.132 & 0.01756 & 1.148 & 0.00968 \\
\hline 4. & ENSG00000221496 & snoRNA & 1.187 & 0.00091 & 1.109 & 0.02166 \\
\hline 5. & ENSG00000238611 & snoRNA & -1.070 & 0.02915 & -1.121 & 0.00132 \\
\hline 6. & ENSG00000238807 & snoRNA & -1.351 & 0.00779 & 1.307 & 0.01494 \\
\hline 7. & ENSG00000239188 & snoRNA & -1.562 & 0.00005 & -1.235 & 0.01288 \\
\hline 8. & ENSG00000252290 & snoRNA & -1.241 & 0.02864 & 1.237 & 0.03033 \\
\hline 9. & hsa-miR-339 & stem-loop & 1.289 & 0.03267 & 1.312 & 0.02403 \\
\hline 10. & hsa-miR-1228* & stem-loop & -1.167 & 0.02415 & 1.160 & 0.02888 \\
\hline 11. & hsa-miR-4309* & stem-loop & 1.448 & 0.00026 & -1.172 & 0.04897 \\
\hline 12. & hsa-miR-4692 & stem-loop & -1.298 & 0.03144 & 1.284 & 0.03749 \\
\hline 13. & hsa-miR-548au & stem-loop & -1.234 & 0.02995 & -1.292 & 0.01113 \\
\hline 14. & hsa-miR-548a-3p* & miRNA & -2.388 & 0.02041 & -2.564 & 0.01362 \\
\hline 15. & hsa-miR-645* & miRNA & 1.194 & 0.03779 & 1.204 & 0.03067 \\
\hline 16. & hsa-miR-1254* & miRNA & -1.671 & 0.02557 & -1.657 & 0.02756 \\
\hline 17. & hsa-miR-2682-5p & miRNA & 1.189 & 0.03746 & 1.316 & 0.00298 \\
\hline 18. & hsa-miR-3618* & miRNA & -1.183 & 0.03511 & -1.194 & 0.02762 \\
\hline 19. & hsa-miR-8083 & miRNA & -1.270 & 0.03868 & -1.287 & 0.03050 \\
\hline
\end{tabular}




\section{c. Cancer associated pathways of arsenite-dependent mRNA differential}

expression (targets of differentially expressed small RNAs)

In order to learn about the potential impact of the 11 differential expressed miRNAs (Table 3.1), potential targets of differentially expressed miRNAS was sought. Only 6 of the 11 miRNAs had predicted targets listed (Fig. 3.2.E). There were 2450 potential targets of these 6 miRNAs listed in TargetScanHuman 6.2 database. By intersecting the list of predicted target mRNAs (2450 mRNAs) with the 323 mRNAs differentially expressed at both 3 and 7 weeks of arsenite exposure (Fig. 3.2.D), 38 predicted target mRNAs were found differentially expressed in arsenic-exposed cells at both time points ( $p$-value $\leq 0.05$ ) (Fig. 3.2.F). Unsupervised hierarchical clustering of the $38 \mathrm{mRNAs}$ showed exposuredependent differential expression of 13 mRNAs with 5 increased and 8 decreased compared to unexposed cells at both time points (Fig. 3.2.G). Timedependent differential expression was also observed for some of the 38 mRNAs. In comparison to 3 weeks, 15 mRNAs were induced and 15 were suppressed at 7 weeks. Expression of twelve mRNAs were reversed by arsenite exposure (Fig. 3.2.H).

In order to gain an understanding of the potential impact of these differentially expressed genes, we performed pathway analysis using Metacore ${ }^{\mathrm{TM}}$ software to place the differentially expressed target mRNAs on pathways. The top ten pathways are listed in Table 3.2. 
Table 3.2. Top 10 pathways of the differentially expressed 38 mRNAs at both 3 and 7 weeks that are predicted targets of miRNAs differentially expressed at both 3 and 7 weeks.

\# Pathway

FDR

1. Development WNT signaling pathway.

1.231E-02

Part 1. Degradation of beta-catenin in the absence WNT signaling

2. Action of GSK3 beta in bipolar disorder

$1.231 \mathrm{E}-02$

3. Cytoskeleton remodeling TGF, WNT and cytoskeletal remodeling

4. Signal transduction PTEN pathway

$1.231 \mathrm{E}-02$

$2.498 \mathrm{E}-02$

5. Immune response NFAT in immune response

2.498E-02

6. Development WNT signaling pathway. Part 2

2.50E-02

7. PGE2 pathways in cancer

2.50E-02

8. Immune response CD28 signaling

$2.50 \mathrm{E}-02$

9. Ligand-independent activation of Androgen receptor in Prostate Cancer

2.92E-02

10. Signal transduction mTORC2 downstream signaling

2.92E-02 
Three of these pathways, cytoskeleton remodeling (predicted to be induced), WNT signaling (predicted to be induced) and signal transduction PTEN (predicted to be suppressed), are all known to play a role in carcinogenesis, and have a single mRNA in common. This mRNA, TCF7L2, was induced at 3 and 7 weeks and is a predicted target for miR-548a-3p, which is significantly suppressed at both 3 and 7 weeks (Table 3.1). TCF7L2 is a transcription factor that participates in the WNT signaling pathway (among others) and promotes cMYC expression (276). TCF7L2 has a known role in colon cancer $(277,278)$. These results suggest that the chronic arsenite exposure at early times decreases the expression of miR-548a-3p, relieving suppression of TCF7L2 expression. The increase in TCF7L2 expression then promotes these oncogenic pathways (Fig. 3.3). 


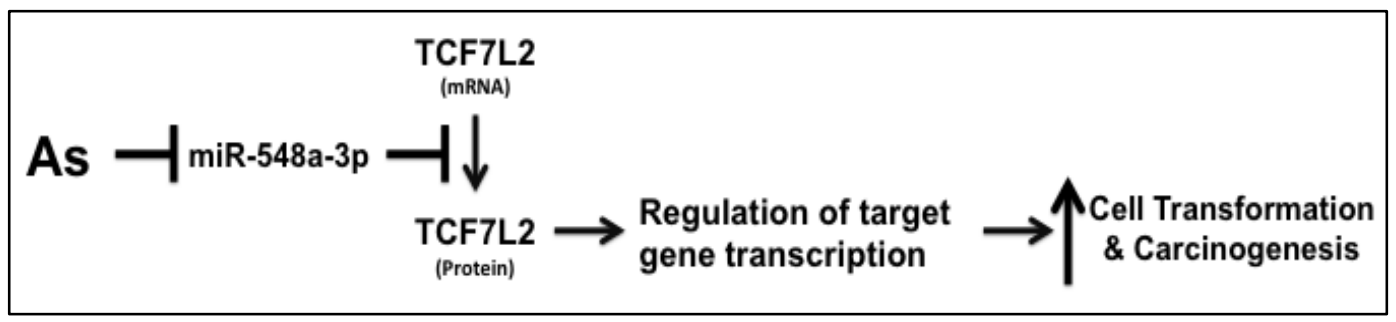

Figure 3.3. Arsenite exposure suppresses miR-548a-3p relieving suppression of TCF7L2 translation and enabling repression of oncogenic pathways. ATCF7L2, a target of miR-548a-3p, expression induction at early stages of arsenite exposure suggests that arsenite decreases the expression of miRNAs $548 a-3 p$ that leads to increasing mRNA levels of TCF7L2 which regulate its target genes participating in transformation and carcinogenesis processes. 
In addition to TCF7L2, MDM2 (mouse double minute 2 homolog) also is among the 38 target mRNAs and also is a predicted target of miR-548a-3p (Fig. 3.4). MDM2 is a well-established suppressor of TP53 expression (279). MDM2 mRNA was induced at 3 and suppressed at 7 weeks by microarray hybridization. Suppression of miR-548a-3p would increase MDM2 levels, which then can act to suppress TP53 (Fig. 3.4) at 3 weeks. HMG1 (High mobility group box 1 protein), a target of multiple differentially expressed miRNAs (Fig. 3.4), also was among the differentially expressed target mRNAs at 3 and 7 weeks by microarray hybridization. HMG1 is a predicted target of three differentially expressed miRNAs: miR-410, miR-548ac and miR-3174 that were all suppressed at 3 and 7 weeks (Fig. 3.3). HMG1 acts to suppress TP53 transcription (280). 


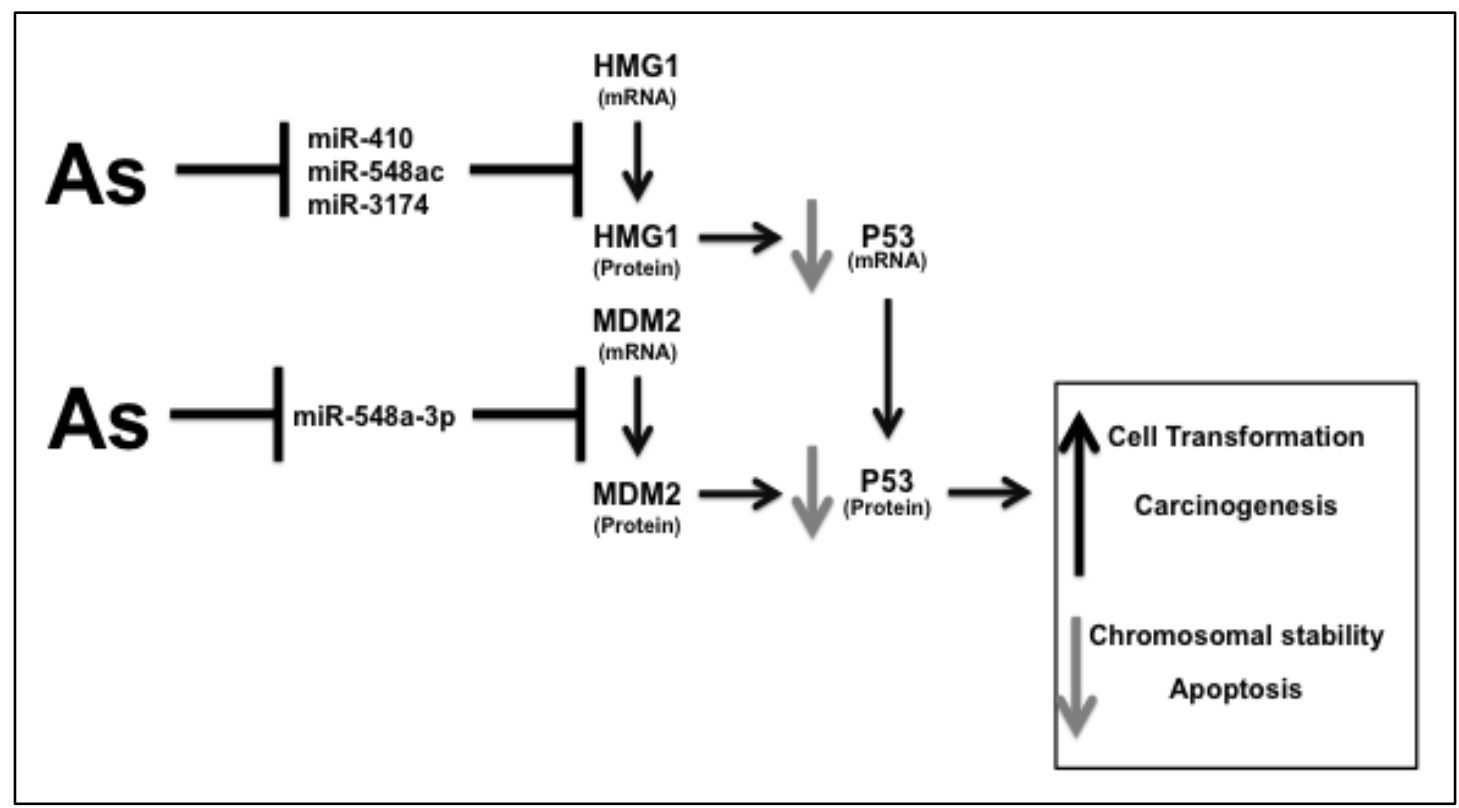

Figure 3.4. miRNA and Target Genes Expression. Arsenite suppressed the expression miR-410, -548ac and -548a-3p. MDM2 mRNA expression levels were induced at 3 weeks of arsenite exposure which might lead to the induction of MDM2 protein levels. HMG1 mRNA expression levels were induced at 3 and 7 weeks of arsenite exposure which might lead to the induction in HMG1 protein levels. Arsenite suppression of miR-410 and -548ac might induce MDM2 and HMG1 at 3 weeks leading to the decrease in the levels of P53 and P73. P53 and P73 increase in autophagy which is important for tumor cells as an adaptive stress response and decrease in chromosomal stability and apoptosis. 
HMG1, MDM2 and TP53 protein levels were examined at 7 weeks (Fig. 3.5). The levels of HMG1 were induced, yet the induction was not statistically significant. Total TP53 and phosphorylated TP53 (TP53-S15P) were induced. In contrast, acetylated TP53 (TP53-K382Ac) was suppressed with arsenite exposure. MDM2 is an oncoprotein that is has multiple isoforms and few of which can bind TP53 $(281,282)$. Several MDM2 isoforms (multiple bands) were detected in exposed and unexposed cells (Fig. 3.5). Although levels of MDM2 isoforms increased in arsenite-exposed cells, only the increase of MDM2-A ( 60 $\mathrm{kDa}$ ) was statistically significant. 


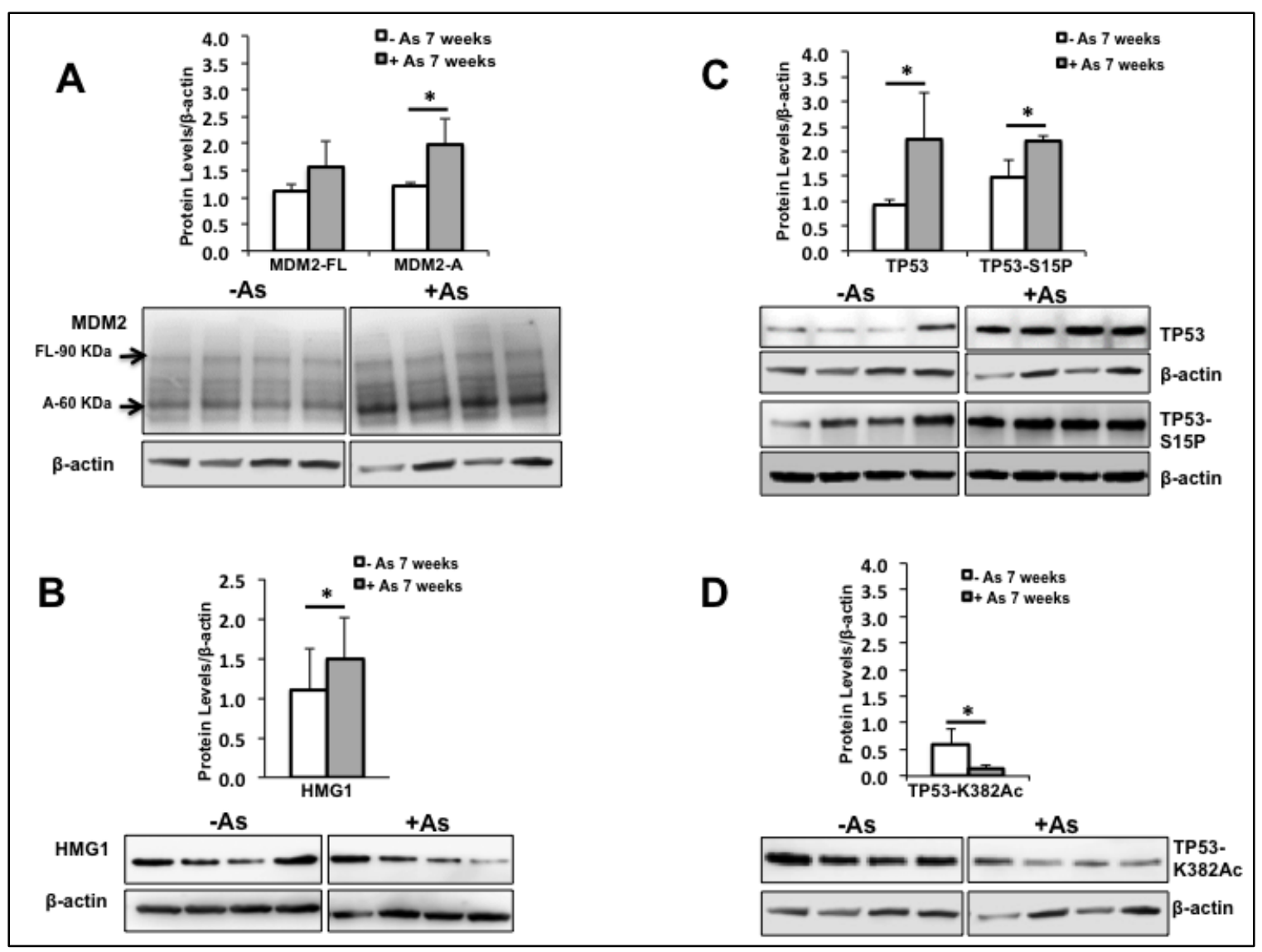

Figure 3.5. Arsenite exposure effects on MDM2, TP53 and HMG1

expression. After 7 weeks chronic exposure A) Western blot and quantitation showing increased expression of MDM2 isoform A (MDM2-A, $60 \mathrm{kDa}$ ), but not MDM2-FL. B) Western blot and quantitation showing no change in HMG1. C) Western blot and quantitation showing both TP53 and phosphorylated TP53 at serine 15 were induced with arsenic exposure. D) Western blot and quantitation showing TP53 hypoacetylated at lysine 382 in arsenite exposed cells. Proteins levels were normalized to $\beta$-actin levels and means \pm SD are plotted. Student TTest was used for statistical analyses. ${ }^{*} p$-value $\leq 0.05$. 


\section{Discussion}

The mechanism of arsenic-induced skin cancer is not well understood, but several studies indicate that mutation is not the driving force as it is for sunlightinduced skin cancers $(256,283,284)$. Different mechanisms of induction and progression of arsenic-induced carcinogenesis are proposed including miRNA expression dysregulation (256). The current chapter focuses on early changes in gene expression linked to arsenic-induced changes in mRNA and small RNA expression in the $\mathrm{HaCaT}$ cell chronic arsenic exposure model using Affymetrix hybridization microarrays. The results showed that arsenite exposure changes the expression pattern of small RNAs, including miRNAs, after 3 and 7 weeks exposure to $100 \mathrm{nM}$ arsenite (Fig. 3.2).

The results identified three of the six miRNAs with predicted targets that were differentially expressed after 3 and 7 weeks (miR-1228, miR-1254, miR645). These miRNAs were associated with cancer in previous studies (285-287). MiR-1228 (suppressed at 3 weeks, induced at 7 weeks) was reported to be induced in breast cancer tissues and cell lines and regulates the levels of mRNA and protein of SCAI (suppressor of cancer cell invasion) (286). MiR-1254 (suppressed at 3 and 7 weeks) was reported to be induced in the sera of nonsmall cell lung cancer patients (285). MiR-645 (induced at 3 and 7 weeks) was induced in head and neck squamous cell carcinoma and its induction was found to promote cell invasion and metastasis (287).

The results also showed that arsenite dysregulated (mostly suppressed) several snoRNAs. SnoRNAs are 60-300 nucleotide small RNAs that are 
concentrated in the nucleolus (288). SnoRNAs are involved in guiding premature ribosomal and other spliceosomal RNAs for nucleoside post-transcriptional modifications, crucial for accurate ribosomes (288). SnoRNAs have two main classes: C/D box and H/ACA box snoRNAs, both reported to be dysregulated in several diseases including cancer $(288,289)$. These results suggest that dysregulation of snoRNAs may play a role in arsenic-induced carcinogenesis.

Arsenite exposure also induced dramatic changes in differential mRNA expression at 3 weeks (1197 mRNAs) and 7 weeks (4840 mRNAs) (Fig. 3.2). This chapter focused on the 38 mRNAs differentially expressed at both time points that also were predicted targets of miRNAs differentially expressed at both time points to gain insight on plausible mechanisms by which the changes in miRNA expression would contribute to carcinogenesis.

Several carcinogenesis-associated pathways such as cytoskeleton remodeling, WNT signaling, and signal transduction PTEN pathways were populated by these 38 differentially expressed target mRNAs. These results support the hypothesis that the differential expression of miRNAs at early stages of arsenite exposure is contributing to the process of transformation to a cancerous phenotype. A mutually differentially expressed mRNA in these pathways was TCF7L2 (Fig. 7). TCF7L2 is the most studied member of the mammalian TCF/LEF family of nuclear factors. TCF7L2 polymorphisms have been associated with type-2 diabetes susceptibility in several studies (290-292) and dysregulation of TCF7L2 may be related to the association of arsenic exposure and diabetes (293). The WNT signaling pathway is one of the main 
signaling mechanisms during embryogenesis and cancer development (290292). The $\beta$-catenin/TCF (including TCF7L2) complex is the key effector in the WNT pathway, which leads to the activation of downstream targets and increased cell differentiation, proliferation, migration and insulin sensitivity (290292). Both $\beta$-catenin and TCF7L2 were induced at 7 weeks (1.41- and 1.13-fold, respectively). However, only TCF7L2 was induced at 3 weeks, suggesting that there is a progression in the gene expression changes with continued arsenite exposure.

E- cadherin is a calcium-dependent cell-cell adhesion protein and a key gene in the epithelial-to-mesenchymal transition (EMT, which is WNT signalingrelated) (290-292). Low E-cadherin expression is associated with induction of EMT in cervical squamous cell carcinoma and breast cancer $(294,295)$. Ecadherin mRNA expression was suppressed at 7 weeks of arsenite exposure (1.46-fold). Enhanced cell migration is an indicator of EMT. However, the migration capability of unexposed and arsenite exposed cells at 3 weeks did not differ (shown in chapter 5 in Fig. 5.1). These results suggest that at these early times of exposure, the changes in the mRNA levels of extracellular matrix components are not yet reflected in cellular phenotype. As for the progression observed with changes in mRNA expression, full development of the EMT phenotype many require longer exposures.

Of the 38 mRNAs differentially expressed after 3 and 7 weeks chronic exposure, MDM2 mRNA was induced at 3 weeks and suppressed after 7 weeks. MDM2 is a potential target of several miRNAs including miR-548a-3p that was 
suppressed in early exposure. Moreover, HMG1 mRNA was induced in early exposure. HMG1 is a potential target for 3 miRNAs found suppressed in early exposure. Both MDM2 and HMG1 can regulate TP53 expression. The induction in MDM2 and HMG1 expression was investigated along with MDM2 and HMG1 effect on TP53 protein levels.

MDM2 is a TP53-specific E3 ubiquitin ligase and the main cellular antagonist of TP53 (296). MDM2 has multiple isoforms, a few of which can bind TP53, such as MDM2-FL $(281,282)$. The protein levels of some MDM2 isoforms were changed at 7 weeks. MDM2 spliced variants expression has been observed in several types of cancer including bladder cancer (297), cancerous and normal breast tissues $(298,299)$, soft tissue sarcomas $(300,301)$, and giant cell tumors of the bone (302). MDM2-FL is the MDM2 isoform responsible for the ubiquitination of p53 for proteasomal degradation because it contains TP53 binding domain $(281,282,303)$. MDM2-FL levels did not change significantly (Fig. 3.5A). MDM2-A is a less common isoform of MDM2 and along with MDM2$B$ it binds to MDM2-FL and the interaction was found to prevent MDM2-mediated TP53 degradation (304). MDM2- A ( 60 kDa) was expressed in higher levels with arsenite exposure. Therefore, the induction in MDM2-A expression may be preventing MDM-FL from regulating TP53, resulting in the higher TP53 levels observed.

HMG1 is a well-known active chromatin-associated protein implicated in autophagy (305). HMG proteins can modulate transcriptional activity of several receptors and protein complexes such as steroid hormone receptors, NF-KB, 
TP53 and TP73 transcriptional complexes, and homeobox containing proteins (TBP), and also facilitates $V(D) J$ recombination (306). HMG1 is overexpressed in several tumors and tumor cells including chemically-induced SCC in mice, human bladder cancer tissue and melanoma cells $(64,306-308)$. Although HMG1 mRNA levels were dysregulated, HMG1 protein levels were variable and did not significantly change after 7 weeks chronic arsenic exposure (Fig. 3.5).

In sunlight-induced skin cancer, unrepaired DNA damage (UV photoproducts) leads to multiple mutations, especially in the TP53. UV signature mutations in TP53 appear several all sunlight-induced SCC $(10,309)$ but not in arsenic-induced skin cancer $(283,284)$. Moreover, preliminary studies found no mutations in TP53 when sequenced exons 5-9 in FFPE samples of arsenicinduced SCC, BCC or hyperkeratoses (J. C. States, personal communication). Thus, TP53 mutations are rare in arsenic-induced skin cancer. Because dominant-negative TP53 mutations can result in stabilized TP53, it was thought that TP53 mutations were present in arsenic-induced skin cancers due to the overexpression of TP53 in keratinocytes exposed to arsenic (310). However, later studies showed that arsenic-induced skin lesions and carcinomas lack TP53 mutations and the gene is functional $(283,284)$. Investigators have also reported that arsenite exposure (0.1-5 $\mu \mathrm{M})$ in several cell lines can induce TP53 (311, 312). Hybridization microarray data showed that TP53 mRNA was suppressed in early chronic exposure. However, TP53 protein levels were induced along with TP53 phosphorylated at Ser-15 (Fig. 3.5). Phosphorylation of TP53 at Ser-15 prevents MDM2 from binding leading to the stabilization of TP53 (313). TP53 at 
Ser-15 phosphorylation also activates ATM-mediated DNA-damage response (313). However, DNA repair genes that are known P53 targets such as DDB2, XPC and DNA polymerase beta were not induced when examined by RNA-seq (RNA_seq experiments are discussed in chapter 5). Therefore, the DNA damage response is being dysregulation. Moreover, the elevated levels of MDM2A (Fig. 3.5) also likely contribute to TP53 stabilization by preventing its ubiquitinylation (314). At $100 \mathrm{nM}$ sodium arsenite exposure, the HaCaT cells do not have high apoptosis indexes. Thus, the induced TP53 might not be active in these cells (315). Acetylation is required for TP53 transcriptional activity. Therefore, acetylation at the key acetylation site Lys-382 (316) was quantified and found lower in exposed cells (Fig. 3.5). TP53 hypoacetylation suggests that TP53 is transcriptionally inactive. These results suggest that inactive TP53 may contribute to increased clastogenesis that arsenic is known to cause contributing to genomic instability (317).

Along with the changes that were observed in the miRNA and mRNA expression in $\mathrm{HaCaT}$ cells at early time points, a recognized change in the growth of these cells was observed (Fig. 3.1). The calculated cumulative population doublings showed that growth rates were slower at early times in arsenite exposed cells. When the cells reached 19 weeks, the growth curves shifted and the arsenite exposed cells grew faster from 19 weeks till 32 weeks (Fig. 5). Others (39) have observed that HaCaT cells chronically exposed to 100 $\mathrm{nM} \mathrm{NaAsO} 2$ grow more slowly than parallel cultures of unexposed cells until approximately 19-20 weeks of exposure when the transformation starts (66). The 
results suggest that 19 weeks is another important time point to study arsenicinduced transformation in which the behavior of the cells is clearly changing. Taken together the results described in this chapter suggest that the early changes in miRNA profiles and their target genes in human keratinocytes contribute to arsenic-induced carcinogenesis. Therefore, studies evaluating gene expression at longer exposure times will be needed to reveal the role miRNA and mRNA expression changes play in arsenic induced carcinogenesis. Testing the hypotheses by looking at protein levels and posttranslational modifications indicate that TP53 was induced, but inactive, stressing the importance of testing predictions based on the RNA data. 


\section{CHAPTER 4}

CELL CYCLE PATHWAY DYSREGULATION IN HUMAN KERATINOCYTES AT EARLY STAGES OF CHRONIC EXPOSURE TO LOW ARSENITE

\section{Introduction}

The mechanism(s) of arsenic-induced carcinogenesis is still controversial $(255,256)$. Arsenic-induced genomic instability is suggested to play a major role in driving carcinogenesis. Arsenic is known to disrupt genomic integrity via cell cycle pathway dysregulation, DNA repair inhibition, epigenetic modifications, chromosomal abnormalities, disabled apoptosis and telomere dysfunction (318). Epigenetic factors modified by arsenic exposure include histone acetylation and methylation, DNA methylation, and miRNA expression (25, 26, 257-259, 318, 319).

In chapter 3, differentially expressed miRNAs and mRNAs in the HaCaT cells after 3 and 7 weeks of arsenic exposure were identified using hybridization microarrays. After 7 weeks exposure, more mRNAs were differently expressed. Furthermore, differentially expressed target mRNAs of differentially expressed miRNAs at both early time points were also identified. These mRNAs were found to be involved in several carcinogenesis related pathways suggesting that miRNAs contribute to the transformation process at early stages of arsenite exposure. 
The various stages starting from the early stages of the transformation process in this HaCaT cell model have not been studied. The mRNA expression profiles are an important tool in identification of dysregulated pathways and alterations in cellular mechanisms. Therefore, in the current chapter, pathways of the differently expressed mRNAs after 7 weeks exposure are identified and investigated.

The pathway analyses reveal differential expression of a wide array of genes responsible for cell cycle regulation. Arsenic has been reported to disrupt and delay cell cycle in its several phases, G1, S, G2/M and G2, in several cell lines (320-324). The gene expression data, supported by cell cycle flow cytometry assay analysis, suggested a delay in entering G1 phase. Therefore, the data suggest that cell cycle dysregulation plays a role in early events leading to arsenic-induced transformation. 


\section{Materials and Methods}

\section{a. Cell Culture and RNA Isolation}

We adopted the HaCaT model of $\mathrm{Pi}$ et al. (2008) for these studies. Multiple cultures of cells ( 4 with and 4 without $100 \mathrm{nM} \mathrm{NaAsO}_{2}$ ) were maintained separately for 3 weeks as detailed in chapter 3 materials and methods. Total RNA was purified and RNA quality was determined as detailed in chapter 3 materials and methods.

\section{b. Microarray Analysis}

Expression profiles of mRNA were obtained using GeneChip $\AA$ PrimeView ${ }^{\mathrm{TM}}$ Human Gene Expression Affymetrix arrays as described in chapter 3. Scheme outlined in Figure 4.1 was followed in data analysis. The list of differentially expressed mRNAs at 7 weeks was narrowed down to 644 by adapting $|1.5|$ as a fold change cutoff. 


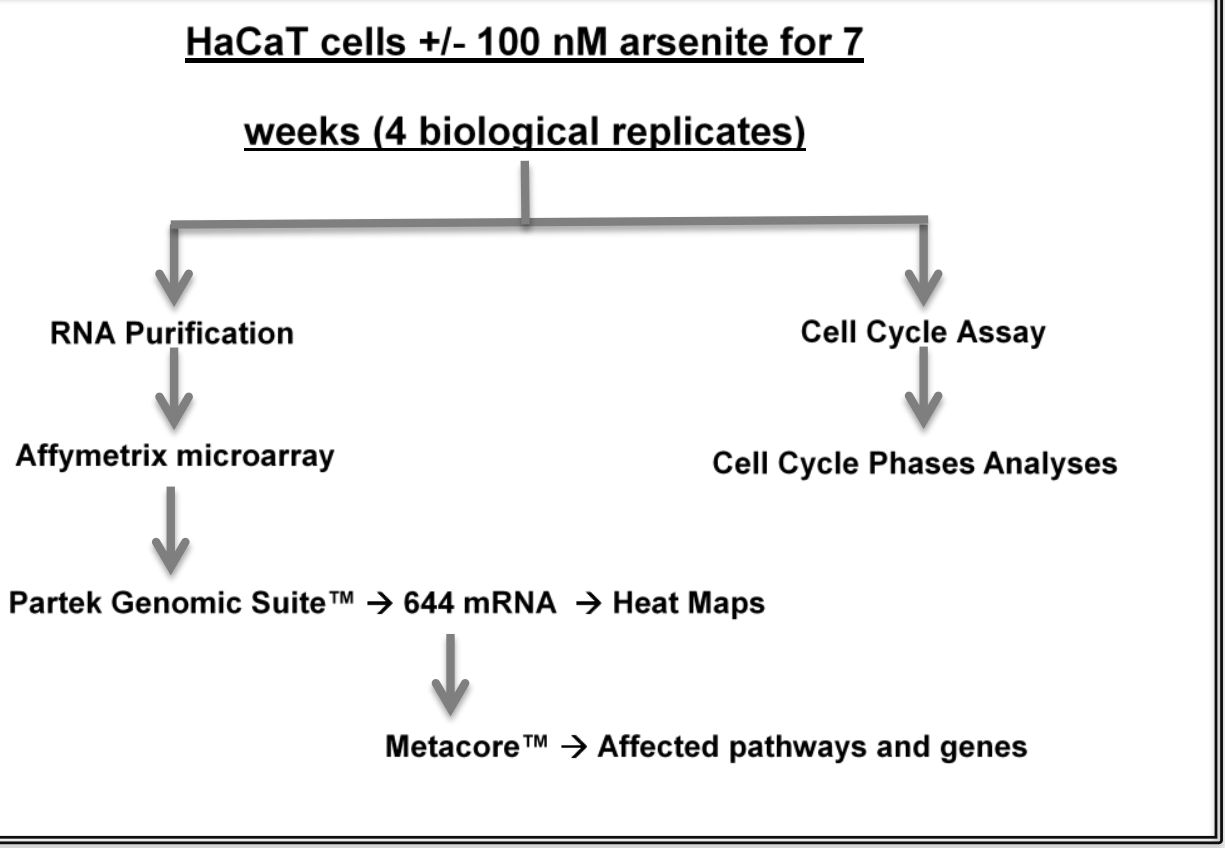

Figure 4.1. HaCaT cells were exposed to 0 or $100 \mathrm{nM} \mathrm{NaAsO} \mathrm{O}_{2}$ for 7 weeks. RNA was purified and expression determined on Affymetrix microarrays and analyzed using Metacore software. Cell cycle analyses were performed by flow cytometry. 


\section{c. Flow cytometry cell cycle assay}

$\mathrm{HaCaT}$ cells exposed to 0 or $100 \mathrm{nM} \mathrm{NaAsO}$ for 7 weeks were seeded at density of $1 \times 10^{6}$ cells per $55 \mathrm{~cm}^{2}$ cell culture dish with arsenite exposure maintained. After $48 \mathrm{~h}$, the cells were harvested by trypsinization, collected by centrifugation at $1000 \mathrm{xg}$ for $1 \mathrm{~min}$, washed twice with PBS, and then fixed in $70 \%$ ethanol for $24 \mathrm{~h}$ at $4^{\circ} \mathrm{C}$. The cells were then centrifuged at $1500 \mathrm{~g}$ for $1 \mathrm{~min}$, suspended in PBS $(400 \mu \mathrm{l})$, then RNaseA $(10 \mathrm{mg} / \mathrm{ml}, 50 \mu \mathrm{l})$ and propidium iodide $(2 \mathrm{mg} / \mathrm{ml}, 10 \mu \mathrm{l})$ were added followed by a 30 minute incubation in the dark at room temperature. Fluorescence was acquired by flow cytometry on a Becton Dickinson FACSCalibur ${ }^{\mathrm{TM}}$ (BD Biosciences) (325). Cell cycle distribution was determined using FlowJo ${ }^{\circledR}$ v10.2. Student's T-Test was used for statistical analyses ( $p$-value $\leq 0.05$, was considered significant). 


\section{Results}

\section{a. Arsenite-dependent differential mRNA expression}

Analysis of the mRNAs data revealed that 644 mRNAs were differentially expressed at |1.5| fold change in $\mathrm{HaCaT}$ cells exposed to $100 \mathrm{nM} \mathrm{NaAsO}$ for seven weeks. More than half of the mRNAs were suppressed with arsenite exposure and the remainder were induced (Fig. 4.2.A). The differentially expressed genes were then loaded into Metacore ${ }^{\mathrm{TM}}$ software for pathways analysis. The 15 pathways with FDR values $\leq 0.05$ are listed in Table 4.1. Cell cycle and cell cycle regulation pathways are highly represented in this list ( 7 of 15). Other pathways that were dysregulated include epithelial-to-mesenchymal transition (EMT), cytoskeleton remodeling, apoptosis, immune response and gap junction pathways. The mRNAs populating these pathways were analyzed for potential interactions. The interacting genes are shown in a network built by Metacore $^{\mathrm{TM}}$ software (Fig. 4.2.B). Three E3 ubiquitin ligase complexes known to regulate cell cycle are present in this network (Siah1/SIP/EBI; CUL1/RBX1; SKP2/TRCP/FBXW) (326-328). A subnetwork of genes involved in regulating licensing of the DNA replication origin (CDT1; MCM4/6/7 complex; MCM2) (329) also is present. 


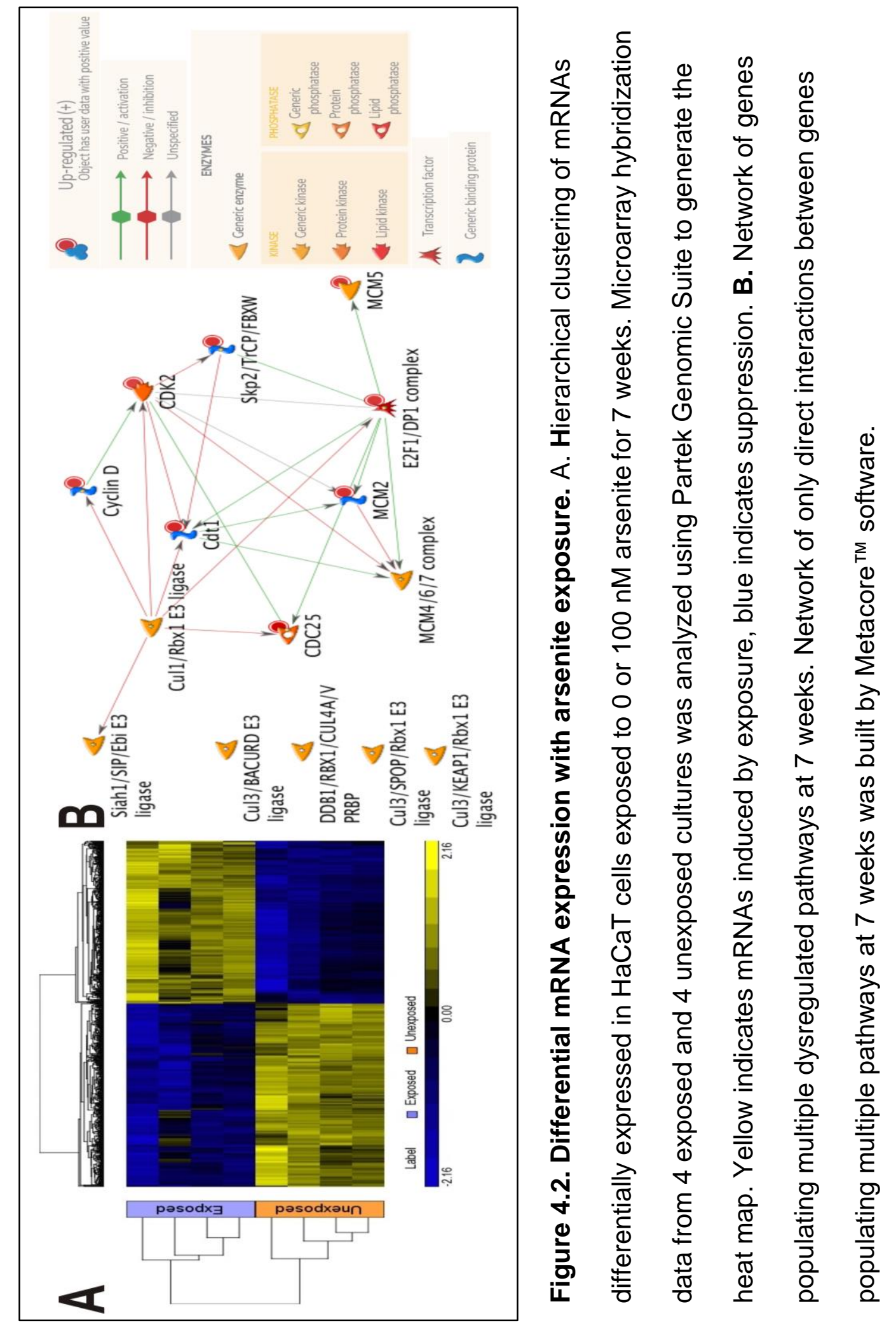




\begin{tabular}{|c|c|c|c|}
\hline Pathway* & FDR & $\begin{array}{l}\text { \# of genes } \\
\text { in pathway }\end{array}$ & $\begin{array}{c}\text { Induction } \uparrow \\
\text { Suppression } \downarrow\end{array}$ \\
\hline $\begin{array}{l}\text { Cell cycle Start of DNA replication in } \\
\text { early S phase }\end{array}$ & $4.54 \mathrm{E}-10$ & 13 & $\uparrow$ \\
\hline $\begin{array}{l}\text { Cell cycle Role of SCF complex in } \\
\text { cell cycle regulation }\end{array}$ & 7.44E-07 & 10 & $\uparrow$ \\
\hline $\begin{array}{l}\text { Cytoskeleton remodeling } \\
\text { Neurofilaments }\end{array}$ & 0.001 & 7 & $\uparrow$ \\
\hline $\begin{array}{l}\text { Cell cycle Transition and termination } \\
\text { of DNA replication }\end{array}$ & 0.001 & 7 & $\uparrow$ \\
\hline $\begin{array}{l}\text { Immune response Antigen } \\
\text { presentation by MHC class I, } \\
\text { classical pathway }\end{array}$ & 0.002 & 9 & $\downarrow$ \\
\hline Cell cycle (generic schema) & 0.002 & 6 & $\uparrow$ \\
\hline $\begin{array}{l}\text { Immune response IL-4-induced } \\
\text { regulators of cell growth, survival, } \\
\text { differentiation and metabolism }\end{array}$ & 0.004 & 9 & $\uparrow$ \\
\hline $\begin{array}{l}\text { Development Regulation of } \\
\text { epithelial-to-mesenchymal transition } \\
\text { (EMT) }\end{array}$ & 0.004 & 9 & $\uparrow$ \\
\hline $\begin{array}{l}\text { Cell cycle Regulation of G1/S } \\
\text { transition (part 2) }\end{array}$ & 0.004 & 6 & $\uparrow$ \\
\hline $\begin{array}{l}\text { Cell cycle Regulation of G1/S } \\
\text { transition (part 1) }\end{array}$ & 0.004 & 7 & $\uparrow$ \\
\hline $\begin{array}{l}\text { Apoptosis and survival Endoplasmic } \\
\text { reticulum stress response pathway }\end{array}$ & 0.008 & 8 & $\downarrow$ Protein folding \\
\hline $\begin{array}{l}\text { Cell cycle ESR1 regulation of G1/S } \\
\text { transition }\end{array}$ & 0.014 & 6 & $\uparrow$ \\
\hline $\begin{array}{l}\text { Proteolysis Putative ubiquitin } \\
\text { pathway }\end{array}$ & 0.016 & 5 & $\uparrow$ \\
\hline $\begin{array}{l}\text { Transcription Ligand-dependent } \\
\text { activation of the ESR1/SP pathway }\end{array}$ & 0.049 & 5 & $\begin{array}{l}\uparrow \text { cell cycle } \\
\text { regulation }\end{array}$ \\
\hline Cell adhesion-Gap junctions & 0.049 & 5 & $\uparrow$ \\
\hline
\end{tabular}




\section{b. Arsenite-dependent increase in G2/M compartment}

The gene expression data suggested dysregulation of cell cycle was occurring in arsenite exposed cells. To confirm cell cycle dysregulation, cell cycle analyses were performed on the four exposed and 4 unexposed cultures. The results indicate that arsenite-exposed cells are accumulating in the G2/M compartment suggesting a delay in either the $G 2$ to $M$ phase or $M$ to $G 1$ phase transition (Fig. 4.3). These results are consistent with the network results of Figure 4.2.B. 


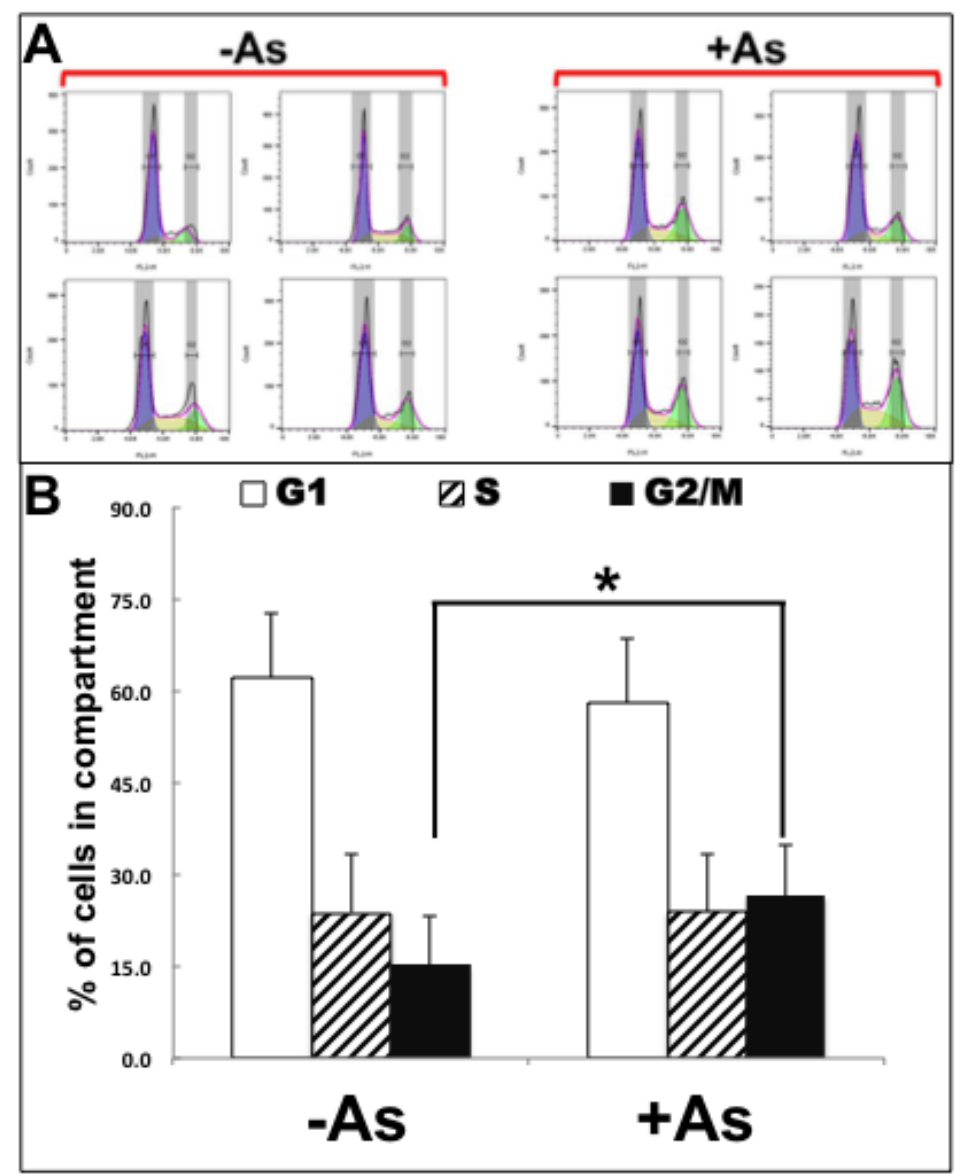

Figure 4.3. Arsenite-exposed $\mathrm{HaCaT}$ cells accumulate in the $\mathrm{G} 2 / \mathrm{M}$ compartment. A. Flow cytomteric analysis of cell cycle in four cultures of HaCaT cells after 7 weeks exposure to 0 or $100 \mathrm{nM} \mathrm{NaAsO}$. Cells were fixed, RNAse A digested and stained with propidium iodide. Data were collected by flow cytometry and analyzed using FloJo software. B. Fraction in each compartment (G1, S, G2/M) were determined and means \pm SD are plotted. Student T-Test was used for statistical analyses. ${ }^{*} p$-value $\leq 0.05$. 


\section{Discussion}

Arsenic is a known human carcinogen (82). Several mechanisms of arsenic carcinogenicity including genomic instability and chromosomal abnormalities have been proposed (319). Arsenic exposure has been associated in several studies with dysregulation of DNA methylation, cell cycle, and DNA repair gene expression $(21,257,258,330)$. However, there is not yet agreement on the mechanism(s) of arsenic transformation. Chronic low arsenic exposure leads to the malignant transformation of cell lines from several tissues $(39,331$ 333). Transformation is likely to be driven by a series of events starting from early times of exposure and extending out to as much as thirty weeks exposure when transformation can be demonstrated to have occurred. Early events in transformation in these model systems have not yet been investigated. Thus, we have examined gene expression changes in the $\mathrm{HaCaT}$ model of arsenicinduced skin carcinogenesis after seven weeks' exposure to gain an understanding of the early events related to transformation.

The population growth curves in chapter 3 and reported by others (39) indicate that $\mathrm{HaCaT}$ cells chronically exposed to $100 \mathrm{nM} \mathrm{NaAsO}{ }_{2}$ grow more slowly than parallel cultures of unexposed cells until approximately 19 weeks exposure. Dysregulation of cell cycle control as suggested by the differential expression and pathways data presented in this chapter is consistent with these earlier observations on cell growth kinetics. This conclusion is further supported by cell cycle assay analysis on HaCaT cells after seven weeks' exposure that showed accumulation of cells in the G2/M compartment (Figure 4.3). This 
observation is consistent with the network analysis showing induction of genes associated with licensing replication origins (CDT1, MCM2/4/6/7, Figure 4.2.B). These observations are consistent with G2/M delays observed in earlier studies in the States laboratory $(323,334-336)$ and by others $(337,338)$.

The E3 ubiquitin ligase complexes identified in the network analysis (Figure 4.2) are all zinc finger RING E3's that regulate cell cycle transitions other than $\mathrm{G} 2$ to $\mathrm{M}$ or $\mathrm{M}$ to $\mathrm{G} 1$. Thus, although the genes involved in replication origin licensing suggest a major impact on $\mathrm{M}$ to $\mathrm{G} 1$ transition, the induction of these $\mathrm{E} 3$ ubiquitin ligase genes suggests that the cells are responding to delays at other cell cycle transitions as well. Impact of arsenite exposure at multiple cell cycle transitions was demonstrated by McCollum et al in U937 cells (337), and by S phase lengthening in MCF7 and H1299 cells by Pozo-Molina et al. (339).

Accumulation in the G0/G1 phase leading to reduction in the S phase also was observed with mouse skin fibroblast cells (m5S), mouse thymocytes and B-cell lymphoma A20 cells $(340,341)$. It was also reported that $\mathrm{HL}-60$, derived from a patient with acute myeloid leukemia $(\mathrm{FAB})$, were arrested at $\mathrm{G} 1$ with arsenic exposure (342). Furthermore, Moghaddaskho et al. 2017 showed that arsenic arrested MDA-MB-231 and MDA-MB-468 cells at G2/M phase (343). Clearly, arsenite exposure can cause cell cycle disruption in all cell cycle phases.

However, delays in $\mathrm{M}$ phase are likely to contribute to genomic instability via induction of aneuploidy. 


\section{CHAPTER 5}

\section{A LONGITUDINAL STUDY ON SMALL RNA AND MRNA EXPRESSION PROFILES IN THE CHRONIC EXPOSURE HACAT MODEL}

\section{Introduction}

The results obtained in chapters 3 and 4 showed that early times of chronic arsenite exposure lead to differential small RNA and mRNA expression with a more differentially expressed mRNAs at 7 weeks. Moreover, arsenite exposed cells grew slower at early times. The growth curves shifted at 19 weeks, and arsenite exposed cells then grew faster than unexposed cell all the way to 32 weeks (Fig. 3.1). Others have also observed that HaCaT cells chronically exposed to $100 \mathrm{nM} \mathrm{NaAsO} 2$ grow slower till 19-20 weeks when transformation starts (66). The results suggest that 19 weeks is another important time point to study arsenic-induced transformation because the behavior of the cells is clearly changing. Further, Pi et al (2008) showed that 28 weeks of exposure of $\mathrm{HaCaT}$ cells to $100 \mathrm{nM}$ sodium arsenite transformed these cells fully and resulted in an aggressive SCC phenotype when inoculated into nude mice (39). Therefore, 28 weeks is a third important time point to study in the transformation path. Thus, in this chapter, a longitudinal study was performed to determine small RNA and mRNA differential expression in HaCaT cells chronically exposed to $100 \mathrm{nM}$ 
$\mathrm{NaAsO}_{2}$ at 3 time points: 7 weeks (transformation related changes), 19 weeks (start of actual transformation) and 28 weeks (fully transformed cells). Next-generation sequencing (NGS) is a high-throughput sequencing tool used for genome sequencing and resequencing, transcriptome profiling (RNA-Seq), DNAprotein interactions (ChIP-sequencing), and epigenome sequencing (344). NGS is very time and cost effective. The entire human genome can be sequenced in few hours with about $\$ 1000$ versus 60 years with $\$ 30$ million using first generation sequencing (Sanger sequencing) (345). RNA sequencing (RNA-seq) was one of the earliest forms of nucleotide sequencing for transcriptome profiling (1972) (346). NGS development has the greatest impact on advancing transcriptomes by allowing massive scale RNA analysis through cDNA sequencing (347). RNA-seq is a quantitative and qualitative measure of the transcriptome (347). RNA-seq is capable of providing expression profiles and mutational status along with gene fusion detection, small RNA characterization and alternative splicing events detection (347). In this chapter, RNA-seq was used to obtain both mRNA and small RNA expression profiles in the HaCaT cell chronic exposure model to study the effects of arsenite on the transcriptome.

The data were further analyzed and miRNAs differentially expressed among all the time points were determined. Moreover, differentially expressed mRNAs targets of differentially expressed miRNA at each time points were determined. Pathway analyses were also performed for both total mRNAs and miRNAs target mRNAs at each of the time points. The pathway analyses show that most of transformation-related changes take place at 19 weeks. Several 
carcinogenesis-related pathways are dysregulated among the different time points. Furthermore, only 1 miRNAs, suppressed in all three time points, is predicted as a novel tumor suppressor miRNA. 


\section{Materials and Methods}

\section{a. Cell Culture and RNA Isolation}

The HaCaT model of Pi et al. (2008) was adopted for these studies.

Multiple cultures of cells ( 4 with and 4 without $100 \mathrm{nM} \mathrm{NaAsO}_{2}$ ) were maintained separately for 7,19 and 28 weeks as detailed in chapter 3 materials and methods. Total RNA was purified and RNA quality was determined as detailed in chapter 3 materials and methods.

\section{b. mRNA and miRNA Next-Generation Sequencing (NGS)}

\section{Library Preparation, Cluster Generation and Sequencing}

Library Preparation, Cluster Generation and Sequencing of all 24 samples were performed in the CGeMM DNA Facility Core at the University of Louisville by Elizabeth Hudson. The Truseq Stranded mRNA kit was used to prepare mRNA libraries from $1 \mu \mathrm{g}$ total RNA. Libraries were validated on the Agilent 2100 Bioanalyzer and quantitated using the Illumina Library Quantification Kit, ABI Prism qPCR Mix from Kapa Biosystems and the ABI7900HT real-time PCR instrument. All samples were pooled and run simultaneously on 4 flow cells, using $2 \times 150$ paired end sequencing with the 500 High-output v2 (300 cycles) sequencing kit on the Illumina NextSeq500 instrument.

The Truseq Small RNA kit was used to prepare miRNA libraries from $1 \mu \mathrm{g}$ total RNA. Each Library was individually gel purified on a Novex TBE $6 \%$ gel and resuspended in $10 \mu \mathrm{L} 10 \mathrm{mM}$ Tris- $\mathrm{HCl}, \mathrm{pH}$ 8.5. Libraries were validated and quantitated by running $1 \mu \mathrm{L}$ on the Agilent Technologies 2100 Bioanalyzer DNA 
High Sensitivity Chip. 36-cycle single sequencing reads were generated on the Illumina NextSeq500 instrument utilizing the 500 High output v2 (75 cycle) sequencing kit.

\section{Data Mapping}

Paired end RNA-Seq data were generated for each condition to which the cell lines were exposed. The data for each replicate were stored, trimmed, mapped, and quantified individually. Trimgalore, a wrapper written for the algorithm cutadapt (348) was used to trim, and quality filter the newly generated reads. The trimmed reads were mapped to the human reference genome hg19 (NCBI build 37.1 released 2009) using the RNA-Seq mapping software TopHat (349) and annotated transcripts were quantified in units of FPKM using Cufflinks (349). The gene annotation used for the quantification was downloaded from ENSEMBL (version 81). This file was filtered to remove all records from the gtf file whose molecular biotype was annotated as either ribosomal RNA (rRNA), or mitochondrial tRNA (Mt_tRNA). The resultant files were used in cufflinks (arguments--GTF Hs_build-37.1.gtf (MT or RRNA filtered out) --compatible-hitsnorm-M Hs_build 37.1_MT_RRNA.gtf (only MT and RRNA)) and cuffdiff (GTF argument set to Hs_build-37.1.gtf (MT or RRNA filtered out)) to ensure no ribosomal RNA or mitochondrial RNA that remained after efforts to remove them during the library prep would not influence the derived FPKM values. Differential analysis was ultimately done using the cuffdiff program, which generated pvalues, as well as $p$-values corrected for multiple testing. 


\section{Statistical Analysis}

Data analysis was performed by comparing the log values of the Fragments Per Kilobase of transcript per Million mapped reads (FPKM) generated from the sample reads $+1 \mathrm{E}^{-5}$ of exposed cells to the unexposed cells at 7, 19 and 28 weeks time points of exposure. The p-values for these comparisons were calculated by two sample T-Test with equal (p_Eq) and unequal variances ( $p \_$Ueq). The fold changes of the compared values were calculated using the equation: $\mathrm{FC}=$ mean $($ Exposed $\mathrm{FPKM}+1 \mathrm{E}-5) /$ mean (Unexposed FPKM+1E-5). All analyses were obtained using SAS System V9. Cary, NC: SAS Institute Inc, 2003.

\section{c. Determining miRNA target mRNAs and Pathway analyses}

Potential targets of differentially expressed miRNAs after 7, 19 and 28 weeks chronic exposure $(p$-value $\leq 0.05)$ were obtained from the TargetScanHuman 6.2 database and compared to mRNA data obtained at the same three time points using Partek Genomic Suite ${ }^{\mathrm{TM}}$ software. Ingenuity ${ }^{\circledR}$ Pathway Analysis (IPA®) was used for all pathway analyses.

\section{d. Silicone Plug Assay (Cell Migration assay):}

HaCaT cells (quadruplicate unexposed and exposed cultures for 3 and 34 weeks) were plated in a 6-well dish (550,000 cells /well; each well containing previously placed silicone plugs) as described in Peterson et. al. (350). Silicone plugs were removed after $48 \mathrm{~h}$ and the cells were photographed before and after $16 \mathrm{~h}$ incubation in serum-free media to measure cell migration. The migration 
area was quantified using automated_migration_assay program developed by Gregory J. R. States at the University of Louisville. Lines to indicate borders at 0 and $16 \mathrm{~h}$ were drawn and significant differences determined by Student's T-Test analyses means unexposed to arsenic exposed cells. 


\section{Results}

\section{a. Differential miRNAs Expression}

The results showed that 59 miRNAs were differentially expressed at the 7 weeks chronic arsenic exposure. Of the 59 differentially expressed miRNAs, 32 were induced and 27 were suppressed. After 19 weeks chronic exposure, 124 miRNAs were differentially expressed. Of the 124 differentially expressed miRNAs, 77 were induced and 47 were suppressed. After 28 weeks chronic exposure, 53 miRNAs were differentially expressed. Of the 53 miRNAs, 25 were induced and 28 were suppressed.

Eighteen miRNAs differentially expressed in more than one of the time points (Table 5.1). One miRNA, miR-6733, was suppressed at all the time points in arsenic exposed cells. Targets of miR-6733 differentially induced in any of the time points were obtained. Pathway analysis of these mRNA did not show associations with several pathways except for 19 weeks targets. 19 weeks miR6733 targets were found to be involved in DNA methylation and transcriptional repression signaling, gap junction signaling and sumoylation pathways.

Eight miRNAs were differentially expressed at both 7 and 19 weeks. Two miRNAs were suppressed at 7 and induced 28 weeks. Furthermore, 7 miRNAs were differentially expressed at 19 and 28 weeks. 


\begin{tabular}{|c|c|c|c|c|c|c|c|c|c|}
\hline \multirow[b]{2}{*}{ microRNAs } & \multicolumn{3}{|c|}{7 weeks } & \multicolumn{3}{|c|}{19 weeks } & \multicolumn{3}{|c|}{28 weeks } \\
\hline & P_Eq & p_UEq & $\begin{array}{c}\text { Fold } \\
\text { Change }\end{array}$ & P_Eq & p_UEq & $\begin{array}{c}\text { Fold } \\
\text { Change }\end{array}$ & p_Eq & p_UEq & $\begin{array}{c}\text { Fold } \\
\text { Change }\end{array}$ \\
\hline \multicolumn{10}{|c|}{ Suppressed at 7, 19 and 28 weeks } \\
\hline hsa-mir-6733 & 0.024 & 0.058 & -19751 & 0.024 & 0.058 & -21501 & 0.037 & 0.075 & -2 \\
\hline \multicolumn{10}{|c|}{ Induced at 7 and 19 weeks } \\
\hline hsa-mir-4786 & 0.019 & 0.050 & 3 & 0.049 & 0.057 & 1 & 0.814 & 0.818 & -1 \\
\hline hsa-mir-7974 & 0.027 & 0.044 & 5 & 0.023 & 0.029 & 2 & 0.535 & 0.539 & 1 \\
\hline \multicolumn{10}{|c|}{ Suppressed at 7 and 19 weeks } \\
\hline hsa-mir-34b & 0.003 & 0.005 & -3 & 0.024 & 0.058 & -4 & 0.532 & 0.537 & 2 \\
\hline hsa-mir-181a-1 & 0.038 & 0.076 & -1 & 0.012 & 0.038 & -1 & 0.364 & 0.371 & -1 \\
\hline hsa-mir-181a-2 & 0.040 & 0.080 & -1 & 0.012 & 0.037 & -1 & 0.330 & 0.337 & -1 \\
\hline \multicolumn{10}{|c|}{ Suppressed at 7 and induced at 19 weeks } \\
\hline hsa-mir-362 & 0.037 & 0.055 & -1 & 0.005 & 0.023 & 1 & 0.378 & 0.395 & -1 \\
\hline hsa-mir-7705 & 0.043 & 0.062 & -2 & 0.001 & 0.011 & -2 & 0.684 & 0.698 & -1 \\
\hline \multicolumn{10}{|c|}{ Induced at 7 and suppressed at 19 weeks } \\
\hline hsa-mir-1268b & 0.040 & 0.080 & 2 & 0.004 & 0.010 & -2 & 0.230 & 0.239 & 1 \\
\hline \multicolumn{10}{|c|}{ Suppressed at 7 and 28 weeks } \\
\hline hsa-mir-218-1 & 0.047 & 0.088 & -2 & 0.977 & 0.977 & -1 & 0.030 & 0.066 & -2 \\
\hline hsa-mir-218-2 & 0.048 & 0.090 & -2 & 0.968 & 0.969 & -1 & 0.025 & 0.059 & -2 \\
\hline \multicolumn{10}{|c|}{ Induced at 19 and 28 weeks } \\
\hline hsa-mir-99a & 0.085 & 0.131 & 1 & 0.018 & 0.024 & 3 & 0.033 & 0.040 & 3 \\
\hline hsa-let-7c & 0.692 & 0.705 & -1 & 0.018 & 0.023 & 2 & 0.030 & 0.036 & 2 \\
\hline \multicolumn{10}{|c|}{ Induced at 19 and suppressed at 28 weeks } \\
\hline hsa-mir-29b-2 & 0.245 & 0.288 & -2 & 0.037 & 0.044 & -1 & 0.002 & 0.004 & -1 \\
\hline hsa-mir-29b-1 & 0.253 & 0.295 & -1 & 0.020 & 0.025 & -1 & 0.003 & 0.005 & -1 \\
\hline hsa-mir-3651 & 0.386 & 0.392 & 1 & 0.015 & 0.020 & -2 & 0.004 & 0.006 & -1 \\
\hline \multicolumn{10}{|c|}{ Suppressed at 19 and Induced at 28 weeks } \\
\hline hsa-mir-934 & 0.434 & 0.464 & -1 & 0.011 & 0.016 & -4 & 0.043 & 0.062 & 1 \\
\hline hsa-mir-378c & 0.435 & 0.465 & -1 & 0.008 & 0.012 & -1 & 0.038 & 0.057 & 1 \\
\hline * P_Eq anp_l & & & & & & & & & \\
\hline
\end{tabular}




\section{b. Differential mRNAs Expression}

The results showed that 3654 mRNAs were differentially expressed after 7 weeks chronic exposure (1805 induced and 1849 suppressed). After 19 weeks chronic exposure, 4665 mRNAs were differentially expressed (2125 induced and 2125 suppressed). After 28 weeks chronic exposure, 2624 were differentially expressed (1154 induced and 1470 suppressed).

\section{c. Pathway Analysis of Differentially Expressed mRNAs}

Pathway analysis of the differentially expressed mRNA from the three time points $(7,19$ and 28 weeks) was performed using Ingenuity® Pathway Analysis (IPA®). Several pathways were predicted to be either induced or suppressed based on their Z-score values (positive value= induced, negative value=suppressed). Pathways with Z-score $\geq|1|$ were selected (Table 5.2). 


\begin{tabular}{|c|c|c|c|c|}
\hline $\begin{array}{l}\text { Ingenuity Canonical } \\
\text { Pathways }\end{array}$ & $\begin{array}{l}-\log \\
\text { (p-value) }\end{array}$ & Ratio & z-score & $\begin{array}{l}\text { Genes } \\
\text { induced/suppressed }\end{array}$ \\
\hline \multicolumn{5}{|l|}{7 weeks } \\
\hline \multicolumn{5}{|l|}{ Induced pathways } \\
\hline Osteoarthritis Pathway & 1.3 & 0.117 & 2.4 & $\begin{array}{l}\text { HDAC4,FGF2,FGFR1,PTC } \\
\text { H1,SMAD7,COL10A1,WNT } \\
\text { 16,SP7,HES1,HIF1A,IL1R1 } \\
\text {,CREB5,ACAN,FZD8,WNT } \\
\text { 3A,CASP9,SP1,CXCR2,C } \\
\text { ASQ1,PRKAA1,FZD5,MYB } \\
\text { BP1A,NOS2,SMAD1, }\end{array}$ \\
\hline HIPPO signaling & 0.56 & 0.105 & 2.236 & $\begin{array}{l}\text { PPP2R2A,AJUBA,FAT4,R } \\
\text { ASSF6,PPP2R5B,DLG2,S } \\
\text { CRIB,SMAD1,SKP2 }\end{array}$ \\
\hline RhoGDI Signaling & 0.76 & 0.105 & 1.807 & $\begin{array}{l}\text { RND2,CDH18,PIKFYVE,R } \\
\text { HOJ,WASF1,PIP5K1B,LIM } \\
\text { K1,DGKZ,CDH2,CDH12,A } \\
\text { RHGEF,GNAO1,ARPC3, } \\
\text { ARHGAP35,GNA13,GNB1 } \\
\text { L,ESR2,ACTA1 }\end{array}$ \\
\hline $\begin{array}{l}\text { Antioxidant Action of } \\
\text { Vitamin C }\end{array}$ & 0.311 & 0.0865 & 1.342 & $\begin{array}{l}\text { LCAT,PLCL1,PAFAH1B1, } \\
\text { MAPK11,SLC23A3,GLRX, } \\
\text { TXNRD1,TXNRD3,PAFAH } \\
\text { 1B3 }\end{array}$ \\
\hline $\begin{array}{l}\text { Cell Cycle: G1/S } \\
\text { Checkpoint Regulation }\end{array}$ & 1.14 & 0.143 & 1.134 & $\begin{array}{l}\text { NRG1,HDAC4,TFDP1,HD } \\
\text { AC7,CDKN2C,CDKN1B,R } \\
\text { BL1,CDC25A,SKP2 }\end{array}$ \\
\hline$\alpha$-Adrenergic Signaling & 0.398 & 0.0941 & 1.134 & $\begin{array}{l}\text { CALM1 (includes } \\
\text { others),CALML5,PRKACG, } \\
\text { ADCY1,GNB1L,MAP2K1,A } \\
\text { DCY7,PRKCG }\end{array}$ \\
\hline $\begin{array}{l}\text { PPAR } / \text { RXR } \alpha \\
\text { Activation }\end{array}$ & 0.512 & 0.0952 & 1 & $\begin{array}{l}\text { PPARA,ACAA1,CYP2C18,I } \\
\text { L1R1,AIP,TRAF6,SHC1,H } \\
\text { SP90B1,APOA1,ADCY1,P } \\
\text { RKACG,PRKAA1,PLCL1,G } \\
\text { OT2,ADCY7,MAP2K1 }\end{array}$ \\
\hline $\begin{array}{l}\text { OX40 Signaling } \\
\text { Pathway }\end{array}$ & 0.307 & 0.0893 & 1 & $\begin{array}{l}\text { BCL2L1,CD3G,CD3E,FCE } \\
\text { R1G,HLA-DRB5 }\end{array}$ \\
\hline Basal Cell Carcinoma & 0.296 & 0.087 & 1 & FZD8,WNT3A,BMP4,PTC \\
\hline
\end{tabular}




\begin{tabular}{|c|c|c|c|c|}
\hline Signaling & & & & H1,WNT16,FZD5 \\
\hline \multicolumn{5}{|l|}{ Suppressed pathways } \\
\hline $\begin{array}{l}\text { Signaling by Rho } \\
\text { Family GTPases }\end{array}$ & 0.784 & 0.101 & -2.558 & $\begin{array}{l}\text { CDH18,PIKFYVE,PIP5K1B } \\
\text {,LIMK1,MAP3K10,ARPC3, } \\
\text { GNA13,GNB1L,MAP2K1,A } \\
\text { CTA1,RND2,SEPT14,MAP } \\
\text { 3K9,SEPT4,FGFR1,WASF } \\
\text { 1,RHOJ,SEPT1,CDH2,CD } \\
\text { H12,GAB1,NCF2,GNAO1, } \\
\text { ARHGEF6,PIK3CD }\end{array}$ \\
\hline $\begin{array}{l}\text { G Beta Gamma } \\
\text { Signaling }\end{array}$ & 0.73 & 0.114 & -2.333 & $\begin{array}{l}\text { SHC1,PRKACG,GNAO1,A } \\
\text { RHGEF6,ADCY1,KCNJ3,G } \\
\text { NA13,GNB1L,CAV3,PRKC } \\
\text { G }\end{array}$ \\
\hline PEDF Signaling & 0.543 & 0.103 & -2.333 & $\begin{array}{l}\text { BCL2L1,GAB1,FGFR1,SE } \\
\text { RPINF1,DOCK3,PIK3CD,Z } \\
\text { EB1,MAPK11,TCF12 }\end{array}$ \\
\hline EIF2 Signaling & 0.663 & 0.0991 & -2.324 & $\begin{array}{l}\text { RPL24,EIF3C,EIF3H,RPL3 } \\
\text {,RPL22L1,FGFR1,RPL7A, } \\
\text { RPL27,RPS6,SHC1,GAB1, } \\
\text { UBA52,RPS9,RPS27L,EIF } \\
\text { 3I,RPL39L,RPL6,PIK3CD, } \\
\text { MAP2K1,ACTA1,RPL38 }\end{array}$ \\
\hline Endothelin-1 Signaling & 0.88 & 0.108 & -2.236 & $\begin{array}{l}\text { NOS1,FGFR1,NOS3,MAP } \\
\text { K11,PRKCG,SHC1,CASP9 } \\
\text {,LCAT,GAB1,GNAO1,CAS } \\
\text { Q1,ADCY1,PIK3CD,GNA1 } \\
\text { 3,PLCL1,PAFAH1B1,SHF, } \\
\text { NOS2,ADCY7,PAFAH1B3 }\end{array}$ \\
\hline $\begin{array}{l}\text { Role of Pattern } \\
\text { Recognition Receptors } \\
\text { in Recognition of } \\
\text { Bacteria and Viruses }\end{array}$ & 0.405 & 0.0916 & -2.121 & $\begin{array}{l}\text { TRAF6,OAS1,C5AR1,GAB } \\
\text { 1,OAS2,FGFR1,PIK3CD,T } \\
\text { LR3,OAS3,RNASEL,RIPK2 } \\
\text {,PRKCG }\end{array}$ \\
\hline Th2 Pathway & 0.371 & 0.089 & -2.111 & $\begin{array}{l}\text { CCR3,CD3E,CHD4,FGFR1 } \\
\text {,PSEN2,CRLF2,TSLP,CD3 } \\
\text { G,NOTCH2,GAB1,CCR4,P } \\
\text { IK3CD,HLA-DRB5 }\end{array}$ \\
\hline Interferon Signaling & 0.464 & 0.111 & -2 & $\begin{array}{l}\text { OAS1,IFNGR2,IFI35,IFNG } \\
\text { R1 }\end{array}$ \\
\hline Integrin Signaling & 0.318 & 0.0849 & -1.886 & $\begin{array}{l}\text { RND2,PARVA,FGFR1,PIK } \\
\text { FYVE,RHOJ,BCAR3,ITGB } \\
\text { 8,SHC1,ITGAM,TLN2,GAB } \\
\text { 1,LIMS1,ARPC3,PIK3CD, } \\
\text { MAP2K1,ACTA1,VASP,CA }\end{array}$ \\
\hline
\end{tabular}




\begin{tabular}{|c|c|c|c|c|}
\hline & & & & PN10 \\
\hline Thrombin Signaling & 0.31 & 0.0846 & -1.807 & $\begin{array}{l}\text { RND2,FGFR1,RHOJ,MAP } \\
\text { K11,F2,PRKCG,SHC1,GA } \\
\text { B1,GNAO1,ADCY1,ARHG } \\
\text { EF6,PIK3CD,GNA13,PLCL } \\
\text { 1,GNB1L,ADCY7,MAP2K1 }\end{array}$ \\
\hline RhoA Signaling & 0.519 & 0.0984 & -1.732 & $\begin{array}{l}\text { SEPT14,SEPT4,PIKFYVE, } \\
\text { LPAR5,ARHGAP35,ARPC } \\
\text { 3,WASF1,PIP5K1B,GNA13 } \\
\text {,SEPT1,ACTA1,LIMK1 }\end{array}$ \\
\hline iNOS Signaling & 1.59 & 0.182 & -1.633 & $\begin{array}{l}\text { TRAF6,CALM1 (includes } \\
\text { others),CALML5,IFNGR2,I } \\
\text { FNGR1,IRAK3,NOS2,MAP } \\
\text { K11 }\end{array}$ \\
\hline $\begin{array}{l}\text { Lymphotoxin } \beta \\
\text { Receptor Signaling }\end{array}$ & 0.505 & 0.104 & -1.633 & $\begin{array}{l}\text { TRAF6,BCL2L1,CASP9,G } \\
\text { AB1,FGFR1,CYCS,PIK3C } \\
\text { D }\end{array}$ \\
\hline $\begin{array}{l}\text { Macropinocytosis } \\
\text { Signaling }\end{array}$ & 0.298 & 0.0864 & -1.633 & $\begin{array}{l}\text { MET,GAB1,FGFR1,PIK3C } \\
\text { D,ITGB8,RAB34,PRKCG }\end{array}$ \\
\hline $\begin{array}{l}\text { Nitric Oxide Signaling } \\
\text { in the Cardiovascular } \\
\text { System }\end{array}$ & 1.23 & 0.13 & -1.604 & $\begin{array}{l}\text { CALML5,FGFR1,PRKG2,N } \\
\text { OS3,PRKCG,PDE1C,BDK } \\
\text { RB2,CALM1 (includes } \\
\text { others),HSP90B1,GAB1,P } \\
\text { RKACG,PRKAA1,PIK3CD, } \\
\text { MAP2K1 }\end{array}$ \\
\hline $\begin{array}{l}\text { RANK Signaling in } \\
\text { Osteoclasts }\end{array}$ & 0.702 & 0.11 & -1.508 & $\begin{array}{l}\text { TRAF6,MAP3K9,MAP3K10 } \\
\text {,CALM1 (includes } \\
\text { others),CALML5,GAB1,FG } \\
\text { FR1,PIK3CD,MAP3K4,MA } \\
\text { P2K1,MAPK11 }\end{array}$ \\
\hline NGF Signaling & 0.409 & 0.0924 & -1.508 & $\begin{array}{l}\text { TRAF6,MAP3K9,SHC1,MA } \\
\text { P3K10,GAB1,FGFR1,SMP } \\
\text { D1,PIK3CD,MAP3K4,CRE } \\
\text { B5,MAP2K1 }\end{array}$ \\
\hline HMGB1 Signaling & 0.286 & 0.084 & -1.508 & $\begin{array}{l}\text { RND2,SP1,GAB1,FGFR1,I } \\
\text { FNGR2,RHOJ,PIK3CD,IFN } \\
\text { GR1,IL1R1,MAP2K1,MAP } \\
\text { K11 }\end{array}$ \\
\hline $\begin{array}{l}\text { FLT3 Signaling in } \\
\text { Hematopoietic } \\
\text { Progenitor Cells }\end{array}$ & 0.441 & 0.0976 & -1.414 & $\begin{array}{l}\text { SHC1,GAB1,FLT3LG,FGF } \\
\text { R1,PIK3CD,CREB5,MAP2 } \\
\text { K1,MAPK11 }\end{array}$ \\
\hline Paxillin Signaling & 0.377 & 0.0909 & -1.414 & $\begin{array}{l}\text { PARVA,TLN2,ITGAM,GAB } \\
\text { 1,FGFR1,ARHGEF6,PIK3 }\end{array}$ \\
\hline
\end{tabular}




\begin{tabular}{|c|c|c|c|c|}
\hline & & & & $\begin{array}{l}\text { CD,ITGB8,MAPK11,ACTA } \\
1\end{array}$ \\
\hline $\begin{array}{l}\text { Acute Myeloid } \\
\text { Leukemia Signaling }\end{array}$ & 0.31 & 0.087 & -1.414 & $\begin{array}{l}\text { KITLG,RUNX1,GAB1,FLT3 } \\
\text { LG,FGFR1,PIK3CD,JUP,M } \\
\text { AP2K1 }\end{array}$ \\
\hline SAPK/JNK Signaling & 1.1 & 0.126 & -1.387 & $\begin{array}{l}\text { MAP3K9,FGFR1,MAP3K4, } \\
\text { HNRNPK,MINK1,MAP3K1 } \\
\text { 0,TRADD,SHC1,GAB1,GA } \\
\text { DD45A,FCER1G,PIK3CD, } \\
\text { GNA13 }\end{array}$ \\
\hline $\begin{array}{l}\text { Mitotic Roles of Polo- } \\
\text { Like Kinase }\end{array}$ & 1.14 & 0.143 & -1.342 & $\begin{array}{l}\text { CDC25C,PLK4,HSP90B1, } \\
\text { PPP2R2A,PPP2R5B,ANA } \\
\text { PC5,CCNB2,PKMYT1,CD } \\
\text { C25A }\end{array}$ \\
\hline Androgen Signaling & 0.928 & 0.118 & -1.342 & $\begin{array}{l}\text { CALML5,POLR2D,CDK7,G } \\
\text { TF2E2,PRKCG,CALM1 } \\
\text { (includes } \\
\text { others),SHC1,POLR2A,GN } \\
\text { AO1,PRKACG,GNA13,GN } \\
\text { B1L,GTF2H3 }\end{array}$ \\
\hline $\begin{array}{l}\text { FcyRIIB Signaling in B } \\
\text { Lymphocytes }\end{array}$ & 0.352 & 0.0943 & -1.342 & $\begin{array}{l}\text { SHC1,GAB1,FGFR1,PIK3 } \\
\text { CD,DOK1 }\end{array}$ \\
\hline $\begin{array}{l}\text { Actin Nucleation by } \\
\text { ARP-WASP Complex }\end{array}$ & 0.307 & 0.0893 & -1.342 & $\begin{array}{l}\text { RND2,ARPC3,WASF1,RH } \\
\text { OJ,VASP }\end{array}$ \\
\hline Sperm Motility & 0.934 & 0.117 & -1.155 & $\begin{array}{l}\text { CALML5,NPPC,PRKG2,C } \\
\text { NGA1,PRKCG,PDE1C,CA } \\
\text { LM1 (includes } \\
\text { others),LCAT,PRKACG,LT } \\
\text { K,PLCL1, PAFAH1B1, } \\
\text { CATSPER1, PAFAH1B3 }\end{array}$ \\
\hline $\begin{array}{l}\text { Role of NANOG in } \\
\text { Mammalian Embryonic } \\
\text { Stem Cell Pluripotency }\end{array}$ & 0.727 & 0.108 & -1.134 & $\begin{array}{l}\text { BMP4,T,FGFR1,WNT16,S } \\
\text { HC1,FZD8,NANOG,WNT3 } \\
\text { A,GAB1,FZD5,PIK3CD,MA } \\
\text { P2K1,SMAD1 }\end{array}$ \\
\hline Prolactin Signaling & 0.275 & 0.0843 & -1.134 & $\begin{array}{l}\text { SHC1,SP1,GAB1,FGFR1, } \\
\text { PIK3CD,MAP2K1,PRKCG }\end{array}$ \\
\hline $\begin{array}{l}\text { Actin Cytoskeleton } \\
\text { Signaling }\end{array}$ & 1.01 & 0.109 & -1.091 & $\begin{array}{l}\text { FGF2,FGF9,MYH14,FGFR } \\
\text { 1,BRK1,PIKFYVE,WASF1, } \\
\text { MYH7,PIP5K1B,SSH1,F2, } \\
\text { LIMK1,SHC1,DIAPH2,TLN } \\
\text { 2,GAB1,ARHGEF6,FGF23, } \\
\text { ARPC3,ARHGAP35,PIK3C } \\
\text { D,GNA13,MAP2K1,ACTA1 }\end{array}$ \\
\hline
\end{tabular}




\begin{tabular}{|c|c|c|c|c|}
\hline AMPK Signaling & 0.4 & 0.0891 & -1.069 & $\begin{array}{l}\text { ULK1,PPP2R2A,FGFR1,S } \\
\text { TK11,PPP2R5B,LIPE,NOS } \\
\text { 3,CREB5,MAPK11,CHRM3 } \\
\text {,PFKM,AK5,GAB1,PRKAC } \\
\text { G,PRKAA1,PIK3CD,GNB1 } \\
\text { L,ADRB2 }\end{array}$ \\
\hline $\begin{array}{l}\text { B Cell Receptor } \\
\text { Signaling }\end{array}$ & 0.701 & 0.102 & -1 & $\begin{array}{l}\text { MAP3K9,CALML5,IGHE,F } \\
\text { GFR1,MAP3K4,CREB5,M } \\
\text { APK11,PTPRC,SYNJ2,PA } \\
\text { X5,SHC1,BCL2L1,CALM1 } \\
\text { (includes } \\
\text { others),MAP3K10,GAB1,IN } \\
\text { PP5B,PIK3CD,INPP5K,MA } \\
\text { P2K1 }\end{array}$ \\
\hline IL-1 Signaling & 0.65 & 0.109 & -1 & $\begin{array}{l}\text { TRAF6,PRKACG,GNAO1, } \\
\text { ADCY1,IRAK3,IL1R1,GNA } \\
\text { 13,GNB1L,MAPK11,ADCY } \\
7\end{array}$ \\
\hline $\begin{array}{l}\text { CD28 Signaling in T } \\
\text { Helper Cells }\end{array}$ & 0.61 & 0.102 & -1 & $\begin{array}{l}\text { PTPRC,CD3G,CALM1 } \\
\text { (includes } \\
\text { others),CALML5,GAB1,CD } \\
\text { 3E,GRAP2,FGFR1,FCER1 } \\
\text { G,ARPC3,PIK3CD,MAP2K } \\
\text { 1,HLA-DRB5 }\end{array}$ \\
\hline Glioma Signaling & 0.516 & 0.0991 & -1 & $\begin{array}{l}\text { SHC1,CALM1 (includes } \\
\text { others),CALML5,TFDP1,G } \\
\text { AB1,FGFR1,CDKN2C,PIK } \\
\text { 3CD,RBL1,MAP2K1,PRKC } \\
\text { G }\end{array}$ \\
\hline Sumoylation Pathway & 0.406 & 0.0938 & -1 & $\begin{array}{l}\text { RND2,SP1,RFC4,SLC19A } \\
\text { 1,RHOJ,SENP2,ZEB1,RFC } \\
\text { 5,SNCA }\end{array}$ \\
\hline Ephrin B Signaling & 0.404 & 0.0959 & -1 & $\begin{array}{l}\text { EFNB2,KALRN,GNAO1,G } \\
\text { NA13,GNB1L,HNRNPK,LI } \\
\text { MK1 }\end{array}$ \\
\hline VEGF Signaling & 0.356 & 0.09 & -1 & $\begin{array}{l}\text { SHC1,BCL2L1,GAB1,FGF } \\
\text { R1,PIK3CD,HIF1A,NOS3, } \\
\text { MAP2K1,ACTA1 }\end{array}$ \\
\hline $\begin{array}{l}\text { PKC } \theta \text { Signaling in T } \\
\text { Lymphocytes }\end{array}$ & 0.313 & 0.0859 & -1 & $\begin{array}{l}\text { MAP3K9,MAP3K10,CD3G, } \\
\text { GAB1,CD3E,GRAP2,FGF } \\
\text { R1,FCER1G,PIK3CD,MAP } \\
\text { 3K4,HLA-DRB5 }\end{array}$ \\
\hline $\begin{array}{l}\text { UVA-Induced MAPK } \\
\text { Signaling }\end{array}$ & 0.301 & 0.0857 & -1 & $\begin{array}{l}\text { BCL2L1,CASP9,GAB1,FG } \\
\text { FR1,CYCS,SMPD1,PIK3C }\end{array}$ \\
\hline
\end{tabular}




\begin{tabular}{|c|c|c|c|c|}
\hline & & & & D,PLCL1,MAPK11 \\
\hline \multicolumn{5}{|l|}{19 weeks } \\
\hline \multicolumn{5}{|l|}{ Induced pathways } \\
\hline RhoGDI Signaling & 0.522 & 0.105 & 1.387 & $\begin{array}{l}\text { PAK4,CDH4,PAK6,RHOC, } \\
\text { GNA12,ARPC5,GNB5,GN } \\
\text { Al1,RHOH,DGKZ,GNB4,G } \\
\text { NG11,CDH12,CDH10,PAK } \\
\text { 2,ARHGDIA,PIP4K2C,MYL } \\
\text { 12A }\end{array}$ \\
\hline TNFR2 Signaling & 0.928 & 0.172 & 1.342 & $\begin{array}{l}\text { MAP3K14,NFKBIA,TBK1,N } \\
\text { FKBIB,TNFRSF1B }\end{array}$ \\
\hline $\begin{array}{l}\text { Mitotic Roles of Polo- } \\
\text { Like Kinase }\end{array}$ & 0.459 & 0.111 & 1.134 & $\begin{array}{l}\text { KIF23,SLK,CDC25C,ESPL } \\
\text { 1,ANAPC5,CCNB2,KIF11 }\end{array}$ \\
\hline $\begin{array}{l}\text { Insulin Receptor } \\
\text { Signaling }\end{array}$ & 0.746 & 0.117 & 1 & $\begin{array}{l}\text { EIF2B4,PDPK1,PPP1R3A, } \\
\text { CRK,VAMP2,PIK3R3,SYN } \\
\text { J2,PRKCI,GAB1,PIK3C3,S } \\
\text { H2B2,PTPN1,PRKACA,IR } \\
\text { S2,INPP5K,SCNN1B }\end{array}$ \\
\hline Eicosanoid Signaling & 0.627 & 0.123 & 1 & $\begin{array}{l}\text { PTGFR,LTA4H,PTGDR,PL } \\
\text { A2R1,PLA2G3,CYSLTR1, } \\
\text { PLA2G2A,PTGER1 }\end{array}$ \\
\hline Interferon Signaling & 0.38 & 0.111 & 1 & IFITM3,TYK2,IFITM1,IRF1 \\
\hline \multicolumn{5}{|l|}{ Suppressed pathways } \\
\hline $\begin{array}{l}\text { Agrin Interactions at } \\
\text { Neuromuscular } \\
\text { Junction }\end{array}$ & 0.582 & 0.119 & -2.121 & $\begin{array}{l}\text { PTK2,PAK4,PAK6,PAK2,E } \\
\text { RBB3,AGRN,RAC3,ITGAL }\end{array}$ \\
\hline $\begin{array}{l}\text { Cholecystokinin/Gastri } \\
\text { n-mediated Signaling }\end{array}$ & 0.508 & 0.109 & -2.111 & $\begin{array}{l}\text { PTK2,PRKCI,RHOC,GNA1 } \\
\text { 2,SRF,EPHA4,MAPK7,ELK } \\
\text { 1,RHOH,MAP2K5,MEF2B }\end{array}$ \\
\hline IL-8 Signaling & 1.09 & 0.122 & -1.964 & $\begin{array}{l}\text { PLD3,ANGPT1,FLT1,RHO } \\
\text { C,GNA12,GNB5,GNAI1,RA } \\
\text { C3,RHOH,NOX1,CSTB,PT } \\
\text { K2,PIK3R3,HMOX1,GNB4, } \\
\text { PRKCI,GNG11,CCND3,GA } \\
\text { B1,PIK3C3,PAK2,IL9,IRS2, } \\
\text { NFKBIB }\end{array}$ \\
\hline Rac Signaling & 0.775 & 0.121 & -1.941 & $\begin{array}{l}\text { PTK2,PIK3R3,PAK4,PRKC } \\
\text { I,PAK6,GAB1,PIK3C3,ARP } \\
\text { C5,PAK2,IRS2,ELK1,NOX } \\
\text { 1,PIP4K2C,IQGAP3 }\end{array}$ \\
\hline
\end{tabular}




\begin{tabular}{|c|c|c|c|c|}
\hline $\begin{array}{l}\text { Renin-Angiotensin } \\
\text { Signaling }\end{array}$ & 0.515 & 0.107 & -1.941 & $\begin{array}{l}\text { PTK2,PIK3R3,PAK4,PRKC } \\
\text { I,PAK6,GAB1,PIK3C3,ADC } \\
\text { Y1,PAK2,PRKACA,IRS2,E } \\
\text { LK1,NOX1 }\end{array}$ \\
\hline $\begin{array}{l}\text { Regulation of Actin- } \\
\text { based Motility by Rho }\end{array}$ & 0.596 & 0.116 & -1.897 & $\begin{array}{l}\text { PAK4,PAK6,RHOC,PAK2, } \\
\text { ARPC5,ARHGDIA,RAC3,R } \\
\text { HOH,PIP4K2C,MYL12A }\end{array}$ \\
\hline $\begin{array}{l}\text { LPS/LL-1 Mediated } \\
\text { Inhibition of RXR } \\
\text { Function }\end{array}$ & 0.278 & 0.0913 & $\mid-1.89$ & $\begin{array}{l}\text { APOE,ALDH4A1,FMO3,SL } \\
\text { C10A1,SLC27A2,SULT1C } \\
\text { 2,IL1RL1,ALDH8A1,SLC35 } \\
\text { A2,HS3ST4,PAPSS2,HS3 } \\
\text { ST2,SULT1A3/SULT1A4,C } \\
\text { PT2,CHST3,SULT1C3,TN } \\
\text { FRSF1B,NDST1,SULT1B1 }\end{array}$ \\
\hline Neuregulin Signaling & 0.278 & 0.093 & -1.89 & $\begin{array}{l}\text { PIK3R3,PRKCI,PDPK1,ER } \\
\text { BB3,ERRFI1,CRK,ELK1,R } \\
\text { NF41 }\end{array}$ \\
\hline Tec Kinase Signaling & 1.28 & 0.131 & -1.807 & $\begin{array}{l}\text { PAK4,PAK6,RHOC,GNA12 } \\
\text {,TYK2,GNB5,GNAI1,TNFS } \\
\text { F10,RHOH,FAS,PTK2,PIK } \\
\text { 3R3,GNB4,YES1,PRKCI,G } \\
\text { NG11,GAB1,TNFSF12,PIK } \\
\text { 3C3,PAK2,IRS2,FGR }\end{array}$ \\
\hline $\begin{array}{l}\text { Signaling by Rho } \\
\text { Family GTPases }\end{array}$ & 0.613 & 0.105 & -1.789 & $\begin{array}{l}\text { ARPC5,GNB5,RHOH,NOX } \\
\text { 1,PTK2,STMN1,GNB4,GN } \\
\text { G11,PIK3C3,IRS2,MYL12A } \\
\text {,SEPT8,PAK4,CDH4,PAK6 } \\
\text {,RHOC,GNA12,GNAI1,PIK } \\
\text { 3R3,PRKCI,CDH12,GAB1, } \\
\text { CDH10,PAK2,ELK1,PIP4K } \\
\text { 2C }\end{array}$ \\
\hline Angiopoietin Signaling & 2.05 & 0.182 & -1.667 & $\begin{array}{l}\text { PAK4,GRB14,PAK6,ANGP } \\
\text { T1,CRK,TIE1,PIK3R3,PTK } \\
\text { 2,NFKBIA,GAB1,PIK3C3,P } \\
\text { AK2,IRS2,NFKBIB }\end{array}$ \\
\hline CD40 Signaling & 0.558 & 0.115 & -1.667 & $\begin{array}{l}\text { PIK3R3,MAP3K14,NFKBIA } \\
\text {,GAB1,PIK3C3,IRS2,MAP } \\
\text { KAPK2,NFKBIB,MAP2K5 }\end{array}$ \\
\hline $\begin{array}{l}\text { Ephrin Receptor } \\
\text { Signaling }\end{array}$ & 0.661 & 0.11 & -1.508 & $\begin{array}{l}\text { MAP3K14,PAK4,KALRN,A } \\
\text { NGPT1,PAK6,GNA12,ARP } \\
\text { C5,GNB5,GNAI1,CRK,EP } \\
\text { HA4,RAC3,RAP1A,PTK2,E } \\
\text { FNB2,GNB4,GNG11,PAK2 } \\
\text {,ADAM10 }\end{array}$ \\
\hline
\end{tabular}




\begin{tabular}{|c|c|c|c|c|}
\hline $\begin{array}{l}\text { April Mediated } \\
\text { Signaling }\end{array}$ & 0.555 & 0.128 & -1.342 & $\begin{array}{l}\text { MAP3K14,NFKBIA,TNFSF } \\
\text { 13,ELK1,NFKBIB }\end{array}$ \\
\hline Ga12/13 Signaling & 1.07 & 0.13 & -1.291 & $\begin{array}{l}\text { LPAR4,CDH4,GNA12,MEF } \\
\text { 2B,PIK3R3,PTK2,CDH12, } \\
\text { NFKBIA,GAB1,PIK3C3,CD } \\
\text { H10,LPAR5,IRS2,MAPK7, } \\
\text { NFKBIB,ELK1,MYL12A }\end{array}$ \\
\hline Thrombin Signaling & 0.333 & 0.0945 & -1.291 & $\begin{array}{l}\text { CAMK1D,RHOC,GNA12,G } \\
\text { NB5,GNAl1,TBP,PDPK1,R } \\
\text { HOH,PTK2,PIK3R3,GNB4, } \\
\text { PRKCI,GNG11,GAB1,PIK3 } \\
\text { C3,ADCY1,IRS2,ELK1,MY } \\
\text { L12A }\end{array}$ \\
\hline $\begin{array}{l}\text { NRF2-mediated } \\
\text { Oxidative Stress } \\
\text { Response }\end{array}$ & 0.692 & 0.111 & -1.265 & $\begin{array}{l}\text { AKR7A2,DNAJC6,DNAJC1 } \\
\text { 9,SLC35A2,JUNB,DNAJA1 } \\
\text {,MAFK,MAFG,PIK3R3,HM } \\
\text { OX1,PRKCI,ERP29,GAB1, } \\
\text { DNAJC4,PIK3C3,DNAJB1 } \\
\text { 1,IRS2,DNAJB6,MAPK7,C } \\
\text { DC34,MAP2K5 }\end{array}$ \\
\hline $\begin{array}{l}\text { Fcy Receptor- } \\
\text { mediated } \\
\text { Phagocytosis in } \\
\text { Macrophages and } \\
\text { Monocytes }\end{array}$ & 0.472 & 0.108 & -1.265 & $\begin{array}{l}\text { PIK3R3,HMOX1,YES1,AR } \\
\text { F6,PRKCI,PLD3,ARPC5,C } \\
\text { RK,RAC3,FGR }\end{array}$ \\
\hline $\begin{array}{l}\text { Corticotropin } \\
\text { Releasing Hormone } \\
\text { Signaling }\end{array}$ & 0.419 & 0.103 & -1.265 & $\begin{array}{l}\text { PRKCI,NPR1,ARPC5,ADC } \\
\text { Y1,PRKACA,GNAI1,POMC } \\
\text {,ELK1,KRT1,RAP1A,MEF2 } \\
\text { B }\end{array}$ \\
\hline PAK Signaling & 0.371 & 0.1 & -1.265 & $\begin{array}{l}\text { PTK2,PIK3R3,PAK4,GAB1 } \\
\text {,PAK6,PIK3C3,PAK2,IRS2, } \\
\text { MYL12A,PDGFRB }\end{array}$ \\
\hline CXCR4 Signaling & 0.966 & 0.122 & -1.213 & $\begin{array}{l}\text { PAK4,PAK6,RHOC,GNA12 } \\
\text {,GNB5,GNAI1,CRK,RHOH, } \\
\text { PIK3R3,PTK2,GNB4,PRK } \\
\text { CI,GNG11,GAB1,PIK3C3, } \\
\text { ADCY1,PAK2,IRS2,ELK1, } \\
\text { MYL12A }\end{array}$ \\
\hline $\begin{array}{l}\text { Actin Cytoskeleton } \\
\text { Signaling }\end{array}$ & 0.347 & 0.095 & -1.213 & $\begin{array}{l}\text { FGF16,PAK4,PAK6,MYH1 } \\
\text { 3,GNA12,MYH14,ARPC5, } \\
\text { CRK,RAC3,PIK3R3,PTK2, } \\
\text { GAB1,PIK3C3,PAK2,FGF1 } \\
\text { 1,IRS2,FGF7,PIP4K2C,IQ } \\
\text { GAP3,FGF5,MYL12A }\end{array}$ \\
\hline
\end{tabular}




\begin{tabular}{|c|c|c|c|c|}
\hline $\begin{array}{l}\text { Role of PI3K/AKT } \\
\text { Signaling in the } \\
\text { Pathogenesis of } \\
\text { Influenza }\end{array}$ & 0.412 & 0.105 & -1.134 & $\begin{array}{l}\text { PIK3R3,NFKBIA,GAB1,PIK } \\
\text { 3C3,GNAI1,CRK,IRS2,NF } \\
\text { KBIB }\end{array}$ \\
\hline $\begin{array}{l}\text { IL-17A Signaling in } \\
\text { Airway Cells }\end{array}$ & 0.381 & 0.103 & -1.134 & $\begin{array}{l}\text { PIK3R3,NFKBIA,GAB1,PIK } \\
\text { 3C3,TYK2,IRS2,NFKBIB,D } \\
\text { EFB4A/DEFB4B }\end{array}$ \\
\hline $\begin{array}{l}\text { fMLP Signaling in } \\
\text { Neutrophils }\end{array}$ & 1.06 & 0.131 & -1.069 & $\begin{array}{l}\text { ARPC5,GNB5,GNAI1,PPP } \\
\text { 3CC,NOX1,PIK3R3,GNB4, } \\
\text { PRKCI,GNG11,NFKBIA,G } \\
\text { AB1,PIK3C3,IRS2,NFKBIB } \\
\text {,ELK1,PPP3CA }\end{array}$ \\
\hline Ephrin B Signaling & 0.665 & 0.123 & -1 & $\begin{array}{l}\text { PTK2,GNB4,EFNB2,GNG1 } \\
\text { 1,KALRN,GNA12,GNB5,G } \\
\text { NAI1,RAC3 }\end{array}$ \\
\hline $\begin{array}{l}\text { Growth Hormone } \\
\text { Signaling }\end{array}$ & 0.467 & 0.108 & -1 & $\begin{array}{l}\text { PIK3R3,PRKCI,GAB1,PIK3 } \\
\text { C3,SOCS6,SRF,PDPK1,IR } \\
\text { S2,ELK1 }\end{array}$ \\
\hline \multicolumn{5}{|l|}{28 weeks } \\
\hline \multicolumn{5}{|l|}{ Induced pathways } \\
\hline TREM1 Signaling & 0.317 & 0.0571 & 2 & CXCL3,TLR6,TLR1,PLCG1 \\
\hline Sperm Motility & 0.571 & 0.0667 & 1.134 & $\begin{array}{l}\text { CACNA1G,PLA2G6,PLCB } \\
\text { 2,NPPC,PLCG1,PLCL2,AD } \\
\text { CY10,PAFAH1B1 }\end{array}$ \\
\hline $\begin{array}{l}\text { UVA-Induced MAPK } \\
\text { Signaling }\end{array}$ & 0.541 & 0.0667 & 1.134 & $\begin{array}{l}\text { PLCB2,CASP3,PIK3C2G,P } \\
\text { LCG1,PIK3CD,PLCL2,PAR } \\
\text { P3 }\end{array}$ \\
\hline $\begin{array}{l}\text { Corticotropin } \\
\text { Releasing Hormone } \\
\text { Signaling }\end{array}$ & 0.517 & 0.0654 & 1.134 & $\begin{array}{l}\text { GNAI3,ADCY2,MAP2K2,U } \\
\text { CN3,PLCG1,ADCY10,PTC } \\
\text { H2 }\end{array}$ \\
\hline $\begin{array}{l}\text { Neuroprotective Role } \\
\text { of THOP1 in } \\
\text { Alzheimer's Disease }\end{array}$ & 0.674 & 0.0714 & 1 & $\begin{array}{l}\text { MME,CFD,TMPRSS15,NF } \\
\text { YA,PRTN3,NTS,TMPRSS7 } \\
\text {,TAC1 }\end{array}$ \\
\hline p70S6K Signaling & 0.648 & 0.0687 & 1 & $\begin{array}{l}\text { GNAI3,IL2RG,PLCB2,MAP } \\
\text { 2K2,PIK3C2G,PLCG1,PIK } \\
\text { 3CD,PLCL2,BCAP31 }\end{array}$ \\
\hline $\begin{array}{l}\text { Lymphotoxin } \beta \\
\text { Receptor Signaling }\end{array}$ & 0.349 & 0.0597 & 1 & $\begin{array}{l}\text { NFKBIA,CASP3,PIK3C2G, } \\
\text { PIK3CD }\end{array}$ \\
\hline
\end{tabular}




\begin{tabular}{|l|l|l|l|l|}
\hline $\begin{array}{l}\text { Cell Cycle: G2/M DNA } \\
\text { Damage Checkpoint } \\
\text { Regulation }\end{array}$ & 0.622 & 0.0816 & $\mathbf{- 2}$ & $\begin{array}{l}\text { MDM4,GADD45A,TOP2A, } \\
\text { AURKA }\end{array}$ \\
\hline $\begin{array}{l}\text { BMP signaling } \\
\text { pathway }\end{array}$ & 0.28 & 0.0541 & $\mathbf{- 2}$ & $\begin{array}{l}\text { SOSTDC1,MAP2K2,TLX2, } \\
\text { BMP10 }\end{array}$ \\
\hline RhoA Signaling & 1.66 & 0.0984 & $-\mathbf{1 . 6 6 7}$ & $\begin{array}{l}\text { MYL10,ABL2,MYL2,PLEK } \\
\text { HG5,EPHA1,ARHGAP4,IG } \\
\text { F1R,RAPGEF6,WASF1,M } \\
\text { YL6B,SEPT11,SEMA3F }\end{array}$ \\
\hline Gaq Signaling & 0.374 & 0.0566 & $\mathbf{- 1 . 4 1 4}$ & $\begin{array}{l}\text { PLCB2,NFKBIA,PLD3,MA } \\
\text { P2K2,PIK3C2G,RGS4,PLC } \\
\text { G1,PIK3CD,HTR2A }\end{array}$ \\
\hline $\begin{array}{l}\text { LPS-stimulated MAPK } \\
\text { Signaling }\end{array}$ & 0.339 & 0.0575 & $-\mathbf{1 . 3 4 2}$ & $\begin{array}{l}\text { PAK1,NFKBIA,MAP2K2,PI } \\
\text { K3C2G,PIK3CD }\end{array}$ \\
\hline $\begin{array}{l}\text { Cardiac Hypertrophy } \\
\text { Signaling }\end{array}$ & 0.52 & 0.0601 & $-\mathbf{1 . 0 6 9}$ & $\begin{array}{l}\text { PLCB2,ADCY2,MYL10,MA } \\
\text { PKAPK3,MYL2,PIK3C2G,P } \\
\text { LCG1,MYLB,PLCL2,GNAI } \\
\text { 3,MAP2K2,IGF1R,PIK3CD, } \\
\text { ADCY10 }\end{array}$ \\
\hline $\begin{array}{l}\text { Huntington's Disease } \\
\text { Signaling }\end{array}$ & 0.612 & 0.0625 & $-\mathbf{1}$ & $\begin{array}{l}\text { HDAC9,PLCB2,CASP3,PI } \\
\text { K3C2G,POLR2H,STX1A,S } \\
\text { NAP25,DNAJC5,TAF4,CA } \\
\text { CNA1B,NTRK1,IGF1R,PIK } \\
\text { 3CD,CAPN10,DNM2 }\end{array}$ \\
\hline STAT3 Pathway & 0.28 & 0.0541 & $\mathbf{- 1}$ & $\begin{array}{l}\text { MAP2K2,PTPN2,NTRK1,I } \\
\text { GF1R }\end{array}$ \\
\hline
\end{tabular}


After 7 weeks chronic exposure, mRNAs in several pathways were induced including cell cycle, e.g. G1/S checkpoint regulation pathway, suggesting a delay in cell cycle. The analyses also showed that mRNAs in the basal cell carcinoma signaling pathway were induced. When examining the suppressed pathways, mRNAs populating several cytoskeleton, extracellular matrix (ECM) and migration signaling associated pathways, such as Integrin Signaling, RhoA Signaling and Actin Cytoskeleton Signaling, were suppressed. However, cellular migration behavior was not significantly affected by arsenic at an earlier time point (3 weeks) as examined by migration assay (Fig. 5.1). Similarly, mRNAs populating cytoskeleton, ECM and migration signaling associated pathways including, regulation of actin-based motility by Rho and actin cytoskeleton signaling were suppressed after 19 weeks chronic exposure. Furthermore, mRNAs in the RhoA signaling pathway were suppressed after 28 weeks chronic exposure. However, the migration assay of the same cells after 34 weeks chronic exposure did not show any significant change in cellular migration ability (Fig. $5.1)$. 


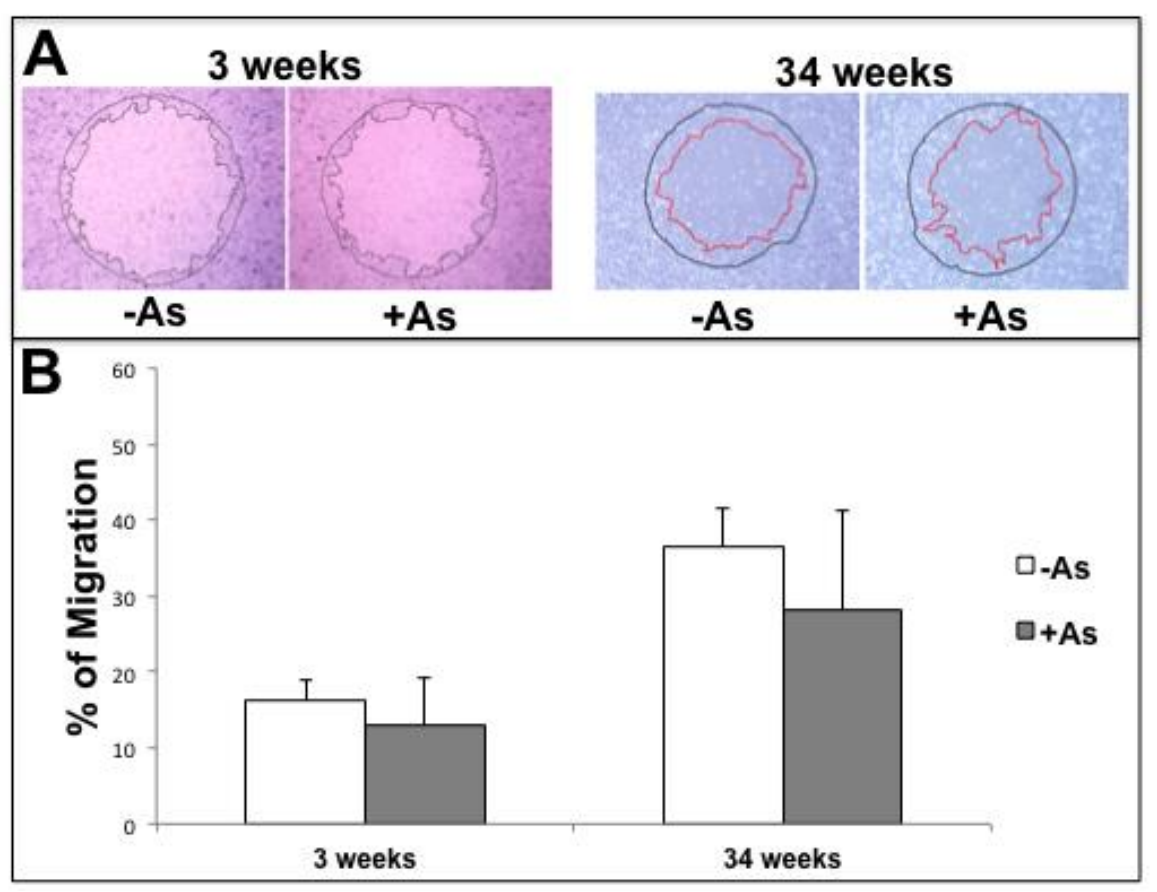

Figure 5.1: Arsenite did not affect cell migration. A. Quadruplicate HaCaT cultures incubated with 0 or $100 \mathrm{nM}$ sodium arsenite for 7 and 34 weeks were photographed after $16 \mathrm{~h}$ incubation $\pm \mathrm{EGF}$ in serum-free media. The migration area was quantified using automated_migration_assay program developed by Gregory J. R. States, M.S. at the University of Louisville. Lines indicate border at $0 \mathrm{~h}$ and 16 hours. B) Quantification of closure. Student's T-Test was used for statistical analyses. 


\section{d. mRNA Targets of Differentially Expressed miRNAs}

Potential targets of differentially expressed miRNAs after 7, 19 and 28 weeks chronic exposure were obtained and compared to mRNA data obtained at the same three time points using. After 7 weeks chronic exposure, 20 of 59 differentially expressed miRNAs were found to target one mRNA or more of a list of 336 mRNAs that are also differently expressed at the same time point. Similarly, 64 of 124 differentially expressed miRNAs were found to target one mRNA or more of a list of 695 mRNAs that are also differently expressed at 19 weeks. After 28 weeks chronic exposure, 28 miRNAs of 53 differentially expressed miRNAs were found to target one mRNA or more of a list of 291 mRNAs differently expressed at the same time point.

\section{e. Pathways of mRNA Targets of Differentially Expressed miRNAs}

Pathway analyses were performed using IPA® for the differentially expressed target mRNAs for each of the three time points obtained and described in the previous section. Based on the Z-score values of each pathway, pathways with Z-score $\geq|1|$ were selected (Table 5.3). After 7 weeks chronic exposure, induced mRNAs populated several pathways including cell cycle pathways, G1/S Checkpoint Regulation, along with cancer related pathways, glioblastoma multiforme signaling and mTOR signaling. However, the glioma signaling, ERK/MAPK signaling and melanocyte development and pigmentation signaling pathways were predicted to be suppressed. Suppression in melanocyte development and pigmentation signaling was also predicted. 
After 19 weeks chronic exposure, several more pathways were predicted to be induced and suppressed. Larger number of cancer and diabetes-related pathways were predicted to be induced. Notably, TP53 and PTEN signaling pathways were suppressed. After 28 weeks chronic exposure, fewer pathways were predicted to be induced and suppressed. Cytoskeleton and ECM remolding-related pathways were also predicted to be induced. 
Table 5.3. Pathway analysis of differentially expressed mRNAs targets of differentially expressed miRNAs

\begin{tabular}{|c|c|c|c|c|}
\hline $\begin{array}{l}\text { Ingenuity Canonical } \\
\text { Pathways }\end{array}$ & $\begin{array}{l}\text {-log } \\
\text { (p-value) }\end{array}$ & Ratio & z-score & $\begin{array}{l}\text { Genes } \\
\text { induced/suppressed }\end{array}$ \\
\hline \multicolumn{5}{|l|}{7 weeks } \\
\hline \multicolumn{5}{|l|}{ Induced pathway } \\
\hline $\begin{array}{l}\text { Cell Cycle: G1/S } \\
\text { Checkpoint Regulation }\end{array}$ & 3.18 & 0.0952 & 1.342 & $\begin{array}{l}\text { NRG1,HDAC4,HDAC7,C } \\
\text { DKN1B,RBL1,CDC25A }\end{array}$ \\
\hline $\begin{array}{l}\text { Glioblastoma Multiforme } \\
\text { Signaling }\end{array}$ & 1.74 & 0.044 & 1.342 & $\begin{array}{l}\text { RND2,WNT3A,GAB1,FG } \\
\text { FR1,FZD5,CDKN1B,MAP } \\
\text { 2K1 }\end{array}$ \\
\hline mTOR Signaling & 0.622 & 0.0254 & 1.342 & $\begin{array}{l}\text { RND2,GAB1,PPP2R2A,F } \\
\text { GFR1,PRKAA1 }\end{array}$ \\
\hline Osteoarthritis Pathway & 4.33 & 0.0634 & 1 & $\begin{array}{l}\text { HDAC4,FGF2,FGFR1,PT } \\
\text { CH1,SMAD7,COL10A1,S } \\
\text { P7,CREB5,WNT3A,SP1, } \\
\text { CASQ1,PRKAA1,FZD5 }\end{array}$ \\
\hline $\begin{array}{l}\text { Huntington's Disease } \\
\text { Signaling }\end{array}$ & 1.68 & 0.0375 & 1 & $\begin{array}{l}\text { BCL2L1,HDAC4,SP1,GA } \\
\text { B1,FGFR1,HDAC7,CASQ } \\
\text { 1,CREB5,SNCA }\end{array}$ \\
\hline \multicolumn{5}{|l|}{ Suppressed pathway } \\
\hline $\begin{array}{l}\text { Protein Kinase A } \\
\text { Signaling }\end{array}$ & 1.9 & 0.0342 & -1.667 & $\begin{array}{l}\text { PTPN23,PTCH1,LIPE,CR } \\
\text { EB5,AKAP11,CALM1 } \\
\text { (includes } \\
\text { others),H3F3A/H3F3B,DU } \\
\text { SP9,ADCY1,GNA13,PTP } \\
\text { RR,MAP2K1,CDC25A }\end{array}$ \\
\hline PEDF Signaling & 2.46 & 0.069 & -1.633 & $\begin{array}{l}\text { BCL2L1,GAB1,FGFR1,D } \\
\text { OCK3,ZEB1,TCF12 }\end{array}$ \\
\hline $\begin{array}{l}\text { Phospholipase C } \\
\text { Signaling }\end{array}$ & 1.35 & 0.0342 & -1.633 & $\begin{array}{l}\text { RND2,CALM1 (includes } \\
\text { others),HDAC4,HDAC7,A } \\
\text { DCY1,GNA13,CREB5,MA } \\
\text { P2K1 }\end{array}$ \\
\hline ERK/MAPK Signaling & 2.18 & 0.0455 & -1.414 & $\begin{array}{l}\text { TLN2,H3F3A/H3F3B,DUS } \\
\text { P9,GAB1,PPP2R2A,FGF } \\
\text { R1,CREB5,MAP2K1,KSR } \\
1\end{array}$ \\
\hline $\begin{array}{l}\text { RANK Signaling in } \\
\text { Osteoclasts }\end{array}$ & 2.82 & 0.07 & -1 & $\begin{array}{l}\text { TRAF6,MAP3K9,CALM1 } \\
\text { (includes } \\
\text { others),GAB1,FGFR1,MA } \\
\text { P3K4,MAP2K1 }\end{array}$ \\
\hline Ceramide Signaling & 2.31 & 0.0645 & -1 & $\begin{array}{l}\text { GAB1,PPP2R2A,FGFR1, } \\
\text { SMPD1,MAP2K1,KSR1 }\end{array}$ \\
\hline
\end{tabular}




\begin{tabular}{|c|c|c|c|c|}
\hline $\begin{array}{l}\text { Melanocyte Development } \\
\text { and Pigmentation } \\
\text { Signaling }\end{array}$ & 2.22 & 0.0619 & -1 & $\begin{array}{l}\text { KITLG,GAB1,FGFR1,AD } \\
\text { CY1,CREB5,MAP2K1 }\end{array}$ \\
\hline HGF Signaling & 1.9 & 0.0526 & -1 & $\begin{array}{l}\text { MET,MAP3K9,GAB1,FGF } \\
\text { R1,MAP3K4,MAP2K1 }\end{array}$ \\
\hline $\begin{array}{l}\text { CREB Signaling in } \\
\text { Neurons }\end{array}$ & 1.45 & 0.0383 & -1 & $\begin{array}{l}\text { CALM1 (includes } \\
\text { others),GAB1,FGFR1,AD } \\
\text { CY1,GNA13,CREB5,MAP } \\
\text { 2K1 }\end{array}$ \\
\hline $\begin{array}{l}\text { Nitric Oxide Signaling in } \\
\text { the Cardiovascular } \\
\text { System }\end{array}$ & 1.44 & 0.0463 & -1 & $\begin{array}{l}\text { CALM1 (includes } \\
\text { others),GAB1,FGFR1,PR } \\
\text { KAA1,MAP2K1 }\end{array}$ \\
\hline Glioma Signaling & 1.4 & 0.045 & -1 & $\begin{array}{l}\text { CALM1 (includes } \\
\text { others),GAB1,FGFR1,RB } \\
\text { L1,MAP2K1 }\end{array}$ \\
\hline $\begin{array}{l}\text { Estrogen-Dependent } \\
\text { Breast Cancer Signaling }\end{array}$ & 1.39 & 0.0519 & -1 & $\begin{array}{l}\text { SP1,GAB1,FGFR1,CREB } \\
5\end{array}$ \\
\hline NF-KB Signaling & 0.74 & 0.0281 & -1 & $\begin{array}{l}\text { TRAF6,AZI2,GAB1,UBE2 } \\
\text { N,FGFR1 }\end{array}$ \\
\hline $\begin{array}{l}\text { Role of NFAT in } \\
\text { Regulation of the } \\
\text { Immune Response }\end{array}$ & 0.72 & 0.0276 & -1 & $\begin{array}{l}\text { CALM1 (includes } \\
\text { others),GAB1,FGFR1,GN } \\
\text { A13,MAP2K1 }\end{array}$ \\
\hline $\begin{array}{l}\text { Aryl Hydrocarbon } \\
\text { Receptor Signaling }\end{array}$ & 0.713 & 0.0296 & -1 & $\begin{array}{l}\text { TRIP11,SP1,CDKN1B,RB } \\
\text { L1 }\end{array}$ \\
\hline \multicolumn{5}{|l|}{19 weeks } \\
\hline \multicolumn{5}{|l|}{ Induced pathway } \\
\hline AMPK Signaling & 0.393 & 0.0396 & 2.646 & $\begin{array}{l}\text { SLC2A1,GAB1,PRKACA, } \\
\text { PRKAA2,PDPK1,IRS2,PP } \\
\text { M1G,ADRB2 }\end{array}$ \\
\hline Fc Epsilon RI Signaling & 0.4 & 0.042 & 2.236 & $\begin{array}{l}\text { GAB1,PLA2G3,PDPK1,IR } \\
\text { S2,INPP5K }\end{array}$ \\
\hline Gas Signaling & 1.89 & 0.0833 & 2 & $\begin{array}{l}\text { GNB4,PTGDR,ADCY1,P } \\
\text { RKACA,GNB5,CNGB3,EL } \\
\text { K1,RAP1A,ADRB2 }\end{array}$ \\
\hline SAPK/JNK Signaling & 1.57 & 0.0777 & 2 & $\begin{array}{l}\text { GAB1,GADD45A,GNA12, } \\
\text { MAPK8IP2,DUSP4,CRK,I } \\
\text { RS2,ELK1 }\end{array}$ \\
\hline Relaxin Signaling & 1.09 & 0.0596 & 2 & $\begin{array}{l}\text { GNB4,GAB1,GNA12,ADC } \\
\text { Y1,PRKACA,GNB5,IRS2, } \\
\text { ELK1,RAP1A }\end{array}$ \\
\hline $\begin{array}{l}\text { fMLP Signaling in } \\
\text { Neutrophils }\end{array}$ & 0.877 & 0.0574 & 2 & $\begin{array}{l}\text { GNB4,GAB1,ARPC5,GN } \\
\text { B5,IRS2,ELK1,PPP3CA }\end{array}$ \\
\hline $\begin{array}{l}\text { Nitric Oxide Signaling in } \\
\text { the Cardiovascular } \\
\text { System }\end{array}$ & 0.76 & 0.0556 & 2 & $\begin{array}{l}\text { PRKG1,GAB1,FLT1,PRK } \\
\text { ACA,ARG2,IRS2 }\end{array}$ \\
\hline $\begin{array}{l}\text { Acute Myeloid Leukemia } \\
\text { Signaling }\end{array}$ & 0.666 & 0.0543 & 2 & $\begin{array}{l}\text { RUNX1,TCF4,GAB1,IRS2 } \\
\text {,PML }\end{array}$ \\
\hline
\end{tabular}




\begin{tabular}{|c|c|c|c|c|}
\hline Sperm Motility & 0.621 & 0.05 & 2 & $\begin{array}{l}\text { PRKG1,SLC12A2,PLA2R } \\
\text { 1,PRKACA,PLA2G3,CNG } \\
\text { B3 }\end{array}$ \\
\hline $\begin{array}{l}\text { cAMP-mediated } \\
\text { signaling }\end{array}$ & 1.35 & 0.0591 & 1.897 & $\begin{array}{l}\text { PTGDR,RGS4,RAP1A,O } \\
\text { PRL1,GABBR2,DUSP9,A } \\
\text { DCY1,S1PR1,PRKACA,C } \\
\text { NGB3,DUSP4,PPP3CA,A } \\
\text { DRB2 }\end{array}$ \\
\hline RhoGDI Signaling & 1.76 & 0.0698 & 1.89 & $\begin{array}{l}\text { DGKZ,GNB4,PAK4,CDH4 } \\
\text {,PAK6,RHOC,GNA12,CD } \\
\text { H10,PAK2,ARPC5,GNB5, } \\
\text { PIP4K2C }\end{array}$ \\
\hline $\begin{array}{l}\text { B Cell Receptor } \\
\text { Signaling }\end{array}$ & 0.69 & 0.0481 & 1.89 & $\begin{array}{l}\text { MAP3K14,GAB1,BCL10, } \\
\text { PDPK1,IRS2,INPP5K,EL } \\
\text { K1,RAP1A,PPP3CA }\end{array}$ \\
\hline eNOS Signaling & 1.6 & 0.0683 & 1.633 & $\begin{array}{l}\text { LPAR4,PRKG1,GAB1,FL } \\
\text { T1,ADCY1,PRKACA,PRK } \\
\text { AA2,LPAR5,PDPK1,CNG } \\
\text { B3,IRS2 }\end{array}$ \\
\hline PEDF Signaling & 1.5 & 0.0805 & 1.633 & $\begin{array}{l}\text { TCF4,GAB1,SRF,IRS2,E } \\
\text { LK1,CASP7,FAS }\end{array}$ \\
\hline $\begin{array}{l}\text { Insulin Receptor } \\
\text { Signaling }\end{array}$ & 0.699 & 0.0511 & 1.633 & $\begin{array}{l}\text { GAB1,PRKACA,PDPK1,C } \\
\text { RK,IRS2,INPP5K,VAMP2 }\end{array}$ \\
\hline $\begin{array}{l}\text { Dopamine-DARPP32 } \\
\text { Feedback in cAMP } \\
\text { Signaling }\end{array}$ & 0.5 & 0.044 & 1.633 & $\begin{array}{l}\text { PRKG1,PPP1R1B,KCNJ1 } \\
\text { 0,ADCY1,PRKACA,CSNK } \\
\text { 1D,PPP3CA }\end{array}$ \\
\hline ERK/MAPK Signaling & 1.67 & 0.0657 & 1.414 & $\begin{array}{l}\text { PAK4,PAK6,SRF,PLA2G } \\
\text { 3,CRK,RAP1A,DUSP9,G } \\
\text { AB1,PAK2,PRKACA,DUS } \\
\text { P4,IRS2,ELK1 }\end{array}$ \\
\hline $\begin{array}{l}\text { Huntington's Disease } \\
\text { Signaling }\end{array}$ & 1.38 & 0.0583 & 1.414 & $\begin{array}{l}\text { HDAC8,PSMF1,PACSIN1 } \\
\text {,TBP,GNB5,RCOR1,PDP } \\
\text { K1,PSME3,GNB4,GAB1, } \\
\text { CASP2,HDAC7,IRS2,CA } \\
\text { SP7 }\end{array}$ \\
\hline PDGF Signaling & 1.43 & 0.0778 & 1.342 & $\begin{array}{l}\text { GAB1,SRF,CRK,IRS2,IN } \\
\text { PP5K,ELK1,PDGFRB }\end{array}$ \\
\hline NGF Signaling & 1.25 & 0.0672 & 1.342 & $\begin{array}{l}\text { MAP3K14,GAB1,PDPK1, } \\
\text { CRK,IRS2,MAPK7,ELK1, } \\
\text { RAP1A }\end{array}$ \\
\hline $\begin{array}{l}\text { Aldosterone Signaling in } \\
\text { Epithelial Cells }\end{array}$ & 0.891 & 0.0539 & 1.342 & $\begin{array}{l}\text { GAB1,SLC12A2,DNAJB1 } \\
\text { 1,DNAJC27,DNAJC6,PD } \\
\text { PK1,IRS2,DNAJB6,PIP4K } \\
\text { 2C }\end{array}$ \\
\hline Prolactin Signaling & 0.79 & 0.0602 & 1.342 & $\begin{array}{l}\text { GAB1,SOCS6,PDPK1,IR } \\
\text { S2,IRF1 }\end{array}$ \\
\hline $\begin{array}{l}\text { iCOS-iCOSL Signaling in } \\
\text { T Helper Cells }\end{array}$ & 0.408 & 0.0424 & 1.342 & $\begin{array}{l}\text { GAB1,IL2,PDPK1,IRS2,P } \\
\text { PP3CA }\end{array}$ \\
\hline $\begin{array}{l}\text { Colorectal Cancer } \\
\text { Metastasis Signaling }\end{array}$ & 0.327 & 0.037 & 1.342 & $\begin{array}{l}\text { GNB4,TCF4,GAB1,RHOC } \\
\text {,ADCY1,PRKACA,GNB5, }\end{array}$ \\
\hline
\end{tabular}




\begin{tabular}{|c|c|c|c|c|}
\hline & & & & FZD5,IRS2 \\
\hline $\begin{array}{l}\text { Cardiac Hypertrophy } \\
\text { Signaling }\end{array}$ & 1.47 & 0.0601 & 1.134 & $\begin{array}{l}\text { MAP3K14,RHOC,GNA12, } \\
\text { GNB5,SRF,ATF6,GNB4, } \\
\text { GAB1,ADCY1,PRKACA,I } \\
\text { RS2,ELK1,PPP3CA,ADR } \\
\text { B2 }\end{array}$ \\
\hline $\begin{array}{l}\text { CD28 Signaling in T } \\
\text { Helper Cells }\end{array}$ & 0.813 & 0.0551 & 1.134 & $\begin{array}{l}\text { GAB1,BCL10,IL2,ARPC5, } \\
\text { PDPK1,IRS2,PPP3CA }\end{array}$ \\
\hline NF-KB Signaling & 0.774 & 0.0506 & 1.134 & $\begin{array}{l}\text { MAP3K14,GAB1,FLT1,B } \\
\text { CL10,TGFBR3,PRKACA,I } \\
\text { RS2,TNFRSF1B,PDGFR } \\
\text { B }\end{array}$ \\
\hline $\begin{array}{l}\text { Renin-Angiotensin } \\
\text { Signaling }\end{array}$ & 1.22 & 0.0661 & 1 & $\begin{array}{l}\text { PAK4,GAB1,PAK6,PAK2, } \\
\text { ADCY1,PRKACA,IRS2,E } \\
\text { LK1 }\end{array}$ \\
\hline ErbB2-ErbB3 Signaling & 1.06 & 0.0735 & 1 & $\begin{array}{l}\text { GAB1,PDPK1,ERBB3,IR } \\
\text { S2,ELK1 }\end{array}$ \\
\hline PAK Signaling & 0.869 & 0.06 & 1 & $\begin{array}{l}\text { PAK4,GAB1,PAK6,PAK2, } \\
\text { IRS2,PDGFRB }\end{array}$ \\
\hline Thrombin Signaling & 0.787 & 0.0498 & 1 & $\begin{array}{l}\text { GNB4,GAB1,RHOC,GNA } \\
\text { 12,ADCY1,GNB5,TBP,PD } \\
\text { PK1,IRS2,ELK1 }\end{array}$ \\
\hline $\begin{array}{l}\text { Type I Diabetes Mellitus } \\
\text { Signaling }\end{array}$ & 0.773 & 0.0561 & 1 & $\begin{array}{l}\text { MAP3K14,IL2,SOCS6,TN } \\
\text { FRSF1B,FAS,IRF1 }\end{array}$ \\
\hline Telomerase Signaling & 0.76 & 0.0556 & 1 & $\begin{array}{l}\text { GAB1,HDAC8,IL2,HDAC7 } \\
\text {,PDPK1,IRS2 }\end{array}$ \\
\hline Apoptosis Signaling & 0.705 & 0.0562 & 1 & $\begin{array}{l}\text { MAP3K14,CASP2,TNFRS } \\
\text { F1B,CASP7,FAS }\end{array}$ \\
\hline HGF Signaling & 0.687 & 0.0526 & 1 & $\begin{array}{l}\text { MAP3K14,GAB1,HGF,IR } \\
\text { S2,ELK1,RAP1A }\end{array}$ \\
\hline $\begin{array}{l}\text { Non-Small Cell Lung } \\
\text { Cancer Signaling }\end{array}$ & 0.554 & 0.0519 & 1 & STK4,GAB1,PDPK1,IRS2 \\
\hline IL-6 Signaling & 0.543 & 0.0469 & 1 & $\begin{array}{l}\text { MAP3K14,GAB1,SRF,IRS } \\
\text { 2,ELK1,TNFRSF1B }\end{array}$ \\
\hline $\begin{array}{l}\text { Neuropathic Pain } \\
\text { Signaling In Dorsal Horn } \\
\text { Neurons }\end{array}$ & 0.439 & 0.0439 & 1 & $\begin{array}{l}\text { GAB1,PRKACA,KCNQ3,I } \\
\text { RS2,ELK1 }\end{array}$ \\
\hline $\begin{array}{l}\text { Synaptic Long Term } \\
\text { Potentiation }\end{array}$ & 0.408 & 0.0424 & 1 & $\begin{array}{l}\text { PPP1R1A,ADCY1,PRKA } \\
\text { CA,RAP1A,PPP3CA }\end{array}$ \\
\hline p38 MAPK Signaling & 0.4 & 0.042 & 1 & $\begin{array}{l}\text { SRF,PLA2G3,ELK1,TNF } \\
\text { RSF1B,FAS }\end{array}$ \\
\hline \multicolumn{5}{|l|}{ Suppressed pathway } \\
\hline $\begin{array}{l}\text { Cholecystokinin/Gastrin- } \\
\text { mediated Signaling }\end{array}$ & 0.855 & 0.0594 & -2 & $\begin{array}{l}\text { RHOC,GNA12,SRF,EPH } \\
\text { A4,MAPK7,ELK1 }\end{array}$ \\
\hline p53 Signaling & 1.4 & 0.0721 & -1 & $\begin{array}{l}\text { TP53INP1,GAB1,GADD4 } \\
\text { 5A,MED1,CSNK1D,IRS2, } \\
\text { PML,FAS }\end{array}$ \\
\hline Regulation of Actin- & 1.1 & 0.0698 & -1 & PAK4,PAK6,RHOC,PAK2 \\
\hline
\end{tabular}




\begin{tabular}{|lllll|}
\hline based Motility by Rho & & & ,ARPC5,PIP4K2C \\
\hline PTEN Signaling & 0.4 & 0.042 & $\mathbf{- 1}$ & $\begin{array}{l}\text { FLT1,TGFBR3,PDPK1,IN } \\
\text { PP5K,PDGFRB }\end{array}$ \\
\hline Ceramide Signaling & 0.392 & 0.043 & -1 & $\begin{array}{l}\text { GAB1,S1PR1,IRS2,TNFR } \\
\text { SF1B }\end{array}$ \\
\hline $\mathbf{2 8}$ weeks & & & & \\
\hline Induced pathway & & & & \\
\hline ERK/MAPK Signaling & 1.18 & 0.0303 & $\mathbf{1 . 6 3 3}$ & $\begin{array}{l}\text { PLA2G6,PAK1,ITGA3,TL } \\
\text { N2,PLCG1,DUSP4 }\end{array}$ \\
\hline Tec Kinase Signaling & 1.03 & 0.0298 & $\mathbf{1}$ & $\begin{array}{l}\text { GNAI3,PAK1,ITGA3,TNF } \\
\text { RSF25,PLCG1 }\end{array}$ \\
\hline $\begin{array}{l}\text { Actin Cytoskeleton } \\
\text { Signaling }\end{array}$ & 1.01 & 0.0271 & $\mathbf{1}$ & $\begin{array}{l}\text { PAK1,ITGA3,TLN2,FGF1 } \\
8, W A S F 1, A P C\end{array}$ \\
\hline Integrin Signaling & 0.443 & 0.0189 & $\mathbf{1}$ & $\begin{array}{l}\text { PAK1,ITGA3,TLN2,PLCG } \\
1\end{array}$ \\
\hline Suppressed pathway & & & & \\
\hline $\begin{array}{l}\text { Macropinocytosis } \\
\text { Signaling }\end{array}$ & 1.54 & 0.0494 & $\mathbf{- 1}$ & MET,PAK1,CSF1,PLCG1 \\
\hline Gaq Signaling & 1.1 & 0.0314 & $\mathbf{- 1}$ & $\begin{array}{l}\text { NFKBIA,PLD3,RGS4,PLC } \\
\text { G1,HTR2A }\end{array}$ \\
\hline
\end{tabular}




\section{Discussion}

The mechanisms of arsenic-induced carcinogenesis are not yet clear. Several mechanisms, including epigenetic alterations are proposed. MiRNAs are part of the epigenome and play an important role in gene regulation and cellular development (351). Master developmental pathways are altered in cancer. Therefore, both small RNA and mRNA expression are very important in mechanistic studies of cancer in general and chemically-induced cancers in particular. RNA-seq is a NGS tool that gives a quantitative and qualitative measure of the transcriptome (347). In this chapter, RNA-seq was used to obtain mRNA and small RNA expression profiles in a longitudinal study of the HaCaT cell chronic exposure model.

The data showed that numerous miRNAs and mRNAs were differentially expressed among all the time points, noticeably after 19 weeks chronic exposure. Only one miRNAs miR-6733, was suppressed at the three time points. MiR-6733 suppression was the highest at 7 and 19 weeks and the lowest at 28 weeks. MiR-6733 has not yet been mentioned or discussed in the literature to be dysregulated with any disease except with bladder cancer (352). Thus, the results suggest that miR-6733 might be a novel tumor suppressor that plays a role at early stages of transformation. Furthermore, the pathway analysis of miR6733 targets, induced at 19 weeks, predicted their involvement in DNA methylation and transcriptional repression signaling, gap junction signaling and sumoylation pathways. Moreover, let-7c and miR-99a were suppressed at 19 and induced 28 weeks indicating that these miRNAs are associates with the 
transformed phenotype. MiR-29b-2, miR-29b-1 and miR-3651 were induced at 19 weeks and suppressed at 28 weeks and vice versa for miR-934 and miR-378c indicating that the changes in expression for some miRNA take opposite direction once the cells are fully transformed.

Pathway analyses were also performed for both total mRNAs and miRNA target mRNAs at each of the time points. The analyses showed most of the transformation and carcinogenesis-related dysregulated pathways were predicted at 19 weeks time point. Several pathways were predicted to be induced including cell cycle: $\mathrm{G} 1 / \mathrm{S}$ checkpoint regulation pathway suggesting a delay in cell cycle after 7 weeks chronic exposure. The suggested cell cycle dysregulation supports the results obtained and discussed at the same time point using the hybridization microarrays in chapter 4 . Similarity, when examining the suppressed pathways, several cytoskeleton, ECM and migration signaling associated pathways were suggested to be suppressed after 7, 19 and 28 weeks chronic exposure. However, the cellular migration behavior was not significantly affected by arsenic exposure as determined by migration assay at early and later exposures (Fig. 5.1). Interestingly, the cells at a later stage, either exposed or unexposed, grew or migrated faster than the same cells at a very early stage of exposure (Fig. 5.1).

Over all, most transformation related changes in pathways signaling direction and miRNA and gene expression and at 19 weeks are at their peak. Notable changes in pathways signaling direction and miRNA and gene expression were at 7 weeks and peaked at 19 weeks of chronic arsenite 
exposure. These arsenite associated changes suggest that the cells transformation process takes place gradually till reaching a critical point, 19 weeks, when the changes peak allowing the cells start transforming. Further mechanistic investigations on the unique changes that take place at 19 weeks are necessary to clarify their role in driving arsenic-induced carcinogenesis. 


\section{CHAPTER 6 \\ MIRNA EXPRESSION PROFILES COMPARISIONS ACROSS THREE DIFFERENT TECHNIQUES}

\section{Introduction}

In chapters 2 through 5, three different techniques were used to measure miRNA expression profiles in skin lesions and a cell line model. The first technique was TaqMan® Array Human MiRNA A Card v2.0 polymerase chain reaction (RT-qPCR) array cards, Life Technologies). The array measures the expression of 384 targets; 377 miRNAs and 7 controls. Card A focuses on more highly characterized miRNAs. TaqMan® Array cards required only minute RNA sample amounts. Low yields of RNA obtained from the set of FFPE skin lesions (discussed in chapter 2) were used to measure miRNA expression profiles using the TaqMan® Array Card A. MiRNA expression profiles obtained from skin lesions were also compared to the miRNA expression profiles of $\mathrm{HaCaT}$ cells chronically exposed to arsenite for 3 weeks obtained as well by TaqMan® Array. However, comparisons showed weak correlations between the profiles.

MiRNAs play an important role in gene regulation and cellular development (351). Therefore, measuring the expression profiles of small RNA and their target mRNAs are important to study mechanisms of altered developmental pathways by chemically-induced cancers. Affymetrix arrays 
(hybridization microarrays) were used to measure both mRNA and small RNA expression profiles of HaCaT cells after 3 and 7 weeks chronic exposure to arsenite. Affymetrix arrays cover a very number of mRNA and small RNA and they are both time and cost effective.

The HaCaT cells chronic arsenite exposure model was reported by Pi et al. as an SCC model (39). However, the model has not been evaluated. Furthermore, the various stages starting from the early stages of the transformation process in the model have not been studied yet. Therefore, one of the goals of this chapter is to evaluate if the HaCaT cell model is a biologically relevant model to study arsenic induced SCC. Therefore, a high-throughput sequencing tool (RNA-Seq) was used to measure mRNA and small RNA expression profiles at three times in $\mathrm{HaCaT}$ cells chronically exposed to arsenite. RNA-Seq is time and cost effective and provides more data than hybridization microarrays including expression profiles, mutational status, gene fusion detection, small RNA characterization and alternative splicing events detection (347).

The miRNA expression profiles obtained by the 3 techniques and comparisons revealed many similarities, but also some differences that are discussed in the current chapter. 


\section{Materials and Methods}

\section{a. MiRNA Profiles at 3 weeks chronic exposure by RT-qPCR Array Cards}

Profiling miRNA expression for HaCaT cells exposed to arsenite for 3 weeks (detailed in chapter 2 and 3 materials and methods) was performed using the TaqMan® Array Human MiRNA A Card v2.0 (RT-qPCR) array cards, Life Technologies) and the data were collected at 0.1 threshold value. Statistical analyses were performed by comparing the $\Delta \mathrm{Ct}$ values of the arsenic unexposed cells to those of exposed cells using two-sample T-Test by SAS System V9. Cary, NC: SAS Institute Inc, 2003.

\section{b. Arsenic unexposed/exposed HaCaT cells (3 weeks) vs. skin lesion}

The $\Delta \mathrm{Ct}$ values were calculated using the means of $\mathrm{Ct}$ values of the arsenic exposed cell or skin lesions (HK, BCC, SCC) in comparison to unexposed cells and normalizing them to the Ct values of the reference RNA U6. Statistical analyses were performed by using two-sample T-Test by SAS System V9. Cary, NC: SAS Institute Inc, 2003. Then the differentially expressed miRNAs obtained from the comparing unexposed cells to skin lesions (HK, BCC and SCC vs. -As) were compared to the differentially expressed mRNAs obtained from unexposed and exposed cells at 3 weeks.

c. Comparison between the 3 weeks small RNAs expression profiles obtained by $\underline{\mathrm{RT}-\mathrm{qPCR} \text { array cards and hybridization microarrays }}$

The significant differentially expressed miRNAs from HaCaT cells chronically exposed to arsenite for 3 weeks from the data obtained from both the 
TaqMan® Array Human MiRNA A Card v2.0 (RT-qPCR array cards) and hybridization microarrays (Affymetrix microarrays) detailed in chapter 3 were compared.

\section{d. Small RNAs Expression Profiles at 7 weeks Obtained by Hybridization}

Microarray vs. Next-Generation Sequencing (NGS)

The significant differentially expressed small RNAs from HaCaT cells chronically exposed to arsenite for 7 weeks from the data obtained from both the hybridization microarrays (Affymetrix microarrays) detailed in chapter 3 and NextGeneration Sequencing (NGS) detailed in chapter 5 were compared.

\section{e. Comparison between the small RNAs expression profiles obtained by} hybridization microarray and Next-Generation Sequencing (NGS) and skin lesion MiRNA expression profiles of multiple cultures of $\mathrm{HaCaT}$ cells (4 with and 4 without $100 \mathrm{nM} \mathrm{NaAsO}$ ) after 7, 19 and 28 weeks chronic exposure as detailed in chapter 5 materials and methods were compared to the MiRNAs expression profiles in skin lesions discussed in chapter 2. 


\section{Results}

a. MiRNA Expression Profiles in Arsenic Unexposed/Exposed HaCaT Cells at 3 Weeks of Exposure.

Eight miRNAs were differentially expressed in exposed $\mathrm{HaCaT}$ cells for 3 weeks compared to unexposed cells (Table 6.1). miRNAs miR-193a-5p, miR892a and miR-570 were induced and miR-296-3p, miR-501, miR-412, miR-509$5 p$ and miR-616 were suppressed. 


\begin{tabular}{|c|c|c|}
\hline microRNAs & p-value & Fold Change \\
\hline \multicolumn{3}{|l|}{ Induced } \\
\hline $\begin{array}{l}\text { hsa-miR-193a-5p } \\
\text { hsa-miR-892a } \\
\text { hsa-miR-570 }\end{array}$ & $\begin{array}{l}0.015 \\
0.007 \\
0.017\end{array}$ & $\begin{array}{l}463 \\
69 \\
19\end{array}$ \\
\hline \multicolumn{3}{|l|}{ Suppressed } \\
\hline $\begin{array}{l}\text { hsa-miR-296-3p } \\
\text { hsa-miR-501 } \\
\text { hsa-miR-412 } \\
\text { hsa-miR-509-5p } \\
\text { hsa-miR-616 }\end{array}$ & \begin{tabular}{|l|}
0.024 \\
0.008 \\
0.043 \\
0.045 \\
0.036
\end{tabular} & $\begin{array}{l}3 \\
6 \\
6 \\
27 \\
86\end{array}$ \\
\hline
\end{tabular}


b. Comparison Between Differential miRNA Expression Profiles Obtained by RTqPCR Array Cards of HaCaT Cells Exposed vs Unexposed to Arsenic for 3 Weeks to Differential miRNA Expression of Skin Lesions vs. Unexposed Cells

The miRNA profiles obtained using RT-qPCR array cards of arsenic unexposed $\mathrm{HaCaT}$ cells for 3 weeks were compared to those obtained similarly from each of the skin lesions (premalignant (HK) and malignant (BCC and SCC)). Several miRNAs were differentially expressed. Sixty-eight miRNAs were differentially expressed compared to HK, 27 were induced and 42 were suppressed. Forty-three miRNAs were differentially expressed compared to BCC, 15 were induced and 28 were suppressed. Forty-three miRNAs were differentially expressed compared to SCC, 31 were induced and 12 were suppressed. Fifty-three miRNAs were mutually differentially expressed among at least 2 of the 3 comparisons.

We also compared the differentially expressed miRNAs obtained from 3 weeks in arsenic exposed cells vs. unexposed cells to those of skin lesions vs. unexposed cells. Only two miRNAs were differentially expressed, miR193a-5p and miR-296-3p (Table 6.2). MiR193a-5p was induced in all comparisons, +As vs. - As, - As vs. HK, BCC and SCC. 


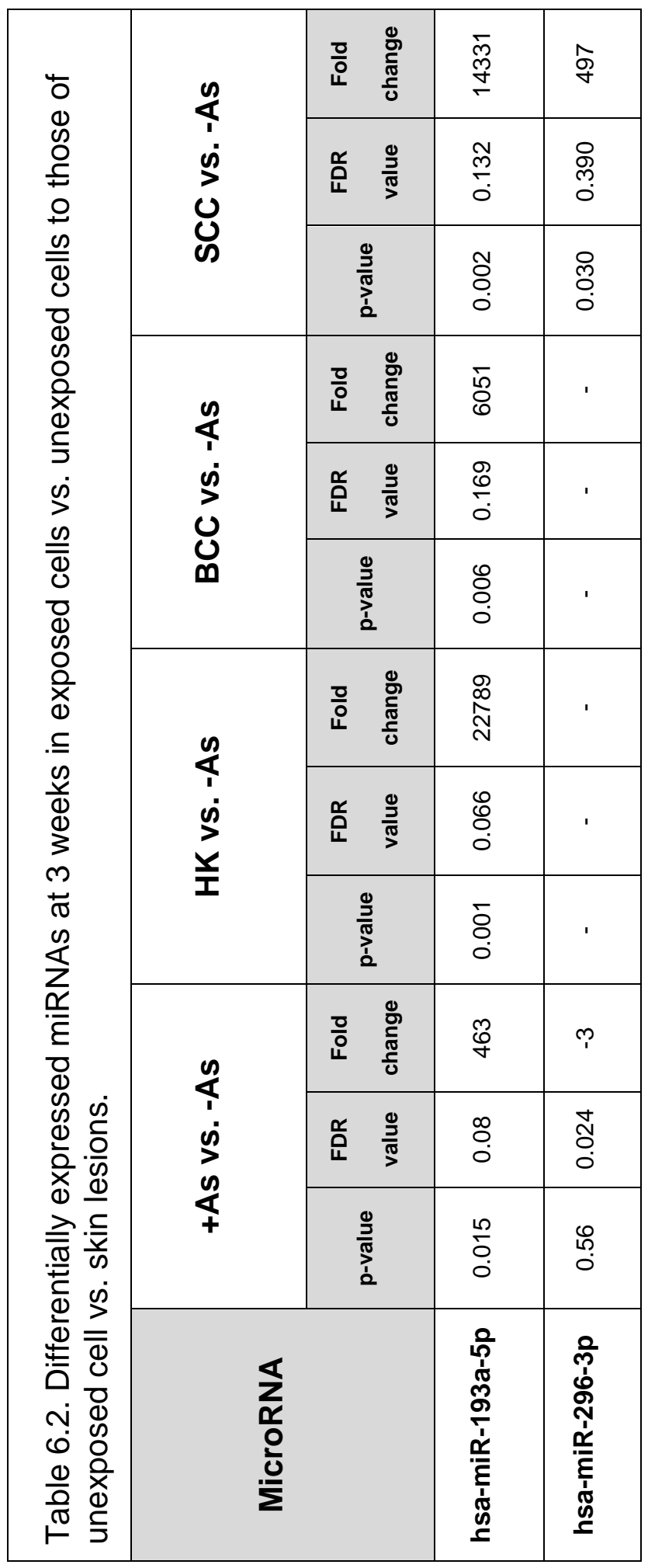


c. Comparison 3 weeks small RNAs expression profiles obtained by both RTQPCR array cards and hybridization microarray

Only 2 miRNAs (miR-296-3p and miR-501) were differentially expressed in both data sets (Table 6.3). However, these 2 miRNAs were induced in RTQPCR array cards and suppressed in hybridization microarrays. 


\begin{tabular}{|c|c|c|c|c|}
\hline \multirow[t]{2}{*}{ miRNA } & \multicolumn{2}{|c|}{ Hybridization microarray } & \multicolumn{2}{|c|}{$\begin{array}{l}\text { RT-qPCR array } \\
\text { cards }\end{array}$} \\
\hline & $p$-value & $\begin{array}{c}\text { Fold } \\
\text { Change }\end{array}$ & $p$-value & $\begin{array}{l}\text { Fold } \\
\text { Change }\end{array}$ \\
\hline hsa-miR-296-3p & 0.039 & 2 & 0.024 & -3 \\
\hline hsa-miR-501 & 0.034 & 1 & 0.008 & -6 \\
\hline
\end{tabular}


d. Comparison 7 weeks small RNAs expression profiles obtained by both hybridization microarray and Next-Generation Sequencing (NGS)

Only 9 miRNAs were differentially expressed in both hybridization microarray and NGS after 7 weeks chronic exposure in both techniques used (Table 6.4). Three miRNAs (miR-222, miR-4461, miR-744) were induced and two (miR-6726, miR-3614) were suppressed in both data sets. Further, two miRNAs (miR-3158-2, miR-3934) were suppressed in hybridization microarrays and induced in NGS and two miRNAs (miR-4738, miR-5580) were induced using hybridization microarrays and suppressed in NGS opposite. 


\begin{tabular}{|c|c|c|c|c|c|}
\hline \multirow{2}{*}{ miRNA } & \multicolumn{2}{|c|}{$\begin{array}{l}\text { Hybridization } \\
\text { microarray }\end{array}$} & \multicolumn{3}{|c|}{$\begin{array}{l}\text { Next-Generation Sequencing } \\
\text { (NGS) }\end{array}$} \\
\hline & p-value & $\begin{array}{l}\text { Fold } \\
\text { Change }\end{array}$ & p_Eq & p_Ueq & $\begin{array}{l}\text { Fold } \\
\text { change }\end{array}$ \\
\hline hsa-miR-4461 & 0.021 & 4 & 0.021 & 0.026 & 3 \\
\hline hsa-miR-744 & 0.010 & 1 & 0.014 & 0.019 & 2 \\
\hline hsa-mir-222 & 0.013 & 1 & 0.011 & 0.015 & 1 \\
\hline hsa-miR-4738 & 0.039 & 1 & 0.025 & 0.058 & -25501 \\
\hline hsa-miR-5580 & 0.018 & 1 & 0.000 & 0.000 & -19501 \\
\hline hsa-miR-6726 & 0.027 & -1 & 0.031 & 0.067 & -3 \\
\hline hsa-miR-3614 & 0.001 & -2 & 0.001 & 0.003 & -2 \\
\hline hsa-mir-3934 & 0.010 & -1 & 0.020 & 0.035 & 2 \\
\hline hsa-mir-3158-2 & 0.045 & -1 & 0.016 & 0.021 & 2 \\
\hline
\end{tabular}


e. MiRNAs Differentially Expressed in both Arsenic-Exposed HaCaT Cells and Arsenic-Induced Skin Lesions

The miRNAs expression profiles of chronically arsenic-exposed $\mathrm{HaCaT}$ cells $(7,19$ and 28 weeks time points) were compared with those obtained from skin lesions (HK, BCC and SCC) from individuals exposed to high levels of arsenic in their drinking water (Chapter2). Three miRNAs (miR-362, miR-381 and miR-452) were differentially expressed in cells and skin lesions (Table 6.5). MiR362 was suppressed at 7 weeks and induced at 19 weeks of HaCaT cells exposure. MiR-362 was also induced in SCC compared to BCC lesions, but not to HK. MiR-381 and miR-452 were induced at 28 and 19 weeks in HaCaT cells, respectively, and suppressed in BCC lesions compared to both HK and SCC lesions. The comparisons confirm the HaCaT chronic model as a SCC model. The comparisons also determine consistency across the methods used. 


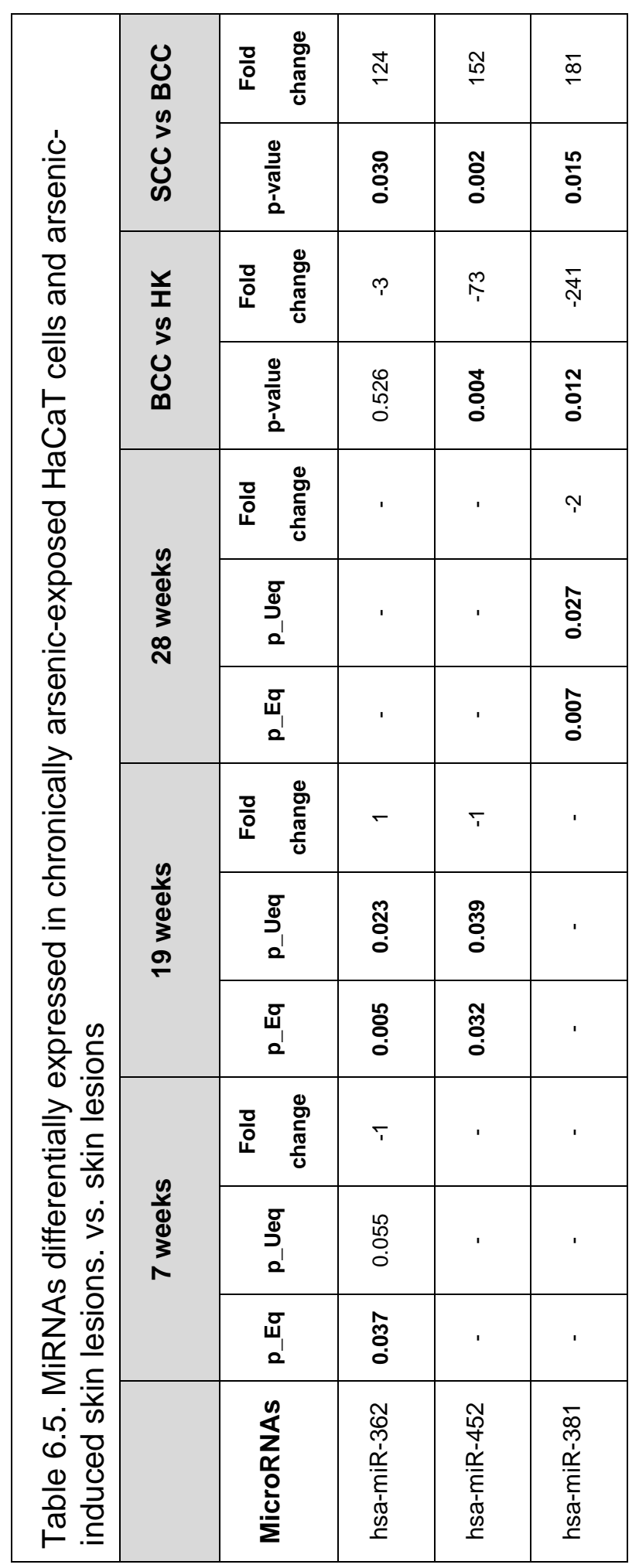




\section{Discussion}

Few miRNAs (eight) were differentially expressed after 3 weeks arsenic exposure. Upregulation of miR193a-5p was detected in comparisons between arsenic exposed cells vs. unexposed cells (3 weeks) and skin lesions vs. unexposed cells using RT-qPCR arrays. MiR193a-5p was associated with several cancers including bladder cancer and malignant pleural mesothelioma (353, 354). MiR-296-3p was suppressed in arsenite-exposed cells compared to unexposed cells. However, it was induced in SCC lesions compared to unexposed cells. miR-296-3p was reported to be associated with several cancers including prostate cancer and glioblastoma $(355,356)$.

Comparing 3 weeks miRNA expression profiles obtained by RT-qPCR to those obtained by hybridization microarrays identified only 2 miRNAs in common. The comparison between 7 weeks miRNA expression profiles obtained by both hybridization microarray (312 differentially expressed small RNAs) and RNA-seq (59 differentially expressed small RNAs) showed lack of reproducibility. Of the miRNAs that were differentially expressed, only 9 and only 5 were in the same direction of expression. A validation in the States lab and reported by other scientists to Affymetrix, Inc. by TaqMan® MicroRNA individual assays of some miRNAs that showed differential expression by hybridization microarrays for the same set of samples could not be replicated. Therefore, the larger number of differentially expressed miRNAs identified in hybridization microarray compared to RNA-seq suggests a higher false positive rate. It has been also reported that RNA-Seq data correlate better with microarrays for genes expressed at medium 
levels, but not for high or low (357). Others reported validation of results from RNA-seq and microarrays showed the most errors with microarrays (358).

When comparing the miRNA expression profiles between chronically arsenic-exposed HaCaT cells and arsenic-induced skin lesions showed (Chapter 2) that miR-362 was suppressed at 7 weeks and induced at 19 weeks in $\mathrm{HaCaT}$ cells by RNA-seq and was induced in SCC compared to BCC lesions (by RTqPCR arrays). MiR-362 was reported to be induced in chronic myeloid leukemia (236) and in metastatic cancers such hepatocellular carcinoma (238) and gastric cancer (239). The results suggest that miR-362 is associated with a malignant and invasive phenotype because it was induced in both SCC and HaCaT cells exposed to arsenic for 19 weeks, the time that transformation starts to occur. Thus, this result supports the hypothesis that $\mathrm{HaCaT}$ cells chronically exposed to arsenic are a model of arsenic-induced SCC.

MiR-381 was induced in HaCaT cells exposed to arsenic for 28 weeks and mir-452 was induced after 19 weeks exposure. The two miRNAs were expression in $\mathrm{HK}$ and SCC lesions was higher than in BCC lesions suggesting induction as transformation occurs. Therefore, that HaCaT cells chronically exposed to arsenic are a good model of arsenic-induced SCC not BCC. Furthermore, the suppression in expression of both miR-381 and mir-452 is suggested to be arsenic-induced BCC phenotype specific. Both miRNAs have been reported to be dysregulated in other cancers as discussed in chapter 2 . MiR-381 is reported to be suppressed in several other cancers including oral squamous cell carcinoma, epithelial ovarian cancer, hepatocellular carcinoma, 
colorectal cancer, gastric cancer, breast cancer, renal cell cancer, colon cancer and lung adenocarcinoma (124-133). MiR-452-5p was induced in several malignancies (hemangiosarcoma, clear cell renal cell carcinoma and bladder cancer), but suppressed in several other cancers and sarcomas (lung adenocarcinoma, chondrosarcoma, gliomas, osteosarcoma, non-small cell lung cancer, prostate cancer and head and neck adenoid cystic carcinoma vs. head and neck squamous cell carcinoma) (134-143). The results indicate that miR362, miR-381 and mir-452 are oncogenes in SCC and tumor suppressors in BCC. The results also indicate that $\mathrm{HaCaT}$ cells chronically exposed to arsenic are a model of arsenic-induced SCC, but not BCC. 


\section{CHAPTER 7}

\section{OVERALL DISCUSSION, CONCLUSIONS AND FUTURE DIRECTIONS}

This dissertation investigated the differential miRNA expression in arsenicinduced human skin cancer and the differential small RNA and mRNA expression in HaCaT cells chronically exposed to arsenic. Three different techniques, RTqPCR arrays, hybridization microarrays, and RNA-seq, were used to generate the expression profiles.

The studies in this dissertation are the first to characterize and identify miRNAs in human arsenic-induced skin lesions. Laser capture microdissection (LCM) was used to isolate keratinocytes from premalignant and malignant lesions to allow purification of total RNA for miRNA profiling without interference from the other skin layers. The results provide original information profiling changes in miRNA expression associated with arsenic-induced malignant transformation from premalignant $\mathrm{HK}$ to SCC and BCC. The results show that the expression of some miRNAs was phenotype-related, e.g., SCC or BCC, or stage-related, e.g. malignancy or metastasis.

Early stages of arsenite exposure in vitro induced differential small RNA (sno, stem-loop and mature miRNAs) and mRNA expression after 3 and 7 weeks chronic exposure, with more differentially expressed mRNAs after 7 weeks. The 
38 mRNAs differentially expressed at both 3 and 7 weeks that are targets of differentially expressed miRNAs, are involved in carcinogenesis pathways such as the WNT signaling pathway. MDM2 mRNA was among the 38 mRNAs identified as miRNA targets. MDM2 mRNA was induced after 3 weeks and suppressed after 7 weeks of arsenite exposure whereas HMG1 was increased at both time points. Both MDM2 and HMG1 can regulate TP53 expression. Moreover, MDM2 and HMG1 are potential targets of miRNAs suppressed by arsenite at both of these time points. The induction in MDM2 and HMG1 expression along with arsenite inhibiting the 4 miRNAs that target them, lead to the prediction that TP53 would be suppressed. However, western blot analyses showed that the opposite, i.e., TP53 was induced. However, acetylation of TP53 was suppressed indicating that the induced TP53 was inactive. Moreover, the RNA-seq data showed that DNA repair genes that are known targets of TP53 were not induced suggesting a dysregulated DNA repair response. Therefore, the induction of an inactive TP53 along with the disruption of DNA repair response by arsenic suggest increased genomic instability and clastogensis that arsenic is known to cause contributing to arsenic-induced carcinogenesis.

In addition, after 7 weeks chronic exposure, low arsenite induced differential gene expression indicated dysregulation of cell cycle control, which was confirmed by cell cycle analysis and the slow growth of these cells at the early times of chronic exposure. The delay could be related to the induction of aneuploidy known to be caused by arsenic exposure $(359,360)$. 
Arsenite exposed HaCaT cells grew slower at early times and faster at later times. The change in growth rate occurred at 19 weeks. Moreover, $\mathrm{HaCaT}$ cells chronically exposed to arsenic transformed fully at 28 weeks. Therefore, studying the small RNA and mRNA expression profiles and pathways at 19 and 28 weeks provides novel insight into the sequential changes in miRNA expression that occur leading to transformation. A high-throughput screening tool, RNA-seq, was used to measure these profiles at 7, 19 and 28 weeks. The results showed that more small RNAs and mRNAs were differentially expressed after 19 weeks chronic arsenic exposure. The pathway analyses of differentially expressed mRNAs and target mRNAs showed that several cancer and development-related pathways were dysregulated after 19 weeks.

The miRNA expression profiles obtained by 3 different techniques in the skin lesions and the HaCaT cells were compared. Results of these comparisons revealed many similarities but some differences. The lack of reproducibility miRNA results between hybridization microarray and validation by RT-qPCR was notable. Similarly, the lack of reproducibility in miRNA expression profiles between both hybridization microarrays and RNA-seq suggests a higher false positive rate with hybridization microarrays, similar to that identified by other investigators in other cell systems (358).

Comparing the miRNA expression profiles between HaCaT cells chronically exposed to arsenic and arsenic-induced skin lesion showed that the expression of 3 miRNAs was phenotype, e.g., SCC or BCC, related and transformation stage related. Moreover, comparing the miRNA profiles of $\mathrm{HaCaT}$ 
cells and skin lesions showed that the HaCaT chronic arsenic exposure model is a good model for arsenic-induced SCC as suggested by Pi et al. (39).

This project used several innovative techniques and approaches that strengthen the conclusions. The first was the unique sample set we used to measure differential miRNA expression in the arsenic-induced skin tumor. Formalin fixed paraffin embedded (FFPE) samples of arsenic-induced HK, BCC and SCC obtained from subjects living in the villages in high arsenic districts (exposed to $>50 \mathrm{ppb}$ ) in West Bengal, India were analyzed. The results are relevant to the U.S. population because the levels of exposure of the subjects are similar to those in many rural areas of the U.S.

In the cell culture studies, four unexposed and exposed independent $\mathrm{HaCaT}$ cell cultures were maintained providing statistical power to the results obtained from the study. Having multiple independent cultures increased confidence level of the results, and allowed statistical analyses with biological replicates.

Studying the miRNA and gene expression changes that a $100 \mathrm{nM}$ sodium arsenite exposure induces in a longitudinal study is another strength. Chronic arsenic exposure has been demonstrated in previous studies to be associated with skin cancers and the hyperproliferation of keratinocytes $(361,362)$. However, the different stages prior to malignant transformation and progression have not been studied. Epigenetic changes are a proposed mechanism to contribute to arsenic-induced carcinogenicity. Thus, the miRNA expression profiling at the different time points of arsenic exposure provide longitudinal 
epigenetic related changes induced by arsenic at different transformation stages in $\mathrm{HaCaT}$ cells.

In addition, we used a concentration of sodium arsenite $(100 \mathrm{nM})$ in our studies that is identical to the concentration of arsenic in the sera of individuals exposed to high levels of arsenic and who developed multiple arsenic-induced cancers including skin cancer that was reported as $100 \mathrm{nM}$ (65). Thus, our study is of physiological relevance to human exposure.

In addition, this dissertation discusses the first obtained miRNA expression profiles from human keratinocytes chronically exposed to arsenic in a longitudinal study. Thus, the analyses on the obtained miRNAs profiles along with their target mRNAs open another avenue in skin cancer research to consider epigenetic changes as major players in the development and progression of arsenic-induced skin cancer.

The study has several acknowledged weaknesses starting from the arsenic-induced tumors. The sample set used was more than seven years old and getting more than $100 \mathrm{ng}$ total RNA for NGS was not possible. Therefore, measuring the small RNA and mRNA expression profiles in a newer set of arsenic-induced skin tumors using NGS is an important future goal.

The results in this dissertation provide insight on the potential role of miRNAs in arsenic-induced carcinogenesis in general and skin cancer in particular. The results suggest that some of the miRNAs described could be considered as potential biomarkers or therapy targets for arsenic-induced internal cancers. In addition, the results obtained from the comparison between miRNA 
profiles in skin lesions and longitudinal study of $\mathrm{HaCaT}$ cells showed that miR362 was suppressed. This result suggests that miR-362 may have a tumor suppressor role in arsenic-induced SCC. Therefore, investigating the role of miR362 suppression in the induction of SCC phenotype is important and identifying therapeutics to increase miR-362 in skin may prevent skin lesions.

Over all, this dissertation embraces the importance of epigenetic changes throughout the different stages of arsenic-induced carcinogenesis. It evaluates different available techniques used for profiling miRNAs. It also validates the use of an arsenic chronic exposure cell line model ( $\mathrm{HaCaT}$ cells) as an appropriate arsenic-induced SCC model for the first time. 


\section{REFERENCES}

1. IARC. Overall Evaluations of Carcinogenicity: An Updating of IARC Monographs Volumes 1 to 42.1987.

2. Hutchinson J. Salvarsan ("606") and Arsenic Cancer. Br Med J. 1911;1(2626):976-7. PubMed PMID: 20765593; PMCID: PMC2333743.

3. Edwin A. Woolson LM, Michael Fleischer, Philip C. Kearney, William B. Buck, S. A. Peoples, Corlette C. Calvert. Arsenic: Medical and Biologic Effects of Environmental Pollutants. Washington (DC) 1977.

4. David PA, Lawson M. Geogenic and Anthropogenic Arsenic Hazard in Groundwaters and Soils. In: States JC, editor. Arsenic: Exposure Sources, Health Risks, and Mechanisms of Toxicity. Canada: John Wiley \& Sons, Inc.; 2015. p. 23-60.

5. Mukherjee A, Sengupta MK, Hossain MA, Ahamed S, Das B, Nayak B, Lodh D, Rahman MM, Chakraborti D. Arsenic contamination in groundwater: a global perspective with emphasis on the Asian scenario. $J$ Health Popul Nutr. 2006;24(2):142-63. PubMed PMID: 17195556.

6. Smith $\mathrm{AH}$, Lingas EO, Rahman M. Contamination of drinking-water by arsenic in Bangladesh: a public health emergency. Bull World Health Organ. 2000;78(9):1093-103. PubMed PMID: 11019458; PMCID: PMC2560840.

7. ATSDR. Toxicological Profile For Arsenic. Atlanta, Georgia: Agency for Toxic Substances and Disease Registry, 2007.

8. Martinez VD, Vucic EA, Becker-Santos DD, Gil L, Lam WL. Arsenic exposure and the induction of human cancers. Journal of toxicology. 2011;2011:431287. doi: 10.1155/2011/431287. PubMed PMID: 22174709; PMCID: 3235889.

9. Stern RS. Prevalence of a history of skin cancer in 2007: results of an incidence-based model. Arch Dermatol. 2010;146(3):279-82. Epub 2010/03/17. doi: 10.1001/archdermatol.2010.4. PubMed PMID: 20231498.

10. Brash DE, Rudolph JA, Simon JA, Lin A, McKenna GJ, Baden HP, Halperin AJ, Ponten J. A role for sunlight in skin cancer: UV-induced p53 mutations in squamous cell carcinoma. Proc Natl Acad Sci U S A. 1991;88(22):10124-8. Epub 1991/11/15. PubMed PMID: 1946433; PMCID: PMC52880.

11. Haque R, Mazumder DN, Samanta S, Ghosh N, Kalman D, Smith MM, Mitra S, Santra A, Lahiri S, Das S, De BK, Smith AH. Arsenic in drinking water and skin lesions: dose-response data from West Bengal, India. Epidemiology. 2003;14(2):174-82. doi:

10.1097/01.EDE.0000040361.55051.54. PubMed PMID: 12606883.

12. Caussy D. A Field Guide for Detection, Management and Surveillance of Arsenicosis Cases. WHO Technical Bulletin. New Delhi: 200531.

13. Centeno JA, Mullick FG, Martinez L, Page NP, Gibb H, Longfellow D, Thompson C, Ladich ER. Pathology related to chronic arsenic exposure. 
Environmental health perspectives. 2002;110 Suppl 5:883-6. PubMed PMID: 12426152; PMCID: 1241266.

14. Maloney ME. Arsenic in Dermatology. Dermatologic surgery : official publication for American Society for Dermatologic Surgery [et al]. 1996;22(3):301-4. PubMed PMID: 8599743.

15. Hunt KM, Srivastava RK, Elmets CA, Athar M. The mechanistic basis of arsenicosis: pathogenesis of skin cancer. Cancer Lett. 2014;354(2):211-9. doi: 10.1016/j.canlet.2014.08.016. PubMed PMID: 25173797; PMCID: PMC4193806.

16. Guha Mazumder DN, Haque R, Ghosh N, De BK, Santra A, Chakraborty D, Smith $\mathrm{AH}$. Arsenic levels in drinking water and the prevalence of skin lesions in West Bengal, India. Int J Epidemiol. 1998;27(5):871-7. PubMed PMID: 9839746.

17. Ho SY, Tsai YC, Lee MC, Guo HR. Merkel cell carcinoma in patients with long-term ingestion of arsenic. Journal of occupational health. 2005;47(2):188-92. PubMed PMID: 15824485.

18. Sarma N. Skin Manifestations of Chronic Arsenicosis. In: States jC, editor. Arsenic: Exposure Sources, Health Risks, and Mechanisms of Toxicity: John Wiley \& Sons, Inc; 2015. p. 127-35.

19. Tseng $\mathrm{CH}$. Blackfoot disease and arsenic: a never-ending story. Journal of environmental science and health Part C, Environmental carcinogenesis \& ecotoxicology reviews. 2005;23(1):55-74. doi: 10.1081/GNC-200051860. PubMed PMID: 16291522.

20. Moore LE, Smith AH, Hopenhayn-Rich C, Biggs ML, Kalman DA, Smith MT. Micronuclei in exfoliated bladder cells among individuals chronically exposed to arsenic in drinking water. Cancer epidemiology, biomarkers \& prevention : a publication of the American Association for Cancer Research, cosponsored by the American Society of Preventive Oncology. 1997;6(1):31-6. PubMed PMID: 8993795.

21. Zhang A, Feng $H$, Yang G, Pan X, Jiang X, Huang X, Dong $X$, Yang D, Xie $Y$, Peng L, Jun L, Hu C, Jian L, Wang X. Unventilated indoor coal-fired stoves in Guizhou province, China: cellular and genetic damage in villagers exposed to arsenic in food and air. Environmental health perspectives. 2007;115(4):653-8. doi: 10.1289/ehp.9272. PubMed PMID: 17450239; PMCID: 1852665.

22. Smith AH, Hopenhayn-Rich C, Warner M, Biggs ML, Moore L, Smith MT. Rationale for selecting exfoliated bladder cell micronuclei as potential biomarkers for arsenic genotoxicity. Journal of toxicology and environmental health. 1993;40(2-3):223-34. Epub 1993/10/01. doi: 10.1080/15287399309531790. PubMed PMID: 8230298.

23. Basu A, Ghosh P, Das JK, Banerjee A, Ray K, Giri AK. Micronuclei as biomarkers of carcinogen exposure in populations exposed to arsenic through drinking water in West Bengal, India: a comparative study in three cell types. Cancer epidemiology, biomarkers \& prevention : a publication of the American Association for Cancer Research, cosponsored by the 
American Society of Preventive Oncology. 2004;13(5):820-7. Epub 2004/05/26. PubMed PMID: 15159315.

24. Ghosh P, Basu A, Mahata J, Basu S, Sengupta M, Das JK, Mukherjee A, Sarkar AK, Mondal L, Ray K, Giri AK. Cytogenetic damage and genetic variants in the individuals susceptible to arsenic-induced cancer through drinking water. Int J Cancer. 2006;118(10):2470-8. Epub 2005/12/15. doi: 10.1002/ijc.21640. PubMed PMID: 16353154.

25. Reichard JF, Puga A. Effects of arsenic exposure on DNA methylation and epigenetic gene regulation. Epigenomics. 2010;2(1):87-104. Epub 2010/06/02. doi: 10.2217/epi.09.45. PubMed PMID: 20514360; PMCID: PMC2877392.

26. Bailey KA, Fry RC. Arsenic-Associated Changes to the Epigenome: What Are the Functional Consequences? Curr Environ Health Rep. 2014;1:2234. doi: 10.1007/s40572-013-0002-8. PubMed PMID: 24860721; PMCID: PMC4026129.

27. Tsunetsugu-Yokota Y, Yamamoto T. Mammalian MicroRNAs: PostTranscriptional Gene Regulation in RNA Virus Infection and Therapeutic Applications. Frontiers in microbiology. 2010;1:108. doi: 10.3389/fmicb.2010.00108. PubMed PMID: 21607080; PMCID: 3095394.

28. Friedman RC, Farh KK, Burge CB, Bartel DP. Most mammalian mRNAs are conserved targets of microRNAs. Genome Res. 2009;19(1):92-105. doi: 10.1101/gr.082701.108. PubMed PMID: 18955434; PMCID: PMC2612969.

29. Li Y, Kowdley KV. MicroRNAs in common human diseases. Genomics Proteomics Bioinformatics. 2012;10(5):246-53. doi: 10.1016/j.gpb.2012.07.005. PubMed PMID: 23200134; PMCID: PMC3611977.

30. Jansson MD, Lund AH. MicroRNA and cancer. Molecular oncology. 2012;6(6):590-610. doi: 10.1016/j.molonc.2012.09.006. PubMed PMID: 23102669.

31. Lee Y, Jeon K, Lee JT, Kim S, Kim VN. MicroRNA maturation: stepwise processing and subcellular localization. EMBO J. 2002;21(17):4663-70. PubMed PMID: 12198168; PMCID: 126204.

32. Bushati N, Cohen SM. microRNA functions. Annual review of cell and developmental biology. 2007;23:175-205. doi: 10.1146/annurev.cellbio.23.090506.123406. PubMed PMID: 17506695.

33. Hayes J, Peruzzi PP, Lawler S. MicroRNAs in cancer: biomarkers, functions and therapy. Trends in molecular medicine. 2014;20(8):460-9. doi: 10.1016/j.molmed.2014.06.005. PubMed PMID: 25027972.

34. Macfarlane LA, Murphy PR. MicroRNA: Biogenesis, Function and Role in Cancer. Curr Genomics. 2010;11(7):537-61. Epub 2011/05/03. doi: 10.2174/138920210793175895. PubMed PMID: 21532838; PMCID: PMC3048316.

35. Iorio MV, Croce CM. MicroRNA dysregulation in cancer: diagnostics, monitoring and therapeutics. A comprehensive review. EMBO molecular 
medicine. 2012;4(3):143-59. doi: 10.1002/emmm.201100209. PubMed PMID: 22351564; PMCID: 3376845.

36. Lagos-Quintana M, Rauhut R, Lendeckel W, Tuschl T. Identification of novel genes coding for small expressed RNAs. Science. 2001;294(5543):853-8. doi: 10.1126/science.1064921. PubMed PMID: 11679670.

37. Sato F, Tsuchiya S, Meltzer SJ, Shimizu K. MicroRNAs and epigenetics. FEBS J. 2011;278(10):1598-609. doi: 10.1111/j.1742-4658.2011.08089.x. PubMed PMID: 21395977.

38. Tsang JS, Ebert MS, van Oudenaarden A. Genome-wide dissection of microRNA functions and cotargeting networks using gene set signatures. Molecular cell. 2010;38(1):140-53. doi: 10.1016/j.molcel.2010.03.007. PubMed PMID: 20385095; PMCID: 3110938.

39. Pi J, Diwan BA, Sun Y, Liu J, Qu W, He Y, Styblo M, Waalkes MP. Arsenicinduced malignant transformation of human keratinocytes: involvement of Nrf2. Free radical biology \& medicine. 2008;45(5):651-8. doi: 10.1016/j.freeradbiomed.2008.05.020. PubMed PMID: 18572023; PMCID: 2658531.

40. Sand M, Gambichler T, Skrygan M, Sand D, Scola N, Altmeyer P, Bechara FG. Expression levels of the microRNA processing enzymes Drosha and dicer in epithelial skin cancer. Cancer investigation. 2010;28(6):649-53. doi: 10.3109/07357901003630918. PubMed PMID: 20210522.

41. Sand M, Skrygan M, Georgas D, Arenz C, Gambichler T, Sand D, Altmeyer $P$, Bechara FG. Expression levels of the microRNA maturing microprocessor complex component DGCR8 and the RNA-induced silencing complex (RISC) components argonaute-1, argonaute-2, PACT, TARBP1, and TARBP2 in epithelial skin cancer. Molecular carcinogenesis. 2012;51(11):916-22. doi: 10.1002/mc.20861. PubMed PMID: 22025453.

42. Banerjee N, Bandyopadhyay AK, Dutta S, Das JK, Roy Chowdhury T, Bandyopadhyay A, Giri AK. Increased microRNA 21 expression contributes to arsenic induced skin lesions, skin cancers and respiratory distress in chronically exposed individuals. Toxicology. 2017;378:10-6. Epub 2017/01/11. doi: 10.1016/j.tox.2017.01.006. PubMed PMID: 28069514.

43. Sturchio E, Colombo T, Boccia P, Carucci N, Meconi C, Minoia C, Macino G. Arsenic exposure triggers a shift in microRNA expression. Sci Total Environ. 2014;472:672-80. Epub 2013/12/10. doi: 10.1016/j.scitotenv.2013.11.092. PubMed PMID: 24317173.

44. Xu W, Ji J, Xu Y, Liu Y, Shi L, Liu Y, Lu X, Zhao Y, Luo F, Wang B, Jiang R, Zhang J, Liu Q. MicroRNA-191, by promoting the EMT and increasing CSC-like properties, is involved in neoplastic and metastatic properties of transformed human bronchial epithelial cells. Molecular carcinogenesis. 2015;54 Suppl 1:E148-61. Epub 2014/09/25. doi: 10.1002/mc.22221. PubMed PMID: 25252218.

45. Michailidi C, Hayashi M, Datta S, Sen T, Zenner K, Oladeru O, Brait M, Izumchenko E, Baras A, VandenBussche C, Argos M, Bivalacqua TJ, 
Ahsan H, Hahn NM, Netto GJ, Sidransky D, Hoque MO. Involvement of epigenetics and EMT-related miRNA in arsenic-induced neoplastic transformation and their potential clinical use. Cancer Prev Res (Phila). 2015;8(3):208-21. Epub 2015/01/15. doi: 10.1158/1940-6207.CAPR-140251. PubMed PMID: 25586904; PMCID: PMC4355280.

46. He J, Wang M, Jiang Y, Chen Q, Xu S, Xu Q, Jiang BH, Liu LZ. Chronic arsenic exposure and angiogenesis in human bronchial epithelial cells via the ROS/miR-199a-5p/HIF-1alpha/COX-2 pathway. Environmental health perspectives. 2014;122(3):255-61. Epub 2014/01/15. doi:

10.1289/ehp.1307545. PubMed PMID: 24413338; PMCID: PMC3948041.

47. Jiang R, Li Y, Zhang A, Wang B, Xu Y, Xu W, Zhao Y, Luo F, Liu Q. The acquisition of cancer stem cell-like properties and neoplastic transformation of human keratinocytes induced by arsenite involves epigenetic silencing of let-7c via Ras/NF-kappaB. Toxicol Lett. 2014;227(2):91-8. Epub 2014/04/08. doi: 10.1016/j.toxlet.2014.03.020. PubMed PMID: 24704393.

48. Ling M, Li Y, Xu Y, Pang Y, Shen L, Jiang R, Zhao Y, Yang X, Zhang J, Zhou J, Wang X, Liu Q. Regulation of miRNA-21 by reactive oxygen species-activated ERK/NF-kappaB in arsenite-induced cell transformation. Free radical biology \& medicine. 2012;52(9):1508-18. Epub 2012/03/06. doi: 10.1016/j.freeradbiomed.2012.02.020. PubMed PMID: 22387281.

49. Ngalame NN, Tokar EJ, Person RJ, Xu Y, Waalkes MP. Aberrant microRNA expression likely controls RAS oncogene activation during malignant transformation of human prostate epithelial and stem cells by arsenic. Toxicol Sci. 2014;138(2):268-77. Epub 2014/01/17. doi: 10.1093/toxsci/kfu002. PubMed PMID: 24431212; PMCID: PMC3968309.

50. Wang Z, Zhao Y, Smith E, Goodall GJ, Drew PA, Brabletz T, Yang C. Reversal and prevention of arsenic-induced human bronchial epithelial cell malignant transformation by microRNA-200b. Toxicol Sci. 2011;121(1):11022. Epub 2011/02/05. doi: 10.1093/toxsci/kfr029. PubMed PMID: 21292642; PMCID: PMC3080188.

51. Diaz-Villasenor A, Sanchez-Soto MC, Cebrian ME, Ostrosky-Wegman P, Hiriart M. Sodium arsenite impairs insulin secretion and transcription in pancreatic beta-cells. Toxicol Appl Pharmacol. 2006;214(1):30-4. Epub 2006/01/18. doi: 10.1016/j.taap.2005.11.015. PubMed PMID: 16413591.

52. Wauson EM, Langan AS, Vorce RL. Sodium arsenite inhibits and reverses expression of adipogenic and fat cell-specific genes during in vitro adipogenesis. Toxicol Sci. 2002;65(2):211-9. Epub 2002/01/29. PubMed PMID: 11812925.

53. Liu S, Guo X, Wu B, Yu H, Zhang X, Li M. Arsenic induces diabetic effects through beta-cell dysfunction and increased gluconeogenesis in mice. Sci Rep. 2014;4:6894. Epub 2014/11/05. doi: 10.1038/srep06894. PubMed PMID: 25367288; PMCID: PMC4219158.

54. Huang CF, Yang CY, Chan DC, Wang CC, Huang KH, Wu CC, Tsai KS, Yang RS, Liu SH. Arsenic Exposure and Glucose Intolerance/Insulin Resistance in Estrogen-Deficient Female Mice. Environmental health 
perspectives. 2015;123(11):1138-44. Epub 2015/04/11. doi: 10.1289/ehp.1408663. PubMed PMID: 25859628; PMCID: PMC4629734.

55. Bodwell JE, Gosse JA, Nomikos AP, Hamilton JW. Arsenic disruption of steroid receptor gene activation: Complex dose-response effects are shared by several steroid receptors. Chem Res Toxicol. 2006;19(12):161929. Epub 2006/12/19. doi: 10.1021/tx060122q. PubMed PMID: 17173375; PMCID: PMC2556599.

56. Lin Q, Gao Z, Alarcon RM, Ye J, Yun Z. A role of miR-27 in the regulation of adipogenesis. FEBS J. 2009;276(8):2348-58. Epub 2009/04/07. PubMed PMID: 19348006; PMCID: PMC5330386.

57. McGregor RA, Choi MS. microRNAs in the regulation of adipogenesis and obesity. Curr Mol Med. 2011;11(4):304-16. Epub 2011/04/22. PubMed PMID: 21506921; PMCID: PMC3267163.

58. Liu W, Bi P, Shan T, Yang X, Yin H, Wang YX, Liu N, Rudnicki MA, Kuang S. miR-133a regulates adipocyte browning in vivo. PLoS Genet. 2013;9(7):e1003626. Epub 2013/07/23. doi: 10.1371/journal.pgen.1003626. PubMed PMID: 23874225; PMCID: PMC3708806.

59. Beezhold K, Klei LR, Barchowsky A. Regulation of cyclin D1 by arsenic and microRNA inhibits adipogenesis. Toxicol Lett. 2017;265:147-55. Epub 2016/12/10. doi: 10.1016/j.toxlet.2016.12.002. PubMed PMID: 27932253; PMCID: PMC5182514.

60. Humphries $\mathrm{B}$, Wang Z, Yang $\mathrm{C}$. The role of microRNAs in metal carcinogen-induced cell malignant transformation and tumorigenesis. Food Chem Toxicol. 2016;98(Pt A):58-65. Epub 2016/10/30. doi: 10.1016/j.fct.2016.02.012. PubMed PMID: 26903202; PMCID: PMC4992468.

61. Waalkes MP, Liu J, Ward JM, Diwan BA. Animal models for arsenic carcinogenesis: inorganic arsenic is a transplacental carcinogen in mice. Toxicol Appl Pharmacol. 2004;198(3):377-84. Epub 2004/07/28. doi: 10.1016/j.taap.2003.10.028. PubMed PMID: 15276417.

62. Germolec DR, Spalding J, Boorman GA, Wilmer JL, Yoshida T, Simeonova PP, Bruccoleri A, Kayama F, Gaido K, Tennant R, Burleson F, Dong W, Lang RW, Luster MI. Arsenic can mediate skin neoplasia by chronic stimulation of keratinocyte-derived growth factors. Mutat Res. 1997;386(3):209-18. Epub 1997/06/01. PubMed PMID: 9219559.

63. Rossman TG, Uddin AN, Burns FJ, Bosland MC. Arsenite is a cocarcinogen with solar ultraviolet radiation for mouse skin: an animal model for arsenic carcinogenesis. Toxicol Appl Pharmacol. 2001;176(1):6471. Epub 2001/10/02. doi: 10.1006/taap.2001.9277. PubMed PMID: 11578149.

64. Boukamp P, Petrussevska RT, Breitkreutz D, Hornung J, Markham A, Fusenig NE. Normal keratinization in a spontaneously immortalized aneuploid human keratinocyte cell line. The Journal of cell biology. 1988;106(3):761-71. PubMed PMID: 2450098; PMCID: 2115116. 
65. Pi J, Kumagai $Y$, Sun G, Yamauchi H, Yoshida T, Iso H, Endo A, Yu L, Yuki K, Miyauchi T, Shimojo N. Decreased serum concentrations of nitric oxide metabolites among Chinese in an endemic area of chronic arsenic poisoning in inner Mongolia. Free radical biology \& medicine. 2000;28(7):1137-42. PubMed PMID: 10832076.

66. Sun Y, Pi J, Wang X, Tokar EJ, Liu J, Waalkes MP. Aberrant cytokeratin expression during arsenic-induced acquired malignant phenotype in human $\mathrm{HaCaT}$ keratinocytes consistent with epidermal carcinogenesis. Toxicology. 2009;262(2):162-70. doi: 10.1016/j.tox.2009.06.003. PubMed PMID: 19524636; PMCID: 2747077.

67. Polya D, Lawson M. Geogenic and Anthropogenic Arsenic Hazard in Groundwaters and Soils: Distribution, Nature, Origin, and Human Exposure Routes. In: States JC, editor. Arsenic: Exposure Sources, Health Risks, and Mechanisms of Toxicity. Hoboken, NY: John Wiley \& Sons, Inc.; 2016.

68. WHO. Guidelines for drinking-water quality - Volume 1: Recommendations Third edition, incorporating first and second addenda: World Health Organization 2008. 668 p.

69. Naujokas MF, Anderson B, Ahsan H, Aposhian HV, Graziano JH, Thompson C, Suk WA. The broad scope of health effects from chronic arsenic exposure: update on a worldwide public health problem. Environmental health perspectives. 2013;121(3):295-302. doi: 10.1289/ehp.1205875. PubMed PMID: 23458756; PMCID: PMC3621177.

70. Chen $\mathrm{Y}$, Ahsan $\mathrm{H}$. Cancer burden from arsenic in drinking water in Bangladesh. American journal of public health. 2004;94(5):741-4. PubMed PMID: 15117692; PMCID: 1448329.

71. Wright RO, Amarasiriwardena C, Woolf $A D$, Jim R, Bellinger DC. Neuropsychological correlates of hair arsenic, manganese, and cadmium levels in school-age children residing near a hazardous waste site. Neurotoxicology. 2006;27(2):210-6. doi: 10.1016/j.neuro.2005.10.001. PubMed PMID: 16310252.

72. Argos M, Kalra T, Rathouz PJ, Chen Y, Pierce B, Parvez F, Islam T, Ahmed A, Rakibuz-Zaman M, Hasan R, Sarwar G, Slavkovich V, van Geen A, Graziano J, Ahsan H. Arsenic exposure from drinking water, and allcause and chronic-disease mortalities in Bangladesh (HEALS): a prospective cohort study. Lancet. 2010;376(9737):252-8. doi: 10.1016/S0140-6736(10)60481-3. PubMed PMID: 20646756; PMCID: 3951449.

73. Ahsan H, Chen $\mathrm{Y}$, Parvez F, Argos M, Hussain Al, Momotaj H, Levy D, van Geen A, Howe G, Graziano J. Health Effects of Arsenic Longitudinal Study (HEALS): description of a multidisciplinary epidemiologic investigation. Journal of exposure science \& environmental epidemiology. 2006;16(2):191-205. doi: 10.1038/sj.jea.7500449. PubMed PMID: 16160703.

74. Chen CL, Chiou HY, Hsu LI, Hsueh YM, Wu MM, Wang YH, Chen CJ. Arsenic in drinking water and risk of urinary tract cancer: a follow-up study 
from northeastern Taiwan. Cancer epidemiology, biomarkers \& prevention : a publication of the American Association for Cancer Research, cosponsored by the American Society of Preventive Oncology. 2010;19(1):101-10. doi: 10.1158/1055-9965.EPI-09-0333. PubMed PMID: 20056628.

75. Smith AH, Steinmaus CM. Health effects of arsenic and chromium in drinking water: recent human findings. Annual review of public health. 2009;30:107-22. doi: 10.1146/annurev.publhealth.031308.100143. PubMed PMID: 19012537; PMCID: 2762382.

76. Yuan Y, Marshall G, Ferreccio C, Steinmaus C, Liaw J, Bates M, Smith AH. Kidney cancer mortality: fifty-year latency patterns related to arsenic exposure. Epidemiology. 2010;21(1):103-8. doi: 10.1097/EDE.0b013e3181c21e46. PubMed PMID: 20010213.

77. Gribble MO, Howard BV, Umans JG, Shara NM, Francesconi KA, Goessler W, Crainiceanu CM, Silbergeld EK, Guallar E, Navas-Acien A. Arsenic exposure, diabetes prevalence, and diabetes control in the Strong Heart Study. American journal of epidemiology. 2012;176(10):865-74. doi: 10.1093/aje/kws153. PubMed PMID: 23097256; PMCID: 3626061.

78. James KA, Byers T, Hokanson JE, Meliker JR, Zerbe GO, Marshall JA. Association between lifetime exposure to inorganic arsenic in drinking water and coronary heart disease in Colorado residents. Environmental health perspectives. 2015;123(2):128-34. doi: 10.1289/ehp.1307839. PubMed PMID: 25350952; PMCID: 4314243.

79. Wasserman GA, Liu X, Loiacono NJ, Kline J, Factor-Litvak P, van Geen A, Mey JL, Levy D, Abramson R, Schwartz A, Graziano JH. A cross-sectional study of well water arsenic and child IQ in Maine schoolchildren.

Environmental health : a global access science source. 2014;13(1):23. doi: 10.1186/1476-069X-13-23. PubMed PMID: 24684736; PMCID: 4104994.

80. Chowdhury TR, Basu GK, Mandal BK, Biswas BK, Samanta G, Chowdhury UK, Chanda CR, Lodh D, Roy SL, Saha KC, Roy S, Kabir S, Quamruzzaman Q, Chakraborti D. Arsenic poisoning in the Ganges delta. Nature. 1999;401(6753):545-6; discussion 6-7. doi: 10.1038/44056. PubMed PMID: 10524620.

81. Paul S, Das N, Bhattacharjee P, Banerjee M, Das JK, Sarma N, Sarkar A, Bandyopadhyay AK, Sau TJ, Basu S, Banerjee S, Majumder P, Giri AK. Arsenic-induced toxicity and carcinogenicity: a two-wave cross-sectional study in arsenicosis individuals in West Bengal, India. Journal of exposure science \& environmental epidemiology. 2013;23(2):156-62. Epub 2012/09/20. doi: 10.1038/jes.2012.91. PubMed PMID: 22990472.

82. IARC. Arsenic, metals, fibres, and dusts. IARC Monogr Eval Carcinog Risks Hum. 2012;100(Pt C):11-465. PubMed PMID: 23189751; PMCID: 4781271.

83. Society AC. Skin Cancer: Basal and Squamous Cell American Cancer Society; 2015. Available from: 
http://www.cancer.org/acs/groups/cid/documents/webcontent/003139pdf.pdf.

84. Mazumder DNG. Diagnosis and treatment of chronic arsenic poisoning. WHO, 2000.

85. Camacho LM, Gutierrez M, Alarcon-Herrera MT, Villalba Mde L, Deng S. Occurrence and treatment of arsenic in groundwater and soil in northern Mexico and southwestern USA. Chemosphere. 2011;83(3):211-25. doi: 10.1016/j.chemosphere.2010.12.067. PubMed PMID: 21216433.

86. Flanagan SM, Belaval M, Ayotte JD. Arsenic, Iron, Lead, Manganese, and Uranium Concentrations in Private Bedrock Wells in Southeastern New Hampshire, 2012-2013. 2014.

87. Nielsen MG, Lombard PJ, Schalk LF. Assessment of Arsenic Concentrations in Domestic Well Water, by Town, in Maine, 2005-09. 2010.

88. Zhang, Li Y, Fan L, Zhao Q, Tan B, Li Z, Zang A. microRNA-425-5p is upregulated in human gastric cancer and contributes to invasion and metastasis in vitro and in vivo. Exp Ther Med. 2015;9(5):1617-22. doi: 10.3892/etm.2015.2318. PubMed PMID: 26136868; PMCID: PMC4471687.

89. Ueda T, Volinia S, Okumura H, Shimizu M, Taccioli C, Rossi S, Alder H, Liu CG, Oue N, Yasui W, Yoshida K, Sasaki H, Nomura S, Seto Y, Kaminishi M, Calin GA, Croce CM. Relation between microRNA expression and progression and prognosis of gastric cancer: a microRNA expression analysis. Lancet Oncol. 2010;11(2):136-46. doi: 10.1016/S14702045(09)70343-2. PubMed PMID: 20022810; PMCID: PMC4299826.

90. Fleming $\mathrm{NH}$, Zhong J, da Silva IP, Vega-Saenz de Miera E, Brady B, Han SW, Hanniford D, Wang J, Shapiro RL, Hernando E, Osman I. Serumbased miRNAs in the prediction and detection of recurrence in melanoma patients. Cancer. 2015;121(1):51-9. doi: 10.1002/cncr.28981. PubMed PMID: 25155861; PMCID: PMC4270907.

91. Weiner-Gorzel K, Dempsey E, Milewska M, McGoldrick A, Toh V, Walsh A, Lindsay S, Gubbins L, Cannon A, Sharpe D, O'Sullivan J, Murphy M, Madden SF, Kell M, McCann A, Furlong F. Overexpression of the microRNA miR-433 promotes resistance to paclitaxel through the induction of cellular senescence in ovarian cancer cells. Cancer Med. 2015;4(5):74558. doi: 10.1002/cam4.409. PubMed PMID: 25684390; PMCID: PMC4430267.

92. Yang Z, Tsuchiya H, Zhang Y, Hartnett ME, Wang L. MicroRNA-433 inhibits liver cancer cell migration by repressing the protein expression and function of cAMP response element-binding protein. J Biol Chem. 2013;288(40):28893-9. doi: 10.1074/jbc.M113.502682. PubMed PMID: 23979134 ; PMCID: PMC3789984.

93. Guo LH, Li H, Wang F, Yu J, He JS. The Tumor Suppressor Roles of miR433 and miR-127 in Gastric Cancer. Int J Mol Sci. 2013;14(7):14171-84. doi: 10.3390/ijms140714171. PubMed PMID: 23880861; PMCID: PMC3742237. 
94. Xu X, Zhu Y, Liang Z, Li S, Xu X, Wang X, Wu J, Hu Z, Meng S, Liu B, Qin $\mathrm{J}$, Xie L, Zheng X. c-Met and CREB1 are involved in miR-433-mediated inhibition of the epithelial-mesenchymal transition in bladder cancer by regulating Akt/GSK-3beta/Snail signaling. Cell Death Dis. 2016;7:e2088. doi: 10.1038/cddis.2015.274. PubMed PMID: 26844702; PMCID: PMC4849142.

95. Furlong F, Fitzpatrick P, O'Toole S, Phelan S, McGrogan B, Maguire A, O'Grady A, Gallagher M, Prencipe M, McGoldrick A, McGettigan P, Brennan D, Sheils O, Martin C, E WK, O'Leary J, McCann A. Low MAD2 expression levels associate with reduced progression-free survival in patients with high-grade serous epithelial ovarian cancer. J Pathol. 2012;226(5):746-55. doi: 10.1002/path.3035. PubMed PMID: 22069160; PMCID: PMC3593171.

96. Schaefer A, Jung M, Mollenkopf HJ, Wagner I, Stephan C, Jentzmik F, Miller K, Lein M, Kristiansen G, Jung K. Diagnostic and prognostic implications of microRNA profiling in prostate carcinoma. Int $\mathrm{J}$ Cancer. 2010;126(5):1166-76. doi: 10.1002/ijc.24827. PubMed PMID: 19676045.

97. Wong TS, Liu XB, Wong BY, Ng RW, Yuen AP, Wei WI. Mature miR-184 as Potential Oncogenic microRNA of Squamous Cell Carcinoma of Tongue. Clin Cancer Res. 2008;14(9):2588-92. doi: 10.1158/10780432.CCR-07-0666. PubMed PMID: 18451220.

98. Fu L, Li Z, Zhu J, Wang P, Fan G, Dai Y, Zheng Z, Liu Y. Serum expression levels of microRNA-382-3p, -598-3p, -1246 and -184 in breast cancer patients. Oncol Lett. 2016;12(1):269-74. doi: 10.3892/ol.2016.4582. PubMed PMID: 27347136; PMCID: PMC4906595.

99. Cui QK, Liu WD, Zhu JX, Wang YH, Wang ZG. MicroRNA-184 promotes proliferation ability of glioma cells by regulating FOXO3. Asian Pac J Trop Med. 2014;7(10):776-9. doi: 10.1016/S1995-7645(14)60135-8. PubMed PMID: 25129459.

100. Hsu CM, Lin PM, Wang YM, Chen ZJ, Lin SF, Yang MY. Circulating miRNA is a novel marker for head and neck squamous cell carcinoma. Tumour Biol. 2012;33(6):1933-42. doi: 10.1007/s13277-012-0454-8. PubMed PMID: 22811001.

101. Foley NH, Bray IM, Tivnan A, Bryan K, Murphy DM, Buckley PG, Ryan J, O'Meara A, O'Sullivan M, Stallings RL. MicroRNA-184 inhibits neuroblastoma cell survival through targeting the serine/threonine kinase AKT2. Mol Cancer. 2010;9:83. doi: 10.1186/1476-4598-9-83. PubMed PMID: 20409325; PMCID: PMC2864218.

102. Loudig O, Wang T, Ye K, Lin J, Wang Y, Ramnauth A, Liu C, Stark A, Chitale D, Greenlee R, Multerer D, Honda S, Daida Y, Spencer Feigelson $\mathrm{H}$, Glass A, Couch FJ, Rohan T, Ben-Dov IZ. Evaluation and Adaptation of a Laboratory-Based cDNA Library Preparation Protocol for Retrospective Sequencing of Archived MicroRNAs from up to 35-Year-Old Clinical FFPE Specimens. Int J Mol Sci. 2017;18(3). doi: 10.3390/ijms18030627. PubMed PMID: 28335433; PMCID: PMC5372640. 
103. Qin CZ, Lou XY, Lv QL, Cheng L, Wu NY, Hu L, Zhou HH. MicroRNA-184 acts as a potential diagnostic and prognostic marker in epithelial ovarian cancer and regulates cell proliferation, apoptosis and inflammation.

Pharmazie. 2015;70(10):668-73. PubMed PMID: 26601424.

104. Tetzlaff MT, Curry JL, Yin V, Pattanaprichakul P, Manonukul J, Uiprasertkul M, Manyam GC, Wani KM, Aldape K, Zhang L, Prieto VG, Esmaeli B.

Distinct pathways in the pathogenesis of sebaceous carcinomas implicated by differentially expressed microRNAs. JAMA Ophthalmol.

2015;133(10):1109-16. doi: 10.1001/jamaophthalmol.2015.2310. PubMed PMID: 26203913.

105. Lin TC, Lin PL, Cheng YW, Wu TC, Chou MC, Chen CY, Lee H. MicroRNA-184 Deregulated by the MicroRNA-21 Promotes Tumor Malignancy and Poor Outcomes in Non-small Cell Lung Cancer via Targeting CDC25A and c-Myc. Ann Surg Oncol. 2015;22 Suppl 3:S1532-9. doi: 10.1245/s10434-015-4595-z. PubMed PMID: 25990966.

106. Zhou R, Zhou X, Yin Z, Guo J, Hu T, Jiang S, Liu L, Dong X, Zhang S, Wu G. Tumor invasion and metastasis regulated by microRNA-184 and microRNA-574-5p in small-cell lung cancer. Oncotarget. 2015;6(42):4460922. doi: 10.18632/oncotarget.6338. PubMed PMID: 26587830; PMCID: PMC4792579.

107. Su Z, Chen D, Li Y, Zhang E, Yu Z, Chen T, Jiang Z, Ni L, Yang S, Gui Y, Ye J, Lai Y. microRNA-184 functions as tumor suppressor in renal cell carcinoma. Exp Ther Med. 2015;9(3):961-6. doi: 10.3892/etm.2015.2199. PubMed PMID: 25667660; PMCID: PMC4316952.

108. Gao B, Gao K, Li L, Huang Z, Lin L. miR-184 functions as an oncogenic regulator in hepatocellular carcinoma (HCC). Biomed Pharmacother. 2014;68(2):143-8. doi: 10.1016/j.biopha.2013.09.005. PubMed PMID: 24183204.

109. Wu GG, Li WH, He WG, Jiang N, Zhang GX, Chen W, Yang HF, Liu QL, Huang YN, Zhang L, Zhang T, Zeng XC. Mir-184 post-transcriptionally regulates SOX7 expression and promotes cell proliferation in human hepatocellular carcinoma. PLoS One. 2014;9(2):e88796. doi: 10.1371/journal.pone.0088796. PubMed PMID: 24558429; PMCID: PMC3928300.

110. Liang Z, Li S, Xu X, Xu X, Wang X, Wu J, Zhu Y, Hu Z, Lin Y, Mao Y, Chen $\mathrm{H}$, Luo J, Liu B, Zheng X, Xie L. MicroRNA-576-3p inhibits proliferation in bladder cancer cells by targeting cyclin D1. Mol Cells. 2015;38(2):130-7. doi: 10.14348/molcells.2015.2146. PubMed PMID: 25556372; PMCID: PMC4332027.

111. Balci S, Ayaz L, Gorur A, Yildirim Yaroglu H, Akbayir S, Dogruer Unal N, Bulut B, Tursen $U$, Tamer $L$. microRNA profiling for early detection of nonmelanoma skin cancer. Clin Exp Dermatol. 2016;41(4):346-51. doi: 10.1111/ced.12736. PubMed PMID: 26299703.

112. Coskun E, Neumann M, Schlee C, Liebertz F, Heesch S, Goekbuget N, Hoelzer D, Baldus CD. MicroRNA profiling reveals aberrant microRNA 
expression in adult ETP-ALL and functional studies implicate a role for miR-222 in acute leukemia. Leuk Res. 2013;37(6):647-56. doi:

10.1016/j.leukres.2013.02.019. PubMed PMID: 23522449.

113. Fan $Y$, Song X, Du H, Luo C, Wang X, Yang X, Wang Y, Wu X. Downregulation of miR-29c in human bladder cancer and the inhibition of proliferation in T24 cell via PI3K-AKT pathway. Med Oncol. 2014;31(7):65. doi: 10.1007/s12032-014-0065-x. PubMed PMID: 24952510.

114. Ding DP, Chen ZL, Zhao XH, Wang JW, Sun J, Wang Z, Tan FW, Tan XG, Li BZ, Zhou F, Shao K, Li N, Qiu B, He J. miR-29c induces cell cycle arrest in esophageal squamous cell carcinoma by modulating cyclin $\mathrm{E}$ expression. Carcinogenesis. 2011;32(7):1025-32. doi:

10.1093/carcin/bgr078. PubMed PMID: 21551130.

115. Han TS, Hur K, Xu G, Choi B, Okugawa Y, Toiyama Y, Oshima H, Oshima M, Lee HJ, Kim VN, Chang AN, Goel A, Yang HK. MicroRNA-29c mediates initiation of gastric carcinogenesis by directly targeting ITGB1. Gut. 2015;64(2):203-14. doi: 10.1136/gutjnl-2013-306640. PubMed PMID: 24870620 ; PMCID: PMC4384419.

116. Fan YC, Mei PJ, Chen C, Miao FA, Zhang H, Li ZL. MiR-29c inhibits glioma cell proliferation, migration, invasion and angiogenesis. J Neurooncol. 2013;115(2):179-88. doi: 10.1007/s11060-013-1223-2. PubMed PMID: 23943502.

117. Kinoshita T, Nohata N, Hanazawa T, Kikkawa N, Yamamoto N, Yoshino H, Itesako T, Enokida H, Nakagawa M, Okamoto Y, Seki N. Tumoursuppressive microRNA-29s inhibit cancer cell migration and invasion by targeting laminin-integrin signalling in head and neck squamous cell carcinoma. British journal of cancer. 2013;109(10):2636-45. doi: 10.1038/bjc.2013.607. PubMed PMID: 24091622; PMCID: PMC3833206.

118. Dong CW, Wang YX, Du FT, Ding W, Hu SY. Low miR-29c expression is a prognostic marker in hepatocellular carcinoma. Genet Mol Res. 2016;15(3). doi: 10.4238/gmr.15037316. PubMed PMID: 27525839.

119. Liu L, Bi N, Wu L, Ding X, Men Y, Zhou W, Li L, Zhang W, Shi S, Song Y, Wang L. MicroRNA-29c functions as a tumor suppressor by targeting VEGFA in lung adenocarcinoma. Mol Cancer. 2017;16(1):50. doi: 10.1186/s12943-017-0620-0. PubMed PMID: 28241836; PMCID: PMC5330136.

120. Sengupta S, den Boon JA, Chen IH, Newton MA, Stanhope SA, Cheng YJ, Chen CJ, Hildesheim A, Sugden B, Ahlquist P. MicroRNA 29c is downregulated in nasopharyngeal carcinomas, up-regulating mRNAs encoding extracellular matrix proteins. Proc Natl Acad Sci U S A. 2008;105(15):58748. doi: 10.1073/pnas.0801130105. PubMed PMID: 18390668; PMCID: PMC2311339.

121. Wang $H$, Zhu $Y$, Zhao M, Wu C, Zhang $P$, Tang L, Zhang H, Chen X, Yang $Y$, Liu G. miRNA-29c suppresses lung cancer cell adhesion to extracellular matrix and metastasis by targeting integrin beta1 and matrix metalloproteinase2 (MMP2). PLoS One. 2013;8(8):e70192. doi: 
10.1371/journal.pone.0070192. PubMed PMID: 23936390; PMCID: PMC3735565.

122. Heegaard NH, Schetter AJ, Welsh JA, Yoneda M, Bowman ED, Harris CC. Circulating micro-RNA expression profiles in early stage nonsmall cell lung cancer. Int J Cancer. 2012;130(6):1378-86. doi: 10.1002/ijc.26153. PubMed PMID: 21544802; PMCID: PMC3259258.

123. Kwon JJ, Willy JA, Quirin KA, Wek RC, Korc M, Yin XM, Kota J. Novel role of miR-29a in pancreatic cancer autophagy and its therapeutic potential. Oncotarget. 2016;7(44):71635-50. doi: 10.18632/oncotarget.11928. PubMed PMID: 27626694; PMCID: PMC5342107.

124. Yang X, Ruan H, Hu X, Cao A, Song L. miR-381-3p suppresses the proliferation of oral squamous cell carcinoma cells by directly targeting FGFR2. Am J Cancer Res. 2017;7(4):913-22. PubMed PMID: 28469963; PMCID: PMC5411798.

125. Xia B, Li H, Yang S, Liu T, Lou G. MiR-381 inhibits epithelial ovarian cancer malignancy via YY1 suppression. Tumour Biol. 2016;37(7):9157-67. doi: 10.1007/s13277-016-4805-8. PubMed PMID: 26768613.

126. Zhang Q, Zhao S, Pang X, Chi B. MicroRNA-381 suppresses cell growth and invasion by targeting the liver receptor homolog-1 in hepatocellular carcinoma. Oncol Rep. 2016;35(3):1831-40. doi: 10.3892/or.2015.4491. PubMed PMID: 26677080.

127. He X, Wei Y, Wang Y, Liu L, Wang W, Li N. MiR-381 functions as a tumor suppressor in colorectal cancer by targeting Twist1. Onco Targets Ther. 2016;9:1231-9. doi: 10.2147/OTT.S99228. PubMed PMID: 27094913; PMCID: PMC4789845.

128. Cao Q, Liu F, Ji K, Liu N, He Y, Zhang W, Wang L. MicroRNA-381 inhibits the metastasis of gastric cancer by targeting TMEM16A expression. J Exp Clin Cancer Res. 2017;36(1):29. doi: 10.1186/s13046-017-0499-z. PubMed PMID: 28193228; PMCID: PMC5307754.

129. Xue $Y, X u$ W, Zhao W, Wang W, Zhang D, Wu P. miR-381 inhibited breast cancer cells proliferation, epithelial-to-mesenchymal transition and metastasis by targeting CXCR4. Biomed Pharmacother. 2017;86:426-33. doi: 10.1016/j.biopha.2016.12.051. PubMed PMID: 28012397.

130. Li Y, Zhao C, Yu Z, Chen J, She X, Li P, Liu C, Zhang Y, Feng J, Fu H, Wang B, Kuang L, Li L, Lv G, Wu M. Low expression of miR-381 is a favorite prognosis factor and enhances the chemosensitivity of osteosarcoma. Oncotarget. 2016;7(42):68585-96. doi: 10.18632/oncotarget.11861. PubMed PMID: 27612424; PMCID: PMC5356575.

131. Liang Y, Zhao Q, Fan L, Zhang Z, Tan B, Liu Y, Li Y. Down-regulation of MicroRNA-381 promotes cell proliferation and invasion in colon cancer through up-regulation of LRH-1. Biomed Pharmacother. 2015;75:137-41. doi: 10.1016/j.biopha.2015.07.020. PubMed PMID: 26320367.

132. Rothschild SI, Tschan MP, Jaggi R, Fey MF, Gugger M, Gautschi O. MicroRNA-381 represses ID1 and is deregulated in lung adenocarcinoma. 
J Thorac Oncol. 2012;7(7):1069-77. doi: 10.1097/JTO.0b013e31824fe976. PubMed PMID: 22592211.

133. Tang H, Liu X, Wang Z, She X, Zeng X, Deng M, Liao Q, Guo X, Wang R, Li X, Zeng F, Wu M, Li G. Interaction of hsa-miR-381 and glioma suppressor LRRC4 is involved in glioma growth. Brain Res. 2011;1390:2132. doi: 10.1016/j.brainres.2011.03.034. PubMed PMID: 21435336.

134. Gan XN, Luo J, Tang RX, Wang HL, Zhou H, Qin H, Gan TQ, Chen G. Clinical value of miR-452-5p expression in lung adenocarcinoma: $A$ retrospective quantitative real-time polymerase chain reaction study and verification based on The Cancer Genome Atlas and Gene Expression Omnibus databases. Tumour Biol. 2017;39(5):1010428317705755. doi: 10.1177/1010428317705755. PubMed PMID: 28488527.

135. Lin CY, Tzeng HE, Li TM, Chen HT, Lee Y, Yang YC, Wang SW, Yang $\mathrm{WH}$, Tang $\mathrm{CH}$. WISP-3 inhibition of miR-452 promotes VEGF-A expression in chondrosarcoma cells and induces endothelial progenitor cells angiogenesis. Oncotarget. 2017. doi: 10.18632/oncotarget.17142. PubMed PMID: 28465477.

136. Grimes JA, Prasad N, Levy S, Cattley R, Lindley S, Boothe HW, Henderson RA, Smith BF. A comparison of microRNA expression profiles from splenic hemangiosarcoma, splenic nodular hyperplasia, and normal spleens of dogs. BMC Vet Res. 2016;12(1):272. doi: 10.1186/s12917-0160903-5. PubMed PMID: 27912752; PMCID: PMC5135805.

137. Zheng Z, Liu J, Yang Z, Wu L, Xie H, Jiang C, Lin B, Chen T, Xing C, Liu Z, Song P, Yin S, Zheng S, Zhou L. MicroRNA-452 promotes stem-like cells of hepatocellular carcinoma by inhibiting Sox7 involving Wnt/beta-catenin signaling pathway. Oncotarget. 2016;7(19):28000-12. doi: 10.18632/oncotarget.8584. PubMed PMID: 27058905; PMCID: PMC5053705.

138. Li RZ, Wang LM. Decreased microRNA-452 expression and its prognostic significance in human osteosarcoma. World J Surg Oncol. 2016;14:150. doi: 10.1186/s12957-016-0900-y. PubMed PMID: 27193084; PMCID: PMC4870789.

139. He Z, Xia Y, Liu B, Qi X, Li Z, Wang J, Chen L, Chen Y. Down-regulation of miR-452 is associated with poor prognosis in the non-small-cell lung cancer. J Thorac Dis. 2016;8(5):894-900. doi: 10.21037/jtd.2016.03.51. PubMed PMID: 27162664; PMCID: PMC4842820.

140. Goto Y, Kojima S, Kurozumi A, Kato M, Okato A, Matsushita R, Ichikawa T, Seki N. Regulation of E3 ubiquitin ligase-1 (WWP1) by microRNA-452 inhibits cancer cell migration and invasion in prostate cancer. British journal of cancer. 2016;114(10):1135-44. doi: 10.1038/bjc.2016.95. PubMed PMID: 27070713; PMCID: PMC4865980.

141. He H, Wang L, Zhou W, Zhang Z, Wang L, Xu S, Wang D, Dong J, Tang C, Tang H, Yi X, Ge J. MicroRNA Expression Profiling in Clear Cell Renal Cell Carcinoma: Identification and Functional Validation of Key miRNAs. PLoS 
One. 2015;10(5):e0125672. doi: 10.1371/journal.pone.0125672. PubMed PMID: 25938468; PMCID: PMC4418764.

142. Veit JA, Scheckenbach K, Schuler PJ, Laban S, Wiggenhauser PS, Thierauf J, Klussmann JP, Hoffmann TK. MicroRNA expression in differentially metastasizing tumors of the head and neck: adenoid cystic versus squamous cell carcinoma. Anticancer Res. 2015;35(3):1271-7. PubMed PMID: 25750274.

143. Puerta-Gil P, Garcia-Baquero R, Jia AY, Ocana S, Alvarez-Mugica M, Alvarez-Ossorio JL, Cordon-Cardo C, Cava F, Sanchez-Carbayo M. miR143, miR-222, and miR-452 are useful as tumor stratification and noninvasive diagnostic biomarkers for bladder cancer. Am J Pathol. 2012;180(5):1808-15. doi: 10.1016/j.ajpath.2012.01.034. PubMed PMID: 22426337.

144. Yi H, Geng L, Black A, Talmon G, Berim L, Wang J. The miR-487b$3 p / G R M 3 / T G F b e t a$ signaling axis is an important regulator of colon cancer tumorigenesis. Oncogene. 2017;36(24):3477-89. doi:

10.1038/onc.2016.499. PubMed PMID: 28114282.

145. Gattolliat CH, Thomas L, Ciafre SA, Meurice G, Le Teuff G, Job B, Richon C, Combaret V, Dessen P, Valteau-Couanet D, May E, Busson P, DoucRasy S, Benard J. Expression of miR-487b and miR-410 encoded by $14 \mathrm{q} 32.31$ locus is a prognostic marker in neuroblastoma. British journal of cancer. 2011;105(9):1352-61. doi: 10.1038/bjc.2011.388. PubMed PMID: 21970883 ; PMCID: PMC3241557.

146. Ames HM, Yuan M, Vizcaino MA, Yu W, Rodriguez FJ. MicroRNA profiling of low-grade glial and glioneuronal tumors shows an independent role for cluster 14q32.31 member miR-487b. Mod Pathol. 2017;30(2):204-16. doi: 10.1038/modpathol.2016.177. PubMed PMID: 27739438; PMCID: PMC5288128.

147. Formosa $A$, Markert EK, Lena AM, Italiano D, Finazzi-Agro E, Levine AJ, Bernardini S, Garabadgiu AV, Melino G, Candi E. MicroRNAs, miR-154, miR-299-5p, miR-376a, miR-376c, miR-377, miR-381, miR-487b, miR-485$3 p$, miR-495 and miR-654-3p, mapped to the $14 q 32.31$ locus, regulate proliferation, apoptosis, migration and invasion in metastatic prostate cancer cells. Oncogene. 2014;33(44):5173-82. doi: 10.1038/onc.2013.451. PubMed PMID: 24166498.

148. Song L, Liu D, Wang B, He J, Zhang S, Dai Z, Ma X, Wang X. miR-494 suppresses the progression of breast cancer in vitro by targeting CXCR4 through the Wnt/beta-catenin signaling pathway. Oncol Rep. 2015;34(1):525-31. doi: 10.3892/or.2015.3965. PubMed PMID: 25955111.

149. Yang YK, Xi WY, Xi RX, Li JY, Li Q, Gao YE. MicroRNA-494 promotes cervical cancer proliferation through the regulation of PTEN. Oncol Rep. 2015;33(5):2393-401. doi: 10.3892/or.2015.3821. PubMed PMID: 25738254.

150. Sun HB, Chen X, Ji H, Wu T, Lu HW, Zhang Y, Li H, Li YM. miR494 is an independent prognostic factor and promotes cell migration and invasion in 
colorectal cancer by directly targeting PTEN. Int J Oncol. 2014;45(6):248694. doi: 10.3892/ijo.2014.2665. PubMed PMID: 25270723.

151. Zhang R, Chen X, Zhang S, Zhang X, Li T, Liu Z, Wang J, Zang W, Wang Y, Du Y, Zhao G. Upregulation of miR-494 Inhibits Cell Growth and Invasion and Induces Cell Apoptosis by Targeting Cleft Lip and Palate Transmembrane 1-Like in Esophageal Squamous Cell Carcinoma. Dig Dis Sci. 2015;60(5):1247-55. doi: 10.1007/s10620-014-3433-7. PubMed PMID: 25480402.

152. He W, Li Y, Chen X, Lu L, Tang B, Wang Z, Pan Y, Cai S, He Y, Ke Z. miR-494 acts as an anti-oncogene in gastric carcinoma by targeting c-myc. J Gastroenterol Hepatol. 2014;29(7):1427-34. doi: 10.1111/jgh.12558. PubMed PMID: 24612089.

153. Lim L, Balakrishnan A, Huskey N, Jones KD, Jodari M, Ng R, Song G, Riordan J, Anderton B, Cheung ST, Willenbring H, Dupuy A, Chen X, Brown D, Chang AN, Goga A. MicroRNA-494 within an oncogenic microRNA megacluster regulates $\mathrm{G} 1 / \mathrm{S}$ transition in liver tumorigenesis through suppression of mutated in colorectal cancer. Hepatology. 2014;59(1):202-15. doi: 10.1002/hep.26662. PubMed PMID: 23913442; PMCID: PMC3877416.

154. Wang J, Chen H, Liao Y, Chen N, Liu T, Zhang H, Zhang H. Expression and clinical evidence of miR-494 and PTEN in non-small cell lung cancer. Tumour Biol. 2015;36(9):6965-72. doi: 10.1007/s13277-015-3416-0. PubMed PMID: 25861022.

155. Liborio-Kimura TN, Jung HM, Chan EK. miR-494 represses HOXA10 expression and inhibits cell proliferation in oral cancer. Oral Oncol. 2015;51(2):151-7. doi: 10.1016/j.oraloncology.2014.11.019. PubMed PMID: 25500095.

156. Kim YW, Kim EY, Jeon D, Liu JL, Kim HS, Choi JW, Ahn WS. Differential microRNA expression signatures and cell type-specific association with Taxol resistance in ovarian cancer cells. Drug Des Devel Ther. 2014;8:293314. doi: 10.2147/DDDT.S51969. PubMed PMID: 24591819; PMCID: PMC3938445.

157. Ma YB, Li GX, Hu JX, Liu X, Shi BM. Correlation of miR-494 expression with tumor progression and patient survival in pancreatic cancer. Genet Mol Res. 2015;14(4):18153-9. doi: 10.4238/2015.December.23.2. PubMed PMID: 26782462.

158. Wang L, Shi S, Zhou Y, Mu X, Han D, Ge R, Mu K. [miR-590-5p inhibits A375 cell invasion and migration in malignant melanoma by directly inhibiting YAP1 expression]. Xi Bao Yu Fen Zi Mian Yi Xue Za Zhi. 2017;33(3):326-30. PubMed PMID: 28274310.

159. Zhou L, Zhao LC, Jiang N, Wang XL, Zhou XN, Luo XL, Ren J. MicroRNA miR-590-5p inhibits breast cancer cell stemness and metastasis by targeting SOX2. Eur Rev Med Pharmacol Sci. 2017;21(1):87-94. PubMed PMID: 28121351. 
160. Chu Y, Ouyang $Y$, Wang $F$, Zheng A, Bai L, Han L, Chen Y, Wang H. MicroRNA-590 promotes cervical cancer cell growth and invasion by targeting CHL1. J Cell Biochem. 2014;115(5):847-53. doi: 10.1002/jcb.24726. PubMed PMID: 24288179.

161. Zhou Q, Zhu Y, Wei X, Zhou J, Chang L, Sui H, Han Y, Piao D, Sha R, Bai Y. MiR-590-5p inhibits colorectal cancer angiogenesis and metastasis by regulating nuclear factor $90 /$ vascular endothelial growth factor $A$ axis. Cell Death Dis. 2016;7(10):e2413. doi: 10.1038/cddis.2016.306. PubMed PMID: 27735951 ; PMCID: PMC5133975.

162. Shen B, Yu S, Zhang Y, Yuan Y, Li X, Zhong J, Feng J. miR-590-5p regulates gastric cancer cell growth and chemosensitivity through RECK and the AKT/ERK pathway. Onco Targets Ther. 2016;9:6009-19. doi: 10.2147/OTT.S110923. PubMed PMID: 27757042; PMCID: PMC5055051.

163. Yang $X, W u X$. miRNA expression profile of vulvar squamous cell carcinoma and identification of the oncogenic role of miR-590-5p. Oncol Rep. 2016;35(1):398-408. doi: 10.3892/or.2015.4344. PubMed PMID: 26498065.

164. Xiao X, Tang C, Xiao S, Fu C, Yu P. Enhancement of proliferation and invasion by MicroRNA-590-5p via targeting PBRM1 in clear cell renal carcinoma cells. Oncol Res. 2013;20(11):537-44. doi: 10.3727/096504013X13775486749335. PubMed PMID: 24063284.

165. Liu X, Duan B, Dong Y, He C, Zhou H, Sheng H, Gao H, Zhang X. MicroRNA-139-3p indicates a poor prognosis of colon cancer. Int J Clin Exp Pathol. 2014;7(11):8046-52. PubMed PMID: 25550849; PMCID: PMC4270559.

166. Yonemori M, Seki N, Yoshino H, Matsushita R, Miyamoto K, Nakagawa M, Enokida $\mathrm{H}$. Dual tumor-suppressors miR-139-5p and miR-139-3p targeting matrix metalloprotease 11 in bladder cancer. Cancer Sci.

2016;107(9):1233-42. doi: 10.1111/cas.13002. PubMed PMID: 27355528; PMCID: PMC5021030.

167. Sun X, Song Y, Tai X, Liu B, Ji W. MicroRNA expression and its detection in human supraglottic laryngeal squamous cell carcinoma. Biomed Rep. 2013;1(5):743-6. doi: 10.3892/br.2013.143. PubMed PMID: 24649021; PMCID: PMC3917082.

168. Feliciano A, Castellvi J, Artero-Castro A, Leal JA, Romagosa C, Hernandez-Losa J, Peg V, Fabra A, Vidal F, Kondoh H, Ramon YCS, Lleonart ME. miR-125b acts as a tumor suppressor in breast tumorigenesis via its novel direct targets ENPEP, CK2-alpha, CCNJ, and MEGF9. PLoS One. 2013;8(10):e76247. doi: 10.1371/journal.pone.0076247. PubMed PMID: 24098452; PMCID: PMC3789742.

169. Khalili M, Sadeghizadeh M, Ghorbanian K, Malekzadeh R, Vasei M, Mowla SJ. Down-regulation of miR-302b, an ESC-specific microRNA, in Gastric Adenocarcinoma. Cell J. 2012;13(4):251-8. PubMed PMID: 23508453; PMCID: PMC3584484. 
170. Liu FY, Wang LP, Wang Q, Han P, Zhuang WP, Li MJ, Yuan H. miR-302b regulates cell cycles by targeting CDK2 via ERK signaling pathway in gastric cancer. Cancer Med. 2016;5(9):2302-13. doi: 10.1002/cam4.818. PubMed PMID: 27465546; PMCID: PMC5055145.

171. Cataldo A, Cheung DG, Balsari A, Tagliabue E, Coppola V, lorio MV, Palmieri D, Croce CM. miR-302b enhances breast cancer cell sensitivity to cisplatin by regulating E2F1 and the cellular DNA damage response. Oncotarget. 2016;7(1):786-97. doi: 10.18632/oncotarget.6381. PubMed PMID: 26623722; PMCID: PMC4808033.

172. Wang L, Yao J, Zhang X, Guo B, Le X, Cubberly M, Li Z, Nan K, Song T, Huang C. miRNA-302b suppresses human hepatocellular carcinoma by targeting AKT2. Mol Cancer Res. 2014;12(2):190-202. doi: 10.1158/15417786.MCR-13-0411. PubMed PMID: 24337067.

173. Iorio MV, Visone R, Di Leva G, Donati V, Petrocca F, Casalini P, Taccioli C, Volinia S, Liu CG, Alder H, Calin GA, Menard S, Croce CM. MicroRNA signatures in human ovarian cancer. Cancer Res. 2007;67(18):8699-707. doi: 10.1158/0008-5472.CAN-07-1936. PubMed PMID: 17875710.

174. Zhang M, Yang Q, Zhang L, Zhou S, Ye W, Yao Q, Li Z, Huang C, Wen Q, Wang J. miR-302b is a potential molecular marker of esophageal squamous cell carcinoma and functions as a tumor suppressor by targeting ErbB4. J Exp Clin Cancer Res. 2014;33:10. doi: 10.1186/1756-9966-33-10. PubMed PMID: 24438167; PMCID: PMC3898821.

175. Chen WC, Lin MS, Ye YL, Gao HJ, Song ZY, Shen XY. microRNA expression pattern and its alteration following celecoxib intervention in human colorectal cancer. Exp Ther Med. 2012;3(6):1039-48. doi: 10.3892/etm.2012.531. PubMed PMID: 22970014; PMCID: PMC3438602.

176. He J, Mai J, Li Y, Chen L, Xu H, Zhu X, Pan Q. miR-597 inhibits breast cancer cell proliferation, migration and invasion through FOSL2. Oncol Rep. 2017;37(5):2672-8. doi: 10.3892/or.2017.5558. PubMed PMID: 28393251; PMCID: PMC5428280.

177. Pronina IV, Loginov VI, Burdennyy AM, Fridman MV, Senchenko VN, Kazubskaya TP, Kushlinskii NE, Dmitriev AA, Braga EA. DNA methylation contributes to deregulation of 12 cancer-associated microRNAs and breast cancer progression. Gene. 2017;604:1-8. doi: 10.1016/j.gene.2016.12.018. PubMed PMID: 27998789.

178. Zhou J, Lu S, Yang S, Chen H, Shi H, Miao M, Jiao B. MicroRNA-127 posttranscriptionally downregulates Sept7 and suppresses cell growth in hepatocellular carcinoma cells. Cell Physiol Biochem. 2014;33(5):1537-46. doi: 10.1159/000358717. PubMed PMID: 24854842.

179. Ahmed FE, Ahmed NC, Vos PW, Bonnerup C, Atkins JN, Casey M, Nuovo GJ, Naziri W, Wiley JE, Mota H, Allison RR. Diagnostic microRNA markers to screen for sporadic human colon cancer in stool: I. Proof of principle. Cancer Genomics Proteomics. 2013;10(3):93-113. PubMed PMID: 23741026. 
180. Lulli V, Buccarelli M, Martini M, Signore M, Biffoni M, Giannetti S, Morgante L, Marziali G, Ilari R, Pagliuca A, Larocca LM, De Maria R, Pallini R, RicciVitiani L. miR-135b suppresses tumorigenesis in glioblastoma stem-like cells impairing proliferation, migration and self-renewal. Oncotarget. 2015;6(35):37241-56. doi: 10.18632/oncotarget.5925. PubMed PMID: 26437223; PMCID: PMC4741927.

181. Chen MB, Liu YY, Cheng LB, Lu JW, Zeng P, Lu PH. AMPKalpha phosphatase Ppm1E upregulation in human gastric cancer is required for cell proliferation. Oncotarget. 2017;8(19):31288-96. doi: 10.18632/oncotarget.16126. PubMed PMID: 28423719; PMCID: PMC5458207.

182. Lee JW, Kim N, Park JH, Kim HJ, Chang H, Kim JM, Kim JW, Lee DH. Differential MicroRNA Expression Between Gastric Cancer Tissue and Non-cancerous Gastric Mucosa According to Helicobacter pylori Status. J Cancer Prev. 2017;22(1):33-9. doi: 10.15430/JCP.2017.22.1.33. PubMed PMID: 28382284; PMCID: PMC5380187.

183. Xu Y, Zhao S, Cui M, Wang Q. Down-regulation of microRNA-135b inhibited growth of cervical cancer cells by targeting FOXO1. Int J Clin Exp Pathol. 2015;8(9):10294-304. PubMed PMID: 26617737; PMCID: PMC4637552.

184. Faltejskova P, Svoboda M, Srutova K, Mlcochova J, Besse A, Nekvindova J, Radova L, Fabian P, Slaba K, Kiss I, Vyzula R, Slaby O. Identification and functional screening of microRNAs highly deregulated in colorectal cancer. J Cell Mol Med. 2012;16(11):2655-66. doi: 10.1111/j.15824934.2012.01579.x. PubMed PMID: 22469014; PMCID: PMC4118234.

185. Xu XM, Qian JC, Deng ZL, Cai Z, Tang T, Wang P, Zhang KH, Cai JP. Expression of miR-21, miR-31, miR-96 and miR-135b is correlated with the clinical parameters of colorectal cancer. Oncol Lett. 2012;4(2):339-45. doi: 10.3892/ol.2012.714. PubMed PMID: 22844381; PMCID: PMC3402725.

186. Xue Y, Ni T, Jiang Y, Li Y. LncRNA GAS5 Inhibits Tumorigenesis and Enhances Radiosensitivity By Suppressing miR-135b Expression in NonSmall Cell Lung Cancer. Oncol Res. 2017. doi: 10.3727/096504017X14850182723737. PubMed PMID: 28117028.

187. Lin CW, Chang YL, Chang YC, Lin JC, Chen CC, Pan SH, Wu CT, Chen HY, Yang SC, Hong TM, Yang PC. MicroRNA-135b promotes lung cancer metastasis by regulating multiple targets in the Hippo pathway and LZTS1. Nat Commun. 2013;4:1877. doi: 10.1038/ncomms2876. PubMed PMID: 23695671.

188. Wang N, Tao L, Zhong H, Zhao S, Yu Y, Yu B, Chen X, Gao J, Wang R. miR-135b inhibits tumour metastasis in prostate cancer by targeting STAT6. Oncol Lett. 2016;11(1):543-50. doi: 10.3892/ol.2015.3970. PubMed PMID: 26870245; PMCID: PMC4727074.

189. Zhang F, Luo Y, Shao Z, Xu L, Liu X, Niu Y, Shi J, Sun X, Liu Y, Ding Y, Zhao L. MicroRNA-187, a downstream effector of TGFbeta pathway, suppresses Smad-mediated epithelial-mesenchymal transition in colorectal 
cancer. Cancer Lett. 2016;373(2):203-13. doi:

10.1016/j.canlet.2016.01.037. PubMed PMID: 26820227.

190. Ren L, Li F, Di M, Fu Y, Hui Y, Xiao G, Sun Q, Liu Y, Ren D, Du X. MicroRNA-187 regulates gastric cancer progression by targeting the tumor suppressor CRMP1. Biochem Biophys Res Commun. 2017;482(4):597603. doi: 10.1016/j.bbrc.2016.11.079. PubMed PMID: 27864146.

191. Li C, Lu S, Shi Y. MicroRNA-187 promotes growth and metastasis of gastric cancer by inhibiting FOXA2. Oncol Rep. 2017;37(3):1747-55. doi: 10.3892/or.2017.5370. PubMed PMID: 28098868.

192. Lin SC, Kao SY, Chang JC, Liu YC, Yu EH, Tseng SH, Liu CJ, Chang KW. Up-regulation of miR-187 modulates the advances of oral carcinoma by targeting BARX2 tumor suppressor. Oncotarget. 2016;7(38):61355-65. doi: 10.18632/oncotarget.11349. PubMed PMID: 27542258; PMCID: PMC5308656.

193. Zhao J, Lei T, Xu C, Li H, Ma W, Yang Y, Fan S, Liu Y. MicroRNA-187, down-regulated in clear cell renal cell carcinoma and associated with lower survival, inhibits cell growth and migration though targeting $\mathrm{B} 7-\mathrm{H} 3$. Biochem Biophys Res Commun. 2013;438(2):439-44. doi: 10.1016/j.bbrc.2013.07.095. PubMed PMID: 23916610.

194. Chao A, Lai CH, Chen HC, Lin CY, Tsai CL, Tang YH, Huang HJ, Lin CT, Chen MY, Huang KG, Chou HH, Chang TC, Chen SJ, Wang TH. Serum microRNAs in clear cell carcinoma of the ovary. Taiwan J Obstet Gynecol. 2014;53(4):536-41. doi: 10.1016/j.tjog.2014.07.005. PubMed PMID: 25510697.

195. Fuse M, Kojima S, Enokida H, Chiyomaru T, Yoshino H, Nohata N, Kinoshita T, Sakamoto S, Naya Y, Nakagawa M, Ichikawa T, Seki N. Tumor suppressive microRNAs (miR-222 and miR-31) regulate molecular pathways based on microRNA expression signature in prostate cancer. $\mathrm{J}$ Hum Genet. 2012;57(11):691-9. doi: 10.1038/jhg.2012.95. PubMed PMID: 22854542

196. Jia X, Li N, Peng C, Deng Y, Wang J, Deng M, Lu M, Yin J, Zheng G, Liu $\mathrm{H}$, He Z. miR-493 mediated DKK1 down-regulation confers proliferation, invasion and chemo-resistance in gastric cancer cells. Oncotarget. 2016;7(6):7044-54. doi: 10.18632/oncotarget.6951. PubMed PMID: 26799283; PMCID: PMC4872767.

197. Okamoto K, Ishiguro T, Midorikawa $Y$, Ohata H, Izumiya M, Tsuchiya N, Sato A, Sakai H, Nakagama $\mathrm{H}$. miR-493 induction during carcinogenesis blocks metastatic settlement of colon cancer cells in liver. EMBO J. 2012;31(7):1752-63. doi: 10.1038/emboj.2012.25. PubMed PMID: 22373578; PMCID: PMC3321205.

198. Yan Y, Zhang F, Fan Q, Li X, Zhou K. Breast cancer-specific TRAlL expression mediated by miRNA response elements of let-7 and miR-122. Neoplasma. 2014;61(6):672-9. doi: 10.4149/neo_2014_082. PubMed PMID: 25150312. 
199. Inamura K, Togashi $\mathrm{Y}$, Nomura K, Ninomiya $H$, Hiramatsu $M$, Satoh $\mathrm{Y}$, Okumura S, Nakagawa K, Ishikawa Y. let-7 microRNA expression is reduced in bronchioloalveolar carcinoma, a non-invasive carcinoma, and is not correlated with prognosis. Lung Cancer. 2007;58(3):392-6. doi: 10.1016/j.lungcan.2007.07.013. PubMed PMID: 17728006.

200. Akao Y, Nakagawa $Y$, Naoe T. let-7 microRNA functions as a potential growth suppressor in human colon cancer cells. Biol Pharm Bull. 2006;29(5):903-6. PubMed PMID: 16651716.

201. He FC, Meng WW, Qu YH, Zhou MX, He J, Lv P, Ming L. Expression of circulating microRNA-20a and let-7a in esophageal squamous cell carcinoma. World J Gastroenterol. 2015;21(15):4660-5. doi: 10.3748/wjg.v21.i15.4660. PubMed PMID: 25914476; PMCID: PMC4402314.

202. Gong W, Zheng J, Liu X, Ma J, Liu Y, Xue Y. Knockdown of NEAT1 restrained the malignant progression of glioma stem cells by activating microRNA let-7e. Oncotarget. 2016;7(38):62208-23. doi:

10.18632/oncotarget.11403. PubMed PMID: 27556696; PMCID: PMC5308721.

203. Takamizawa J, Konishi H, Yanagisawa K, Tomida S, Osada H, Endoh H, Harano T, Yatabe Y, Nagino M, Nimura Y, Mitsudomi T, Takahashi T. Reduced expression of the let-7 microRNAs in human lung cancers in association with shortened postoperative survival. Cancer Res. 2004;64(11):3753-6. doi: 10.1158/0008-5472.CAN-04-0637. PubMed PMID: 15172979.

204. Karube $\mathrm{Y}$, Tanaka H, Osada H, Tomida S, Tatematsu Y, Yanagisawa K, Yatabe Y, Takamizawa J, Miyoshi S, Mitsudomi T, Takahashi T. Reduced expression of Dicer associated with poor prognosis in lung cancer patients. Cancer Sci. 2005;96(2):111-5. doi: 10.1111/j.1349-7006.2005.00015.x. PubMed PMID: 15723655.

205. Yu S, Liu Y, Wang J, Guo Z, Zhang Q, Yu F, Zhang Y, Huang K, Li Y, Song $\mathrm{E}$, Zheng $\mathrm{XL}$, Xiao $\mathrm{H}$. Circulating microRNA profiles as potential biomarkers for diagnosis of papillary thyroid carcinoma. J Clin Endocrinol Metab. 2012;97(6):2084-92. doi: 10.1210/jc.2011-3059. PubMed PMID: 22472564.

206. Wong TS, Man OY, Tsang CM, Tsao SW, Tsang RK, Chan JY, Ho WK, Wei WI, To VS. MicroRNA let-7 suppresses nasopharyngeal carcinoma cells proliferation through downregulating c-Myc expression. J Cancer Res Clin Oncol. 2011;137(3):415-22. doi: 10.1007/s00432-010-0898-4. PubMed PMID: 20440510; PMCID: PMC3036828.

207. Torrisani J, Bournet B, du Rieu MC, Bouisson M, Souque A, Escourrou J, Buscail L, Cordelier P. let-7 MicroRNA transfer in pancreatic cancerderived cells inhibits in vitro cell proliferation but fails to alter tumor progression. Hum Gene Ther. 2009;20(8):831-44. doi:

10.1089/hum.2008.134. PubMed PMID: 19323605.

208. Luo Q, Li X, Li J, Kong X, Zhang J, Chen L, Huang Y, Fang L. MiR-15a is underexpressed and inhibits the cell cycle by targeting CCNE1 in breast 
cancer. Int J Oncol. 2013;43(4):1212-8. doi: 10.3892/ijo.2013.2034. PubMed PMID: 23900351.

209. Calin GA, Croce CM. Genomics of chronic lymphocytic leukemia microRNAs as new players with clinical significance. Semin Oncol. 2006;33(2):167-73. doi: 10.1053/j.seminoncol.2006.01.010. PubMed PMID: 16616063.

210. Bottoni A, Piccin D, Tagliati F, Luchin A, Zatelli MC, degli Uberti EC. miR$15 a$ and miR-16-1 down-regulation in pituitary adenomas. J Cell Physiol. 2005;204(1):280-5. doi: 10.1002/jcp.20282. PubMed PMID: 15648093.

211. Bonci D, Coppola V, Musumeci M, Addario A, Giuffrida R, Memeo L, D'Urso L, Pagliuca A, Biffoni M, Labbaye C, Bartucci M, Muto G, Peschle C, De Maria R. The miR-15a-miR-16-1 cluster controls prostate cancer by targeting multiple oncogenic activities. Nat Med. 2008;14(11):1271-7. doi: 10.1038/nm.1880. PubMed PMID: 18931683.

212. Wang X, Wang J, Ma H, Zhang J, Zhou X. Downregulation of miR-195 correlates with lymph node metastasis and poor prognosis in colorectal cancer. Med Oncol. 2012;29(2):919-27. doi: 10.1007/s12032-011-9880-5. PubMed PMID: 21390519.

213. Liu SG, Qin XG, Zhao BS, Qi B, Yao WJ, Wang TY, Li HC, Wu XN. Differential expression of miRNAs in esophageal cancer tissue. Oncol Lett. 2013;5(5):1639-42. doi: 10.3892/ol.2013.1251. PubMed PMID: 23761828; PMCID: PMC3678876.

214. Wu C, Zheng X, Li X, Fesler A, Hu W, Chen L, Xu B, Wang Q, Tong A, Burke S, Ju J, Jiang J. Reduction of gastric cancer proliferation and invasion by miR-15a mediated suppression of Bmi-1 translation. Oncotarget. 2016;7(12):14522-36. doi: 10.18632/oncotarget.7392. PubMed PMID: 26894855; PMCID: PMC4924733.

215. Ye X, Wei W, Zhang Z, He C, Yang R, Zhang J, Wu Z, Huang Q, Jiang Q. Identification of microRNAs associated with glioma diagnosis and prognosis. Oncotarget. 2017;8(16):26394-403. doi: 10.18632/oncotarget.14445. PubMed PMID: 28060761; PMCID: PMC5432266.

216. Yang T, Thakur A, Chen T, Yang L, Lei G, Liang Y, Zhang S, Ren H, Chen M. MicroRNA-15a induces cell apoptosis and inhibits metastasis by targeting BCL2L2 in non-small cell lung cancer. Tumour Biol.

2015;36(6):4357-65. doi: 10.1007/s13277-015-3075-1. PubMed PMID: 25874488.

217. Tian X, Zhang J, Yan L, Dong JM, Guo Q. MiRNA-15a inhibits proliferation, migration and invasion by targeting TNFAIP1 in human osteosarcoma cells. Int J Clin Exp Pathol. 2015;8(6):6442-9. PubMed PMID: 26261520; PMCID: PMC4525854.

218. Zhang XJ, Ye H, Zeng CW, He B, Zhang H, Chen YQ. Dysregulation of miR-15a and miR-214 in human pancreatic cancer. J Hematol Oncol. 2010;3:46. doi: 10.1186/1756-8722-3-46. PubMed PMID: 21106054; PMCID: PMC3002909. 
219. Guo S, Xu X, Tang Y, Zhang C, Li J, Ouyang Y, Ju J, Bie P, Wang H. miR15 a inhibits cell proliferation and epithelial to mesenchymal transition in pancreatic ductal adenocarcinoma by down-regulating Bmi-1 expression. Cancer Lett. 2014;344(1):40-6. doi: 10.1016/j.canlet.2013.10.009. PubMed PMID: 24252251.

220. Xuan H, Xue W, Pan J, Sha J, Dong B, Huang Y. Downregulation of miR$221,-30 \mathrm{~d}$, and -15 a contributes to pathogenesis of prostate cancer by targeting Bmi-1. Biochemistry (Mosc). 2015;80(3):276-83. doi: 10.1134/S0006297915030037. PubMed PMID: 25761682.

221. Bandi N, Zbinden S, Gugger M, Arnold M, Kocher V, Hasan L, Kappeler A, Brunner T, Vassella E. miR-15a and miR-16 are implicated in cell cycle regulation in a Rb-dependent manner and are frequently deleted or downregulated in non-small cell lung cancer. Cancer Res. 2009;69(13):5553-9. doi: 10.1158/0008-5472.CAN-08-4277. PubMed PMID: 19549910.

222. de Groen FL, Timmer LM, Menezes RX, Diosdado B, Hooijberg E, Meijer GA, Steenbergen RD, Carvalho B. Oncogenic Role of miR-15a-3p in 13q Amplicon-Driven Colorectal Adenoma-to-Carcinoma Progression. PLoS One. 2015;10(7):e0132495. doi: 10.1371/journal.pone.0132495. PubMed PMID: 26148070; PMCID: PMC4492490.

223. Long J, Jiang C, Liu B, Fang S, Kuang M. MicroRNA-15a-5p suppresses cancer proliferation and division in human hepatocellular carcinoma by targeting BDNF. Tumour Biol. 2016;37(5):5821-8. doi: 10.1007/s13277015-4427-6. PubMed PMID: 26581909.

224. Huang Z, Huang S, Wang Q, Liang L, Ni S, Wang L, Sheng W, He X, Du X. MicroRNA-95 promotes cell proliferation and targets sorting Nexin 1 in human colorectal carcinoma. Cancer Res. 2011;71(7):2582-9. doi: 10.1158/0008-5472.CAN-10-3032. PubMed PMID: 21427358.

225. Chen X, Chen S, Hang W, Huang H, Ma H. MiR-95 induces proliferation and chemo- or radioresistance through directly targeting sorting nexin1 (SNX1) in non-small cell lung cancer. Biomed Pharmacother. 2014;68(5):589-95. doi: 10.1016/j.biopha.2014.04.008. PubMed PMID: 24835695.

226. Ye J, Yao Y, Song Q, Li S, Hu Z, Yu Y, Hu C, Da X, Li H, Chen Q, Wang QK. Up-regulation of miR-95-3p in hepatocellular carcinoma promotes tumorigenesis by targeting p21 expression. Sci Rep. 2016;6:34034. doi: 10.1038/srep34034. PubMed PMID: 27698442; PMCID: PMC5048429.

227. Fan B, Jiao BH, Fan FS, Lu SK, Song J, Guo CY, Yang JK, Yang L. Downregulation of miR-95-3p inhibits proliferation, and invasion promoting apoptosis of glioma cells by targeting CELF2. Int J Oncol. 2015;47(3):102533. doi: 10.3892/ijo.2015.3080. PubMed PMID: 26165303.

228. Nurul-Syakima AM, Yoke-Kqueen C, Sabariah AR, Shiran MS, Singh A, Learn-Han L. Differential microRNA expression and identification of putative miRNA targets and pathways in head and neck cancers. Int $\mathrm{J}$ Mol Med. 2011;28(3):327-36. doi: 10.3892/ijmm.2011.714. PubMed PMID: 21637912. 
229. Zhang $Y$, Li M, Wang $H$, Fisher WE, Lin $P H$, Yao Q, Chen C. Profiling of 95 microRNAs in pancreatic cancer cell lines and surgical specimens by realtime PCR analysis. World J Surg. 2009;33(4):698-709. doi: 10.1007/s00268-008-9833-0. PubMed PMID: 19030927; PMCID: PMC2933040.

230. Shi C, Zhang Z. MicroRNA-362 is downregulated in cervical cancer and inhibits cell proliferation, migration and invasion by directly targeting SIX1. Oncol Rep. 2017;37(1):501-9. doi: 10.3892/or.2016.5242. PubMed PMID: 27878258.

231. Wang C, Hu J, Lu M, Gu H, Zhou X, Chen X, Zen K, Zhang CY, Zhang T, Ge J, Wang J, Zhang C. A panel of five serum miRNAs as a potential diagnostic tool for early-stage renal cell carcinoma. Sci Rep. 2015;5:7610. doi: 10.1038/srep07610. PubMed PMID: 25556603; PMCID: PMC5154588.

232. Li LL, Qu LL, Fu HJ, Zheng XF, Tang CH, Li XY, Chen J, Wang WX, Yang SX, Wang L, Zhao GH, Lv PP, Zhang M, Lei YY, Qin HF, Wang H, Gao HJ, Liu XQ. Circulating microRNAs as novel biomarkers of ALK-positive nonsmall cell lung cancer and predictors of response to crizotinib therapy. Oncotarget. 2017. doi: 10.18632/oncotarget.17535. PubMed PMID: 28514730.

233. Choi YW, Song YS, Lee H, Yi K, Kim YB, Suh KW, Lee D. MicroRNA Expression Signatures Associated With BRAF-Mutated Versus KRASMutated Colorectal Cancers. Medicine (Baltimore). 2016;95(15):e3321. doi: 10.1097/MD.0000000000003321. PubMed PMID: 27082577; PMCID: PMC4839821.

234. Ni F, Gui Z, Guo Q, Hu Z, Wang X, Chen D, Wang S. Downregulation of miR-362-5p inhibits proliferation, migration and invasion of human breast cancer MCF7 cells. Oncol Lett. 2016;11(2):1155-60. doi: 10.3892/ol.2015.3993. PubMed PMID: 26893711; PMCID: PMC4734047.

235. Wu K, Yang L, Chen J, Zhao H, Wang J, Xu S, Huang Z. miR-362-5p inhibits proliferation and migration of neuroblastoma cells by targeting phosphatidylinositol 3-kinase-C2beta. FEBS Lett. 2015;589(15):1911-9. doi: 10.1016/j.febslet.2015.05.056. PubMed PMID: 26073258.

236. Yang $P$, Ni F, Deng RQ, Qiang G, Zhao H, Yang MZ, Wang $X Y, X u Y Z$, Chen L, Chen DL, Chen ZJ, Kan LX, Wang SY. MiR-362-5p promotes the malignancy of chronic myelocytic leukaemia via down-regulation of GADD45alpha. Mol Cancer. 2015;14:190. doi: 10.1186/s12943-015-04653. PubMed PMID: 26545365; PMCID: PMC4636774.

237. Tanoglu A, Balta AZ, Berber U, Ozdemir Y, Emirzeoglu L, Sayilir A, Sucullu I. MicroRNA expression profile in patients with stage II colorectal cancer: a Turkish referral center study. Asian Pac J Cancer Prev. 2015;16(5):1851-5. PubMed PMID: 25773836.

238. Ni F, Zhao H, Cui H, Wu Z, Chen L, Hu Z, Guo C, Liu Y, Chen Z, Wang X, Chen D, Wei $\mathrm{H}$, Wang S. MicroRNA-362-5p promotes tumor growth and metastasis by targeting CYLD in hepatocellular carcinoma. Cancer Lett. 
2015;356(2 Pt B):809-18. doi: 10.1016/j.canlet.2014.10.041. PubMed PMID: 25449782.

239. Xia JT, Chen LZ, Jian WH, Wang KB, Yang YZ, He WL, He YL, Chen D, Li W. MicroRNA-362 induces cell proliferation and apoptosis resistance in gastric cancer by activation of NF-kappaB signaling. J Transl Med. 2014;12:33. doi: 10.1186/1479-5876-12-33. PubMed PMID: 24495516; PMCID: PMC3916099.

240. Zhai H, Song B, Xu X, Zhu W, Ju J. Inhibition of autophagy and tumor growth in colon cancer by miR-502. Oncogene. 2013;32(12):1570-9. doi: 10.1038/onc.2012.167. PubMed PMID: 22580605; PMCID: PMC3422411.

241. Jin H, Yu M, Lin Y, Hou B, Wu Z, Li Z, Sun J. MiR-502-3P suppresses cell proliferation, migration, and invasion in hepatocellular carcinoma by targeting SET. Onco Targets Ther. 2016;9:3281-9. doi: 10.2147/OTT.S87183. PubMed PMID: 27330307; PMCID: PMC4898420.

242. Sun LL, Wang J, Zhao ZJ, Liu N, Wang AL, Ren HY, Yang F, Diao KX, Fu WN, Wan EH, Mi XY. Suppressive role of miR-502-5p in breast cancer via downregulation of TRAF2. Oncol Rep. 2014;31(5):2085-92. doi: 10.3892/or.2014.3105. PubMed PMID: 24677135.

243. Larsen AC. Conjunctival malignant melanoma in Denmark: epidemiology, treatment and prognosis with special emphasis on tumorigenesis and genetic profile. Acta Ophthalmol. 2016;94 Thesis 1:1-27. doi: 10.1111/aos.13100. PubMed PMID: 27192168.

244. Ning MS, Kim AS, Prasad N, Levy SE, Zhang H, Andl T. Characterization of the Merkel Cell Carcinoma miRNome. J Skin Cancer. 2014;2014:289548. doi: 10.1155/2014/289548. PubMed PMID: 24627810; PMCID: PMC3929981.

245. Wang W, Zhao LJ, Tan YX, Ren H, Qi ZT. Identification of deregulated miRNAs and their targets in hepatitis $B$ virus-associated hepatocellular carcinoma. World J Gastroenterol. 2012;18(38):5442-53. doi: 10.3748/wjg.v18.i38.5442. PubMed PMID: 23082062; PMCID: PMC3471114.

246. Wang W, Zhao LJ, Tan YX, Ren H, Qi ZT. MiR-138 induces cell cycle arrest by targeting cyclin D3 in hepatocellular carcinoma. Carcinogenesis. 2012;33(5):1113-20. doi: 10.1093/carcin/bgs113. PubMed PMID: 22362728; PMCID: PMC3334515.

247. Xu G, Li JY. Differential expression of PDGFRB and EGFR in microvascular proliferation in glioblastoma. Tumour Biol. 2016;37(8):1057786. doi: 10.1007/s13277-016-4968-3. PubMed PMID: 26857280.

248. Harvey H, Piskareva O, Creevey L, Alcock LC, Buckley PG, O'Sullivan MJ, Segura MF, Gallego S, Stallings RL, Bray IM. Modulation of chemotherapeutic drug resistance in neuroblastoma SK-N-AS cells by the neural apoptosis inhibitory protein and miR-520f. Int $\mathrm{J}$ Cancer. 2015;136(7):1579-88. doi: 10.1002/ijc.29144. PubMed PMID: 25137037.

249. Hong S, Bi M, Chen S, Zhao P, Li B, Sun D, Tai J. MicroRNA-520f suppresses growth of gastric carcinoma cells by target ATPase family AAA 
domain-containing protein 2 (ATAD2). Neoplasma. 2016;63(6):873-9. doi: 10.4149/neo_2016_606. PubMed PMID: 27565325.

250. Xiong Y, Zhang L, Holloway AK, Wu X, Su L, Kebebew E. MiR-886-3p regulates cell proliferation and migration, and is dysregulated in familial non-medullary thyroid cancer. PLoS One. 2011;6(10):e24717. doi: 10.1371/journal.pone.0024717. PubMed PMID: 21998631; PMCID: PMC3187745.

251. Bi N, Cao J, Song Y, Shen J, Liu W, Fan J, He J, Shi Y, Zhang X, Lu N, Zhan $Q$, Wang $L$. A microRNA signature predicts survival in early stage small-cell lung cancer treated with surgery and adjuvant chemotherapy. PLoS One. 2014;9(3):e91388. doi: 10.1371/journal.pone.0091388. PubMed PMID: 24637927; PMCID: PMC3956664.

252. Liu C, Iqbal J, Teruya-Feldstein J, Shen Y, Dabrowska MJ, Dybkaer K, Lim MS, Piva R, Barreca A, Pellegrino E, Spaccarotella E, Lachel CM, Kucuk C, Jiang CS, Hu X, Bhagavathi S, Greiner TC, Weisenburger DD, Aoun P, Perkins SL, McKeithan TW, Inghirami G, Chan WC. MicroRNA expression profiling identifies molecular signatures associated with anaplastic large cell lymphoma. Blood. 2013;122(12):2083-92. doi: 10.1182/blood-2012-08447375. PubMed PMID: 23801630; PMCID: PMC3778551.

253. Gao W, Shen H, Liu L, Xu J, Xu J, Shu Y. MiR-21 overexpression in human primary squamous cell lung carcinoma is associated with poor patient prognosis. J Cancer Res Clin Oncol. 2011;137(4):557-66. doi: 10.1007/s00432-010-0918-4. PubMed PMID: 20508945.

254. Rass K, Reichrath J. UV damage and DNA repair in malignant melanoma and nonmelanoma skin cancer. Adv Exp Med Biol. 2008;624:162-78. doi: 10.1007/978-0-387-77574-6_13. PubMed PMID: 18348455.

255. States JC. Arsenic-Induced Skin Cancers Arise without UV-Induced P53 Mutations. Perspectives in Cytology and Genetics 2011;15:13-8.

256. States JC. Disruption of Mitotic Progression by Arsenic. Biol Trace Elem Res. 2015;166(1):34-40. doi: 10.1007/s12011-015-0306-7. PubMed PMID: 25796515.

257. Andrew AS, Burgess JL, Meza MM, Demidenko E, Waugh MG, Hamilton $\mathrm{JW}$, Karagas MR. Arsenic exposure is associated with decreased DNA repair in vitro and in individuals exposed to drinking water arsenic. Environmental health perspectives. 2006;114(8):1193-8. PubMed PMID: 16882524; PMCID: PMC1552016.

258. Ren X, McHale CM, Skibola CF, Smith AH, Smith MT, Zhang L. An emerging role for epigenetic dysregulation in arsenic toxicity and carcinogenesis. Environmental health perspectives. 2011;119(1):11-9. doi: 10.1289/ehp.1002114. PubMed PMID: 20682481; PMCID: PMC3018488.

259. Al-Eryani L, Waigel S, Jala V, Jenkins SF, Christopher States J. Cell cycle pathway dysregulation in human keratinocytes during chronic exposure to low arsenite. Toxicol Appl Pharmacol. 2017. doi: 10.1016/j.taap.2017.06.002. PubMed PMID: 28595984. 
260. Ahmad J, Hasnain SE, Siddiqui MA, Ahamed M, Musarrat J, Al-Khedhairy AA. MicroRNA in carcinogenesis \& cancer diagnostics: a new paradigm. The Indian journal of medical research. 2013;137(4):680-94. Epub 2013/05/25. PubMed PMID: 23703335; PMCID: PMC3724248.

261. Zhu W, He J, Chen D, Zhang B, Xu L, Ma H, Liu X, Zhang Y, Le H. Expression of miR-29c, miR-93, and miR-429 as potential biomarkers for detection of early stage non-small lung cancer. PLoS One. 2014;9(2):e87780. Epub 2014/02/14. doi: 10.1371/journal.pone.0087780. PubMed PMID: 24523873; PMCID: PMC3921142.

262. van Kampen JGM, van Hooij O, Jansen CF, Smit FP, van Noort PI, Schultz I, Schaapveld RQJ, Schalken JA, Verhaegh GW. miRNA-520f Reverses Epithelial-to-Mesenchymal Transition by Targeting ADAM9 and TGFBR2. Cancer Res. 2017;77(8):2008-17. doi: 10.1158/0008-5472.CAN-16-2609. PubMed PMID: 28209612.

263. Park SJ, Cheon EJ, Lee MH, Kim HA. MicroRNA-127-5p regulates matrix metalloproteinase 13 expression and interleukin-1beta-induced catabolic effects in human chondrocytes. Arthritis Rheum. 2013;65(12):3141-52. doi: 10.1002/art.38188. PubMed PMID: 24022470.

264. Isokpehi RD, Udensi UK, Anyanwu MN, Mbah AN, Johnson MO, Edusei K, Bauer MA, Hall RA, Awofolu OR. Knowledge building insights on biomarkers of arsenic toxicity to keratinocytes and melanocytes. Biomarker insights. 2012;7:127-41. doi: 10.4137/BMI.S7799. PubMed PMID: 23115478; PMCID: 3480875.

265. Gonzalez H, Lema C, Kirken RA, Maldonado RA, Varela-Ramirez A, Aguilera RJ. Arsenic-exposed Keratinocytes Exhibit Differential microRNAs Expression Profile; Potential Implication of miR-21, miR-200a and miR-141 in Melanoma Pathway. Clinical cancer drugs. 2015;2(2):138-47. doi: 10.2174/2212697X02666150629174704. PubMed PMID: 27054085; PMCID: 4819983.

266. Su LJ, Mahabir S, Ellison GL, McGuinn LA, Reid BC. Epigenetic Contributions to the Relationship between Cancer and Dietary Intake of Nutrients, Bioactive Food Components, and Environmental Toxicants. Frontiers in genetics. 2011;2:91. doi: 10.3389/fgene.2011.00091. PubMed PMID: 22303385; PMCID: 3266615.

267. Felekkis K, Touvana E, Stefanou C, Deltas C. microRNAs: a newly described class of encoded molecules that play a role in health and disease. Hippokratia. 2010;14(4):236-40. PubMed PMID: 21311629; PMCID: 3031315.

268. Kunej T, Godnic I, Horvat S, Zorc M, Calin GA. Cross talk between microRNA and coding cancer genes. Cancer journal. 2012;18(3):223-31. doi: 10.1097/PPO.0b013e318258b771. PubMed PMID: 22647358; PMCID: 3389046.

269. Williams KA, Kolappaswamy K, Detolla LJ, Vucenik I. Protective effect of inositol hexaphosphate against UVB damage in HaCaT cells and skin 
carcinogenesis in SKH1 hairless mice. Comparative medicine. 2011;61(1):39-44. PubMed PMID: 21819680; PMCID: 3060432.

270. Chowdhari S, Saini N. hsa-miR-4516 mediated downregulation of STAT3/CDK6/UBE2N plays a role in PUVA induced apoptosis in keratinocytes. J Cell Physiol. 2014;229(11):1630-8. doi: 10.1002/jcp.24608. PubMed PMID: 24610393.

271. Syed DN, Khan MI, Shabbir M, Mukhtar H. MicroRNAs in skin response to UV radiation. Current drug targets. 2013;14(10):1128-34. PubMed PMID: 23834148; PMCID: 3985496.

272. Cha HJ, Kim OY, Lee GT, Lee KS, Lee JH, Park IC, Lee SJ, Kim YR, Ahn $\mathrm{KJ}$, An IS, An S, Bae S. Identification of ultraviolet $B$ radiationinduced microRNAs in normal human dermal papilla cells. Mol Med Rep. 2014;10(4):1663-70. doi: 10.3892/mmr.2014.2418. PubMed PMID: 25069581; PMCID: 4148374.

273. Bruegger C, Kempf W, Spoerri I, Arnold AW, Itin PH, Burger B. MicroRNA expression differs in cutaneous squamous cell carcinomas and healthy skin of immunocompetent individuals. Experimental dermatology. 2013;22(6):426-8. doi: 10.1111/exd.12153. PubMed PMID: 23711067.

274. Jian Q, An Q, Zhu D, Hui K, Liu Y, Chi S, Li C. MicroRNA 340 Is Involved in UVB-Induced Dendrite Formation through the Regulation of RhoA Expression in Melanocytes. Mol Cell Biol 2014;34(18 ):3407-20.

275. Soifer HS, Rossi JJ, Saetrom P. MicroRNAs in disease and potential therapeutic applications. Molecular therapy : the journal of the American Society of Gene Therapy. 2007;15(12):2070-9. doi: 10.1038/sj.mt.6300311. PubMed PMID: 17878899.

276. Shao W, Wang D, Chiang YT, Ip W, Zhu L, Xu F, Columbus J, Belsham DD, Irwin DM, Zhang $H$, Wen $X$, Wang $Q$, Jin T. The Wnt signaling pathway effector TCF7L2 controls gut and brain proglucagon gene expression and glucose homeostasis. Diabetes. 2013;62(3):789-800. doi: 10.2337/db12-0365. PubMed PMID: 22966074; PMCID: 3581223.

277. Chen J, Yuan T, Liu M, Chen P. Association between TCF7L2 gene polymorphism and cancer risk: a meta-analysis. PLoS One. 2013;8(8):e71730. doi: 10.1371/journal.pone.0071730. PubMed PMID: 23951231 ; PMCID: 3739728.

278. Rosales-Reynoso MA, Arredondo-Valdez AR, Juarez-Vazquez Cl, WenceChavez LI, Barros-Nunez P, Gallegos-Arreola MP, Flores-Martinez SE, Moran-Moguel MC, Sanchez-Corona J. TCF7L2 and CCND1 polymorphisms and its association with colorectal cancer in Mexican patients. Cellular and molecular biology. 2016;62(11):13-20. PubMed PMID: 27755946.

279. Shangary S, Wang S. Targeting the MDM2-p53 interaction for cancer therapy. Clin Cancer Res. 2008;14(17):5318-24. doi: 10.1158/10780432.CCR-07-5136. PubMed PMID: 18765522; PMCID: 2676446.

280. Stros M, Ozaki T, Bacikova A, Kageyama H, Nakagawara A. HMGB1 and HMGB2 cell-specifically down-regulate the p53- and p73-dependent 
sequence-specific transactivation from the human Bax gene promoter. $\mathrm{J}$ Biol Chem. 2002;277(9):7157-64. doi: 10.1074/jbc.M110233200. PubMed PMID: 11748232.

281. Bartel $F$, Taubert $H$, Harris LC. Alternative and aberrant splicing of MDM2 mRNA in human cancer. Cancer cell. 2002;2(1):9-15. PubMed PMID: 12150820.

282. Schuster K, Fan L, Harris LC. MDM2 splice variants predominantly localize to the nucleoplasm mediated by a $\mathrm{COOH}$-terminal nuclear localization signal. Mol Cancer Res. 2007;5(4):403-12. doi: 10.1158/1541-7786.MCR06-0146. PubMed PMID: 17426254.

283. Castren $\mathrm{K}$, Ranki A, Welsh JA, Vahakangas $\mathrm{KH}$. Infrequent p53 mutations in arsenic-related skin lesions. Oncol Res. 1998;10(9):475-82. PubMed PMID: 10223623.

284. Hsu CH, Yang SA, Wang JY, Yu HS, Lin SR. Mutational spectrum of p53 gene in arsenic-related skin cancers from the blackfoot disease endemic area of Taiwan. British journal of cancer. 1999;80(7):1080-6. doi: 10.1038/sj.bjc.6690467. PubMed PMID: 10362120; PMCID: 2363055.

285. Foss KM, Sima C, Ugolini D, Neri M, Allen KE, Weiss GJ. miR-1254 and miR-574-5p: serum-based microRNA biomarkers for early-stage non-small cell lung cancer. J Thorac Oncol. 2011;6(3):482-8. doi:

10.1097/JTO.0b013e318208c785. PubMed PMID: 21258252.

286. Lin L, Liu D, Liang H, Xue L, Su C, Liu M. MiR-1228 promotes breast cancer cell growth and metastasis through targeting SCAI protein. Int $\mathrm{J}$ Clin Exp Pathol. 2015;8(6):6646-55. PubMed PMID: 26261546; PMCID: 4525880.

287. Sun Q, Chen S, Zhao X, Yan M, Fang Z, Wang H, Zhao J, Sun M, Han X, Chen W, Li X. Dysregulated miR-645 affects the proliferation and invasion of head and neck cancer cell. Cancer cell international. 2015;15:87. doi: 10.1186/s12935-015-0238-5. PubMed PMID: 26388702; PMCID: 4573489.

288. Williams GT, Farzaneh F. Are snoRNAs and snoRNA host genes new players in cancer? Nature reviews Cancer. 2012;12(2):84-8. doi: 10.1038/nrc3195. PubMed PMID: 22257949.

289. Dong XY, Guo P, Boyd J, Sun X, Li Q, Zhou W, Dong JT. Implication of snoRNA U50 in human breast cancer. Journal of genetics and genomics. 2009;36(8):447-54. doi: 10.1016/S1673-8527(08)60134-4. PubMed PMID: 19683667; PMCID: 2854654.

290. Cadigan KM, Peifer M. Wnt signaling from development to disease: insights from model systems. Cold Spring Harbor perspectives in biology. 2009;1(2):a002881. doi: 10.1101/cshperspect.a002881. PubMed PMID: $20066091 ;$ PMCID: 2742092.

291. Hrckulak D, Kolar M, Strnad H, Korinek V. TCF/LEF Transcription Factors: An Update from the Internet Resources. Cancers. 2016;8(7). doi: 10.3390/cancers8070070. PubMed PMID: 27447672; PMCID: 4963812. 
292. Jin T. Current understanding and dispute on the function of the Wnt signaling pathway effector TCF7L2 in hepatic gluconeogenesis, Genes \& Diseases, 2016;3 (1):Pages 48-55.

293. Murea M, Ma L, Freedman BI. Genetic and environmental factors associated with type 2 diabetes and diabetic vascular complications. The review of diabetic studies : RDS. 2012;9(1):6-22. doi:

10.1900/RDS.2012.9.6. PubMed PMID: 22972441; PMCID: 3448170.

294. Ma Y, Zheng X, Zhou J, Zhang Y, Chen K. ZEB1 promotes the progression and metastasis of cervical squamous cell carcinoma via the promotion of epithelial-mesenchymal transition. Int J Clin Exp Pathol. 2015;8(9):1125867. PubMed PMID: 26617850; PMCID: 4637665.

295. Cappellesso R, Marioni G, Crescenzi M, Giacomelli L, Guzzardo V, Mussato A, Staffieri A, Martini A, Blandamura S, Fassina A. The prognostic role of the epithelial-mesenchymal transition markers E-cadherin and Slug in laryngeal squamous cell carcinoma. Histopathology. 2015;67(4):491500. doi: 10.1111/his.12668. PubMed PMID: 25684546.

296. Moll UM, Petrenko O. The MDM2-p53 interaction. Mol Cancer Res. 2003;1(14):1001-8. PubMed PMID: 14707283.

297. Sigalas I, Calvert AH, Anderson JJ, Neal DE, Lunec J. Alternatively spliced mdm2 transcripts with loss of p53 binding domain sequences: transforming ability and frequent detection in human cancer. Nat Med. 1996;2(8):912-7. PubMed PMID: 8705862.

298. Matsumoto R, Tada M, Nozaki M, Zhang CL, Sawamura Y, Abe H. Short alternative splice transcripts of the $\mathrm{mdm} 2$ oncogene correlate to malignancy in human astrocytic neoplasms. Cancer Res. 1998;58(4):60913. PubMed PMID: 9485008.

299. Lukas J, Gao DQ, Keshmeshian M, Wen WH, Tsao-Wei D, Rosenberg S, Press MF. Alternative and aberrant messenger RNA splicing of the mdm2 oncogene in invasive breast cancer. Cancer Res. 2001;61(7):3212-9. PubMed PMID: 11306511.

300. Bartel F, Meye A, Wurl P, Kappler M, Bache M, Lautenschlager C, Grunbaum U, Schmidt H, Taubert H. Amplification of the MDM2 gene, but not expression of splice variants of MDM2 MRNA, is associated with prognosis in soft tissue sarcoma. Int J Cancer. 2001;95(3):168-75. PubMed PMID: 11307150.

301. Tamborini E, Della Torre G, Lavarino C, Azzarelli A, Carpinelli P, Pierotti MA, Pilotti S. Analysis of the molecular species generated by MDM2 gene amplification in liposarcomas. Int J Cancer. 2001;92(6):790-6. doi: 10.1002/ijc.1271. PubMed PMID: 11351297.

302. Evdokiou A, Atkins GJ, Bouralexis S, Hay S, Raggatt LJ, Cowled PA, Graves SE, Clayer M, Findlay DM. Expression of alternatively-spliced MDM2 transcripts in giant cell tumours of bone. Int $\mathrm{J}$ Oncol. 2001;19(3):625-32. PubMed PMID: 11494046. 
303. Honda $R$, Tanaka $H$, Yasuda $H$. Oncoprotein MDM2 is a ubiquitin ligase E3 for tumor suppressor p53. FEBS Lett. 1997;420(1):25-7. PubMed PMID: 9450543.

304. Zheng T, Wang J, Zhao Y, Zhang C, Lin M, Wang X, Yu H, Liu L, Feng Z, Hu W. Spliced MDM2 isoforms promote mutant p53 accumulation and gain-of-function in tumorigenesis. Nat Commun. 2013;4:2996. doi: 10.1038/ncomms3996. PubMed PMID: 24356649; PMCID: 3960723.

305. Tang D, Kang R, Zeh HJ, 3rd, Lotze MT. High-mobility group box 1 and cancer. Biochim Biophys Acta. 2010;1799(1-2):131-40. doi: 10.1016/j.bbagrm.2009.11.014. PubMed PMID: 20123075; PMCID: 2818552.

306. Sharma A, Ray R, Rajeswari MR. Overexpression of high mobility group (HMG) B1 and B2 proteins directly correlates with the progression of squamous cell carcinoma in skin. Cancer investigation. 2008;26(8):843-51 . doi: 10.1080/07357900801954210. PubMed PMID: 18798064.

307. Poser I, Golob M, Buettner R, Bosserhoff AK. Upregulation of HMG1 leads to melanoma inhibitory activity expression in malignant melanoma cells and contributes to their malignancy phenotype. Mol Cell Biol. 2003;23(8):29918. PubMed PMID: 12665595; PMCID: 152547.

308. Wang W, Jiang H, Zhu H, Zhang H, Gong J, Zhang L, Ding Q. Overexpression of high mobility group box 1 and 2 is associated with the progression and angiogenesis of human bladder carcinoma. Oncol Lett. 2013;5(3):884-8. doi: 10.3892/ol.2012.1091. PubMed PMID: 23426143; PMCID: 3576183.

309. Bodak N, Queille S, Avril MF, Bouadjar B, Drougard C, Sarasin A, DayaGrosjean L. High levels of patched gene mutations in basal-cell carcinomas from patients with xeroderma pigmentosum. Proc Natl Acad Sci U S A. 1999;96(9):5117-22. PubMed PMID: 10220428; PMCID: 21826.

310. Chang $\mathrm{CH}$, Tsai RK, Chen GS, Yu HS, Chai CY. Expression of bcl-2, p53 and Ki-67 in arsenical skin cancers. Journal of cutaneous pathology. 1998;25(9):457-62. PubMed PMID: 9821074.

311. Huang Y, Zhang J, McHenry KT, Kim MM, Zeng W, Lopez-Pajares V, Dibble CC, Mizgerd JP, Yuan ZM. Induction of cytoplasmic accumulation of p53: a mechanism for low levels of arsenic exposure to predispose cells for malignant transformation. Cancer Res. 2008;68(22):9131-6. doi: 10.1158/0008-5472.CAN-08-3025. PubMed PMID: 19010883; PMCID: 2717853.

312. Sandoval M, Morales M, Tapia R, del Carmen Alarcon L, Sordo M, Ostrosky-Wegman P, Ortega A, Lopez-Bayghen E. p53 response to arsenic exposure in epithelial cells: protein kinase B/Akt involvement. Toxicol Sci. 2007;99(1):126-40. doi: 10.1093/toxsci/kfm153. PubMed PMID: 17567589.

313. Sakaguchi K, Herrera JE, Saito S, Miki T, Bustin M, Vassilev A, Anderson CW, Appella E. DNA damage activates p53 through a phosphorylation- 
acetylation cascade. Genes Dev. 1998;12(18):2831-41. Epub 1998/09/23. PubMed PMID: 9744860; PMCID: PMC317174.

314. Shieh SY, Ikeda M, Taya Y, Prives C. DNA damage-induced phosphorylation of p53 alleviates inhibition by MDM2. Cell. 1997;91(3):32534. Epub 1997/11/18. PubMed PMID: 9363941.

315. Luo J, Li M, Tang Y, Laszkowska M, Roeder RG, Gu W. Acetylation of p53 augments its site-specific DNA binding both in vitro and in vivo. Proc Natl Acad Sci U S A. 2004;101(8):2259-64. Epub 2004/02/26. PubMed PMID: 14982997; PMCID: PMC356938.

316. Gu W, Roeder RG. Activation of p53 sequence-specific DNA binding by acetylation of the p53 C-terminal domain. Cell. 1997;90(4):595-606. Epub 1997/08/22. PubMed PMID: 9288740.

317. Salazar AM, Ostrosky-Wegman P. Genotoxicity. In: States JC, editor. Arsenic: Exposure Sources, Health Risks, and Mechanisms of Toxicity. Hoboken, NY: John Wiley \& Sons, Inc.; 2016.

318. Bhattacharjee $P$, Banerjee $M$, Giri AK. Role of genomic instability in arsenic-induced carcinogenicity. A review. Environ Int. 2013;53:29-40. Epub 2013/01/15. doi: 10.1016/j.envint.2012.12.004. PubMed PMID: 23314041.

319. Chih-Hung Lee W-TL, Hsin-Su Yu. Mechanisms and Immune Dysregulation in Arsenic Skin Carcinogenesis. Journal of Cancer Therapy. 2010;1: 76-86.

320. Banerjee N, Banerjee M, Ganguly S, Bandyopadhyay S, Das JK, Bandyopadhay A, Chatterjee M, Giri AK. Arsenic-induced mitochondrial instability leading to programmed cell death in the exposed individuals. Toxicology. 2008;246(2-3):101-11. Epub 2008/02/29. doi: 10.1016/j.tox.2007.12.029. PubMed PMID: 18304716.

321. Hernandez-Zavala A, Cordova E, Del Razo LM, Cebrian ME, Garrido E. Effects of arsenite on cell cycle progression in a human bladder cancer cell line. Toxicology. 2005;207(1):49-57. Epub 2004/12/14. doi: 10.1016/j.tox.2004.08.013. PubMed PMID: 15590121.

322. Jiang XH, Wong BC, Yuen ST, Jiang SH, Cho CH, Lai KC, Lin MC, Kung HF, Lam SK. Arsenic trioxide induces apoptosis in human gastric cancer cells through up-regulation of p53 and activation of caspase-3. Int J Cancer. 2001;91(2):173-9. Epub 2001/01/09. PubMed PMID: 11146441.

323. States JC, Reiners JJ, Jr., Pounds JG, Kaplan DJ, Beauerle BD, McNeely SC, Mathieu P, McCabe MJ, Jr. Arsenite disrupts mitosis and induces apoptosis in SV40-transformed human skin fibroblasts. Toxicol Appl Pharmacol. 2002;180(2):83-91. Epub 2002/04/24. doi: 10.1006/taap.2002.9376. PubMed PMID: 11969375.

324. Taylor BF, McNeely SC, Miller HL, States JC. Arsenite-induced mitotic death involves stress response and is independent of tubulin polymerization. Toxicol Appl Pharmacol. 2008;230(2):235-46. Epub 2008/05/20. doi: 10.1016/j.taap.2008.02.030. PubMed PMID: 18485433; PMCID: PMC2504415. 
325. Chowdhury R, Chatterjee R, Giri AK, Mandal C, Chaudhuri K. Arsenicinduced cell proliferation is associated with enhanced ROS generation, Erk signaling and CyclinA expression. Toxicol Lett. 2010;198(2):263-71. doi: 10.1016/j.toxlet.2010.07.006. PubMed PMID: 20654705.

326. Matsuzawa SI, Reed JC. Siah-1, SIP, and Ebi collaborate in a novel pathway for beta-catenin degradation linked to p53 responses. Molecular cell. 2001;7(5):915-26. PubMed PMID: 11389839.

327. Zheng N, Schulman BA, Song L, Miller JJ, Jeffrey PD, Wang P, Chu C, Koepp DM, Elledge SJ, Pagano M, Conaway RC, Conaway JW, Harper JW, Pavletich NP. Structure of the Cul1-Rbx1-Skp1-F boxSkp2 SCF ubiquitin ligase complex. Nature. 2002;416(6882):703-9. doi: 10.1038/416703a. PubMed PMID: 11961546.

328. Frescas D, Pagano M. Deregulated proteolysis by the F-box proteins SKP2 and beta-TrCP: tipping the scales of cancer. Nature reviews Cancer. 2008;8(6):438-49. doi: 10.1038/nrc2396. PubMed PMID: 18500245; PMCID: 2711846.

329. Nishitani H, Lygerou Z. Control of DNA replication licensing in a cell cycle. Genes to cells : devoted to molecular \& cellular mechanisms. 2002;7(6):523-34. PubMed PMID: 12059957.

330. Treas J, Tyagi T, Singh KP. Chronic exposure to arsenic, estrogen, and their combination causes increased growth and transformation in human prostate epithelial cells potentially by hypermethylation-mediated silencing of MLH1. The Prostate. 2013;73(15):1660-72. doi: 10.1002/pros.22701. PubMed PMID: 23804311.

331. Barrett JC, Lamb PW, Wang TC, Lee TC. Mechanisms of arsenic-induced cell transformation. Biol Trace Elem Res. 1989;21:421-9. PubMed PMID: 2484623.

332. Achanzar WE, Brambila EM, Diwan BA, Webber MM, Waalkes MP. Inorganic arsenite-induced malignant transformation of human prostate epithelial cells. Journal of the National Cancer Institute. 2002;94(24):188891. PubMed PMID: 12488483.

333. Chang Q, Pan J, Wang X, Zhang Z, Chen F, Shi X. Reduced reactive oxygen species-generating capacity contributes to the enhanced cell growth of arsenic-transformed epithelial cells. Cancer Res. 2010;70(12):5127-35. doi: 10.1158/0008-5472.CAN-10-0007. PubMed PMID: 20516118; PMCID: 4048957.

334. McNeely SC, Belshoff AC, Taylor BF, Fan TW, McCabe MJ, Jr., Pinhas AR, States JC. Sensitivity to sodium arsenite in human melanoma cells depends upon susceptibility to arsenite-induced mitotic arrest. Toxicol Appl Pharmacol. 2008;229(2):252-61. doi: 10.1016/j.taap.2008.01.020. PubMed PMID: 18328521; PMCID: 2474465.

335. Taylor BF, McNeely SC, Miller HL, Lehmann GM, McCabe MJ, Jr., States JC. p53 suppression of arsenite-induced mitotic catastrophe is mediated by p21CIP1/WAF1. The Journal of pharmacology and experimental 
therapeutics. 2006;318(1):142-51. doi: 10.1124/jpet.106.103077. PubMed PMID: 16614167.

336. Muenyi CS, Trivedi AP, Helm CW, States JC. Cisplatin plus sodium arsenite and hyperthermia induces pseudo-G1 associated apoptotic cell death in ovarian cancer cells. Toxicol Sci. 2014;139(1):74-82. doi: 10.1093/toxsci/kfu029. PubMed PMID: 24519527; PMCID: 4038788.

337. McCollum G, Keng PC, States JC, McCabe MJ, Jr. Arsenite delays progression through each cell cycle phase and induces apoptosis following G2/M arrest in U937 myeloid leukemia cells. The Journal of pharmacology and experimental therapeutics. 2005;313(2):877-87. doi: 10.1124/jpet.104.080713. PubMed PMID: 15722406.

338. Ma DC, Sun YH, Chang KZ, Ma XF, Huang SL, Bai YH, Kang J, Liu YG, Chu JJ. Selective induction of apoptosis of NB4 cells from G2+M phase by sodium arsenite at lower doses. European journal of haematology. 1998;61(1):27-35. PubMed PMID: 9688289.

339. Pozo-Molina G, Ponciano-Gomez A, Rivera-Gonzalez GC, HernandezZavala A, Garrido E. Arsenic-induced $S$ phase cell cycle lengthening is associated with ROS generation, p53 signaling and CDC25A expression. Chemico-biological interactions. 2015;238:170-9. doi: 10.1016/j.cbi.2015.06.040. PubMed PMID: 26148435.

340. Chayapong J, kumar H, Radha M, Queen M, Nurrahmah I, Nakajima Y, Choijookhuu N, Hishikawa Y, Maruyama M. Arsenic trioxide induces ROS activity and DNA damage, leading to G0/G1 extension in skin fibroblasts through the ATM-ATR-associated Chk pathway. Environmental Science and Pollution Research. 2017;24(6):5316-25. doi: 10.1007/s11356-0168215-7.

341. Nohara K, Ao K, Miyamoto Y, Suzuki T, Imaizumi S, Tateishi Y, Omura S, Tohyama C, Kobayashi T. Arsenite-induced thymus atrophy is mediated by cell cycle arrest: a characteristic downregulation of E2F-related genes revealed by a microarray approach. Toxicol Sci. 2008;101(2):226-38. doi: 10.1093/toxsci/kfm268. PubMed PMID: 17998272.

342. Zhang W, Ohnishi K, Shigeno K, Fujisawa S, Naito K, Nakamura S, Takeshita K, Takeshita A, Ohno R. The induction of apoptosis and cell cycle arrest by arsenic trioxide in lymphoid neoplasms. Leukemia. 1998;12(9):1383-91. PubMed PMID: 9737686.

343. Moghaddaskho F, Eyvani H, Ghadami M, Tavakkoly-Bazzaz J, Alimoghaddam K, Ghavamzadeh A, Ghaffari SH. Demethylation and alterations in the expression level of the cell cycle-related genes as possible mechanisms in arsenic trioxide-induced cell cycle arrest in human breast cancer cells. Tumour Biol. 2017;39(2):1010428317692255. doi: 10.1177/1010428317692255. PubMed PMID: 28218039.

344. de Magalhaes JP, Finch CE, Janssens G. Next-generation sequencing in aging research: emerging applications, problems, pitfalls and possible solutions. Ageing Res Rev. 2010;9(3):315-23. Epub 2009/11/11. doi: 
10.1016/j.arr.2009.10.006. PubMed PMID: 19900591; PMCID:

PMC2878865.

345. Pillai S, Gopalan V, Lam AK. Review of sequencing platforms and their applications in phaeochromocytoma and paragangliomas. Crit Rev Oncol Hematol. 2017;116:58-67. Epub 2017/07/12. doi:

10.1016/j.critrevonc.2017.05.005. PubMed PMID: 28693800.

346. Min Jou W, Haegeman G, Ysebaert M, Fiers W. Nucleotide sequence of the gene coding for the bacteriophage MS2 coat protein. Nature. 1972;237(5350):82-8. Epub 1972/05/12. PubMed PMID: 4555447.

347. Ozsolak F, Milos PM. RNA sequencing: advances, challenges and opportunities. Nat Rev Genet. 2011;12(2):87-98. Epub 2010/12/31. doi: 10.1038/nrg2934. PubMed PMID: 21191423; PMCID: PMC3031867.

348. Martin M. Cutadapt removes adapter sequences from high-throughput sequencing reads. EMBnetjournal. 2011(17.1):10-2. doi: http://dx.doi.org/10.14806/ej.17.1.200.

349. Trapnell C, Roberts A, Goff L, Pertea G, Kim D, Kelley DR, Pimentel H, Salzberg SL, Rinn JL, Pachter L. Differential gene and transcript expression analysis of RNA-seq experiments with TopHat and Cufflinks. Nat Protoc. 2012;7(3):562-78. Epub 2012/03/03. doi: 10.1038/nprot.2012.016. PubMed PMID: 22383036; PMCID: PMC3334321.

350. Peterson JL, Phelps ED, Doll MA, Schaal S, Ceresa BP. The role of endogenous epidermal growth factor receptor ligands in mediating corneal epithelial homeostasis. Investigative ophthalmology \& visual science. 2014;55(5):2870-80. doi: 10.1167/iovs.13-12943. PubMed PMID: 24722692 ; PMCID: 4008048.

351. Leichter AL, Sullivan MJ, Eccles MR, Chatterjee A. MicroRNA expression patterns and signalling pathways in the development and progression of childhood solid tumours. Mol Cancer. 2017;16(1):15. Epub 2017/01/21. doi: 10.1186/s12943-017-0584-0. PubMed PMID: 28103887; PMCID: PMC5248531.

352. Xu X, Wang X, Fu B, Meng L, Lang B. Differentially expressed genes and microRNAs in bladder carcinoma cell line 5637 and T24 detected by RNA sequencing. Int J Clin Exp Pathol. 2015;8(10):12678-87. Epub 2016/01/02. PubMed PMID: 26722457; PMCID: PMC4680402.

353. Zhou J, Duan H, Xie Y, Ning Y, Zhang X, Hui N, Wang C, Zhang J, Zhou J. MiR-193a-5p Targets the Coding Region of AP-2alpha mRNA and Induces Cisplatin Resistance in Bladder Cancers. J Cancer. 2016;7(12):1740-6. Epub 2016/10/05. doi: 10.7150/jca.15620. PubMed PMID: 27698912; PMCID: PMC5039396.

354. Williams M, Kirschner MB, Cheng YY, Hanh J, Weiss J, Mugridge N, Wright CM, Linton A, Kao SC, Edelman JJ, Vallely MP, McCaughan BC, Cooper W, Klebe S, Lin RC, Brahmbhatt H, MacDiarmid J, van Zandwijk N, Reid G. miR-193a-3p is a potential tumor suppressor in malignant pleural mesothelioma. Oncotarget. 2015;6(27):23480-95. Epub 2015/07/01. doi: 
10.18632/oncotarget.4346. PubMed PMID: 26125439; PMCID:

PMC4695131.

355. Liu X, Chen Q, Yan J, Wang Y, Zhu C, Chen C, Zhao X, Xu M, Sun Q, Deng R, Zhang H, Qu Y, Huang J, Jiang B, Yu J. MiRNA-296-3p-ICAM-1 axis promotes metastasis of prostate cancer by possible enhancing survival of natural killer cell-resistant circulating tumour cells. Cell Death Dis. 2013;4:e928. Epub 2013/11/23. doi: 10.1038/cddis.2013.458. PubMed PMID: 24263102; PMCID: PMC3847334.

356. Bai Y, Liao H, Liu T, Zeng X, Xiao F, Luo L, Guo H, Guo L. MiR-296-3p regulates cell growth and multi-drug resistance of human glioblastoma by targeting ether-a-go-go (EAG1). Eur J Cancer. 2013;49(3):710-24. Epub 2012/09/25. doi: 10.1016/j.ejca.2012.08.020. PubMed PMID: 22999387.

357. Wang Z, Gerstein M, Snyder M. RNA-Seq: a revolutionary tool for transcriptomics. Nat Rev Genet. 2009;10(1):57-63. Epub 2008/11/19. doi: 10.1038/nrg2484. PubMed PMID: 19015660; PMCID: PMC2949280.

358. Marioni JC, Mason CE, Mane SM, Stephens M, Gilad Y. RNA-seq: an assessment of technical reproducibility and comparison with gene expression arrays. Genome Res. 2008;18(9):1509-17. Epub 2008/06/14. doi: 10.1101/gr.079558.108. PubMed PMID: 18550803; PMCID: PMC2527709.

359. Ochi T, Suzuki T, Barrett JC, Tsutsui T. A trivalent dimethylarsenic compound, dimethylarsine iodide, induces cellular transformation, aneuploidy, centrosome abnormality and multipolar spindle formation in Syrian hamster embryo cells. Toxicology. 2004;203(1-3):155-63. Epub 2004/09/15. doi: 10.1016/j.tox.2004.06.006. PubMed PMID: 15363591.

360. Klein CB, Leszczynska J, Hickey C, Rossman TG. Further evidence against a direct genotoxic mode of action for arsenic-induced cancer. Toxicol Appl Pharmacol. 2007;222(3):289-97. Epub 2007/02/24. doi: 10.1016/j.taap.2006.12.033. PubMed PMID: 17316729; PMCID: PMC1986829.

361. Alain G, Tousignant J, Rozenfarb E. Chronic arsenic toxicity. Int $\mathrm{J}$ Dermatol. 1993;32(12):899-901. Epub 1993/12/01. PubMed PMID: 8125698.

362. Udensi UK, Graham-Evans BE, Rogers C, Isokpehi RD. Cytotoxicity patterns of arsenic trioxide exposure on $\mathrm{HaCaT}$ keratinocytes. Clin Cosmet Investig Dermatol. 2011;4:183-90. Epub 2012/01/19. doi: 10.2147/CCID.S24677. PubMed PMID: 22253543; PMCID: PMC3257883. 


\section{ABBREVIATION}

$\begin{array}{ll}\text { As } & \text { arsenic } \\ \text { CCA } & \text { copper-chromium-arsenic } \\ \text { miRNA } & \text { microRNA } \\ \text { mRNA } & \text { messenger RNA } \\ \text { snoRNA } & \text { human small nucleolar RNA } \\ \text { scaRNA } & \text { small Cajal body RNA } \\ \text { Drosha } & \begin{array}{l}\text { ribonuclease (RNase) III double-stranded RNA-specific } \\ \text { ribonuclease Drosha }\end{array} \\ \text { Dicer } & \text { helicase with RNase motif } \\ \text { TRBP } & \text { HIV-1 TAR RNA binding protein } \\ \text { RISC } & \text { RNA-induced silencing complex } \\ \text { UTRs } & \text { untranslated regions } \\ \text { ORF } & \text { open reading frame } \\ \text { HK } & \text { hyperkeratoses } \\ \text { SCC } & \text { squamous cell carcinoma } \\ \text { CSCC } & \text { cutaneous squamous cell carcinoma } \\ \text { BD } & \text { Bowen's disease } \\ \text { BCC } & \text { basal cell carcinoma } \\ \text { TPA } & \text { 12-O-tetradecanoyl phorbol-13- acetate } \\ \text { UV } & \text { ultraviolet } \\ \text { HaCaT } & \text { immortalized human keratinocytes } \\ \text { NGS } & \text { Next-Generation Sequencing } \\ \text { WHO } & \text { World Health Organization } \\ \text { IARC } & \text { International Agency for Research on Cancer } \\ \text { FFPE } & \text { formalin (light fixation) and embedded in paraffin } \\ & \end{array}$




\begin{tabular}{|c|c|}
\hline $\mathrm{H} \& \mathrm{E}$ & hematoxylin and eosin \\
\hline LCM & Laser Capture Microdissection System \\
\hline RT-qPCR & reverse transcription quantitative polymerase chain reaction \\
\hline DALRD3 & DALR anticodon binding domain containing 3 gene \\
\hline RTL1 & retrotransposon Gag like 1 \\
\hline $\begin{array}{l}\text { ANKRD34C- } \\
\text { AS }\end{array}$ & ANKRD34C antisense RNA 1 \\
\hline SEC24B & SEC24 homolog B, COPII coat complex component gene \\
\hline C1orf132 & chromosome 1 open reading frame 132 \\
\hline MIR381HG & MIR381 host gene \\
\hline GABRE & gamma-aminobutyric acid type A receptor epsilon subunit gene \\
\hline EIF4H & eukaryotic translation initiation factor $4 \mathrm{H}$ gene \\
\hline PANC-1 & human pancreatic carcinoma \\
\hline ATSDR & United States Agency for Toxic Substances and Disease Registry \\
\hline stRNAs & small temporal RNAs \\
\hline RMA & Robust Multi-Array \\
\hline TCF7L2 & Transcription factor 7-like 2 \\
\hline PTEN & Phosphatase and tensin homolog \\
\hline MDM2 & mouse double minute 2 homolog \\
\hline MDM2-FL & Full length MDM2 \\
\hline TP53 & tumor suppressor p53 \\
\hline EMT & epithelial to mesenchymal transition \\
\hline HMG1 & High mobility group box 1 protein \\
\hline SCAI & suppressor of cancer cell invasion \\
\hline RNA-seq & RNA sequencing \\
\hline p_Eq & two sample t-test with equal variances \\
\hline p_Ueq & two sample t-test with unequal variances \\
\hline
\end{tabular}


NGS Next-generation sequencing

IPA® Ingenuity ${ }^{\circledR}$ Pathway Analysis

ECM extracellular matrix 
CURRICULUM VITAE

Laila AI-Eryani

Date of birth: August 01 1986, Sana'a, Yemen

Email address: laila.aleryani@louisville.edu

\section{EDUCATION}

7/2010 Bachelor of Pharmacy, Sana'a University

5/2014 Master of Science, Pharmacology \& Toxicology, University Of

Louisville

8/2017 Ph.D., Pharmacology \& Toxicology (anticipated), University Of

Louisville

WORK EXPERIENCE

7 - 8/2006 Trainee, (Emergency Department). Sana'a, Yemen

7 - 8/2008 Intern, Al Thawra Central Pharmacy. Sana'a, Yemen

7 - 9/2008 Supervisor/Accountant, Abjad Schools. Sana'a, Yemen

7 - 8/2009 Trainee, Dar Al Dawa Pharmacy. Sana'a, Yemen 
7/2009 Intern, Shaphaco - Medicine Factory. Sana'a, Yemen

$8-11 / 2010 \quad$ Trainee, Pharmacy World Pharmacies (No.7). Sana'a, Yemen

8/2010 -7/2012 Registration Director, Shiba Pharmaceuticals \& Chemicals Manufacturing Company. Sana'a, Yemen

\section{AWARDS AND HONORS}

2012

The Fulbright award for Foreign Student to pursue graduate studies in the U.S.A.

2014

Graduate Student Council-Travel award, University of Louisville

2015

$2^{\text {nd }}$ place Graduate Student Award, Metals Specialty Section, Society of Toxicology (SOT)

2015 Sinclair Student Award, Dermal Toxicology Specialty Section, Society of Toxicology (SOT)

2015 Graduate Student Council-Travel award, University of Louisville

2015 Best Poster Presentation of PhD students award Ohio Valley Society of Toxicology (OVSOT)

2016 miRNA Biomarkers for Toxicology-Travel award

2016 Best Poster Presentation of PhD students award Ohio Valley Society of Toxicology (OVSOT) 
2016 Carcinogenesis Specialty Section Graduate Student travel award, Society of Toxicology (SOT)

2016 Supplemental Training for Education Program (STEP) funding from the Society of Toxicology (SOT) to attend a $\mathrm{NIH} / \mathrm{NCl}$ molecular prevention summer course in Rockville, Maryland, Aug $1-5,2016$

2016 Graduate Student Council-Travel award, University of Louisville 2016 2nd place best poster presentation of Louisville Chapter-Women in Medicine and Science, Research Louisville, University of Louisville

2016 1st place best poster presentation of Doctoral Basic Science Graduate Student, Research Louisville, University of Louisville 2016 Best poster presentation of PhD students, The 9th Conference on Metal Toxicity and Carcinogenesis

2017 Battelle Student Research Award for the Dermal Toxicology Specialty Section, Society of Toxicology (SOT)

\section{TRAINING AND DEVELOPMENT}

2015 Processing formalin fixed paraffin embedded (FFPE) tissue samples

10/13-14/2015 UCSC Genome Browser, Louisville, KY 
8/1-5/2016 Molecular prevention summer course, $\mathrm{NIH} / \mathrm{NCI}$, Rockville, Maryland

11/10/2016 Overview of Ingenuity (IPA) in RNA-seq data analysis, Louisville, KY

\section{PROFESSIONAL MEMBERSHIPS}

2013- Present Member, Ohio Valley Chapter of the Society of Toxicology (OVSOT)

2014- Present Member, Society of Toxicology (SOT)

2015- Present Member, Metals Specialty Section, Society of Toxicology

2015- Present Member, Dermal Toxicology Specialty Section, Society of Toxicology

2016- Present Member, Women in Toxicology Special Interest Group, Society of Toxicology

\section{LEADERSHIP / SERVICE}

2015- 2016 Vice Graduate Student Representative, Dermal Toxicology Specialty Section, SOT

2016- Present Graduate Student Representative, Dermal Toxicology Specialty Section, SOT 


\section{VOLUNTEER EXPERIENCE}

2015-Present Lab assistant, science class about DNA, The Bio-Rad Science Ambassador Program, middle and high schools, Louisville, KY

2013 Judge, Louisville Regional Science \& Engineering Fair, Louisville, KY

2016 Judge, Louisville Regional Science \& Engineering Fair, Louisville, KY

2017 Judge, Louisville Regional Science \& Engineering Fair, Louisville, KY

2017 Session mentor, Undergraduate Diversity Program, SOT, Baltimore, MD Leadership Committee (GSLC) \#Youtox Initiative, SOT, Baltimore, MD

\section{PEER-REVIEWED PUBLICATIONS}

1. Wahlang B, Song M, Beier JI, Cameron Falkner K, Al-Eryani L, Clair HB, Prough RA, et al. Evaluation of Aroclor 1260 exposure in a mouse model of diet-induced obesity and non-alcoholic fatty liver disease. Toxicol Appl Pharmacol 2014;279:380-390.

2. Wahlang B, Falkner KC, Clair HB, Al-Eryani L, Prough RA, States JC, Coslo DM, et al. Human receptor activation by aroclor 1260, a polychlorinated biphenyl mixture. Toxicol Sci 2014;140:283-297.

3. Al-Eryani L, Wahlang B, Falkner KC, Guardiola JJ, Clair HB, Prough RA, Cave M. Identification of Environmental Chemicals Associated with the 
Development of Toxicant-associated Fatty Liver Disease in Rodents. Toxicol Pathol 2015;43:482-497.

4. Al-Eryani L, Waigel S, Jala V, Jenkins S.F., States JC. Cell cycle pathway dysregulation in human keratinocytes during chronic exposure to low arsenite. Toxicol Appl Pharmacol. 2017. doi: 10.1016/j.taap.2017.06.002.

5. Al-Eryani L, Jenkins S.F., States V., Pan J, C. Malone J.C., Rai S., Galandiuk S., Giri A.K., States J.C. miRNA Expression Profiles of Premalignant and Malignant Arsenic-Induced Skin Lesions. (In preparation)

6. Al-Eryani L, Waigel S, Peremarti J, Jenkins S.F., States J.C. Differentially Expressed mRNA Targets of Differentially Expressed miRNAs Predict Changes in The TP53 Axis and Carcinogenesis Related Pathways. (In preparation)

7. Al-Eryani L, Jenkins S.F., Kalbfleisch T., Pan J, Rai S., States J.C. longitudinal changes in miRNA and gene expression profiles in $\mathrm{HaCaT}$ cells chronically exposed to low-arsenite. (In preparation)

8. Jiguo Wu, Laila Al-Eryani, Jouett Mason Hoffman, Mark Doll, Sandra S. Wise, Shesh N. Rai, J. Christopher States. Overexpression of hsa-miR-186 induces numerical and structural chromosomal aberrations in arsenicexposed human keratinocytes. (In preparation)

9. Josiah E. Hardesty, Laila Al-Eryani, Banrida Wahlang, K. Cameron Falkner, Heather B. Clair, Hongxue Shi, Jian Jin, Brian P. Ceresa, Russell A. Prough, Matthew C. Cave. Diverse Metabolic Disrupting Chemicals are Potent EGFR Antagonists that are Associated with Elevation of Metabolic Disease Biomarkers. (In preparation)

\section{ABSTRACTS}

1. Identification Of Xenobiotic Receptor Agonists Which Could Contribute To Nonalcoholic Fatty Liver Disease - L. Al-Eryani, B. Wahlang, H.B. Clair, J. J. Guardiola, K.C. Falkner, R.A. Prough, J.C. States and M. Cave - Research Of Louisville, University Of Louisville (2013).

2. Database Mining For Pregnane Xenobiotic Receptor (PXR) Ligands Using Toxcast Database And PXR Activation By Organochlorine Pesticides - L. AlEryani, B. Wahlang, H.B. Clair, J. J. Guardiola, K.C. Falkner, R.A. Prough and M. Cave-AASLD (2013).

3. Data Mining For Pesticides And Environmental Chemicals Associated With NAFLD - L. Al-Eryani, B. Wahlang, H.B. Clair, J. J. Guardiola, K.C. Falkner, R.A. Prough and M. Cave-AASLD (2013). 
4. Aroclor 1260 Exposure Worsens Hepatic And Systemic Inflammation In An Animal Model Of Diet-Induced Obesity And Nonalcoholic Fatty Liver Disease - B. Wahlang, M. Song, J. Beier, L. Al-Eryani, H.B. Clair, J.J. Guardiola, K.C. Falkner, R.A. Prough, and M. Cave-AASLD (2013).

5. Hepatic Receptor Activation By Polychlorinated Biphenyls - Implications For Xenobiotic/Energy Metabolism And Nonalcoholic Fatty Liver Disease - B. Wahlang, K.C. Falkner, H.B. Clair, L. Al-Eryani, J.J. Guardiola, R.A. Prough, and M. Cave-AASLD (2013).

6. Human transcription factor activation by polychlorinated biphenyls and organochlorine pesticides. B. Wahlang, Laila Al-Eryani, K.C. Falkner, H.J. Bellis-Jones, H.B. Clair, R.A. Prough, and M. Cave. Society of Toxicology (SOT), 2013.

7. Identification Of Environmental Chemicals Which Could Contribute To Nonalcoholic Fatty Liver Disease By Nuclear Receptor Activation. L. AlEryani, B. Wahlang, K.C. Falkner, H.B. Clair, R.A. Prough, J.C. States and M. Cave- SOT (2014).

8. PCB Regulation of Hepatic Nuclear Receptors: Implications for Hepatic Steatosis. R.A. Prough, B. Wahlang, K.C. Falkner, H.B. Clair, L.A. Al-Eryani, J. C. States, C.J. Omiecinski, and M.C. Cave. Presentation S6, 5th Asia Pacific International Society for the Study of Xenobiotics. Tianjin, China, 2014.

9. Overexpression Of miR-186 Induces Polyploidization In HaCaT Cell Line. Jiguo Wu, Laila Al-Eryani, Vanessa States, Jouett Hoffman, Mark Doll, Sandra Wise, Shesh Rai, Susan Galandiuk, Ashok K. Giri, J. Christopher States- Research Of Louisville, University Of Louisville (2015).

10. Chronic Low Level Arsenite Exposure Induces Matrix Remodeling Pathways In Human Keratinocytes. Samantha Jenkins, Laila Al-Eryani, J. Christopher States- Research Of Louisville, University Of Louisville (2015).

11.Purification Of The C-Terminal Domain Of ANAPC2 And Evidence Supporting The Interaction Of Lead Compounds For Inhibition Of Mitosis. J. Mason Hoffman, Laila Al-Eryani, Douglas Saforo, B. Frazier Taylor, John O. Trent, Nichola C. Garbett, J. Christopher States- Research Louisville, University Of Louisville (2015).

12. MicroRNA Profile Changes In Immortalized Human Keratinocytes After Low Arsenic Exposure. L. Al-Eryani, J. Pan, S. N. Rai, and J. C. States, The Toxicologist, Supplement to Toxicological Sciences, 144 (1), Abstract \# 1973, 2015.

13. Differential miRNA and mRNA Expression In Immortalized Human Keratinocytes (HaCaT) After Low Arsenic Exposure Suggest Changes In Cell 
Proliferation, Cell Migration, Cytoskeleton Remodeling And Carcinogenesis Pathways. Laila Al-Eryani, Samantha Jenkins, Sabine Waigel, Vanessa A. States, Vennila Arumugam, Shesh N. Rai \& J. Christopher States. Ohio Valley Society of Toxicology-SOT (2016), miRNA Biomarkers for Toxicology (2016).

14. Induction of Cell Cycle Pathways in Human Keratinocytes at Early Stages of Chronic Exposure To Low Arsenite. Laila Al-Eryani, Samantha Jenkins, Sabine Waigel, Vennila Arumugam, \& J. Christopher States. Research Louisville, University Of Louisville; The 9th Conference on Metal Toxicity and Carcinogenesis (2016).

15. Arsenic Induces Functional Changes of ZRANB2 and Expression of hsa-miR186. Collin Stocke, Laila Al Eryani, Camille Gordon, Vanessa A.R. States, Shesh N. Rai, Susan Galandiuk, and Ashok K. Giri, \& J. Christopher States. Society of Toxicology-SOT (2017).

16. Cell Cycle Pathway Dysregulation in Human Keratinocytes During Chronic Exposure To Low Arsenite. Laila Al-Eryani, Samantha Jenkins, Sabine Waigel, Vennila Arumugam, \& J. Christopher States. Society of ToxicologySOT (2017).

\section{PRESENTATIONS}

2013 Poster presentation, Research! Louisville, Louisville, Louisville, KY

2013 Poster Presentation, OVSOT, Annual Meeting, Louisville, KY

2013 Poster presentation, AASLD, Washington D.C.

2014 Poster presentation, SOT, Phoenix, AZ

2014 Poster presentation, Great Lakes Drug Metabolism and Disposition Meeting, Indianapolis, IN

2014 Poster presentation, NIEHS Tamburro Symposium on Environmental Chemicals and Liver Disease, Louisville, KY

2014 Poster presentation, OVSOT, Annual Meeting, Dayton, $\mathrm{OH}$ 
2015 Poster presentation, Research! Louisville, Louisville, Louisville, KY

2015 Poster presentation, OVSOT, Annual Meeting, Cincinnati, OH

2015 Poster presentation, SOT, San Diego, CA

2016 Poster presentation, CCT miRNA Biomarkers for Toxicology, New Orleans, LA

2016 Poster presentation, Research! Louisville, Louisville, Louisville, KY

2016 Oral presentation, Society of Toxicology (SOT), New Orleans, LA

2016 Poster presentation, UT-KBRIN Bioinformatics Summit 2016, Lake Barkley, KY

2016 Poster presentation, OVSOT, Annual Meeting, Indianapolis, IN

2016 Poster presentation, Research! Louisville, Louisville, Louisville, KY

2016 Poster presentation, The 9th Conference on Metal Toxicity and Carcinogenesis, Lexington, $\mathrm{KY}$

2017 Poster presentation, Society of Toxicology (SOT), Baltimore, MD

$2017 \mathrm{NCl}$ Graduate Student Recruiting Program 